\title{
Accountability in Ontario's Health Care System: The Role of Governance and Information in Managing Stakeholder \\ Demands
}

by

Marc Pilon

A thesis submitted to the Faculty of Graduate and Postdoctoral Affairs in partial fulfillment of the requirements for the degree of

Doctor of Philosophy

in

Management

Carleton University

Ottawa, Ontario

(C) 2019, Marc Pilon 


\begin{abstract}
This research focuses on nonprofit accountability because accountability failures, such as frauds and scandals, impede an organisation's ability to deliver on its mission and have raised concerns about an organisation's ability to manage their accountability demands. Previous nonprofit studies have focused on what accountability is and to whom organisations are accountable, while less focus has been given to how accountability is managed. Through the concepts of stakeholder relationships, governance mechanisms and information strategies, an accountability system is proposed and serves as the conceptual framework to understand how nonprofit accountability is managed.
\end{abstract}

The objective of this research is to gain a better understanding of the nonprofit accountability system. As such, the study's research question is how do nonprofit organisations manage their accountability system?

To answer the research question, a multiple-case study research strategy using a cross-sectional sample of health care organisations, with a particular focus on nonprofit hospitals and two of its salient stakeholders, Local Health Integration Networks (LHINs) and foundations.

This study has provided a clearer understanding of the relationship between accountability, governance and information, which contrasts with a majority of studies that have concentrated on specific aspects of accountability. At the practical level, to 
view accountability as a system, makes it easier to identify weaknesses, which could be used as a governance tool to help nonprofit leaders improve their accountability management practices. 


\section{Acknowledgements}

I would like to thank my research supervisor, François Brouard, for his valuable support. He guided me through the completion of this thesis with rigour, critical sense, sound advice, and a sense of humour.

I would like to thank the other members of my thesis committee Merridee Bujaki, Gerald Grant, Noel Hyndman and Paloma Raggo. I would like to thank Jo-Anne Ryan, Yves Robichaud and Heather Moise for their assistance and guidance. I would also like to acknowledge the financial support from Chartered Professional Accountants of Ontario and the Faculty of Management, Laurentian University.

The participation of organisational leaders constituted a crucial condition to the realisation of this project. Through their generosity, the organisations and participants who took time out of their busy days to be interviewed made this project possible.

Finally, this thesis would not have been possible without the unwavering support of my loving and patient wife Jasmine, who agreed to take this adventure with me. Merci mille fois! This thesis is dedicated to our two children, Pascale and Hugo. 


\section{Table of Contents}

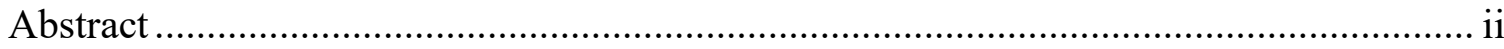

Acknowledgements ............................................................................................. iv

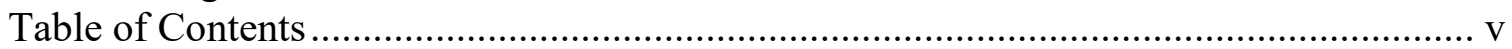

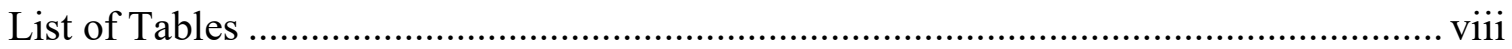

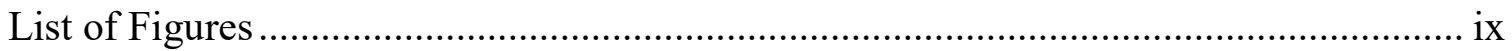

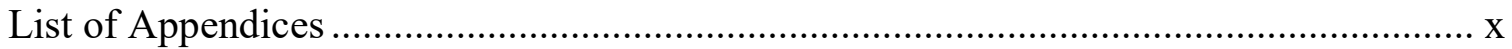

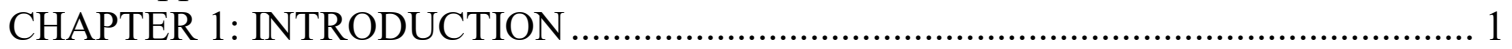

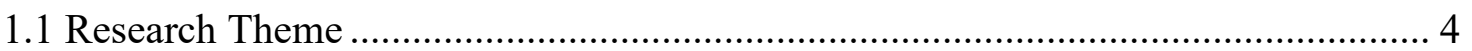

1.1.1 Importance of the Nonprofit Sector ................................................................ 4

1.1.2 Definition and Characteristics of Nonprofit Organisations ................................ 7

1.1.3 Health Care Sector Organisations................................................................ 11

1.2 Source of the Research Problem .......................................................................... 12

1.2.1 Accountability Failures: Frauds and Inefficiencies ......................................... 12

1.2.2 Accountability Challenges: Internal and External Environment ....................... 16

1.3 Managerial Problem ...................................................................................... 18

1.4 Research Objective and Research Questions ........................................................ 19

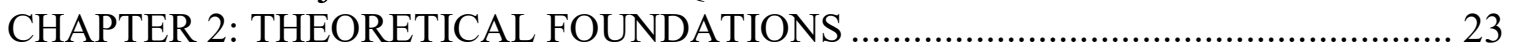

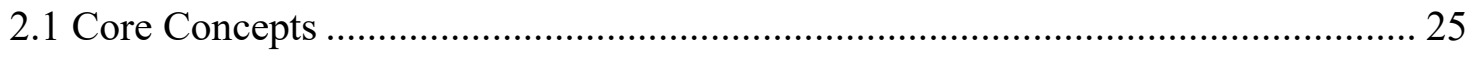

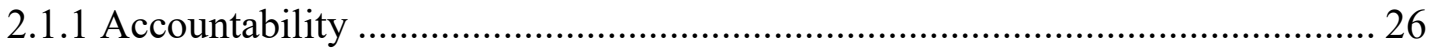

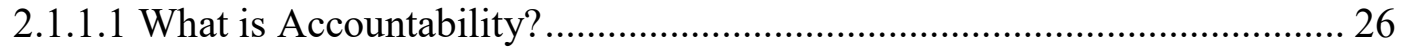

2.1.1.2 Accountability Conceptions in Nonprofit Organisations............................ 31

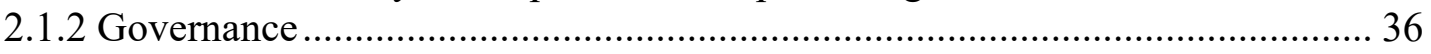

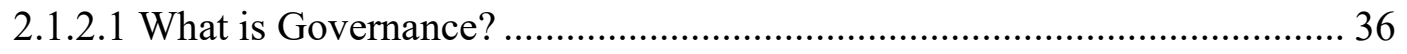

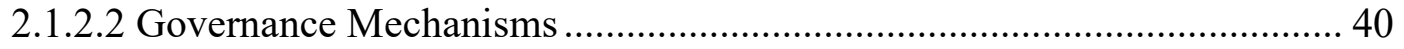

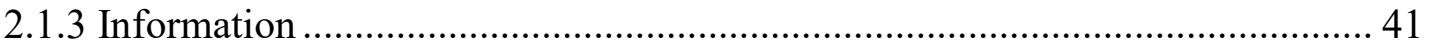

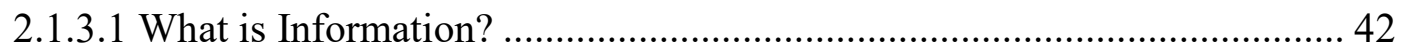

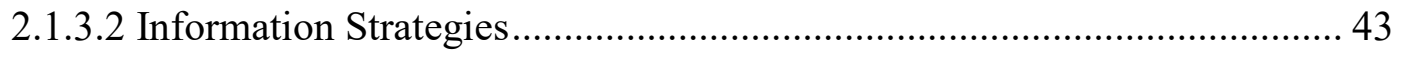

2.2 Relevant Management Theories.......................................................................... 47

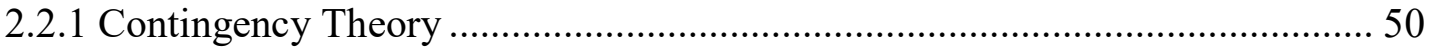

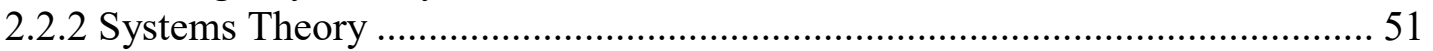

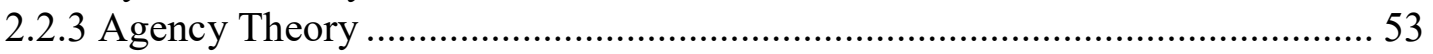

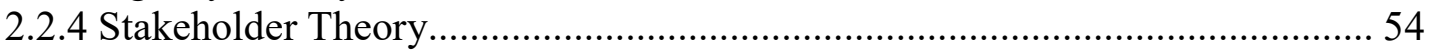

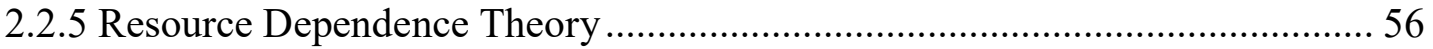

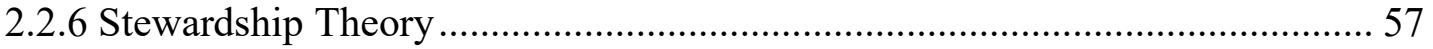

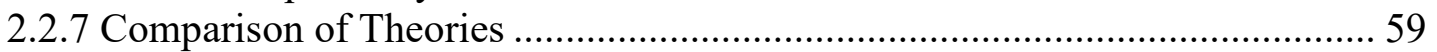

2.3 Accountability System as a Conceptual Framework........................................... 61

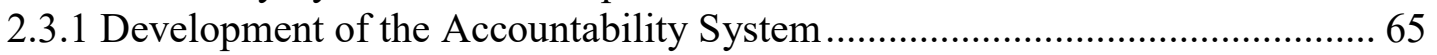

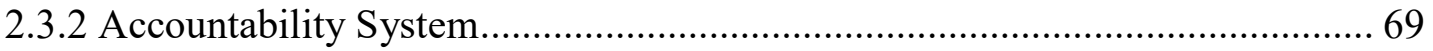

2.3.3 Accountability Values and Purposes ............................................................... 73

2.3.4 Accountability Stakeholder Relationships Sub-System .................................... 77

2.3.5 Accountability Governance Mechanisms Sub-System........................................ 81

2.3.6 Accountability Information Strategies Sub-System .......................................... 83 


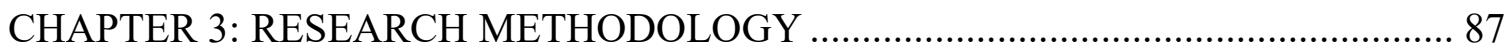

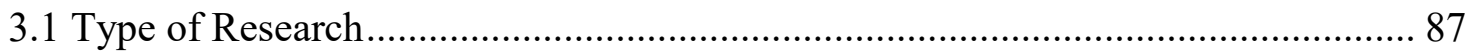

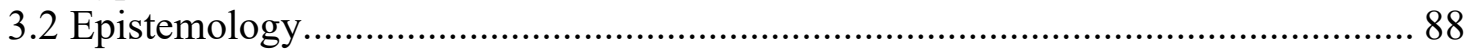

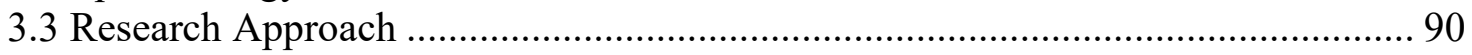

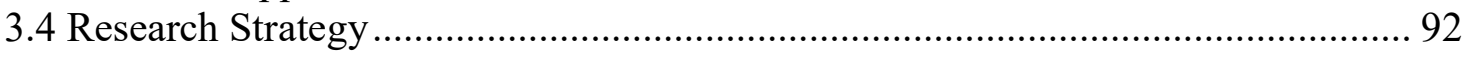

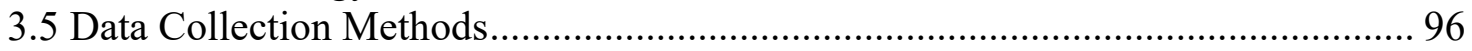

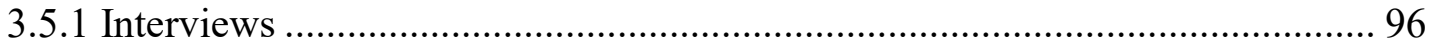

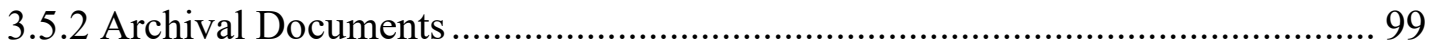

3.6 Organisation and Participant Selection ............................................................ 100

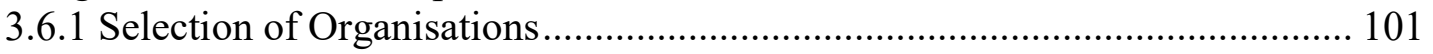

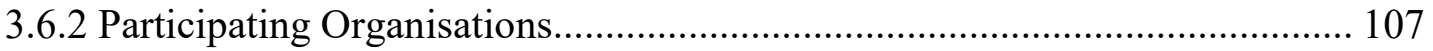

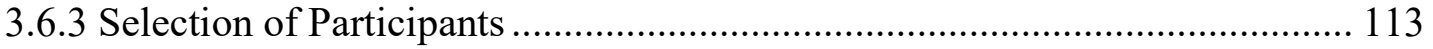

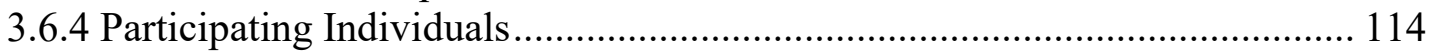

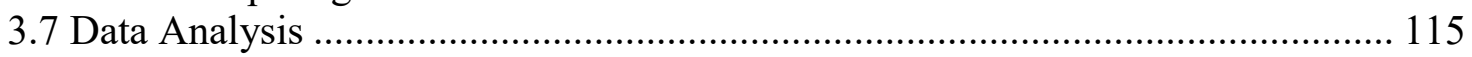

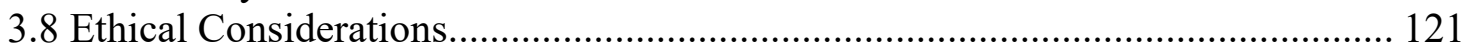

CHAPTER 4: OVERVIEW OF ONTARIO'S HEALTH CARE SYSTEM ................... 123

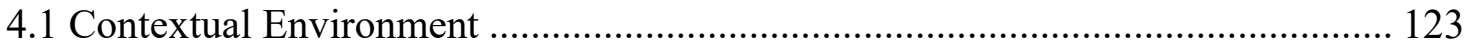

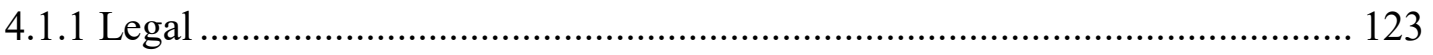

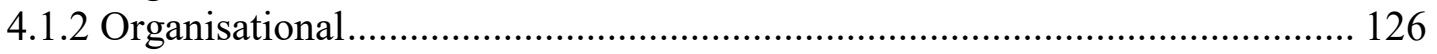

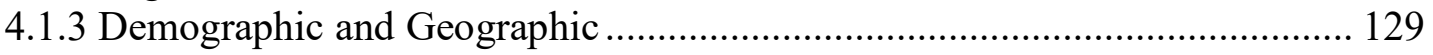

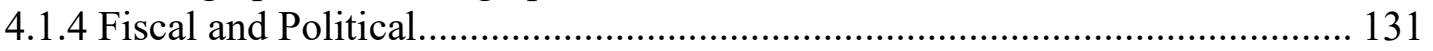

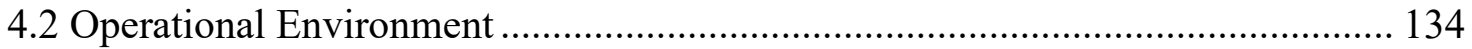

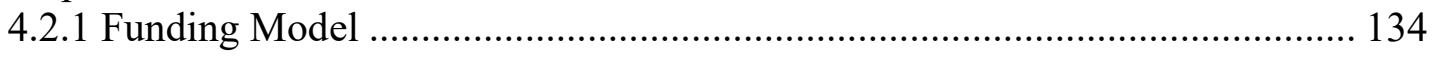

4.2.2 Organisational Interdependency ……………………….............................. 136

CHAPTER 5: ANALYSIS AND DISCUSSION ………........................................ 141

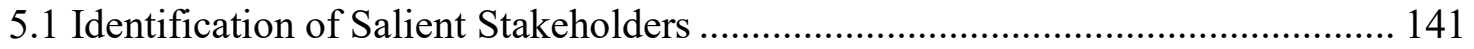

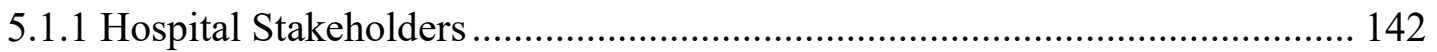

5.1.2 LHIN Stakeholders ............................................................................... 145

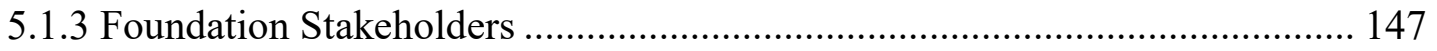

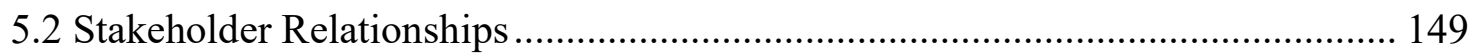

5.2.1 Hospital-Patients Relationship ……………………................................. 150

5.2.2 Hospital-LHIN Relationship................................................................. 152

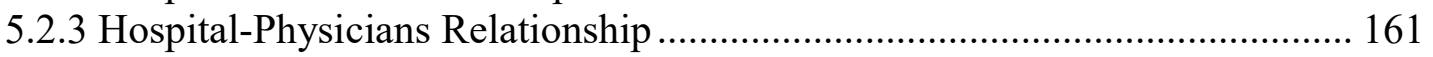

5.2.4 Hospital-Foundation Relationship ................................................................. 164

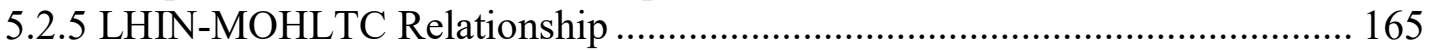

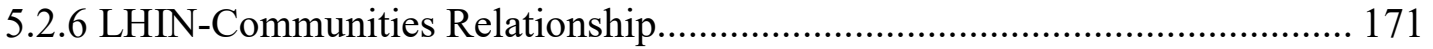

5.2.7 Foundation-Donors Relationship................................................................ 173

5.2.8 Accountability Evaluations........................................................................ 175

5.2.9 Summary of Stakeholder Relationships …………..................................... 177

5.2.9.1 Accountability Demands .................................................................... 179

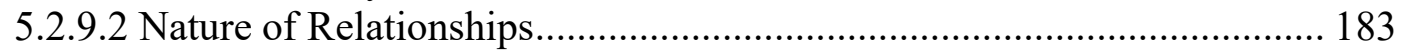

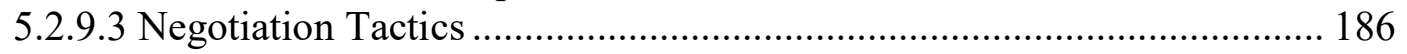

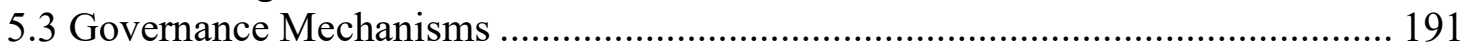

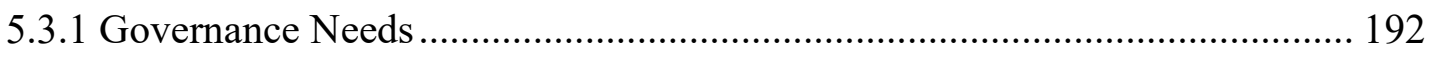

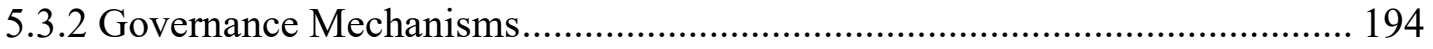

5.3.3 Summary of Governance Mechanisms ........................................................... 203 


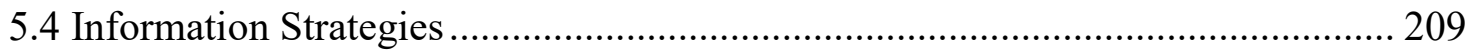

5.4.1 Corporate-Level Information Strategies ..................................................... 210

5.4.2 Personal-Level Information Strategies ...................................................... 212

5.4.3 Summary of Information Strategies .......................................................... 219

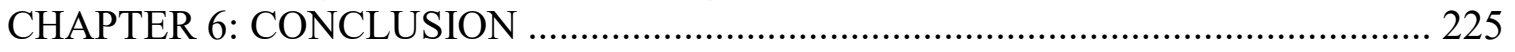

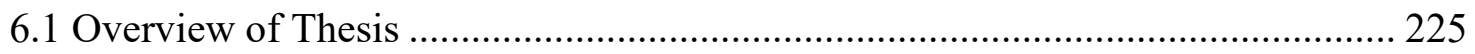

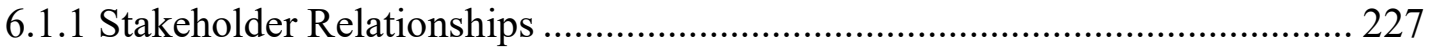

6.1.2 Governance Mechanisms...................................................................... 230

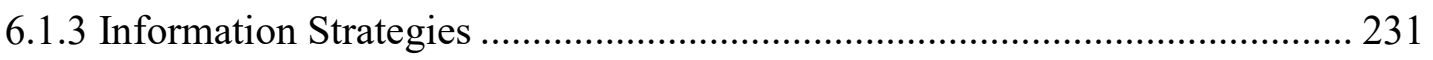

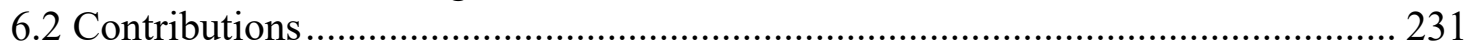

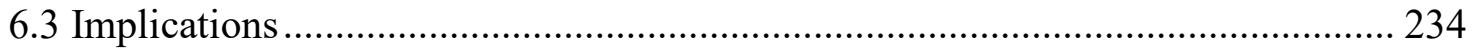

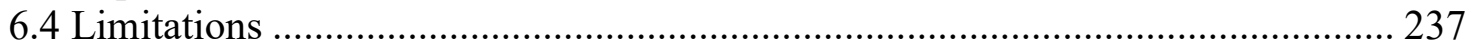

6.5 Suggestions for Future Research .................................................................... 239

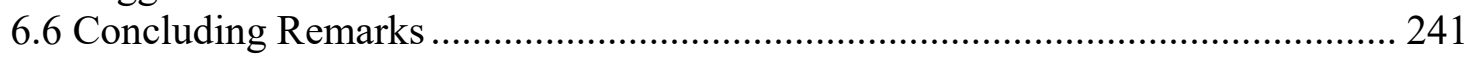

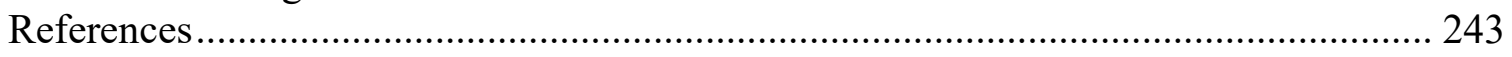




\section{List of Tables}

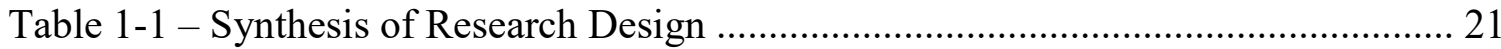

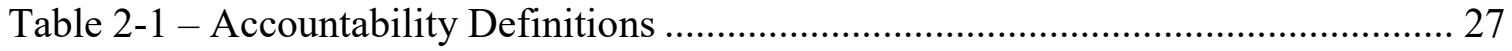

Table 2-2 - Summary of Accountability Conceptions ................................................ 31

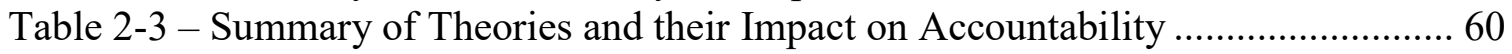

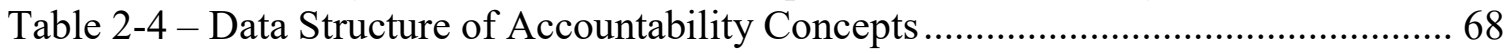

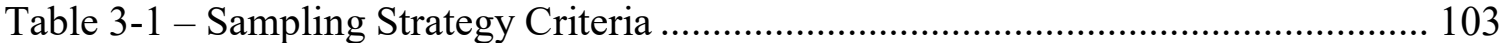

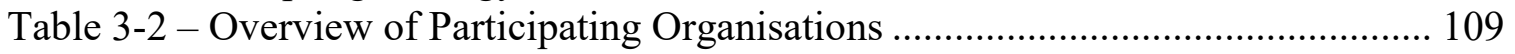

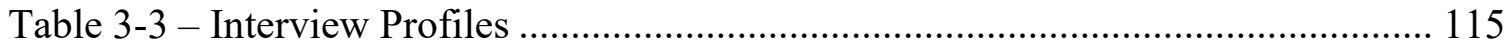

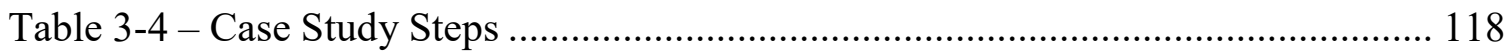

Table 3-5 - Synthesis of Research Design with Methodology................................... 120

Table 5-1 - Summary of Accountability Demands ................................................... 181

Table 5-2 - Summary of Accountability Demands with Governance Mechanisms....... 207

Table 5-3 - Summary of Information Strategies ....................................................... 220 


\section{List of Figures}

Figure 1-1 - Economic Sectors by Type of Organisation................................................ 8

Figure 2-1 - Characteristics of Accountability …………............................................ 29

Figure 2-2 - Characteristics of Governance ……………........................................... 39

Figure 2-3 - Characteristics of Information.................................................................. 45

Figure 2-4 - Adaptation of Murtaza's (2012) Accountability Framework........................ 62

Figure 2-5 - Adaptation of Taylor et al.'s (2014) Accountability Framework ................. 63

Figure 2-6 - Reproduction of Raggo (2014) Accountability Puzzle ................................ 63

Figure 2-7 - Proposed Accountability System …………………………………….... 70

Figure 2-8 - Environment of the Accountability System ................................................ 73

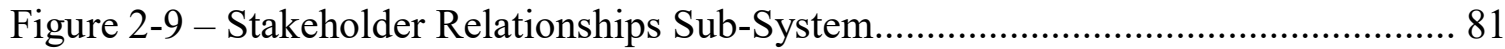

Figure 2-10 - Accountability Governance Mechanisms Sub-System ............................ 83

Figure 2-11 - Accountability Information Strategies Sub-System.................................. 85

Figure 3-1 - Relationship Between Participating Organisations .................................... 112

Figure 4-1 - Overview of Organisations within Ontario's Health Care System ............ 128

Figure 4-2 - Reproduction of Ontario Hospital Association's (2015) Stakeholders...... 128

Figure 5-1 - Qualitative Classes of Hospital Stakeholders .......................................... 145

Figure 5-2 - Qualitative Classes of LHIN Stakeholders ............................................. 147

Figure 5-3 - Qualitative Classes of Foundation Stakeholders........................................ 148

Figure 5-4 - The Stakeholder Relationships Cycle ..................................................... 179 


\section{List of Appendices}

Appendix A - The International Classification of Non-Profit Organisations ............... 263

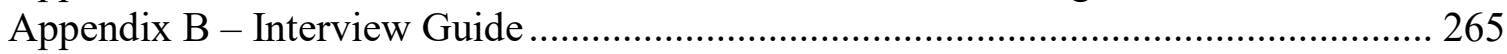

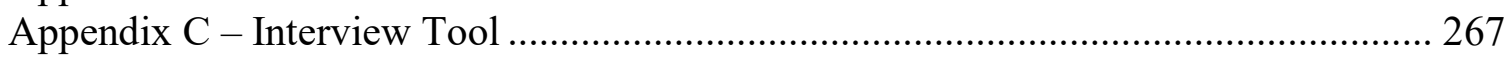

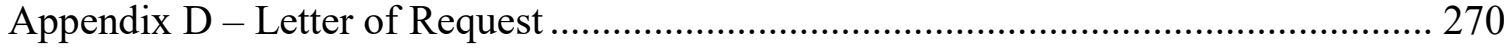

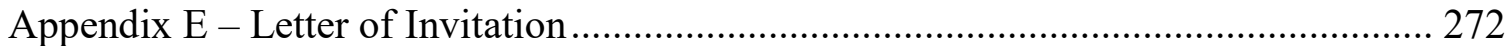

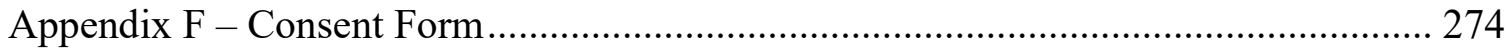

Appendix G - List of Organisations within Ontario's Health Care System .................. 276

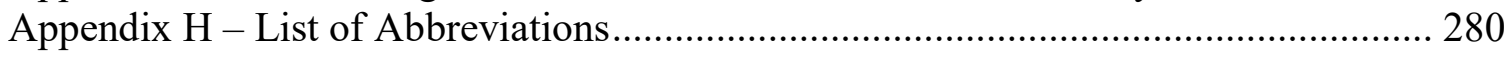

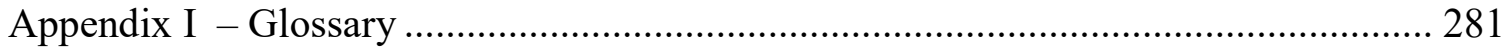




\section{CHAPTER 1: INTRODUCTION}

Nonprofit organisations are an omnipresent part of society. Whether they are cultural, sport, religious or recreational clubs and associations, professional bodies, educational institutions or health care providers, these organisations are driven to improve the lives of citizens in meaningful ways. This diverse set of organisations consists of small to large, simple to sophisticated, and local to national organisations, which have an eclectic mix of missions and objectives. These organisations also operate within a multi-stakeholder environment with diverging interests and objectives (Rehli \& Jäger, 2011; Weerawardena, McDonald, \& Mort, 2010). Consequently, research on nonprofit organisations is complex and generalizations are often limited by their heterogeneity.

In addition, compared to for-profit organisations, systematic collection of comparable and reliable data for research purposes is a greater challenge (Blumberg, 2017; Katz, 1999). While some countries have improved the availability of data resources, Canada has lagged behind in its data collection, and much more will need to be done to better understand the sector fully (Lenczner \& Phillips, 2012).

Therefore, given the importance of the nonprofit sector, the heterogeneity of organisations, the multiplicity of stakeholders, the complexity of the research field and 
the challenges in obtaining comparable and reliable data, more research concerning the nonprofit sector is warranted.

This research topic was chosen because there is general public interest in the accountability of nonprofit organisations and the underlying issues are of broad importance to society. In recent years, there has been an abundance of research on nonprofit accountability (Crawford, Morgan, \& Cordery, 2018; O'Leary, 2017). Given recent scandals that have occurred in all types of organisations; at the corporate level (e.g. Sino Forest, Valeant) and the nonprofit level (e.g. United Way Toronto, Salvation Army Ontario) - this attention is assuredly warranted. Yet, despite concerns about accountability, little is known about how nonprofits in a Canadian context manage their accountability systems.

Drawing from management scholarship, this thesis explores the central question of how nonprofit organisations manage their accountability systems. Specifically, this research integrates the concepts of governance and information from the accounting and management literature to help elucidate our understanding of accountability systems in a nonprofit context. This study argues that a systematic approach to accountability may better help researchers understand the intricacies of nonprofit accountability and help practitioners improve their accountability management practices. Thus, this topic is both useful to management scholars and practitioners alike. 
The rest of this thesis is organised as follows. The remainder of chapter 1 defines nonprofit organisations and further justifies why it is important to study their accountability systems. It also elaborates on the source of the research and managerial problems, as well as the research objective and questions.

In chapter 2, a literature review is conducted and theoretical foundations are established. In this chapter, the research themes of accountability, governance and information are discussed and defined. Relevant theories to the study of nonprofit accountability are analysed. The chapter then proposes a comprehensive accountability system. This system serves as the conceptual framework for this study and helps to better conceptualise the accountability management practices of nonprofit organisations.

In chapter 3, the research methodology is presented to address the research questions. Given the research questions, a qualitative research approach is utilised to understand how nonprofit organisations manage their accountability systems. Other research design choices are also described in this chapter.

In chapter 4 , an overview of the relevant contextual and operational environment within Ontario's health care system is provided. For the purposes of this study, there are four prominent groups of contextual factors that have an impact on Ontario's health care system. These factors include legal, organisational, demographic and geographic, and fiscal and political. The factors relevant to the health care system's operational environment include the hospitals' funding model and organisational interdependency. 
In chapter 5, the analysis and discussion of the results of this study are detailed. The chapter contains four sections, including the identification of salient stakeholders, stakeholder relationships, governance mechanisms, and information strategies.

Finally, the thesis concludes in chapter 6 . An overview of results is presented, theoretical and practical contributions are put forward, and the study's implications, limitations and avenues for future research are enumerated.

\subsection{Research Theme}

The research theme revolves around nonprofit organisations. The following section discusses the importance of studying such organisations and the characteristics that make these types of organisations different from for-profit and public sector organisations.

\subsubsection{Importance of the Nonprofit Sector}

The study of nonprofit organisations is important because the sector is a vital contributor to the economy, as well as the social fabric and quality of life of many individuals. However, its contribution to the Canadian economy is sometimes underappreciated. While some of the following data may seem dated, much of is the latest available data from Statistics Canada. 
In Canada, there are an estimated 170,000 nonprofit organisations (Imagine Canada, 2017). In 2007, the Canadian nonprofit sector contributed an estimated $\$ 100.7$ billion to the Canadian economy, amounting to 7.0 percent of the country's gross domestic product (GDP) (Statistics Canada, 2019). By 2017, the sector accounted for \$169.2 billion, composing of 8.5 percent of the country’s GDP (Statistics Canada, 2019), representing an increase between 2007 and 2017 of 68.0 percent. For hospitals, universities and colleges revenues amounted to $\$ 65.1$ billion in 2007 , amounting to 4.5 percent of the country's GDP (Statistics Canada, 2019). In 2017, the contribution of hospitals, universities and colleges increased to $\$ 123.9$ billion, representing 6.2 percent of the Canadian economy for the same period (Statistics Canada, 2019). This represents an increase of 90.3 percent over a 10-year period (2007-2017).

In comparison to other countries, the Canadian nonprofit sector's GDP contribution is significant and was highest in a 16 country study by Johns Hopkins University (Salamon, Sokolowski, Haddock, \& Tice, 2013), making the sector a particularly important part of the Canadian economy. In fact, its growth continues to outpace the economic importance of the private and public sectors (Haggar-Guenette, Hamdad, Laronde-Jones, Pan, \& Yu, 2009). In 2004, the sector employed 12 percent of Canada's economically active population (Hall, Barr, Easwaramoorthy, Sokolowski, \& Salamon, 2005). This proportion is above the international average and only behind the Netherlands, making Canada's nonprofit sector, as a share of Canada's economically active population, the second largest in the world (Hall et al., 2005). 
For comparison purposes, in the United States (U.S.) there were approximately 1.4 million registered nonprofits in 2013, a small increase of 2.8 percent from 2003 (McKeever, 2015). In 2010, the U.S. nonprofit sector contributed an estimated $\$ 804.8$ billion USD to the U.S. economy (Blackwood, Roeger, \& Pettijohn, 2012). By 2015, the nonprofit sector contributed an estimated $\$ 984.9$ billion USD to the U.S. economy, composing of 5.4 percent of the country's GDP (U.S. Bureau of Economic Analysis, 2016), and representing an increase from 2010 of 22.4 percent.

These numbers, even if somewhat dated, make evident the sector's importance to the Canadian and U.S. economies. While the relative number of nonprofit organisations has remained fairly constant over the last decade, their size and relative contribution to the economy of both countries has grown significantly. Canada's nonprofit sector has therefore become a significant part of the Canadian economy and it undeniably says something about its value to Canadian society.

Scholars have provided various reasons for this growth, which include an increase in aid channels (Edwards \& Hulme, 1996), an increase in international development (Najam, 1996), an increase in the overall number of nonprofits worldwide (Ebrahim, 2003b; Schmitz, Raggo, \& Bruno-van Vijfeijken, 2012; Williams \& Taylor, 2013), the transfer of responsibilities from governments to nonprofits (Flack \& Ryan, 2005; Hall et al., 2003; Smith, 2008), and growth as a result of their success (Murtaza, 2012). Some argue that governments have purposefully transferred the provision of societal services to 
nonprofits because nonprofits can be discarded when they are no longer needed, and they provide governments with less risk and instability (Smith, 2008).

\subsubsection{Definition and Characteristics of Nonprofit Organisations}

Many terms have been used in the literature to refer to this sector, and its organisations. This sector is generally referred to as the nonprofit sector, the third sector, the independent sector or the civil society sector (Abzug, 1999; Katz, 1999), while organisations within this sector are sometimes called nonprofit organisations (NPO), notfor-profit organisations (NFP), non-governmental organisations (NGO), voluntary organisations, and community service organisations (CSO) (Gibelman \& Gelman, 2001, 2004). This study refers to this sector as the nonprofit sector and to these organisations as nonprofits as these seem to be the most commonly used terms in the literature.

Entities within the nonprofit sector are characterised as non-governmental, not profit-distributing, self-governing, voluntary and organised (Hall et al., 2005; Salamon et al., 2013). It should be noted that while most nonprofits are formally registered, a certain number of nonprofits are informal. Informal groups include grass-roots and citizens' groups that are not formally incorporated or registered (Hall et al., 2004). These groups are difficult to identify and measure economically.

CPA Canada defines a nonprofit as "an entity, normally without transferable ownership interests, organized and operated exclusively for social, educational, 
professional, religious, health, charitable or any other not-for-profit purposes." (CPA Canada, 2019, preface, section 3 (c)). These organisations are neither public sector organisations, nor for-profit organisations (Unerman \& O’Dwyer, 2006a); it is “the space between the state and the market economy" (Katz, 1999, p.76). Figure 1-1 conceptualises where the nonprofit sector fits within the economic sectors. See also Crawford et al. (2018) and Salamon and Sokolowski (2016) for other visual schematics of economic sectors.

Figure 1-1 - Economic Sectors by Type of Organisation

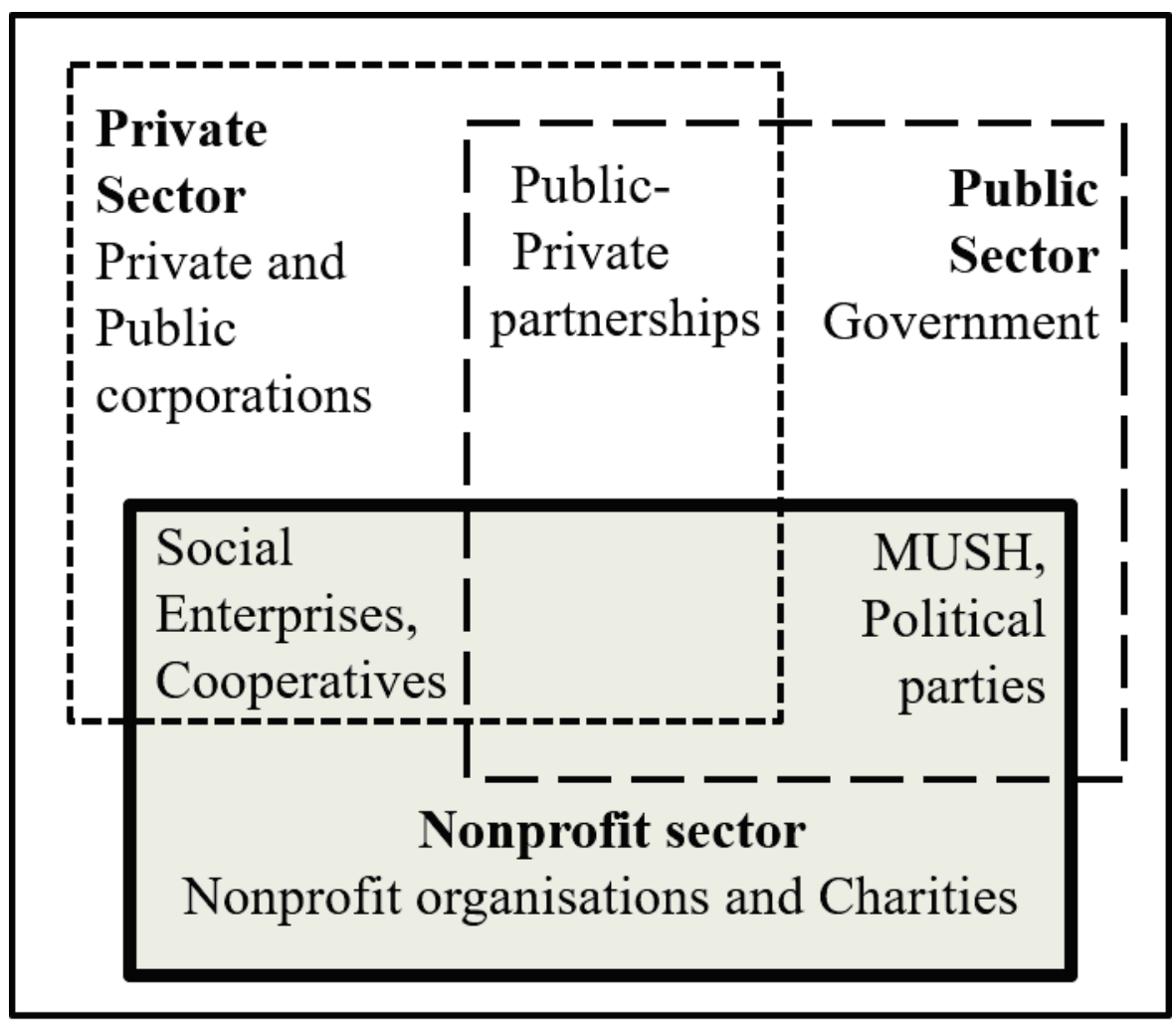

MUSH $=$ Municipalities, universities, school boards and hospitals

Registered charities, a sub-group of nonprofit organisations (Hyndman, 1990), have characteristics that distinguish them from other nonprofits. In Canada, there are an 
estimated 86,000 registered charities (Blumberg, 2017), representing slightly more than half of all nonprofits. Even though there has not been an increase in the number of charities, the sector has expanded rapidly over the last two decades (Emmett \& Emmett, 2015). In 2016 alone, these charities collectively spent $\$ 142$ Billion on salaries and other compensation and issued \$16.6 Billion in official donation receipts (Blumberg \& Sawyer, 2018).

In Canada, a registered charity (or simply a charity) is an organisation that uses its resources for charitable purposes (Canada Revenue Agency, 2016). While the Income Tax Act (ITA) does not define what is charitable or describe the nature of "charitable purposes', guidance from the Canada Revenue Agency (CRA), which enforces the ITA, states that such purposes must relate to poverty relief, educational advancement, religious advancement or other purposes that benefit the community (Canada Revenue Agency, 2013). The proportion of charities is broken down by purpose as follows: poverty relief (22\%), educational advancement (16\%), religious advancement (39\%) and other purposes (23\%) (Canada Revenue Agency, 2015).

Registered charities are split between three types: charitable organisations, public foundations and private foundations. Charitable organisations use all of their resources for charitable activities (ITA, 149.1(1)(a)), while public or private foundations are essentially funding organisations which distribute more than $50 \%$ of their income to other charities (ITA, 149.1(6)(b)). Examples of registered charities include food banks, low- 
cost housing units, churches, missionary organisations, animal shelters, libraries and volunteer fire departments (Canada Revenue Agency, 2016).

At one end of the spectrum of the nonprofit sector, there are also political parties and the MUSH sub-sector (municipalities, universities, schools and hospitals). While municipalities and schools are officially part of the public sector, universities and hospitals are indeed nonprofits. MUSH organisations are subject to greater scrutiny from a variety of government agencies (Salterio \& Legresley, 2011). The MUSH sector tends to have very large, highly structured organisations that rely heavily on government funding and generally operate as para-public or quasi-governmental organisations. Some hospitals, universities and colleges are also sometimes formalised as registered charities or have a related foundation.

At the other end of the spectrum, there is also the social enterprises and cooperatives sub-sector which differs from traditional nonprofit organisations (Salamon \& Sokolowski, 2016). Social enterprises and cooperatives are hybrid organisations with objectives that go beyond profit-maximization (Alter, 2007). With these organisations, the boundaries that separate them from the private sector are sometimes blurred (Dart, 2004). Social enterprises could be defined as "organizations created to pursue social missions or purposes that operate to create community benefit regardless of ownership or legal structure and with various degrees of financial self-sufficiency, innovation and social transformation" (Madill, Brouard, \& Hebb, 2010, p.141). A cooperative is "an autonomous association of persons united voluntarily to meet their common economic, 
social, and cultural needs and aspirations through a jointly owned and democraticallycontrolled enterprise" (International Co-operative Alliance, 2017). Therefore, a cooperative may be seen as a form of social enterprise, wherein the members democratically control the enterprise.

The nonprofit sector is also represented by many subcategories. The International Classification of Nonprofit Organizations (ICNPO) is widely used to categorise different types of nonprofit activity. The ICNPO classification identifies 12 different activity groups: culture and recreation, education and research, health, social services, environment, development and housing, law, advocacy and politics, philanthropic intermediaries and voluntarism promotion, international, religion, business and professional associations, unions, and other (Salamon \& Anheier, 1996; United Nations, 2003). These groupings are described in Appendix A. In Canada, small nonprofits tend to be in the culture and recreation, social services, and religion groups, while larger nonprofits tend to be in health, education and research, such as hospitals, universities and colleges (Hall et al., 2005).

\subsubsection{Health Care Sector Organisations}

For the purpose of this study, the focus is on health care related nonprofit organisations with diverging stakeholder interests. The target organisations include hospitals, LHINs (Local Health Integration Networks) and foundations. Organisations that are accountable to a broad range of stakeholders will highlight the accountability 
challenges that need to be managed when dealing with multiple stakeholders with competing interests. Tying the target organisations back to figure 1-1, hospitals are part of the MUSH sector, LHINs are public sector government agencies and foundations are registered charities. The integration of these three types of organisation is detailed in section 3.6.1.

\subsection{Source of the Research Problem}

The source of the research problem can serve as a motivator for the research objective (Robson, 2002) and can help justify the need for the research (Maxwell, 2013). The source of the research problem for this study focuses on accountability failures and accountability challenges. Accountability failures, such as fraud, scandals and inefficiencies and accountability challenges, such as resource constraints and competitive external environments, create accountability needs to better understand and manage accountability. This need to better understand and manage accountability acts as the source of the research problem.

\subsubsection{Accountability Failures: Frauds and Inefficiencies}

Accountability failures refer to events or disclosures that put into doubt the ability of organisations, as accountors, to achieve their mission in the eyes of stakeholders. At the corporate level, there have been many large accountability failures. Accounting frauds have been particularly damaging. Examples include Enron (Downes \& Russ, 
2005), WorldCom (Zekany, Braun, \& Warder, 2004), Tyco (Giroux, 2008) and Parmalat (Melis, 2005). These scandals have had an enormous impact on corporate shareholders, stakeholders, and society at large, made worse by the perception that the perpetrators 'got away with it'. For example, Sherron Watkins, whistleblower at Enron, said in an interview with Bloomberg that banks, lawyers and some Enron executives were complicit in the fraud and have never been punished for their involvement (Bartimoro, 2006).

Recent examples of nonprofit accountability failures further highlight the troubles that the sector faces. Examples in the press are numerous. In 2015, a 62 year-old Sudbury, Ontario woman was convicted of misappropriating funds from her employer, Christ the King Development Corporation, and sentenced to 15 months in prison (CBC News, 2015). As a bookkeeper with a gambling addiction, she defrauded the social housing unit for seniors of more than $\$ 380,000$. For at least 2 years, the employee siphoned funds from the coin laundry operation, stole cash rental payments and wrote cheques to herself without authorisation from her employer (Carmichael, 2014).

In another recent case, a 50 year-old Ottawa, Ontario woman was convicted of fraud in 2014 for stealing from her employer, Total Communications Environment, and sentenced to four years in prison (Cobb, 2014b). As financial director, she defrauded a social services charity for disabled adults of more than $\$ 900,000$. For at least seven years, the employee siphoned funds by using a company credit card and adjusting the books to cover up the fraud. The funds were used to purchase personal items such as beauty products, home furnishings, groceries and travel expenditures (Cobb, 2014a). 
More recently, the Cancer Fund of America (and three of its affiliates - Children's Cancer Fund of America, The Breast Cancer Society and Cancer Support Services), were dissolved in what is possibly one of the largest international nonprofit frauds ever. The organisations where found guilty of stealing virtually all of the $\$ 187$ million in donations they received over a number of years (Federal Trade Commission, 2016; Fitzpatrick \& Griffin, 2016; Ruiz, 2015).

Nonprofits also face problems relating to the inefficient use of their resources, which can be perceived by stakeholders as accountability failures. Inefficiencies in the sector have been attributed to a lack of expertise, to a lack of regulatory enforcement (Steen-Johnsen, Eynaud, \& Wijkström, 2011; Sugin, 2007), and to income tax exemptions which create a lack of incentive to be efficient when competing against forprofit organisations in the same market (Bolton \& Mehran, 2006).

Furthermore, while frauds are clearly illegal, even the perceptions of accountability failures can tarnish a reputation (Sarstedt \& Schloderer, 2010). News coverage in recent years of nonprofit frauds and waste has harmed the sector's reputation and overall social capital (Hall et al., 2003; Picco, 2017). When publicly disclosed, these scandals shine the spotlight on management issues and shortcomings of nonprofits and point to a clear problem of accountability (Gibelman \& Gelman, 2001, 2004). These accountability failures raise concerns about the ability of nonprofit organisations to 
manage their accountability systems and impede an organisation's ability to deliver on its mission (Costa, Ramus, \& Andreaus, 2011).

Accountability failures have hurt the nonprofit sector by reducing its credibility (Gibelman \& Gelman, 2004). These failures erode public confidence for all nonprofits and related institutions, and to the point where nonprofits have developed an image problem (Young, Bania, \& Bailey, 1996). The accountability failures undermine the trust that citizens have in the sector and negatively impact its ability to effectively solicit donations, attract members and recruit volunteers. If the lack of accountability were to become so pervasive that citizens were to reduce their donating and volunteering, it could have serious consequences on the economy and society. Reputational effects are especially damaging to smaller organisations because they are more vulnerable and dependent on donations, members and volunteers (Puentes, Mozas, Bernal, \& Chaves, 2012).

Therefore, accountability failures have required nonprofits to be more accountable and to demonstrate greater accountability (Ossewaarde, Nijhof, \& Heyse, 2008). As such, many scholars have made calls for greater research on accountability within the nonprofit literature (Gray, Bebbington, \& Collison, 2006; Murtaza, 2012; O’Dwyer \& Unerman, 2007, 2008). 


\subsubsection{Accountability Challenges: Internal and External Environment}

In addition to accountability failures, accountability management is further complicated by internal and external challenges (Salm, 1999). As with many organisations and in any resource-limited sector, nonprofits face challenges that affect their ability to manage their accountability and achieve their objectives. Hall et al. (2003) distinguish between two prominent nonprofit challenges: internal capacity factors and external environmental factors.

Internal capacity is defined as "the human and financial resources, technology, skills, knowledge and understanding required to permit organisations to do their work and fulfill what is expected of them by stakeholders" (Broadbent et al., 1999, p.118). While, the external environment consists of factors relevant outside the boundaries of the organisation (Duncan, 1972). The external environment is composed of numerous factors which can impact the organisation's capacity by creating or amplifying organisational challenges (Hall et al., 2003).

Two prominent accountability challenges include resource constraints and a competitive external environment. First, organisations are facing capacity challenges relating to their financial resources. One reason for this is an increase in demand for their products and services (Hall et al., 2004; Lasby \& Barr, 2014). A study by Imagine Canada found that $53 \%$ of organisations reported this type of challenge (Lasby \& Barr, 2014). Another explanation is that governments have downloaded many services to the 
nonprofit sector (Flack \& Ryan, 2005; Hall et al., 2003; Smith, 2008). Furthermore, there has been a shift from stable, long-term funding to project specific funding (Barr et al., 2006; Hall et al., 2003). A study by Statistics Canada found that $98 \%$ of organisations reported an unwillingness by funders to fund core operations (Hall et al., 2004). As a result, funding has become more cyclical and uncertain, which has made it more difficult for nonprofits to do long-term planning (Hall et al., 2004). This increase in demand and a shift in revenue sources has created a lack of resources, which has been suggested in prior research to be a significant potential barrier to nonprofit accountability (Alexander \& Weiner, 1998; Christensen \& Mohr, 2003; Harris, 2014; Palmer, 2013; Yetman \& Yetman, 2012).

Second, organisations face a competitive external environment for the attention of donors and funders (Hall et al., 2003, 2004; Salm, 1999), as well as employees (Barr et al., 2006). Donations, as a percentage of GDP, continue to decrease (Emmett \& Emmett, 2015). In addition, competition for skilled personnel, especially skilled managers, and an inability to compete with the for-profit sector for such employees because of financial constraints has negatively impacted the nonprofit sector's ability to manage its accountability (Barr et al., 2006). Furthermore, nonprofits, especially smaller organisations, are often volunteer driven and may be unable to acquire or train key personnel to acquire the necessary managerial knowledge and expertise (Barr et al., 2006). 


\subsection{Managerial Problem}

Accountability is essentially a management issue, since "dilemmas of accountability [...] cannot be 'solved' - they have to be managed" (Edwards \& Hulme, 1995, p.223, italics original). Given the challenges previously identified, questions remain about how organisations, and their leaders, can improve their accountability management practices. An organisational practice is defined "as particular ways of conducting organisational functions" (Kostova, 1999, p.309). For the focus of this study, accountability management practices encompass stakeholder relationships, governance mechanisms and information strategies.

Therefore, given that nonprofits continue to struggle in the area of accountability management, it suggests that there are hurdles to overcome. A better understanding of how accountability may be managed is important to nonprofit research because academic studies and press articles have shown that nonprofit organisations are having difficulty meeting the accountability demands of their stakeholders. But why do organisations persist in having accountability problems? Part of the answer may "[lie] in the inability [of organisations] to take a system approach to accountability" (Raggo, 2014, p.147). As a result of this deficiency, the way in which nonprofit accountability is conceptualised and managed should be of prime importance to management scholars, and is the focus of this thesis. 


\subsection{Research Objective and Research Questions}

The determination of research objectives is an essential and preliminary step in the research process (Maxwell, 2013; Robson, 2002). In fact, research objectives help to focus research on a particular problem, act as a guide in the fulfillment of the research endeavor and help to formulate research questions (Maxwell, 2013). Given the accountability failures and the accountability challenges that have been discussed previously, the research objective of this thesis is to:

Gain a better understanding of the nonprofit accountability system.

The research questions are at the centre of the research design and should be formulated to achieve the research objectives (Maxwell, 2013; Robson, 2002). The research questions have two primary purposes. First, they should explain what the study is intended to understand, and second, they serve as a guide in the optimal selection of research methods (Maxwell, 2013). The general research question is motivated by the research problems identified and derived from the necessity to better understand how nonprofits manage their accountability systems. As such, the general research question is:

How do nonprofit organisations manage their accountability system?

Specifically, this research focuses on three important aspects of accountability management: relationship, governance and information. As described in chapter 2, relationship, governance and information are important concepts that affect how 
accountability is managed. As such, the research problem will be addressed by focusing on the following specific research questions:

$R Q$ 1: How do nonprofit organisations use stakeholder relationships, governance mechanisms and information strategies to manage their accountability system?

$R Q$ 2: How do nonprofit organisations manage their stakeholder relationships?

$R Q$ 3: How do nonprofit organisations manage their governance mechanisms?

RQ 4: How do nonprofit organisations manage their information strategies?

Table 1-1 summarises the thesis in regards to the problematization. This provides a snapshot for the reader to understand the foundations of the study. 
Table 1-1 - Synthesis of Research Design

\begin{tabular}{|c|}
\hline $\begin{array}{c}\text { Research theme } \\
\text { Nonprofit accountability, governance and information }\end{array}$ \\
\hline $\begin{array}{l}\text { Source of the problem } \\
\text { Practical problems: Accountability failures have raised concerns about the ability of } \\
\text { nonprofits to manage their accountability demands and impede an organisation's ability } \\
\text { to deliver on its mission. Accountability management is further complicated by resource } \\
\text { constraints and a competitive external environment. } \\
\text { Theoretical problems: Studies within the nonprofit sector have focused on what } \\
\text { accountability is and to whom it should be given, not on what an accountability system } \\
\text { might contain and how accountability is managed. }\end{array}$ \\
\hline $\begin{array}{c}\text { Managerial problem } \\
\text { How can nonprofit leaders improve accountability management practices? }\end{array}$ \\
\hline $\begin{array}{c}\text { Research objective } \\
\text { To gain a better understanding of the nonprofit accountability system. }\end{array}$ \\
\hline $\begin{array}{c}\text { General research question } \\
\text { How do nonprofit organisations manage their accountability system? }\end{array}$ \\
\hline $\begin{array}{c}\text { Specific research questions } \\
\text { How do nonprofit organisations use stakeholder relationships, governance mechanisms } \\
\text { and information strategies to manage their accountability system? } \\
\text { How do nonprofit organisations manage their stakeholder relationships? } \\
\text { How do nonprofit organisations manage their governance mechanisms? } \\
\text { How do nonprofit organisations manage their information strategies? }\end{array}$ \\
\hline
\end{tabular}




\section{CHAPTER 2: THEORETICAL FOUNDATIONS}

The theoretical foundations in the research developed here revolve around the concepts of accountability, governance and information in the context of nonprofit organisations. While governance and information constitute a vast body of research that cuts across many fields and is often researched independently from accountability, the focus here is on the governance mechanisms and information strategies used within an accountability system.

A review of the literature has found that studies within the nonprofit sector have focused on what accountability is and to whom it should be given. However, studies have not focused on how accountability is managed by nonprofits (Tacon, Walters, \& Cornforth, 2017) and on what an accountability system might contain. Also, there are gaps in the nonprofit literature on addressing the association between accountability systems and the concepts of governance and information.

Within the nonprofit accountability literature, there also continues to be ambiguity in the way terminology and constructs are used (Williams \& Taylor, 2013). The concept of accountability "resembles a dustbin filled with good intentions, loosely defined concepts and vague images of good governance" (Bovens, 2007, p.449). Poor terminology and loosely defined concepts impede scholarly analysis, and as such, defining vocabulary is important to advance a field of research because it facilitates a focused discussion (Bovens, 2010). Words that evoke dimensions of accountability, such as transparency, 
responsiveness, responsibility, trust, answerability, effectiveness, equity, and good governance are sometimes used interchangeably as synonyms (Bovens, 2007, 2010; Koppell, 2005; Mulgan, 2000; Raggo, 2014). For example, Brinkerhoff (2004, p.372) stated that "the essence of accountability is answerability". Raggo (2014, p.20-21) also found something similar: "The various dimensions of accountability most often discussed by NGO scholars include: transparency, effectiveness, participation, liability, controllability, responsibility, evaluation and responsiveness (Blagescu et al., 2005; Koppell, 2005, 2010; Kovach et al., 2003), transparency probably being one of the most emphasized aspects of accountability, as it is central to assuring future donations (Lawrence and Nezhad, 2009)".

The term accountability has therefore come to mean many different things, resulting in a word that may become meaningless, as also written by Raggo (2014, p.14): "An important lesson to be learned from the scholarship related to NGO accountability is that although accountability is a core governance concern for any type of organization, the concept can have different meanings for various people, and often lacks conceptual clarity in popular use (Kearns, 1996, 94; Koppell, 2005, 43). [...] Although these concepts are related to accountability discussions, their interchangeable use has only confused definitions further". Other common concepts with poor constructs are also found in the management literature. For instance, Bujaki and Richardson (1997) found that 'firm size' is also used to mean many things, and therefore is meaningless in a manner that is consistent with 'accountability'. 
Therefore, more research is needed to clarify these and other concepts of nonprofit accountability. Specifically, there appears to be little knowledge on what stakeholder relationships, governance mechanisms and information strategies are used to manage the accountability system and how the accountability demands of stakeholders affect relationships, governance mechanisms and information strategies.

In this chapter, the management literature on accountability, governance and information helps build a conceptual framework and justify the proposed accountability system. Furthermore, applicable management theories are reviewed. These theories help explain different facets of nonprofit accountability.

\subsection{Core Concepts}

The research developed here is based on three core concepts: accountability, governance and information. These concepts are often studied separately in accounting and management literature. While research in each one of these fields has grown, they have remained fairly siloed. In studying accountability, and accountability systems, it is important to integrate governance and information concepts, as each of these topics has important implications for accountability. Namely, governance mechanisms may be used as a means of managing accountability practices (Tacon et al., 2017; Tandon, 1995), while information strategies may be used as a means of demonstrating accountability (i.e. giving account) (Brinkerhoff, 2004; Chisolm, 1995). 


\subsubsection{Accountability}

The following discussion addresses what accountability is and reviews accountability conceptions in the nonprofit context.

\subsubsection{What is Accountability?}

Accountability is an abstract, elusive and complex concept (Ebrahim, 2003b; Edwards \& Hulme, 1996; Kearns, 1994; Sinclair, 1995). It is context dependent (Mulgan, 2000; Williams \& Taylor, 2013; Young, 2002), subjectively constructed (Sinclair, 1995) with little consensus on its definition (Dhanani \& Connolly, 2012; Raggo, 2014). Ebrahim (2003b, p.193) noted that "it is an irony of accountability that the term itself has often evaded clear definition". However, if one begins to specify the constructs under study, one can attempt to describe accountability within a specific context. In this case, the focus of accountability is at the organisational level in the context of nonprofits. Definitions from the literature were gathered to identify common themes. Presented chronologically, table 2-1 presents a sample of accountability definitions found within the management literature on the nonprofit and public sector. 
Table 2-1 - Accountability Definitions

\begin{tabular}{|c|c|}
\hline Author, Year & Accountability Definitions \\
\hline Friedrich, 1940 & $\begin{array}{l}\text { "account for the action in terms of a somewhat rationalized and previously established set of } \\
\text { hypotheses" (p.12) }\end{array}$ \\
\hline Finer, 1941 & $\begin{array}{l}\text { "responsibility may mean that X is accountable for Y to Z" (p.336) } \\
\text { "inward personal sense of moral obligation" (p.336) }\end{array}$ \\
\hline Medawar, 1982 & $\begin{array}{l}\text { "a process by which someone is held responsible for something he proposes to do, is doing } \\
\text { or has done" (p.156) }\end{array}$ \\
\hline $\begin{array}{l}\text { Roberts \& Scapens, } \\
1985\end{array}$ & "the giving and demanding of reasons for conduct" (p.447) \\
\hline $\begin{array}{l}\text { Romzek \& Dubnick, } \\
1987\end{array}$ & $\begin{array}{l}\text { "the means by which public agencies and their workers manage the diverse expectations } \\
\text { generated within and outside the organization" (p.228) }\end{array}$ \\
\hline Josephson, 1988 & $\begin{array}{l}\text { "accept responsibility for decisions and the foreseeable consequences of actions and } \\
\text { inactions, and for setting an example for others" (p.29-30) }\end{array}$ \\
\hline Paul, 1991 & $\begin{array}{l}\text { "holding individuals and organizations responsible for performance measured as objectively } \\
\text { as possible" (p.2) }\end{array}$ \\
\hline Mason, 1992 & "willingness to accept responsibility for decisions and their consequences" (p.24) \\
\hline Shafritz, 1992 & $\begin{array}{l}\text { "(1) The extent to which one must answer to higher authority - legal or organisational - for } \\
\text { one's action in society at large or within one's particular organization. (2) An obligation for } \\
\text { keeping accurate records of property, documents, or funds." (p.4) }\end{array}$ \\
\hline $\begin{array}{l}\text { Munro \& Hatherly, } \\
1993\end{array}$ & "the willingness and ability to explain and justify one's acts to self and others" (p.369) \\
\hline Chisolm, 1995 & $\begin{array}{l}\text { "an obligation to meet prescribed standards of behavior or an obligation to disclose } \\
\text { information about one's actions even in the absence of a prescribed standard of behavior" } \\
\text { (p.141) (definition in reference to 'legal accountability') }\end{array}$ \\
\hline Lawry, 1995 & "is 'answerability', the giving of a justification or explanation" (p.175) \\
\hline Sinclair, 1995 & $\begin{array}{l}\text { "a relationship in which people are required to explain and take responsibility for their } \\
\text { actions" (p.220-221) }\end{array}$ \\
\hline $\begin{array}{l}\text { Edwards \& Hulme, } \\
1996\end{array}$ & $\begin{array}{l}\text { "the means by which individuals and organizations report to a recognized authority (or } \\
\text { authorities) and are held responsible for their actions" (p.967) }\end{array}$ \\
\hline $\begin{array}{l}\text { Gray, Dey, Owen, } \\
\text { Evans \& Zadek, } \\
1997\end{array}$ & "the duty to provide an account of the actions for which one is held responsible" (p.334) \\
\hline Fox \& Brown, 1998 & "the process of holding actors responsible for actions" (p.12) \\
\hline $\begin{array}{l}\text { Cornwall, Lucas \& } \\
\text { Pasteur, } 2000\end{array}$ & "giving an account to another party who has a stake in what has been done" (p.3) \\
\hline Mulgan, 2000 & "called to account for one's actions" (p.555) \\
\hline Romzek, 2000 & "answerability for performance" (p.22) \\
\hline Shearer, 2002 & $\begin{array}{l}\text { "one who is obligated to demonstrate the reasonableness of his or her actions to a } \\
\text { community of others, through the activity of giving accounts" (p.545) }\end{array}$ \\
\hline Young, 2002 & "the process of holding an organisation responsible for its behavior and performance" (p.3) \\
\hline Ebrahim, 2003a & $\begin{array}{l}\text { "It may be defined not only as a means through which individuals and organizations are held } \\
\text { responsible for their actions (e.g., through legal obligations and explicit reporting and } \\
\text { disclosure requirements), but also as a means by which organizations and individuals take } \\
\text { internal responsibility for shaping their organizational mission and values, for opening } \\
\text { themselves to public or external scrutiny, and for assessing performance in relation to } \\
\text { goals." (p.815) }\end{array}$ \\
\hline Ebrahim, 2003b & $\begin{array}{l}\text { "the means through which individuals and organizations are held externally to account for } \\
\text { their actions and as the means by which they take internal responsibility for continuously } \\
\text { shaping and scrutinizing organisational mission, goals, and performance" (p.194) }\end{array}$ \\
\hline Brinkerhoff, 2004 & $\begin{array}{l}\text { "the obligation of individuals or agencies to provide information about, and/or justification } \\
\text { for, their actions to other actors, along with the imposition of sanctions for failure to comply } \\
\text { and/or to engage in appropriate action" (p.372) }\end{array}$ \\
\hline
\end{tabular}




\begin{tabular}{|c|c|}
\hline Author, Year & Accountability Definitions \\
\hline Flack \& Ryan, 2005 & $\begin{array}{l}\text { "being responsible to stakeholders who are external to the organisation for the results of the } \\
\text { organisation" (p.71) }\end{array}$ \\
\hline $\begin{array}{l}\text { Christensen \& } \\
\text { Ebrahim, } 2006\end{array}$ & $\begin{array}{l}\text { "being answerable to stakeholders for the actions of the organization, whether by internal or } \\
\text { external initiation" (p.196) }\end{array}$ \\
\hline $\begin{array}{l}\text { Gray, Bebbington \& } \\
\text { Collison, } 2006\end{array}$ & $\begin{array}{l}\text { "Accountability is, definitionally, about the rights of society (or groups/stakeholders within } \\
\text { society) and relates to the rights that emerge from the relationship between the accountable } \\
\text { organisation (the accountor) and the accountee" (p.334) }\end{array}$ \\
\hline $\begin{array}{l}\text { Unerman \& } \\
\text { O’Dwyer, 2006b }\end{array}$ & $\begin{array}{l}\text { "Accountability can be broadly conceived of as a relational issue - being answerable to and } \\
\text { held responsible by others, or as an identity issue - being answerable to ideals or missions } \\
\text { and one's own sense of responsibility" (p.353) }\end{array}$ \\
\hline Bovens, 2007 & $\begin{array}{l}\text { "A relationship between an actor and a forum, in which the actor has an obligation to explain } \\
\text { and to justify his or her conduct, the forum can pose questions and pass judgement, and the } \\
\text { actor may face consequences" (p.450) }\end{array}$ \\
\hline Messner, 2009 & "the exchange of reasons for conduct" (p.920) \\
\hline $\begin{array}{l}\text { Costa, Ramus \& } \\
\text { Andreaus, } 2011\end{array}$ & "a promise to perform and a moral or legal responsibility to provide an account of it" (p.475) \\
\hline $\begin{array}{l}\text { Dhanani \& } \\
\text { Connolly, } 2012\end{array}$ & $\begin{array}{l}\text { "holding one (an organisation or individual) to account for their actions; giving (voluntarily) } \\
\text { an account of one's actions; and taking responsibility for one's actions" (p.1142) }\end{array}$ \\
\hline Murtaza, 2012 & $\begin{array}{l}\text { "the right to be involved in all phases and levels of the performance management cycle of an } \\
\text { entity" (p.112) }\end{array}$ \\
\hline Raggo, 2014 & $\begin{array}{l}\text { "Balanced definition: } \\
\text { Accountability is the governance of organizational resources and the transparent } \\
\text { communication of outcomes. It is rooted in an organization's values, mandate, and principles } \\
\text { and seeks to balance short-term and long-term organizational goals. } \\
\text { Material definition: } \\
\text { Accountability is the governance of organizational resources provided by the principals of } \\
\text { the organization, as well as the transparent communication of outcomes. It is guided by } \\
\text { achieving short-term organizational goals defined by the principals' expectations. } \\
\text { Principled definition: } \\
\text { Accountability is the achievement of the long-term goals and mandate of an organization, } \\
\text { while consistently respecting the founding principles, values, and ethics of the organization. } \\
\text { Complex definition: } \\
\text { Accountability is the informal and formal duty to govern organizational resources and } \\
\text { disseminate the outcomes of the actions of the organization transparently to all stakeholders. } \\
\text { Rules of appropriate behavior are imposed or adopted by the organization in keeping with } \\
\text { the organizing principles, values, mandates, as well as the short-term and long-term goals of } \\
\text { the organization." (p.105) }\end{array}$ \\
\hline $\begin{array}{l}\text { O’Dwyer \& } \\
\text { Boomsma, } 2015\end{array}$ & $\begin{array}{l}\text { "the means through which organisations and individuals voluntarily take responsibility for } \\
\text { shaping organisational mission and values and for opening themselves up to scrutiny" (p.41) }\end{array}$ \\
\hline Deloffre, 2016 & $\begin{array}{l}\text { "a process by which individuals or institutions answer for their actions and the consequences } \\
\text { that follow from them" (p.726) }\end{array}$ \\
\hline $\begin{array}{l}\text { Connolly, Hyndman } \\
\text { \& Liguori, } 2018\end{array}$ & "the requirement to be answerable for one's conduct and responsibilities" (p.129) \\
\hline
\end{tabular}

Based on the definitions identified in table 2-1, three themes of accountability are found in a majority of the definitions. These themes can be described as accountability 'to whom?', accountability 'for what?' and accountability 'how?' (Cordery \& Sim, 2018; Fowler \& Cordery, 2015; Kearns, 1996; Raggo, 2014; Romzek, 2000). As Drucker 
(1988, p.74) put it: "So we must think through what management should be accountable for; and how and through whom its accountability can be discharged." (italics added). A similar argument is put forward by Raggo (2014, p.3): “Aside from suffering from conceptual blurriness and disagreement on how to define accountability beyond the traditional models of the donor-recipient relationship or upward accountability (Kearns, 1996; Najam, 1996), most scholars interested in NGO accountability have agreed on the central question of these debates: accountable to what, to whom, and how? (see Ebrahim 2003a; Edwards and Hulme, 1996; Kearns, 1996)". Figure 2-1 depicts the characteristics of accountability described above.

Figure 2-1 - Characteristics of Accountability

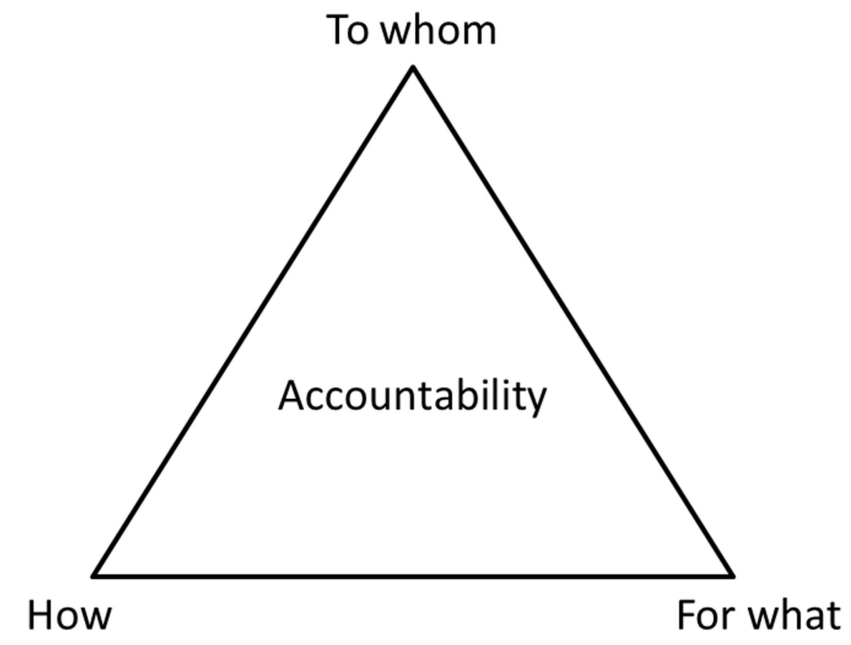

First, accountability 'to whom' emerges from the relationship created between the accountor (the organisation) and the accountee (the other) (Bovens, 2007; Gray et al., 2006; Sinclair, 1995). Without another party, there is no need or logic for accountability 
(Messner, 2009). The accountor is responsible to someone and the accountee is the audience which receives the account giving (Raggo, 2014).

Second, accountability 'for what' is about accepting responsibility (Connolly, Hyndman, \& Liguori, 2018; Dhanani \& Connolly, 2012; Ebrahim, 2003b, 2003a; Edwards \& Hulme, 1996; Finer, 1941; Flack \& Ryan, 2005; Fox \& Brown, 1998; Gray, Dey, Owen, Evans, \& Zadek, 1997; Josephson, 1988; Mason, 1992; O’Dwyer \& Boomsma, 2015; Paul, 1991; Sinclair, 1995; Unerman \& O’Dwyer, 2006b; Young, 2002) for the actions and inactions of the organisation (Brinkerhoff, 2004; Chisolm, 1995; Christensen \& Ebrahim, 2006; Deloffre, 2016; Dhanani \& Connolly, 2012; Ebrahim, 2003b, 2003a; Edwards \& Hulme, 1996; Fox \& Brown, 1998; Friedrich, 1940; Gray et al., 1997; Josephson, 1988; Mulgan, 2000; Munro \& Hatherly, 1993; Shafritz, 1992; Shearer, 2002; Sinclair, 1995) and for what the organisation "proposes to do" (Medawar, 1982, p.156).

Third, accountability 'how' is about the means of giving an account (Cornwall, Lucas, \& Pasteur, 2000; Costa et al., 2011; Dhanani \& Connolly, 2012; Gray et al., 1997; Mulgan, 2000; Shearer, 2002) by providing information (Brinkerhoff, 2004; Chisolm, 1995 ) to explain or justify (Bovens, 2007; Lawry, 1995; Munro \& Hatherly, 1993) or otherwise "demonstrate the reasonableness" of its actions (Shearer, 2002, p.545). 


\subsubsection{Accountability Conceptions in Nonprofit Organisations}

While the characteristics of accountability have been established, articulating to whom, for what and how this accountability should be given is fraught with challenges. Many scholars have highlighted the accountability challenges that nonprofits face in regards to managing the accountability demands of divergent stakeholder interests (Raggo, 2014). Scholars have used various dichotomies to conceptualise these accountability demands. Two prominent accountability conceptions are described as narrow and broad (Coule, 2015; Knutsen \& Brower, 2010; Morrison \& Salipante, 2007; Najam, 1996; O’Dwyer \& Unerman, 2008; Ospina, Diaz, \& O’Sullivan, 2002; Tacon et al., 2017). A classification of the main accountability dichotomies within narrow and broad conceptions can be found in Pilon \& Brouard (2016). These dichotomies include upward versus downward, functional versus strategic and imposed versus felt. Table 2-2 summarises the accountability conceptions, which are described below.

Table 2-2 - Summary of Accountability Conceptions

\begin{tabular}{|l|l|l|}
\hline $\begin{array}{l}\text { Accountability } \\
\text { Question }\end{array}$ & Narrow (possible related theory) & Broad (possible related theory) \\
\hline To whom? & Upward (agency) & Downward (stakeholder) \\
\hline For what? & Functional (resource dependence) & Strategic (stewardship) \\
\hline Why? & Imposed (public interest) & Felt (democratic; stakeholder) \\
\hline
\end{tabular}

Narrow conceptions of accountability can be seen as upward (Christensen \& Ebrahim, 2006; Ebrahim, 2003a, 2003b; Edwards \& Hulme, 1996; O’Dwyer \& Unerman, 2008; Ospina et al., 2002), functional (Coule, 2015; Ebrahim, 2003b, 2003a; Hug \& Jäger, 2014; Knutsen \& Brower, 2010; O’Dwyer \& Unerman, 2007) and imposed 
(Cordery \& Baskerville, 2011; Ebrahim, 2003b; Morrison \& Salipante, 2007; O’Dwyer \& Boomsma, 2015). While broad conceptions of accountability can be seen as downward (Christensen \& Ebrahim, 2006; Ebrahim, 2003a, 2003b; Edwards \& Hulme, 1996; O’Dwyer \& Unerman, 2008; Ospina et al., 2002), strategic (Coule, 2015; Ebrahim, 2003b, 2003a; Hug \& Jäger, 2014; Knutsen \& Brower, 2010; O’Dwyer \& Unerman, 2007) and felt (Cordery \& Baskerville, 2011; Ebrahim, 2003b; Morrison \& Salipante, 2007; O’Dwyer \& Boomsma, 2015).

Upward accountability seems to be conceptually salient because it evokes the principal-agent relationship found in agency theory (Fowler \& Cordery, 2015). Upward accountability is based on the pressure that is exerted by upward forces to control agents (Munro \& Hatherly, 1993). Nonprofits are pressured to meet the needs of upward stakeholders as a result of their ability to 'punish' nonprofits for not meeting their demands (Najam, 1996). Upward stakeholders can punish nonprofits by ceasing their funding, or by imposing penalties and sanctions for noncompliance.

Functional accountability focuses on the organisation's short-term objectives (Ebrahim, 2003a), on gaining resources (Hug \& Jäger, 2014; Raggo, 2014) and prioritises funders (O’Dwyer \& Unerman, 2007). Such a view seems to align with the principles of resource dependence theory. Resource dependence theory focuses on the behavioural pressures organisations face to secure external resources (Pfeffer \& Salancik, 1978). Under a resource dependence perspective, the nonprofit organisation is concerned with 
being accountable to resource providers (Hug \& Jäger, 2014) and can help explain the control pressures that nonprofits face.

Imposed accountability prioritises formal, coercive and compliance-based forms using mainly quantitative measures (O’Dwyer \& Boomsma, 2015). They are explicit rules (Morrison \& Salipante, 2007), often legal requirements to achieve at specified and regular intervals. Such a view seems to align with the principles of public interest theory. Public interest theory focuses on the regulatory requirements that are forced upon organisations due to inefficient or inequitable practices (Baker, 2005). Under public interest theory, the organisation demonstrates accountability by producing and disseminating the non-voluntary information that is demanded by regulators in order to reduce information asymmetries with the public (Cordery, 2013).

A downward perspective of accountability evokes a stakeholder theory approach (Ebrahim, 2003a; Fowler \& Cordery, 2015). Under this approach, organisations are motivated to balance the competing needs of divergent stakeholders. In contrast to upward stakeholders, downward stakeholders are characterised by limited inducements (Ebrahim, 2003a; Najam, 1996). Tackling this issue is important to meeting the needs of downward stakeholders (Christensen \& Ebrahim, 2006; Costa et al., 2011). To balance stakeholder relationships and broaden accountability, it is suggested that organisations move away from an over emphasis on 'control' (Munro \& Hatherly, 1993) and create feedback mechanisms that engage with downward stakeholders (O’Dwyer \& Unerman, 2008; Tacon et al., 2017). 
Strategic accountability focuses on the organisation's long-term objectives (Ebrahim, 2003a), is value-driven (Knutsen \& Brower, 2010) and prioritises the mission of the organisation (Coule, 2015). Strategic accountability augments short-term objectives by de-emphasizing functional and financially fixed accountability forms by embracing the broader social aspects of its actions (O’Dwyer \& Unerman, 2007). This perspective seems to align with the principles of stewardship theory. Stewardship theory focuses on improving the strategic priorities of the organisation (Davis, Schoorman, \& Donaldson, 1997). Under a stewardship theory perspective the nonprofit is concerned with being accountable for the performance of the organisation (Coule, 2015) and can help explain the organisation's role in supporting management and developing strategy (Cornforth, 2004; Kreutzer \& Jacobs, 2011; Maier \& Meyer, 2011; McCambridge, 2004).

Felt accountability privileges the nonprofit's sense of its own moral (i.e. felt) responsibility, regardless if it is imposed or not (Cordery \& Baskerville, 2011; Fry, 1995; O’Dwyer \& Boomsma, 2015). It is concerned with the negotiations that exist with all stakeholders, regardless of their relative power to impose requirements upon the organisation (Morrison \& Salipante, 2007). Such accountability may best be explained by democratic theory, or again with stakeholder theory. Under democratic theory, the organisation is concerned with being accountable to its members or its constituents, and decisions are made by majority, while under stakeholder theory the organisation is accountable to all those affected by the actions of the organisation (Coule, 2015). 
In summary, a narrow conception of accountability can be seen as an upward and functional process to meet imposed requirements. It can be defined as accountability with a short-term focus (Najam, 1996) to the organisation's principals only (Knutsen \& Brower, 2010). These principals may include donors, funders and regulators (Ebrahim, 2003a, 2003b; Knutsen \& Brower, 2010; Ospina et al., 2002).

In contrast to narrow conceptions of accountability, a broad conception of accountability is a downward and strategic process to provide information that is based on felt responsibility. Broad accountability extends past the short-term focus and to less direct stakeholders. It can be described as a responsibility that organisations have to all those affected by the actions of the organisation (Unerman \& O'Dwyer, 2006b) and is about the negotiation between the organisation and its stakeholders (Ospina et al., 2002). In addition to donors, funders and regulators, these stakeholders may include members, employees, clients, beneficiaries, board of directors, management, volunteers, partner organisations, communities and the public as large (Ebrahim, 2003a, 2003b; Knutsen \& Brower, 2010; Ospina et al., 2002). The following quote summarizes well the concept of broad accountability.

"In terms of accountability, this implies that NPOs should be not only accountable to stakeholders for the financial sustainability and for the social impact of their activities as defined in their mission, but also for the impact they have on stakeholders and society at large in carrying out their social mission" (Costa et al., 2011, p.477). 
Therefore, broad accountability can be framed as a larger concept which also encompasses narrow accountability forms (O'Dwyer \& Unerman, 2008). For the purposes of this study, the larger concept of broad accountability is adopted.

\subsubsection{Governance}

The following discussion addresses what governance is, discusses the role of governance mechanisms and addresses governance in the context of nonprofits.

\subsubsection{What is Governance?}

In management research, governance is one of the most widely researched topics (Tihanyi, Graffin, \& George, 2014). The traditional view in corporate governance research has referred to governance as "the ways in which suppliers of finance to corporations assure themselves of getting a return on their investment" (Shleifer \& Vishny, 1997, p.737). This view stems from an agency perspective wherein governance is intended to align the interests of agents with those of the principals (Jensen \& Meckling, 1976). Corporate governance has become synonymous with an agency perspective, and has therefore been seen as a way principals put constraints on agents (Daily, Dalton, \& Cannella, 2003). Such a view can also be found within the nonprofit literature, where "nonprofit corporate governance refers to the set of internal and external mechanisms designed to ensure that managers are working to fulfill their organization's charitable mission and fiduciary responsibilities and, in turn, to minimize the misuse of charitable 
assets." (Harris, Petrovits, \& Yetman, 2015, p.580). However, this view has been seen as a rather traditional and narrow perspective of governance (Daily et al., 2003; Tihanyi et al., 2014).

A broader view of governance has emerged and defines it as "the determination of the broad uses to which organizational resources will be deployed and the resolution of conflicts among the myriad participants in organizations" (Daily et al., 2003, p.371). Another recent view has defined governance as the "leadership systems, managerial control protocols, property rights, decision rights, and other practices that give organizations their authority and mandates for action" (Tihanyi et al., 2014, p.1535). These views have extended governance beyond agency perspectives by looking at how organisations are managed beyond merely financial prudence towards a wider strategic role (Daily et al., 2003; Tihanyi et al., 2014).

Definitions of governance can also be found in the accounting profession dictionary. Governance (gouvernance) has been defined as the: “organisation du pouvoir à la tête d'une entité, qui repose sur un ensemble de structures et de règles internes régissant les relations entre la direction, le conseil d'administration, les actionnaires ou associés et les autres parties prenantes, de même que les droits et responsabilités de chacun, dans la conduite et le contrôle des affaires de l'entité, et définissant les objectifs à poursuivre, conformes aux intérêts de l'entité et de ses parties 
prenantes, et les moyens que l'on se donne pour les atteindre et assurer le suivi des activités et des résultats" (Ménard, 2014). (author translation: "organisation of power at the head of an entity, which is based on a set of structures and internal rules governing relations between management, the Board of Directors, the shareholders or partners, and other stakeholders, as well as the rights and responsibilities of each, in the conduct and control of the affairs of the entity, and defining the objectives to be pursued in line with the interests of the entity and its stakeholders, and means that the entity gives itself to reach and keep track of the activities and results").

Governance has further been referred to as the role of the persons or entities "with responsibility for overseeing the strategic direction of the entity and obligations related to the accountability of the entity" (CPA Canada, 2019, CAS 200.13.(o)). These definitions are more consistent with broader views of governance because they are not solely associated with control of agents.

These broader views of governance demonstrate the similarities between contemporary views of corporate governance and the nonprofit governance literature. Within nonprofit research, governance has been defined as the "system and processes concerned with ensuring the overall direction, control and accountability of an organization" (Cornforth, 2012, p.1121). Schnurbein (2009, p.100) defines governance as "a set of instruments and mechanisms that support the board of directors". Stone \& 
Ostrower (2007, p.417) find that governance is about "fulfilling legal and fiduciary responsibilities".

Based on these definitions of governance, three characteristics of governance can be distinguished: purposes, resources and actions. First, governance has purposes; it is not an end in itself. A key purpose of governance is that resources are deployed with the intention of achieving organisational objectives (Jepson, 2005; Speckbacher, 2008). Second, governance is about resource deployment or how organisational resources are used (Daily et al., 2003; Tihanyi et al., 2014). Third, governance is ultimately about actions resulting from decision making by those in a leadership position (Tihanyi et al., 2014). Figure 2-2 depicts the characteristics of governance described above.

Figure 2-2 - Characteristics of Governance

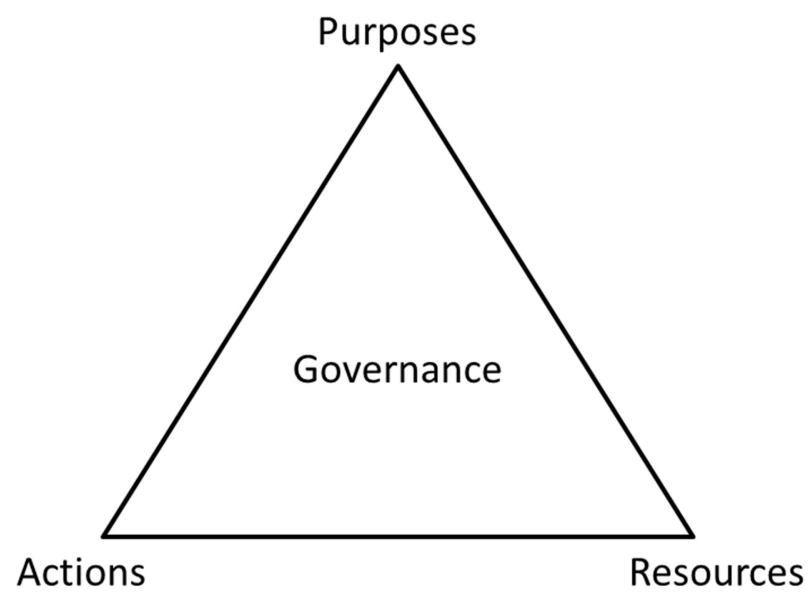




\subsubsection{Governance Mechanisms}

A 'mechanism' is defined as "a process or technique employed for achieving a result" (Christensen \& Ebrahim, 2006, p.196). Governance mechanisms are the ways in which governance is executed (Tihanyi et al., 2014). It can be seen as the actions of organisational actors (Stone \& Ostrower, 2007) which are put in place to achieve specified objectives. For example, if the organisational purpose is control (to align agents' interests with those of the organization), then a governance mechanism, such as budgetary oversight, can be put in place to achieve the organisational purpose of control. In the context of accountability, governance mechanisms are a means in "how accountability will happen" (Williams \& Taylor, 2013, p.572).

The literature discusses two broad categories of governance mechanisms, either internal mechanisms put in place by internal organisational actors or external mechanisms originating from the organisation's environment (Walsh \& Seward, 1990; Weir, Laing, \& McKnight, 2002). A classification of governance mechanisms can be found in Brouard (2016) and a detailed description can be found in Brouard \& Di Vito (2010). While Brouard \& Di Vito (2010) was prepared for small and medium enterprises (SME), many of the governance mechanisms are relevant to nonprofits. Categories of internal governance mechanisms include: beliefs and values, board of directors, audit committee, other board committees, advisory boards, family groups and rules, remuneration plans, management systems and ownership structure. Categories of external governance mechanisms include: the market, shareholders/members (stakeholders), 
employees, legal system, disclosure requirements, accounting profession, results and performance, media pressures and societal ethics and morality.

Research on nonprofit governance mechanisms has evolved and expanded, looking at many variables of what could be called 'good governance'. For example, nonprofit governance has studied the characteristics of the Board of Directors (such as board independence, diversity, size, level of professionalization, members' roles, etc.) (Aggarwal, Evans, \& Nanda, 2012; Brown, 2002; Cornforth \& Simpson, 2002;

Cumberland, Kerrick, D’Mello, \& Petrosko, 2015; O’Regan \& Oster, 2005; Ostrower \& Stone, 2010; Paulus \& Lejeune, 2013; Zimmermann \& Stevens, 2008), stakeholder participatory mechanisms (Christensen \& Ebrahim, 2006; Cordery \& Baskerville, 2011; Costa et al., 2011; O’Dwyer \& Unerman, 2008; Ospina et al., 2002; Unerman \& O'Dwyer, 2006b) and employee training on governance issues (Duncan \& Schoor, 2015; Gibelman \& Gelman, 2001; Wellens \& Jegers, 2014). This list is not exhaustive, and the focus of nonprofit governance research is not limited to these examples.

\subsubsection{Information}

The following discussion addresses what information is and describes, through information strategies, how information is enacted. 


\subsubsection{What is Information?}

Information is a message with meaning which is derived from data (Davenport \& Prusak, 1998). It is “data endowed with relevance and purpose” (Drucker, 1988b, p.46). Information is transmitted by a sender to a receiver via a communication channel (Davenport \& Prusak, 1998). Assuming the communication is understood, the information received is interpreted and converted into some form of knowledge by the receiver (Capurro \& Hjorland, 2003). Therefore, knowledge is created through the socialising process of information transfer between individuals, organisations and societies, and as such, information is the building blocks of knowledge (Nonaka, 1994).

While knowledge is an important organisational concept, the focus of this study is on information, and the transfer of information (i.e. communication) from the perspective of the sender (i.e. the organisation). The way the information is interpreted by the receiver and converted into knowledge falls outside the scope of this study.

Information is important to organisations because they are "open social systems that must process information" for strategic purposes (Daft \& Lengel, 1986, p.555). Organisations collect information for all kinds of reasons, such as decision making, surveillance, and as a source of organisational legitimacy (Feldman \& March, 1981).

One could argue that information is a source of organisational value (Davenport \& Prusak, 1998), and that information can be evaluated based on its quality and quantity. 
Information quality is characterised in relation to user usefulness (Nelson, Todd, \& Wixom, 2005), of which usefulness is information that meets or exceeds the needs of users (Kahn, Strong, \& Wang, 2002) and includes characteristics of relevance, faithful representation, comparability, verifiability, timeliness and understandability (CPA Canada, 2019, Part I, Chapter 2, para. 2.4). Information quantity is characterised in relation to its sufficiency. Too much information makes it harder to make sense of it (Davenport \& Prusak, 1998), while too little of it increases the risk of making poor decisions (Feldman \& March, 1981).

\subsubsection{Information Strategies}

Closely related to information is the concept of reporting. Reporting is defined as the:

“transmission d'informations de nature financière ou non financière à des parties prenantes au sujet de l'entité" (Ménard, 2014). (author translation: "transmission of financial or non-financial information to stakeholders about the entity").

Information is the vehicle through which organisations demonstrate accountability to stakeholders (Connolly \& Hyndman, 2013a). More broadly, the act of reporting can refer to any form of communication or disclosure of information to the organisation's stakeholders. 
Accountability information strategies, often referred to as reporting in the nonprofit literature, has been viewed as the "provision of information that meets the needs of stakeholders" (Connolly \& Hyndman, 2013, p.60), and may contribute to accountability by connecting the results of the organisation with information provided to external parties (Lee, 2004). Accountability information strategies involve some form of communication, which can range from the simple disclosure of information (Christensen \& Ebrahim, 2006; Ebrahim, 2003a; Ospina et al., 2002) to various strategies that enable dialogue with stakeholders (Costa et al., 2011; Gray et al., 2006; Schmitz et al., 2012; Williams \& Taylor, 2013). These strategies might include community surveys, informal visits and conversations, impact assessments and appraisals, public meetings and formal and informal dialogue (Costa et al., 2011; Ebrahim, 2003a; Ospina et al., 2002).

Accountability information strategies can help foster relationships with stakeholders and enable them to evaluate the actions of the organisation vis-à-vis the assumed ex ante demands. Accountability information strategies may further empower some stakeholders to act upon the information and possibly make corrective actions or to help with decision-making (Elliott \& Jacobson, 1994).

Organisations have various content choices for collecting and communicating information (Gibbins, Richardson, \& Waterhouse, 1990). For instance, information communication can be viewed as voluntary or mandatory (Skinner, 1994), narrative or numerical (Dumay \& Roslender, 2013), financial or non-financial (Abrahamson \& Amir, 1996), or even based on visual imagery (Davison, 2004; Davison \& Warren, 2009). As 
such, there are many ways in how to present information. These content choices have important implications in how the information is understood by its users. Content choices are especially important for an organisation attempting to demonstrate accountability. In doing so, information is gathered and decisions are made as to whom (the audience), for what (the content), how (the medium used to communicate) and when (the timing) this information is communicated. Figure 2-3 depicts the characteristics of information strategies described above. These characteristics are addressed again in the accountability information strategies sub-system in figure 2-11 and the accountability framework presented by Murtaza (2012), Taylor et al. (2014) and Raggo (2014) in figures 2-4, 2-5 and 2-6.

Figure 2-3 - Characteristics of Information Strategies

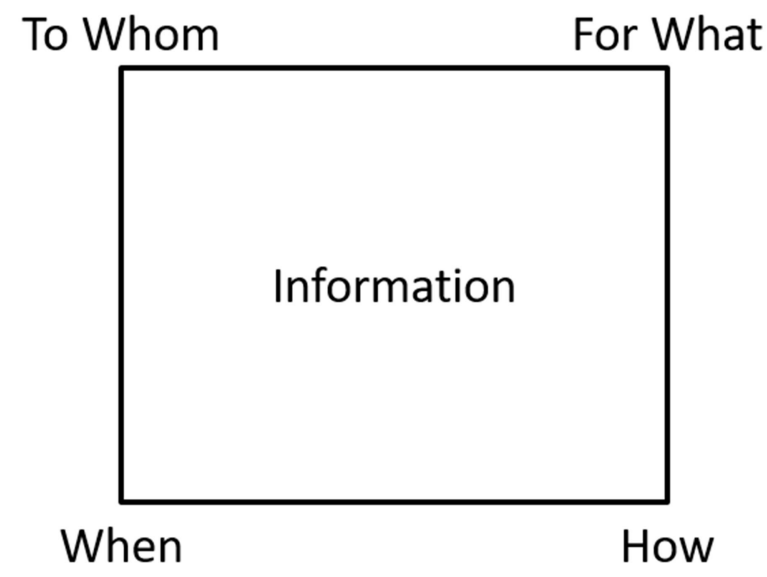

Research on accountability information strategies has looked at the strategic decisions made as to whom, for what, how and when information is communicated. For example, organisations may communicate information about their financial situation, performance results (Dainelli, Manetti, \& Sibilio, 2013), program outcomes (Schmitz et 
al., 2012), how well the organisation achieved their mission (Ospina et al., 2002), and the decision making process and their rationale (Oakes \& Young, 2008). Modes of communication may include such means as web disclosures (Dainelli et al., 2013; Saxton \& Guo, 2011; Tremblay-Boire \& Prakash, 2015), annual reviews and annual reports (Dhanani \& Connolly, 2012), and annual general meetings (AGM) along with other public oral presentations (Fowler \& Cordery, 2015).

Organisations have various motivations to communicate with their stakeholders. Examples of organisational communication motivations may be to reduce legal liability (Skinner, 1994), to maintain or enhance reputation (Skinner, 1994), and to demonstrate accountability (Elliott \& Jacobson, 1994; Palmer, 2013). The focus of this study is on the latter motivation of demonstrating accountability through means of communicating with organisational stakeholders.

One challenge with organisational motivations to communicate is that they can often be manipulated (or misconstrued) by organisational actors for personal or selfish reasons, thereby reducing information quality. Some techniques to persuade readers may include obfuscation (Courtis, 1998), impression management (Brennan, GuillamonSaorin, \& Pierce, 2009) and hegemonic discourse (Spence, 2007). For example, in the case of corporate voluntary environmental disclosures, reporting manipulations may be used as a technique to mitigate poor environmental performance and manage corporate reputations (Cho, Guidry, Hageman, \& Patten, 2012). In the case of nonprofits, reporting manipulations may also serve to misallocate indirect expenses (such as fundraising costs 
to program expenditures) (Froelich, Knoepfle, \& Pollak, 2000). To counter such motivations, the use of governance mechanisms may be used as a means of increasing the quality of such communications (Yetman \& Yetman, 2012).

\subsection{Relevant Management Theories}

This section reviews a series of management theories applicable to nonprofit accountability. The goal is to demonstrate how different theories can illuminate and enrich our understanding of organisational accountability phenomena. This study adopts the theories of contingency, system, agency, stakeholder, resource dependence and stewardship. Contingency theory is likely to play a role in the makeup of accountability management practices, systems theory is used as the framework for developing, operationalising and presenting what is known about nonprofit accountability, while the other four theories help clarify to whom nonprofits might be accountable (i.e. the 'accountees'), for what nonprofits might be accountable and how nonprofits might be accountable.

A theory is defined as "a statement of relations among concepts within a set of boundary assumptions and constraints" (Bacharach, 1989, p.496). Another definition explains a theory as "a set of interconnected propositions that have the same form as laws but are more general or abstract" (Singleton \& Straits, 2010, p.24). In short, a theory is a series of concepts intended to explain phenomena. The broader the ideas are at explaining something, the more they are deserving to be called theory (Weick, 1989). Therefore, a 
theory's value is derived from its ability to explain a phenomenon. As a result, it is important to understand theory because it helps make sense of organisational activity (Weick, 1989). Theories also help explain phenomena at different levels or units of analysis.

While theories cannot always provide a complete representation of a particular phenomenon, criticism seems to revolve around their apparent weaknesses. Given that good theories tend to be parsimonious (Eisenhardt, 1989b; Langley, 1999), such an aspiration of completeness seems unreasonable. Therefore, individual theories on their own cannot readily be expected to explain and predict all phenomena; they can only be expected to explain partial realities. For instance, agency theory is not sufficient to capture all the organisational complexities that exist and, therefore, needs to be coupled with other complimentary, but often conflicting, theories (Eisenhardt, 1989a). As each theory may offer partial predictions or explanations, particularly in situations of complex phenomena, multiple theories may be required to more completely explain phenomena (Watts \& Zimmerman, 1986, 1990). Therefore, the following theories are chosen for their utility in explaining partial realities of organisational accountability phenomena in the context of nonprofit organisations.

Kreutzer's (2009) study on nonprofit board roles proposes the following theories to explain board roles: agency, stakeholder, resource dependence, stewardship, democratic and managerial hegemony. Cumberland et al. (2015) put forward the management theories of agency, stakeholder, resource dependence and stewardship that 
align with and explain four key nonprofit board governance roles of monitoring, supporting, partnering and representing. The first four of Kreutzer's (2009) theories support Cumberland et al.'s (2015) assessment of relevant management theories, while the two last theories help explain the boards' representativeness of multiple constituencies (i.e. democratic theory) and the board's symbolic rubber-stamping roles (i.e. managerial hegemony theory). Even though these two theories are mentioned in the literature, they are less relevant in explaining nonprofit accountability and for that reason less relevant to this study. Another theory discussed in the literature and used to explain imposed accountability is public interest theory. However, other theories, notably agency theory, can be substituted to explain to whom, for what and how nonprofits might be accountable. As such, public interest theory is also less relevant to this study.

While the theories put forward by Cumberland et al. (2015) are related to board governance, it is argued that these same theories also help explain facets of nonprofit accountability (see Coule, 2015; Tacon et al., 2017). Cornforth and Edwards (1999) put forward similar theories to explain board roles: including agency, democratic (describing it as a need to reconcile the interests of different stakeholders), resource dependence and stewardship.

Therefore, the four theories of agency, stakeholder, resource dependence and stewardship are chosen help to explain different facets of accountability to whom, for what and how. First, contingency theory and systems theory are reviewed. 


\subsubsection{Contingency Theory}

Contingency theory is the position that specific strategies are not optimal for all organisations; they vary in response to a variety of both internal and external factors (Hofer, 1975). The theory "emphasizes the multivariate nature of organizations and attempts to understand how organizations operate under various conditions and in specific circumstances. Contingency views are ultimately directed toward suggesting organizational designs and managerial systems most appropriate for specific situations" (Kast \& Rosenzweig, 1972, p.460). It assumes "that there is no one best way to organize" and "that any way of organizing is not equally effective under all conditions"; it must be appropriate for a specific situation (Schoonhoven, 1981, p.350). In other words, what may work for one organisation, may not necessarily work for another.

Important contingency factors put forward by Hofer (1975) include organisational characteristics, resource constraints and environmental circumstances. In addition, when contingency factors change, strategies must be carefully reassessed for their appropriateness (Hofer, 1975).

For the purposes of the research conducted here, the theory is likely to play a role in the makeup of accountability management practices (Bradshaw, 2009), wherein the adoption of governance mechanisms and information strategies may work for one organisation, but not for others. Specific considerations such as the level of expertise, 
maturity, size and resources are all likely to play a role in the adoption of specific accountability management practices.

\subsubsection{Systems Theory}

Systems theory, or general systems theory, was used as the framework for developing, operationalising and presenting what is known about nonprofit accountability. A system may be defined as "a set of elements standing in interrelation among themselves and with the environment" (Bertalanffy, 1972, p.417). A system is set within an environment and is composed of distinct parts that interact to form a complex whole (Emery \& Trist, 1965; Kast \& Rosenzweig, 1972). The theory argues that complex concepts are interdependent and can only be understood through 'wholeness' (Bertalanffy, 1950), and to study parts without the whole cannot provide a complete understanding of the phenomena (Bertalanffy, 1972).

To study a phenomenon through systems theory is to view science though a new perspective (Bertalanffy, 1950, 1972), much like Kuhn’s (1996) paradigm. The systems approach differs from that of positive research approaches, like Descartes' method of understanding, of which his second tenet is "de diviser chacune des difficultés [...] en autant de parcelles qu'il se pourrait et qu'il serait requis pour les mieux résoudre" (Descartes, 1996, p.18) (“to divide each of the difficulties [...] into as many parts as possible, and as would be required to resolve it better" (translation in Descartes, 2007, 
p.25)). Therefore, epistemologically, knowledge comes to be known from systems theory as a result of the dynamic interaction among concepts (Bertalanffy, 1972).

The goal of systems theory is to integrate the various parts of the phenomenon under study into a systemic whole by showing the relationships, interdependencies and hierarchies between the parts (Emery \& Trist, 1965; Kast \& Rosenzweig, 1972). This theory is useful in addressing complexity; complexity from the environment and from the interactions between the parts (Kast \& Rosenzweig, 1972). It provides a level of abstraction that helps clarify the complexities of an otherwise complex phenomenon and helps with problem solving (Kast \& Rosenzweig, 1972). Also, expressing a system pictorially may enhance a clearer understanding of the phenomena (Checkland, 1994).

A summary of key tenets under systems theory include (Kast \& Rosenzweig, 1972):

- Systems have an input-throughput-output process, for which outputs are released into the environment;

- Systems have boundaries which separate them from their environments, of which environments are everything that is external to the system under consideration;

- Systems have feedback loops that provide information to the organisation by connecting the outputs to the inputs to either confirm the system's functioning or signal that corrections are needed; and

- Systems can be elaborated at various levels of detail, allowing for subsystems and suprasystems, and a hierarchy of parts. 
It is purposeful to associate or call the phenomenon under study an accountability 'system' because the individual parts within the system are not whole without consideration of the other interdependent parts. For example, accountability information strategies on their own are incomplete without some point of reference to an audience, a target or a stakeholder to communicate with. These two parts are interrelated which makes systems theory useful for the purposes of this study. Also, the boundaries of the accountability system need to be delineated from its environment. For the purposes of this study, the boundaries of the accountability system are the parts that the organisation can control and in relation to the stakeholders' demands.

\subsubsection{Agency Theory}

From its roots in economics, agency theory focuses on how organisations can control agency problems by aligning the interests of agents with the interests of principals (Fama \& Jensen, 1983; Jensen \& Meckling, 1976). The theory is based on the underlying concept of principals holding agents to account for their actions (Eisenhardt, 1989a). The agents themselves are assumed to be a priori individualistic, opportunistic, self-serving (Davis et al., 1997) and materialistic (Hirsch, Michaels, \& Friedman, 1987).

From a nonprofit perspective, the organisation, as an agent, is controlled by its principals and is thus only concerned with being answerable to them (Christensen \& Ebrahim, 2006). Those in control of the organisation are the salient accountees to which the organisation accounts (Munro \& Hatherly, 1993). Therefore, under an agency theory 
perspective, the accountability objective is to satisfy the needs of the principal. Examples of principals in a nonprofit context include donors, funders and regulators (Ebrahim, 2003a, 2003b; Knutsen \& Brower, 2010; Ospina et al., 2002).

Under an agency theory perspective, the primary governance objective is to create governance structures that control agents by aligning their interests with those of the organisation's principals (Eisenhardt, 1989a; Jensen \& Meckling, 1976). Examples of governance mechanisms include budgets and target incentives. In addition, information strategies are used to control managerial opportunism by reducing information asymmetry between the agents and the principals (Watts \& Zimmerman, 1986, 1990). As such, the organisation demonstrates accountability by reducing information asymmetry in order to respond to internal and external monitoring and control mechanisms.

\subsubsection{Stakeholder Theory}

Stakeholder theory is rooted in business ethics (Goodpaster, 1991; Jones, 1995). A stakeholder is defined as "any group or individual who can affect or is affected by the achievement of the organization's objectives" (Freeman, 1994, p.46). Stakeholder theory focuses on the organisation's concerns beyond that of principals (Freeman, 1994); it "require[s] corporations to move beyond their legal and statutory responsibilities" (Coule, 2015, p.79). As such, organisations have a moral obligation to those affected by their actions beyond a purely legal perspective (Donaldson \& Preston, 1995) and "to be afforded stakeholder status, a relationship must exist” (Miles, 2017, p.440). 
Under a stakeholder perspective, the question of to whom accountability should be given, would be answered as all those affected by the actions of the organisation (Fowler \& Cordery, 2015; Unerman \& O’Dwyer, 2006a, 2006b). Although these stakeholders can be operationalised and bounded with the theory of stakeholder identification and salience (Mitchell, Agle, \& Wood, 1997). Therefore, nonprofit accountability is concerned with being accountable to a wide range of constituencies (Dhanani \& Connolly, 2012; Ebrahim, 2003a; Fowler \& Cordery, 2015). Under this perspective, the primary accountability objective is to meet the demands of stakeholders. This perspective requires nonprofits to manage their stakeholder relationships to a broad set of constituents. From this viewpoint, organisations have a responsibility to honor their stakeholders' needs ethically and equally (Dainelli et al., 2013; Dhanani \& Connolly, 2012). It is therefore "concerned with how the power of stakeholders and their competing interests are managed by the organization in terms of broader accountability" (Dainelli et al., 2013, p.651). As such, mechanisms must be created to ensure fairness among the constituents concerned (Dhanani \& Connolly, 2012). These stakeholders are commonly identified as donors, funders and regulators, as well as members, employees, clients, beneficiaries, board of directors, management, volunteers, partner organisations, communities, and the public at large (Ebrahim, 2003a, 2003b; Knutsen \& Brower, 2010; Ospina et al., 2002).

Under this perspective, the primary governance objective is to balance the competing interests of the various stakeholders (Kochan \& Rubinstein, 2000). This helps 
to explain the organisation's activities of engaging stakeholders in dialogue and information gathering related to their demands (Cordery \& Baskerville, 2011; Cornforth, 2004; Maier \& Meyer, 2011; McCambridge, 2004; Rehli \& Jäger, 2011; Schnurbein, 2009; Speckbacher, 2008; Wellens \& Jegers, 2011, 2014). Information strategies are used to provide the necessary information that meets the demands of stakeholders (Dumay \& Roslender, 2013; Spence, 2007). As such, the organisation demonstrates accountability by engaging in stakeholder dialogue in order to balance the competing interests of stakeholders.

\subsubsection{Resource Dependence Theory}

Resource dependence theory focuses on the behavioral pressures organisations face to secure external resources in order to ensure the organisation's continued stability (Pfeffer \& Salancik, 1978). The organisation is therefore focused on securing resources rather than specifically trying to achieve the organisation's mission. From this perspective, the goal of the organisation is "to maintain good relations with external stakeholders in order to ensure the flow of resources into and from the organization" (Cornforth \& Edwards, 1999, p.350). Therefore, resource dependence theory can help explain the importance organisations place on narrow forms of accountability, and the difficulty they face in implementing broader forms of accountability (Hug \& Jäger, 2014). 
From a resource dependence perspective, the organisation is concerned with being accountable to resource providers (Hug \& Jäger, 2014). This can help explain the control pressures that nonprofits face to maintain good relations with resource providers (Kreutzer, 2009). As such, the accountability objective is to acquire and maintain the necessary resources to ensure the organisation's continued stability (Hug \& Jäger, 2014; O’Brien, 2010). Examples of resource providers include donors and funders (Hug \& Jäger, 2014).

Resource dependence theory helps to explain the organisation's boundaryspanning activities (Cornforth, 2004; Duncan \& Schoor, 2015; Maier \& Meyer, 2011; Miller-Millesen, 2003; Rehli \& Jäger, 2011). For example, Amans et al. (2015) found that nonprofits with limited resources where forced to develop budgets with heterogeneous uses. Specifically, budgets within a performing arts organisation were used as an 'implicative' tool for resource allocation and also used to negotiate with large external funders. As such, the organisation demonstrates accountability by communicating information that allows it to maintain good relations with resource providers and enables its boundary-spanning activates.

\subsubsection{Stewardship Theory}

Stewardship theory, from its roots in sociology and psychology, challenges the economic assumptions that underlie agency theory (Davis et al., 1997). As opposed to agency theory, subordinates are a priori collectivists, pro-organisational, trustworthy 
(Davis et al., 1997) and idealist (Hirsch et al., 1987). Given these personal traits, stewardship theory assumes that subordinates are not self-interested and share the same interests as principals (Barney, 1990; Davis et al., 1997; Sundaramurthy \& Lewis, 2003).

Under stewardship theory, the board and management, as internal actors, are accountable to each other. In this way, internal actors are motivated to act in the interest of the organisation in ensuring that the organisation's assets are protected and performance is improved (Coule, 2015).

Under a stewardship perspective, the primary governance objective is to enable individuals to achieve their full potential in order to protect the organisation's resources and improve performance in the long term (Davis et al., 1997). The theory helps to explain the organisation's role in supporting management and developing strategy (Cornforth, 2004; Kreutzer \& Jacobs, 2011; Maier \& Meyer, 2011; McCambridge, 2004). Examples of governance mechanisms include the activities that build trust between the principals and subordinates, the activities that support management in its endeavours and the activities that develop a cohesive strategic plan (Davis et al., 1997). In addition, information strategies are designed to help inform strategic priorities and are used to facilitate the self-actualizing behaviour of individuals working for the organisation (Davis et al., 1997). As such, the organisation demonstrates accountability by informing others of strategic priorities in order to build trust and support management. 


\subsubsection{Comparison of Theories}

The above conducted review has revealed several insights. First, this analysis has shown that each theory explains a partial view of accountability. This helps to highlight the real-life complexities of nonprofit accountability and why organisations might have difficulty managing their accountability systems. Organisations often need to make conflicting choices between alternatives which are not always obvious to outsiders. A report on accountability in Canada's nonprofit sector explained the complexity: "Accountability in the voluntary sector is multi-layered. It means accountability to different audiences, for a variety of activities and outcomes, through many different means. This multidimensional nature is the principal complexity of accountability in the voluntary sector." (Broadbent et al., 1999, p.11).

Second, understanding various theories is also important in understanding governance mechanisms and information strategies in the context of accountability. It helps to explain the adoption of specific governance mechanisms and explain the information strategies of organisations. As such, understanding various theories can help to explain to whom nonprofits might be accountable, for what nonprofits might be accountable and how nonprofits might be accountable. Table 2-3 summarizes the key theoretical distinctions relating to nonprofit accountability. For instance, we can see that for what the organisation is accountable is multifaceted and can include: satisfying the needs of principals (Eisenhardt, 1989a), meeting the demands of stakeholders (Freeman, 
1994), ensuring the organisation's stability (Pfeffer \& Salanick, 1978) and protecting assets and improving performance (Davis et al., 1997).

Table 2-3 - Summary of Relevant Theories and their Impact on Accountability

\begin{tabular}{|c|c|c|c|c|}
\hline \multirow[b]{2}{*}{ Characteristics } & \multicolumn{4}{|c|}{ Theory } \\
\hline & Agency & Stakeholder & $\begin{array}{c}\text { Resource } \\
\text { Dependence }\end{array}$ & Stewardship \\
\hline $\begin{array}{l}\text { Accountability } \\
\text { to Whom }\end{array}$ & $\begin{array}{l}\text { Those in control } \\
\qquad . . . . . . . . . . \\
\text { donors } \\
\text { funders } \\
\text { regulators }\end{array}$ & $\begin{array}{l}\begin{array}{c}\text { All those affected } \\
\text { by the actions of } \\
\text { the organization }\end{array} \\
\quad \ldots . . . . . . . . . \\
\text { donors } \\
\text { funders } \\
\text { regulators } \\
\text { members } \\
\text { employees } \\
\text { clients } \\
\text { beneficiaries } \\
\text { board } \\
\text { management } \\
\text { volunteers } \\
\text { partner } \\
\text { organisations } \\
\text { communities } \\
\text { public at large }\end{array}$ & $\begin{array}{l}\begin{array}{l}\text { Resource } \\
\text { providers }\end{array} \\
\qquad \begin{array}{l}\text {.............. } \\
\text { donors } \\
\text { funders }\end{array}\end{array}$ & ............ \\
\hline $\begin{array}{l}\text { Accountability } \\
\text { for What }\end{array}$ & $\begin{array}{l}\text { Satisfy needs of } \\
\text { principals }\end{array}$ & $\begin{array}{c}\text { Meet stakeholder } \\
\text { demands }\end{array}$ & $\begin{array}{l}\text { Acquire and } \\
\text { maintain the } \\
\text { resources } \\
\text { necessary to } \\
\text { ensure the } \\
\text { organisation's } \\
\text { continued } \\
\text { stability } \\
\end{array}$ & $\begin{array}{l}\text { Act in the } \\
\text { interest of the } \\
\text { organisation to } \\
\text { protect assets, } \\
\text { improve } \\
\text { performance }\end{array}$ \\
\hline $\begin{array}{l}\text { Accountability } \\
\text { How }\end{array}$ & $\begin{array}{c}\text { Reduce } \\
\text { information } \\
\text { asymmetry to } \\
\text { monitor and } \\
\text { control }\end{array}$ & $\begin{array}{l}\text { Engage in } \\
\text { stakeholder } \\
\text { dialogue to } \\
\text { balance } \\
\text { competing } \\
\text { stakeholder } \\
\text { interests }\end{array}$ & $\begin{array}{l}\text { Maintain good } \\
\text { relations to } \\
\text { enable boundary- } \\
\text { spanning } \\
\text { activities }\end{array}$ & $\begin{array}{c}\text { Inform strategic } \\
\text { priorities to build } \\
\text { trust and support } \\
\text { management }\end{array}$ \\
\hline
\end{tabular}


Third, this comparison also helps demonstrate the complexities of researching organisations in the context in which they operate (Hopwood, 1983). Notably, conclusions drawn are necessarily shaped by the assumptions underlying each theory, and researchers need to be aware of them in order to avoid potential blind spots (Maxwell, 2013).

\subsection{Accountability System as a Conceptual Framework}

A conceptual framework is a "system of concepts, assumptions, expectations, beliefs, and theories that supports and informs [...] research" (Maxwell, 2013, p.39). This section proposes an accountability system as a conceptual framework that clarifies how nonprofit accountability could be conceptualised.

While other accountability systems or frameworks have been found within the literature (e.g. Costa et al., 2011; Dainelli et al., 2013; Kearns, 1994; Keating \& Frumkin, 2003; Murtaza, 2012; Taylor, Tharapos, \& Sidaway, 2014; Williams \& Taylor, 2013), the constructs within the accountability system remain unclear. For example, the 'accountability system' of Keating and Frumkin (2003) focuses on financial reporting; the one from Costa et al. (2011) focuses on the forces acting upon the accountability demands; Dainelli et al. (2013) view the accountability system as a means of communicating with stakeholders; Kearns (1994) offers a framework that focuses on performance measurement and response practices; and Williams and Taylor (2013) focus 
on the association between different stakeholders, accountability conceptions and corresponding values and purposes of accountability. In the public sector, Brandsma and Schillemans (2013) describe their view of an accountability system as a three phase process of information sharing, discussion and consequences, and Romzek and Dubnick's (1987) accountability system speaks to the different types of relationships that may exist, such as bureaucratic, legal, professional, and political.

From the literature, we gather that the accountability system is a tool used to meet the demands of stakeholders (Costa et al., 2011; Dainelli et al., 2013; Kearns, 1994; Keating \& Frumkin, 2003; Murtaza, 2012; Taylor et al., 2014; Williams \& Taylor, 2013) and to meet the organisations' mission objectives (Costa et al., 2011). The frameworks that appear most complete are those of Murtaza (2012), Taylor et al. (2014) and Raggo (2014) because they encompass the concepts of 'to whom', 'for what', and 'how'. These frameworks are presented in figures 2-4, 2-5 and 2-6.

Figure 2-4 - Adaptation of Murtaza's (2012) Accountability Framework

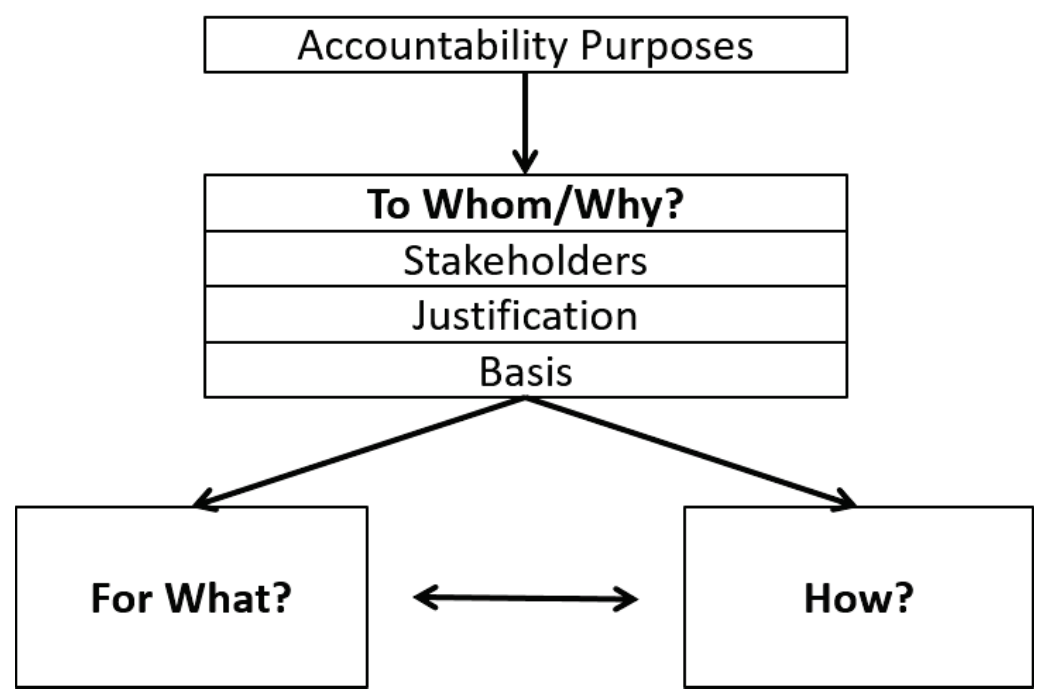


Figure 2-5 Adaptation of Taylor et al.'s (2014) Accountability Framework

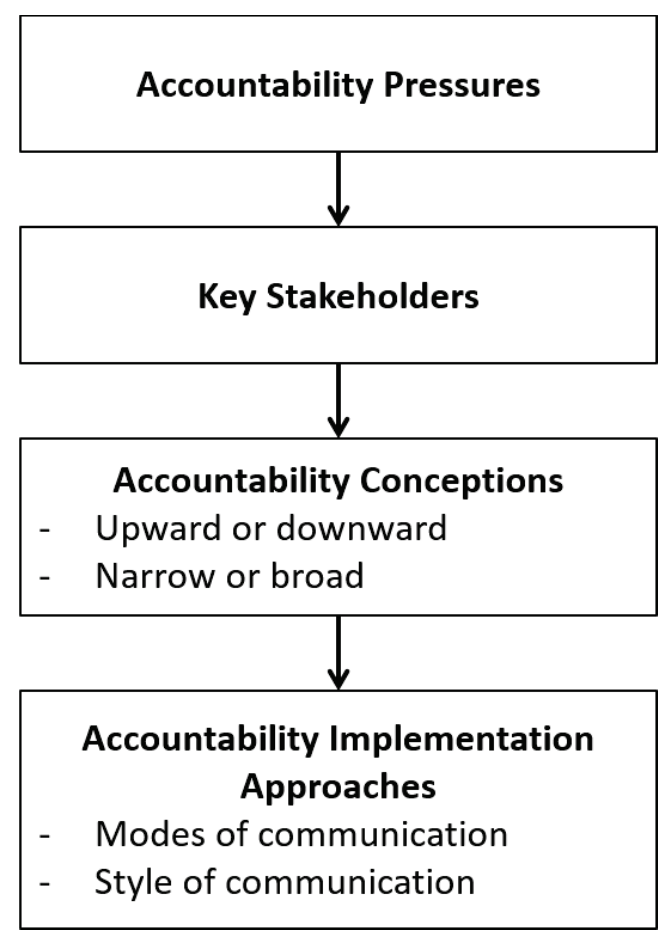

Figure 2-6 Reproduction of Raggo (2014) Accountability Puzzle

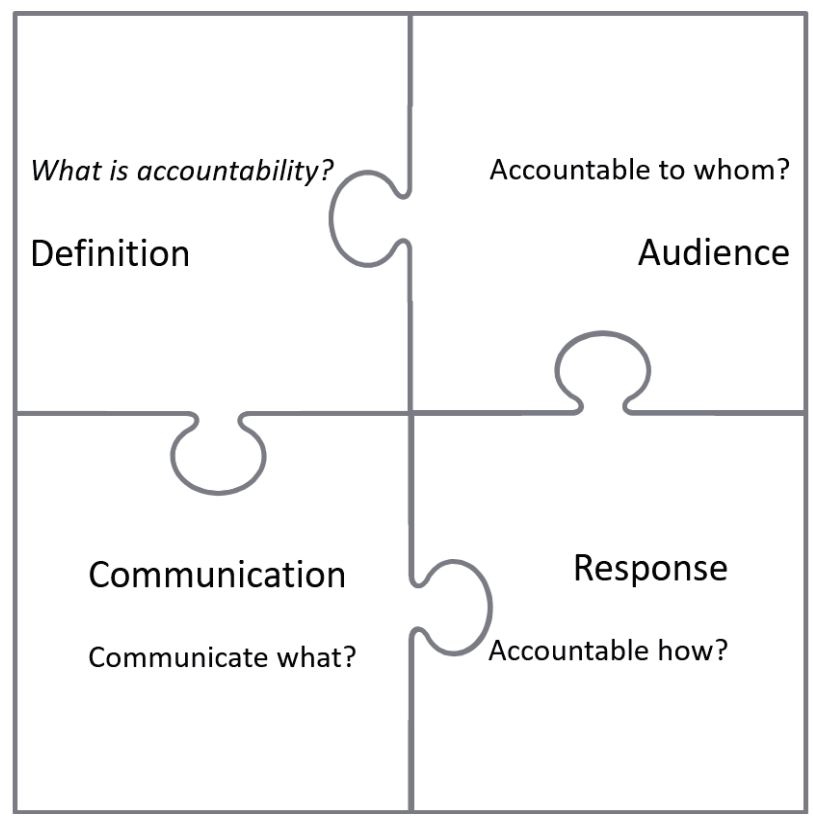


In each of the above frameworks, the concepts within them are integrated within this study's accountability system. The frameworks proposed in the literature do not, however, address the accountability system as a transformative strategic process (see O'Leary, 2017), and a social practice that is managed rather than discharged (Bovens, 2007; Roberts, 2009). To this point, Taylor et al. (2014, p.650) wrote: "the motivation of management to discharge downward accountability through published voluntary organisational reports would be strongly over-ridden $[\ldots] "$.

The focus of this study is not on what makes for 'good' accountability (e.g. Geer, Maher, \& Cole, 2008) or how it is 'discharged', but on how accountability is managed through its processes. To this point, accountability cannot be discharged if it is seen as an ethical dilemma that requires the accountor to attempt a reconciliation of conflicting stakeholder demands (Messner, 2009). Therefore, none of the accountability frameworks found in the literature are fully suitable for the intended purposes of this research because they do not explicitly have a feedback loop to reflect how accountability is managed.

For the purposes of this study, the aim of the accountability system is to disentangle the main accountability concepts in order to better understand how accountability is managed and to answer the research questions. This is supported by the following quote: "The ability to understand not only the connections among core questions of accountability, but also the ideas and motivations of the practitioners providing the answers, is key to moving to an integrated understanding of accountability views and practices in global governance" (Raggo, 2014, p.12). To accomplish this, the 
salient concepts of nonprofit accountability are explored systematically and in detailed way. In doing so, terminology used in the nonprofit accountability literature is also clarified.

\subsubsection{Development of the Accountability System}

A series of systematic steps consistent with the method recommendations of Gioia, Corley and Hamilton (2012) were used to gather the main accountability concepts found in the literature. To do so, the method's flexible boundaries were used to modify it to fit the research objectives (Gioia et al., 2012). The series of steps outlined below allowed for the formation of a data structure. A data structure is a visual representation of the inductive step-by-step process that flows from the raw data to the theoretical dimensions. This compels the researcher to think "about the data theoretically, not just methodologically" (Gioia et al., 2012, p.21). This process made it possible to step-up from the data in order to identify the main theoretical accountability concepts.

The first task was to search for recurring words, key words or topics in the articles collected in order to identify preliminary categories called first-order codes. Such codes included, for example, the papers' objectives, the theoretical findings or other salient comments about accountability. The use of qualitative content analysis was more appropriate than the use of more quantitative techniques since the number or frequency of words was less important than how the salient words were being interpreted and used by the individual scholars within the body of research. 
To start the review process, a search of the databases Business Source Complete and Proquest were used to identify relevant articles. The keywords "nonprofit accountability" were used in the abstract search criteria. Next, the table of contents of three nonprofit journals were scanned to identify other articles not caught by the keywords. The selected journals were Nonprofit and Voluntary Sector Quarterly, Voluntas and Nonprofit Management and Leadership. These journals were selected because, according to database searches, they were more likely to publish research on nonprofit accountability, and they are also regarded as being of high quality within each of the disciplines included in the review. After reading the abstracts of potential articles, the relevant articles were downloaded. The reference list of the articles obtained was also scanned to identify other relevant works.

Over 300 passages were extracted from the literature (see Pilon \& Brouard, 2016). Extraction ceased when it was felt that theoretical saturation was achieved (Eisenhardt, 1989b) because no new concepts emerged and further investigation resulted in diminishing returns (Mason, 2010). Saturation in qualitative research may be used to various ends, such as theoretical, inductive thematic, and data saturation, and is not a discrete event but a matter of degree (Saunders et al., 2018). Saturation is "an ongoing, cumulative judgment that one makes, and perhaps never completes" (Saunders et al., 2018, p.1901). 
As the research progressed, it was possible to look for similarities and differences among the many codes (Gioia et al., 2012). This process then made it possible to group the codes into a set of second-order themes. Finally, third-order theoretical concepts were able to be aggregated from the second-order themes. From this process, salient concepts of nonprofit accountability were identified. For example, accountability values and accountability purposes were identified as distinct concepts. While looking at the papers' objectives, we also found similarities between researchers looking at accountability demands and accountability pressures (Christensen \& Ebrahim, 2006; Cordery \& Baskerville, 2011; O’Dwyer \& Boomsma, 2015; O’Dwyer \& Unerman, 2008). This final level provided a basis for theorizing about a nonprofit accountability system.

The findings from the analysis revealed six different concepts of nonprofit accountability: the system, values, purposes, relationships, mechanisms and information. Each of these concepts are explained in the following sub-sections. The three 'orders' (from the codes, to the themes and finally to the concepts) are depicted in table 2-4. This data structure helps readers visualize how the researcher got from the raw data to the theoretical dimensions (Gioia et al., 2012). The first-order codes provided in table 2-4 are examples of representative passages from the articles reviewed, essentially the 'raw data' that served as the basis for the second-order themes. Following table 2-4, each concept is examined. 
Table 2-4 - Data Structure of Accountability Concepts

\begin{tabular}{|c|c|c|}
\hline First-Order Codes (Examples) & $\begin{array}{l}\text { Second- } \\
\text { Order } \\
\text { Themes }\end{array}$ & $\begin{array}{l}\text { Third- } \\
\text { Order } \\
\text { Concepts }\end{array}$ \\
\hline $\begin{array}{l}\text { - "The aim of the research is to verify if the accountability system adopted by [the } \\
\text { nonprofit] satisfies their need for multiple level information (operational, } \\
\text { legitimacy, and social value)" (Costa et al., 2011, p.470) } \\
\text { - "This raises a question about the type of accountability system that might be best } \\
\text { suited for this type of organization, given the priority placed on other types of } \\
\text { stakeholders other than beneficiaries" (Raggo, 2014, p.118). }\end{array}$ & System & $\begin{array}{l}\text { Accountability } \\
\text { system }\end{array}$ \\
\hline $\begin{array}{l}\text { - "public discourse is characterized by transparency, a cornerstone of } \\
\text { accountability such that disclosures are complete, truthful and objective" } \\
\text { (Dhanani \& Connolly, 2012, p.1144) }\end{array}$ & Transparency & \multirow{7}{*}{$\begin{array}{l}\text { Accountability } \\
\text { values }\end{array}$} \\
\hline $\begin{array}{l}\text { - "To be accountable means to accept responsibility for actions and inactions" } \\
\text { (Lawry, 1995, p.174) }\end{array}$ & Responsibility & \\
\hline $\begin{array}{l}\text { - "accountability is rooted in integrity, understood as adherence in a complete and } \\
\text { unified way to the mission of the organization" (Lawry, 1995, p.174) }\end{array}$ & Integrity & \\
\hline $\begin{array}{l}\text { - "Effective accountability requires a statement of goals, transparency of decision } \\
\text { making and relationships, honest reporting of what resources have been used and } \\
\text { what has been achieved" (Edwards \& Hulme, 1996, p.967) }\end{array}$ & Honesty & \\
\hline $\begin{array}{l}\text { - "accountability implies a willingness to endure public scrutiny, even an invitation } \\
\text { for the public to scrutinize the behaviors of the organization's leadership" } \\
\text { (Lawry, 1995, p.175) }\end{array}$ & Openness & \\
\hline $\begin{array}{l}\text { - "For these managers, responsiveness becomes a key component to manage the } \\
\text { organization's accountability environment" (Ospina et al., 2002, p.15) }\end{array}$ & Responsiveness & \\
\hline $\begin{array}{l}\text { - "In this and in other definitions, the essence of accountability is answerability, } \\
\text { since being accountable means having the obligation to answer questions } \\
\text { regarding decisions, activities, and actions" (Dainelli et al., 2013, p.653) }\end{array}$ & Answerability & \\
\hline $\begin{array}{l}\text { - "the purposes of accountability also include adjusting stated goals in line with a } \\
\text { fluid environment, proactively avoiding poor performance, converting acceptable } \\
\text { performance into excellence" (Murtaza, 2012, p.113) }\end{array}$ & Performance & \multirow{3}{*}{$\begin{array}{l}\text { Accountability } \\
\text { purposes }\end{array}$} \\
\hline $\begin{array}{l}\text { - "Accountability is also significant for nonprofit organisations if they are to } \\
\text { maintain their legitimacy in the eyes of the public" (Ospina et al., 2002, p.8) }\end{array}$ & Legitimacy & \\
\hline $\begin{array}{l}\text { - "[accountability is] not only a reactive response to overseers but a proactive one } \\
\text { linked to ensuring that the public trust is served" (Ebrahim, 2003b, p.194) }\end{array}$ & Trust & \\
\hline $\begin{array}{l}\text { - "The paper uses archival evidence collected from a variety of sources to } \\
\text { investigate the accountability relationships and practices employed in Nelson } \\
\text { educational organisations and related entities from } 1844 \text { until 1859" (Fowler \& } \\
\text { Cordery, 2015, p.129) }\end{array}$ & Relationships & \multirow{7}{*}{$\begin{array}{l}\text { Accountability } \\
\text { relationships }\end{array}$} \\
\hline $\begin{array}{l}\text { - "the key to resolving accountability issues is to engage in deliberative dialogue } \\
\text { with all stakeholders" (Williams \& Taylor, 2013, p.567) }\end{array}$ & Dialogue & \\
\hline $\begin{array}{l}\text { - "In addition, we found that each organisation negotiated accountability at } \\
\text { different levels and to different degrees" (Ospina et al., 2002, p.13) }\end{array}$ & Negotiations & \\
\hline $\begin{array}{l}\text { - "This research explores the tactics employed by beneficiaries and the donating } \\
\text { public to escalate their accountability demands on such charities" (Cordery \& } \\
\text { Baskerville, 2011, p.197) }\end{array}$ & Demands & \\
\hline $\begin{array}{l}\text { - "A key purpose of this article is to examine how these accountability pressures } \\
\text { play out in day-to-day organisational life" (Christensen \& Ebrahim, 2006, p.196) }\end{array}$ & Pressures & \\
\hline $\begin{array}{l}\text { - "We assume that the increasing managerialism-driven accountability obligations } \\
\text { have a considerable influence on nonprofit-government relations" (Greiling \& } \\
\text { Stotzer, 2015, p.1694) }\end{array}$ & Obligations & \\
\hline $\begin{array}{l}\text { - "[This paper] focuses on how funder accountability requirements are shaped by } \\
\text { both parties" (O'Dwyer \& Boomsma, 2015, p.37) }\end{array}$ & Requirements & \\
\hline $\begin{array}{l}\text { - "this study examines reasons why Amnesty's historical reliance on internal forms } \\
\text { of accountability has been augmented with a range of ad hoc external } \\
\text { accountability mechanisms" (O'Dwyer \& Unerman, 2008, p.801) }\end{array}$ & Mechanisms & \multirow{3}{*}{$\begin{array}{l}\text { Accountability } \\
\text { mechanisms }\end{array}$} \\
\hline $\begin{array}{l}\text { - "The main NGO accountability process managed by NGO coordination or } \\
\text { watchdog bodies are self-regulated accreditation mechanisms" (Murtaza, 2012, } \\
\text { p.118) }\end{array}$ & Processes & \\
\hline - "This paper develops a framework of NFP accountability through public & Practices & \\
\hline
\end{tabular}




\begin{tabular}{|c|c|c|}
\hline First-Order Codes (Examples) & $\begin{array}{l}\text { Second- } \\
\text { Order } \\
\text { Themes }\end{array}$ & $\begin{array}{l}\text { Third- } \\
\text { Order } \\
\text { Concepts }\end{array}$ \\
\hline $\begin{array}{l}\text { discourse and examines the accountability practices of a sample of large UK } \\
\text { charities through their annual reports and reviews" (Dhanani \& Connolly, 2012, } \\
\text { p.1159) }\end{array}$ & & \\
\hline $\begin{array}{l}\text {-So, in a simple (i.e. non political) world the principles of accountability can be } \\
\text { relatively easily framed through transparency and the notion of rights to } \\
\text { information within relationships mediated by closeness. Accountability can be } \\
\text { considered discharged if the information can be obtained through an existing } \\
\text { channel." (Gray et al., 2006, p.336) }\end{array}$ & Information & \multirow{5}{*}{$\begin{array}{l}\text { Accountability } \\
\text { information }\end{array}$} \\
\hline $\begin{array}{l}\text { - "[This paper] describes the accountability relationships and mechanisms used to } \\
\text { discharge accountability" (Fowler and Cordery, 2015, p.129) }\end{array}$ & Discharge & \\
\hline $\begin{array}{l}\text { - "through its reporting, a charity projects an image of its ability to achieve its } \\
\text { mission and be accountable to its funders and other stakeholders" (Cordery and } \\
\text { Baskerville, 2011, p.201) }\end{array}$ & Reporting & \\
\hline $\begin{array}{l}\text { - "Communication mechanisms are important tools to negotiate the accountability } \\
\text { environment, to learn about and respond to the needs of the community when } \\
\text { setting priorities, and to gain legitimacy with important stakeholders" (Ospina et } \\
\text { al., 2002, p.17-18) }\end{array}$ & Communication & \\
\hline $\begin{array}{l}\text { - "Public disclosure and justification constitute the way in which nonprofits can be } \\
\text { accountable" (Lawry, 1995, p.178) }\end{array}$ & Disclosure & \\
\hline
\end{tabular}

\subsubsection{Accountability System}

The accountability system is the overall framework that integrates all the concepts of accountability into a coherent whole. This system proposes a sequential order of stakeholder relationships, governance mechanisms, and information strategies, on the foundation of underlying values and purposes of accountability. The sequence proposed seems to be the more 'natural' way for the study of the accountability process and appears to be the most widely accepted sequence within the nonprofit accountability literature. The proposed accountability system is depicted in figure 2-7. 
Figure 2-7 - Proposed Accountability System

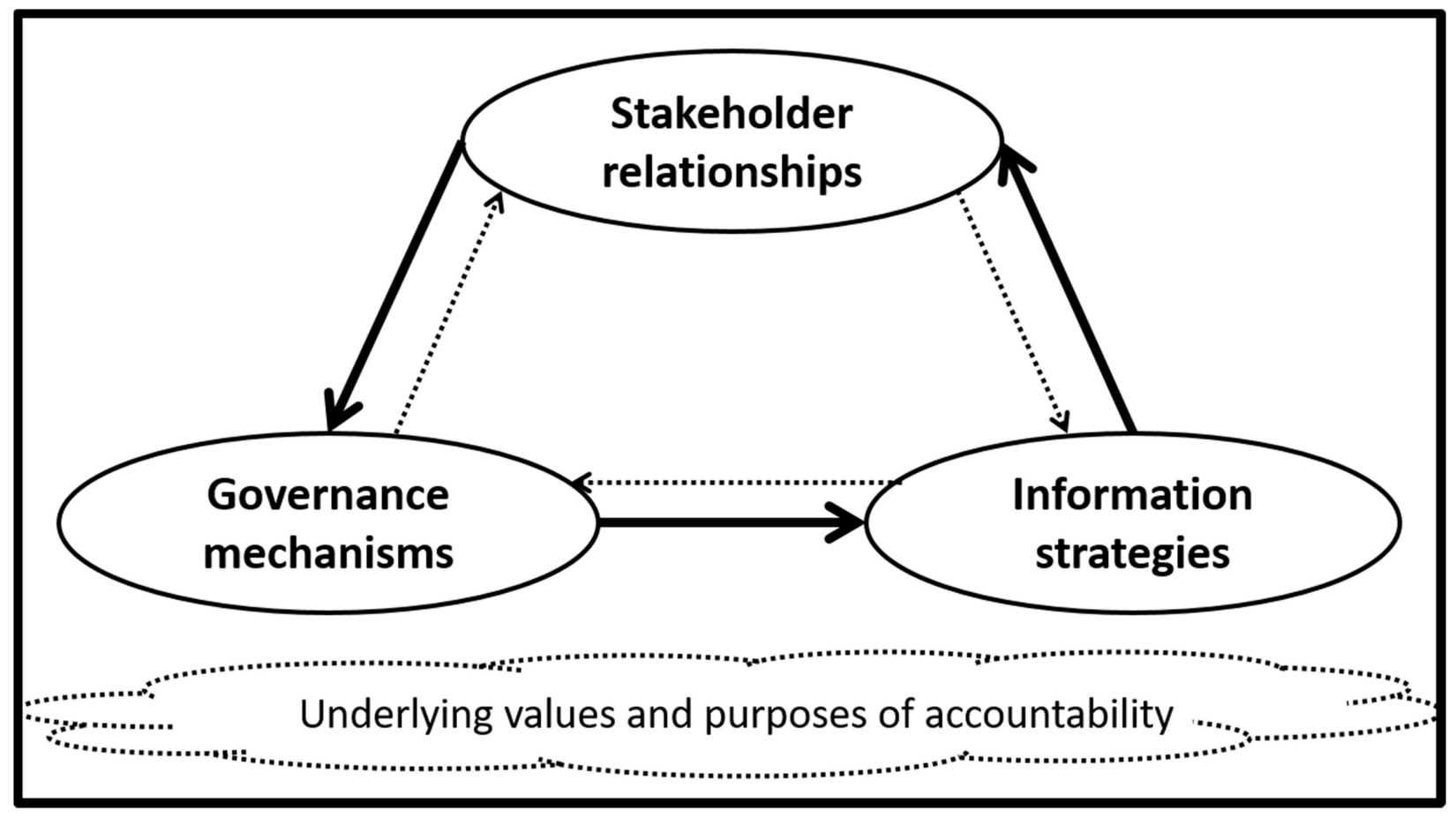

First, it is the stakeholder relationship that allows for dialogue and negotiations between the organisation (the accountee) and its stakeholders (the accountors). Second, governance mechanisms support the accountability system. The implementation of governance mechanisms affects the way in which information is collected and communicated to stakeholders and how stakeholder relationships are managed. This makes the connection between the stakeholder relationships, governance mechanisms and information strategies a dynamic process as each construct may affect the other. Third, once governance mechanisms are implemented, information strategies are selected. These stakeholder relationships, governance mechanisms and information strategies are supported by a set of accountability values and purposes. Of note, is the notion that accountability has both an ex ante and an ex post component, recognizing that 
accountability has temporal properties (which is rarely acknowledged in the literature), except by Raggo (2014, p.15): “This is an important distinction: accountability is the a posteriori evaluation of one? $[\mathrm{sic}]$ impact on other stakeholders, and relies on the notion of responsibility, which is the a priori rule setting expectations before an action has even occurred. Being accountable includes the a priori rules, standards and shared understandings of those in charge, as well as the a posteriori evaluations of relevant impacts. How one designs these rules is contingent on the context, the actors, and the activities being considered".

Temporality refers to the fluidity of activities as a result of environments, contexts and actors that can change and evolve over time and have an impact on the phenomenon under study (Langley, Smallman, Tsoukas, \& Van de Ven, 2013). In this sense, accountability practices are in a mutually interacting flux and can depend on past activities.

By integrating the concepts identified, the following definition of an accountability system is proposed:

A relational process, founded on values and purposes, to implement governance mechanisms and information strategies in order to manage the relationships with the organisation's stakeholders.

Beyond the accountability system, and in the logic of suprasystems found in systems theory, the accountability system sits within the context of an internal and 
external environment. The internal environment is separated from the external environment by the boundaries of the organization.

The internal environment may include strategy, structure, culture, process, resources, and competence (Liu, 1998). The external environment may include contextual factors such as demographics, competition, economic, technological, cultural, social, political, legal, ecological and physical factors (Albrecht, 2000) and stakeholders. The external environment also influences the organisation's resources, demands, constraints and information (Liu, 1998).

It should be noted that the internal and external environment (including the stakeholders within the environment) are mutually influential through actions and information flows (Emery \& Trist, 1965; Liu, 1998) and therefore act upon the accountability system. In addition, different organisations are not confronted with the same environments; they are affected by different factors at varying degrees (Emery \& Trist, 1965). Figure 2-8 situates the accountability system within its environment. 
Figure 2-8 - Environment of the Accountability System

\section{External Environment}

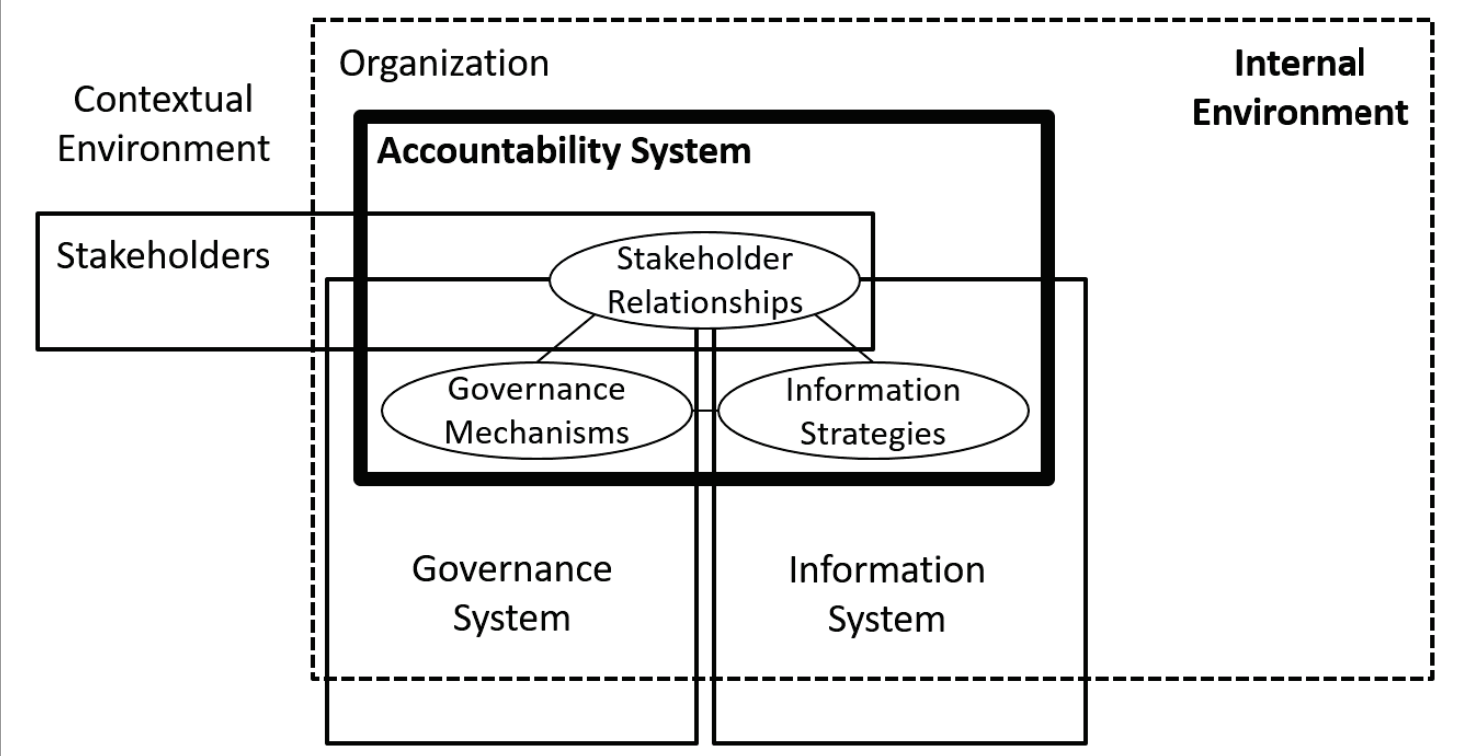

After the examination of the accountability system's environment, the next four sub-sections examine the components of the accountability system.

\subsubsection{Accountability Values and Purposes}

Accountability values and purposes serve as foundations of the accountability system, as they influence other core concepts within the accountability system. Accountability values are attributes that contribute to accountability purposes (Williams \& Taylor, 2013). Another way to distinguish between the two concepts is to view accountability values as ingredients (Wyatt, 2018) that are internal to the organisation, while accountability purposes are what the organisation tries to project outward (external objective). 
As identified in table 2-4, accountability values include 7 themes: transparency (Christensen \& Ebrahim, 2006; Dhanani \& Connolly, 2012; Edwards \& Hulme, 1996; Gray et al., 2006; Schmitz et al., 2012), responsibility (Christensen \& Ebrahim, 2006; Costa et al., 2011; Coule, 2015; Dhanani \& Connolly, 2012; Lawry, 1995; O’Dwyer \& Boomsma, 2015; Unerman \& O’Dwyer, 2006b), integrity (Lawry, 1995; Schmitz et al., 2012; Young, 2002), honesty (Edwards \& Hulme, 1996; Young, 2002), openness (Lawry, 1995; O’Dwyer \& Boomsma, 2015), responsiveness (Ospina et al., 2002) and answerability (Dainelli et al., 2013; Lawry, 1995). Stakeholders may place more emphasis on some values rather than others (Romzek, 2000), but this list appears to include the most salient values within the literature. The values adopted by organisations help to shape the way accountability is perceived and managed (Kilby, 2006). Without these guiding values, decision making and account giving may be misguided or misconstrued for self-serving purposes, which may ultimately compromise the organisation's mission (Young, 2002).

Accountability purposes have been defined as "the intended outcome or impact of establishing accountability for a particular actor” (Williams \& Taylor, 2013, p.571). Accountability purposes are the organisation's ultimate accountability goals; it is what the organisation hopes to achieve by implementing accountability. Based on the analysis, accountability purposes may include performance, legitimacy and trust. 
First, organisations are accountable for their performance (Costa et al., 2011; Dainelli et al., 2013; Ebrahim, 2003b; Fowler \& Cordery, 2015; Gray et al., 2006; Morrison \& Salipante, 2007; Murtaza, 2012; O’Dwyer \& Unerman, 2008; Ospina et al., 2002). Performance is the:

“degré de réalisation d'un objectif, de mise en œuvre d'une stratégie ou d'accomplissement d'un travail ou d'une activité" (Ménard, 2014). (author translation: "degree of achievement of a goal, of the implementation of a strategy or of the accomplishment of a task or an activity").

Performance is not fixed or clear, rather different measures (both quantitative and qualitative) can be used for evaluating 'performance' and can be oriented towards inputs, outputs, outcomes, and processes (Fowler, 1995; Romzek, 2000).

In order to be accountable for performance, organisations attempt to perform in a specified way and account for their performance achievements (Costa et al., 2011; Fowler \& Cordery, 2015; O’Dwyer \& Unerman, 2008). It is through performance information that stakeholders can evaluate the success of an organisation (Morrison \& Salipante, 2007). Nonprofit performance is not measured solely in terms of economic or financial activity (like it could be in for-profits) but is linked to an organisation's mission (Costa et al., 2011; Dainelli et al., 2013; Ebrahim, 2003b) and determined in relation to stakeholder relationships (Gray et al., 2006; Murtaza, 2012). 
Second, organisations implement accountability to maintain or gain legitimacy (Coule, 2015; Edwards \& Hulme, 1996; Jepson, 2005; Morrison \& Salipante, 2007; Najam, 1996; Ospina et al., 2002; Ossewaarde et al., 2008; Unerman \& O’Dwyer, 2006a; Williams \& Taylor, 2013). Legitimacy is defined as "a generalized perception or assumption that the actions of an entity are desirable, proper, or appropriate within some socially constructed system of norms, values, beliefs, and definitions" (Suchman, 1995, p.574). Legitimacy theory considers the needs of organisations to seek societal approval by acting in desirable and appropriate ways (Suchman, 1995). Under legitimacy theory, organisations are concerned with being accountable to those that legitimise them and requires their support (Dhanani \& Connolly, 2012). As such, legitimacy is conferred by acting legitimately, by being perceived legitimately and by showing or demonstrating legitimacy (Ossewaarde et al., 2008).

A third accountability purpose is trust. Trust is "the willingness of a party to be vulnerable to the actions of another party based on the expectation that the other will perform a particular action important to the trustor, irrespective of the ability to monitor or control the other party" (Mayer, Davis, \& Schoorman, 1995, p.712). Organisations must earn the trust of others because achieving an organisation's goals often requires interdependence with another party and a willingness of the other party to be vulnerable (Mayer et al., 1995).

When trust is eroded, the "assets upon which [the nonprofit] builds the capacity to deliver on its mission risk being weakened or destroyed" (Jepson, 2005, p.521). Trust is 
therefore built and maintained by demonstrating accountability (Dainelli et al., 2013; Fowler \& Cordery, 2015; Hyndman \& McConville, 2018; Jepson, 2005; O’Dwyer \& Unerman, 2007, 2008; Yang \& Northcott, 2019). As a result, when trust is low or broken, organisations are forced to demonstrate greater accountability in order to rebuild its trust (Dainelli et al., 2013; Hyndman \& McConville, 2018b; O’Dwyer \& Unerman, 2007).

Other purposes of accountability such as liability and controllability (Koppell, 2005; Williams and Taylor, 2013) are also found in the literature. But they are only sparsely documented. As it is only necessary to demonstrate that the concept of accountability purposes exists within the proposed accountability system these other purposes were therefore excluded.

\subsubsection{Accountability Stakeholder Relationships Sub-System}

Based on the analysis in table 2-4, the accountability concept of relationships includes dialogue, negotiations, demands, pressures, obligations and requirements. By taking note of accountability demands from stakeholders ex ante and giving account ex post, a relationship is created between an organisation and its stakeholders.

One of the main roles of this relationship is to respond to the accountability demands of stakeholders (Unerman \& O’Dwyer, 2006b). As stated by Raggo (2014, p.3) "Broadly, accountability is a relational concept and refers to the idea that some stakeholders are entitled to hold others responsible for their actions according to certain 
expectations of proper behavior (Ebrahim, 2005; Grant and Keohane, 2005)".

Accountability demands include the pressures, obligations and requirements exerted on an organisation by its stakeholder environment. Examples of accountability demands may ask organisations to demonstrate that funded projects are successful (Greiling \& Stötzer, 2015), prevent fraud, ensure efficient use of resources, ensure resources are adequate to fulfill mission, fulfill specified expectations, adopt certain mechanisms, perform certain tasks, deploy resources to specific areas or to communicate in certain ways.

Among its stakeholders, an organisation must negotiate its relationships (Coule, 2015; Edwards \& Hulme, 1995; Hug \& Jäger, 2014; Ospina et al., 2002; Raggo, 2014; Shah \& Shah, 1995) in order to find a balance between the many, and often conflicting, demands of its stakeholders. As Edwards \& Hulme (1996, p.968) put it, "equal accountability to all at all times is an impossibility". Raggo (2014, p.4) also commented: "TNGO [Transnational nongovernmental organisations] leaders have the authority to shape the answers to each of the central accountability questions, yet they have systematically been ignored in these debates. They not only have an active role in setting the various agendas of organizations, but also manage, negotiate, and supervise all accountability relationships with stakeholders. These leaders must implement accountability across various borders and balance financial incentives, organizing principles, and operational constraints, while addressing multiple accountability demands". This impossibility to satisfy all stakeholders requires nonprofits and their stakeholders to negotiate (and attempt to establish an accountability balance). A diverse group of stakeholders makes it difficult to achieve consensus. Efforts to appease one 
stakeholder group can alienate another. Compromises may result in watered down plans that miss crucial objectives (Salm, 1999). A difficulty in measuring or evaluating performance further compounds this issue (Fowler, 1995).

The pressure to balance these demands obliges nonprofits to keep an open, continuous and proactive dialogue with their stakeholders (Costa et al., 2011; Fowler \& Cordery, 2015; Oakes \& Young, 2008; Ospina et al., 2002; Saxton \& Guo, 2011; Schmitz et al., 2012; Williams \& Taylor, 2013). This dialogue may be internal or external to the organization. Dialogue may be sustained by seeking community input (Ospina et al., 2002; Saxton \& Guo, 2011), by giving beneficiaries a greater voice (Hug \& Jäger, 2014; Schmitz et al., 2012), by encouraging stakeholders to participate in the evaluation process (Costa et al., 2011), by remaining in close proximity to stakeholders (Gray et al., 2006), by treating the relationship as a partnership (O'Dwyer \& Unerman, 2007), or by entering into negotiations with stakeholders and providing them with adequate information to weigh the options (Ospina et al., 2002). These dialogue activities help nonprofits better understand the demands of their stakeholders.

Previous research into stakeholder relationships demonstrates the complexity with which accountability demands must be managed. Some research has looked at how different stakeholders have attempted to escalate their accountability demands (Cordery \& Baskerville, 2011; Greiling \& Stötzer, 2015; O’Dwyer \& Unerman, 2008). Other studies have looked at how organisations can potentially influence the accountability demands exerted upon them (O’Dwyer \& Boomsma, 2015). Research findings in this 
area have been rather revealing. Notably, there is empirical support for the idea that certain types of accountability demands impede mission achievement (Christensen \& Ebrahim, 2006; Cordery \& Baskerville, 2011; O’Dwyer \& Unerman, 2008; Young, 2002). Other studies have also noted that the complexity of accountability demands depends on the nature of the types of stakeholders (Christensen \& Ebrahim, 2006; Greiling \& Stötzer, 2015), such that some stakeholders may require, among other things, more formal forms of account giving than others.

Figure 2-9 shows the stakeholder relationships sub-system. Within an accountability system, the dialogue and negotiation process is triggered by the stakeholder demands. During this dialogue and negotiation process, an organisation and its stakeholders are in continuous reaction to and evaluation of the accountability system, after which governance mechanisms and information strategies are formed. Information is also communicated back into the stakeholder relationship and serves as a feedback loop. 
Figure 2-9 -Stakeholder Relationships Sub-System

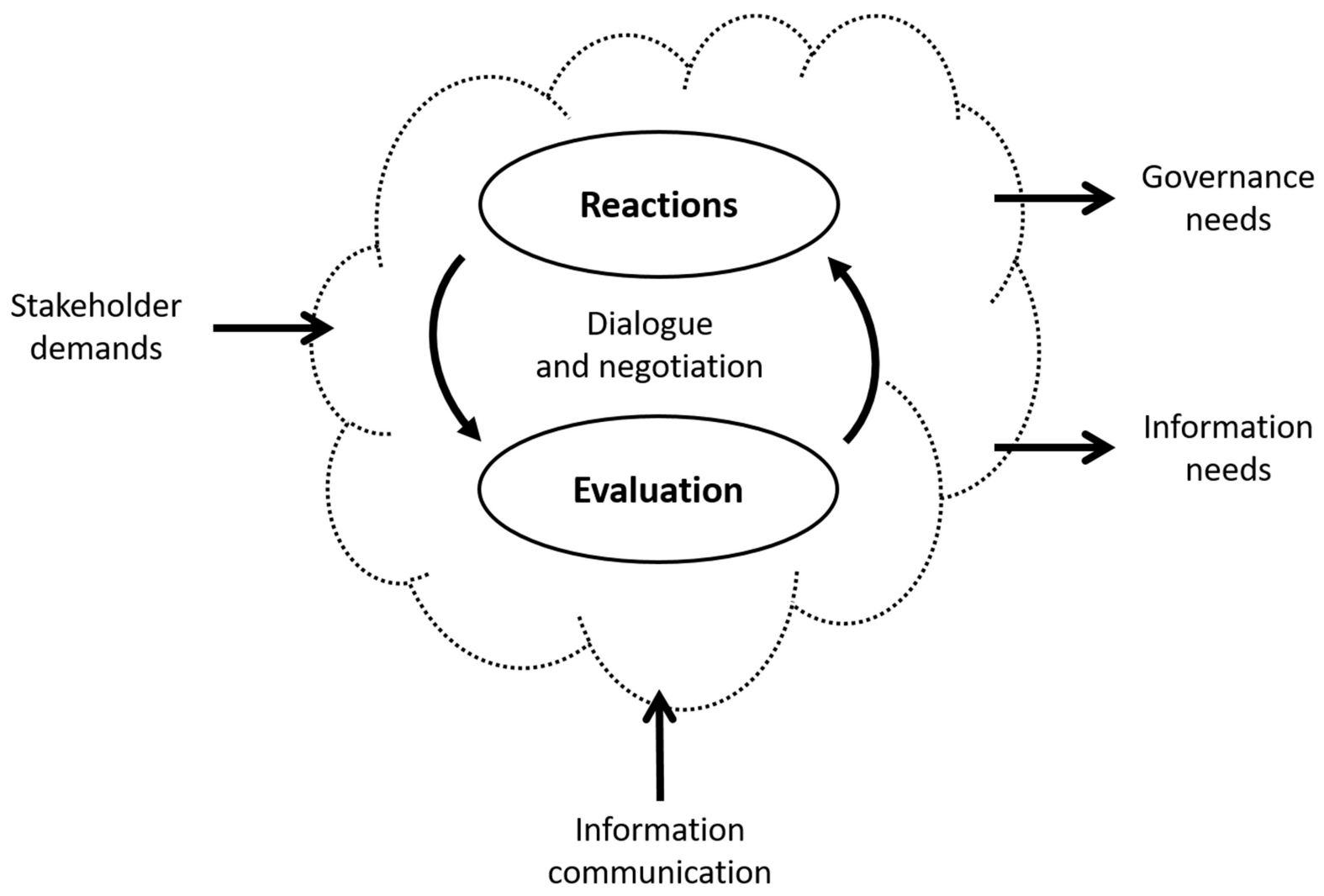

\subsubsection{Accountability Governance Mechanisms Sub-System}

Accountability mechanisms have been described as tools and processes (Ebrahim, 2003a) that refer to 'how' organisations go about implementing their accountability (Raggo, 2014). The use of effective accountability mechanisms is required to sustain relationships in the midst of stakeholder demands (Ospina et al., 2002). These mechanisms are likely to vary by organisation (Christensen \& Ebrahim, 2006; Gray et al., 2006; Unerman \& O’Dwyer, 2006a) given the heterogeneity in stakeholder demands (Dainelli et al., 2013). 
There are variations in how the term mechanism is used in the literature, yet the term is rarely defined. An exception is Christensen \& Ebrahim (2006, p.196), who define "a mechanism as a process or technique employed to achieve a result. Accountability mechanisms are distinct activities or processes designed to ensure particular kinds of results". Goodin (2003, p.365) defines accountability mechanisms as "the devices that serve to secure whatever it is (actions, results or intentions) for which people are accountable". For the purposes of the research conducted here, accountability mechanisms refer to governance mechanisms and are viewed as the actions taken to manage accountability practices (Christensen \& Ebrahim, 2006).

The combination of both internal and external governance mechanisms may be integrated into a governance mechanisms system. For the purposes of this study, a governance mechanisms system is defined as a series of governance mechanisms imposed or chosen by a set of governance actors. Governance actors are those organisations or individuals that make decisions and take actions in regard to governance mechanisms. These governance mechanisms are constructed from the pressures faced by the organisation from its environment (Ostrower \& Stone, 2010) and enabled by the governance system in place. There is evidence to suggest that governance systems play a crucial accountability role (Cavalluzzo \& Ittner, 2004). For instance, cases of fraud have shown that poor governance systems will not hold senior managers and board of directors accountable for their actions (Downes \& Russ, 2005; Melis, 2005). 
Figure 2-10 shows the accountability governance mechanisms sub-system. Within this system, governance needs are determined by accountability demands. Governance mechanisms are then put in place, within the confines of the governance mechanisms system, to meet these needs. The governance mechanisms system also serves as a valuable tool for the collection of meaningful information (Speklé \& Verbeeten, 2014), which enables organisations to communicate more effectively with stakeholders (Sundin, Granlund, \& Brown, 2010; Townley, Cooper, \& Oakes, 2003).

Figure 2-10 - Accountability Governance Mechanisms Sub-System

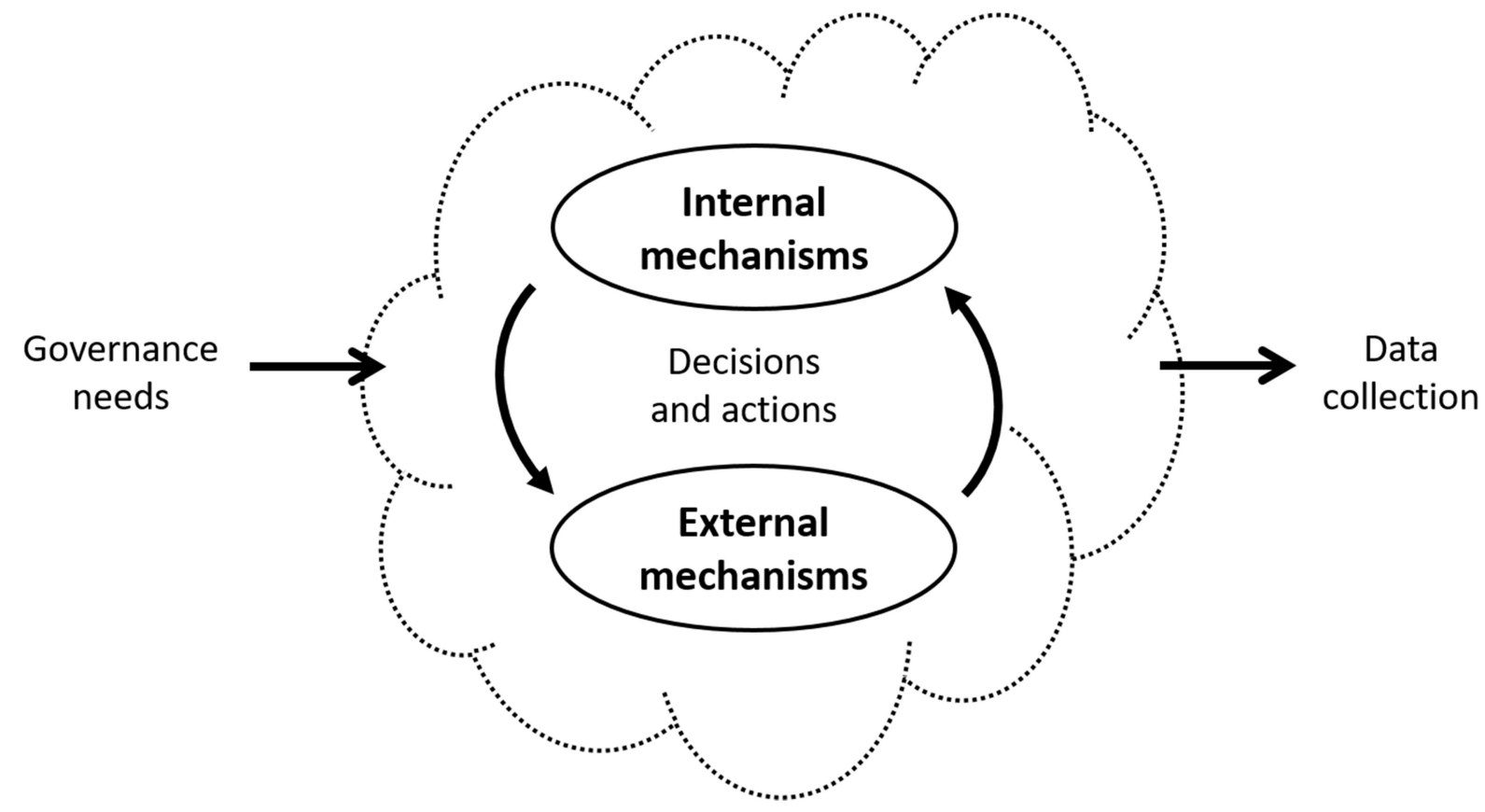

\subsubsection{Accountability Information Strategies Sub-System}

Communicating accountability information to stakeholders is a crucial part of the accountability process (Mulgan, 2000). While stakeholders may pass judgment on 
accountors at any time, the dissemination of such information arguably helps the organisation meet its accountability demands. It is therefore said to be the final step in the accountability loop (Raggo, 2014). Therefore, accountability has not been fulfilled (assuming such is possible) without the communication of information (i.e. giving account). When stakeholder expectations are fulfilled, accountability can arguably be considered as discharged (Gray et al., 2006). Such a notion implies, however, that accountability demands have been clearly established, and that performance achievements can be clearly assessed (Raggo, 2014). The multitude of information choices that are required to communicate and their importance to stakeholder relationships make the transfer of accountability information a strategic process. Information strategies refer to whom, for what, how, and when information is communicated.

An information system is an "organized combination of people, hardware, software, communications networks and data resources that collects, transforms and disseminates information in an organization" (O’Brien, 1999, p.9). Information systems perform input, processing, output and storage functions; transforming data into information products (O’Brien, 2004). Information systems have several roles; notably they serve a strategic role by helping organisations line up and explicate their objectives (Premkumar \& King, 1992). The concept of information was developed earlier in section 2.1.3.1. 
Figure 2-11 depicts the accountability information strategies sub-system. First, information needs and data collection flow into the information strategies system where it is gathered and stored (Davenport \& Prusak, 1998; Kahn et al., 2002). Information is then processed and analysed into to whom, for what, how, and when before being communicated or used for organisational action and decision making. Information is, therefore, the output of the information strategies system (Nelson et al., 2005). Managing the information strategies system is a key determinant of the quality of information produced (Nelson et al., 2005), as well as its quantity.

Figure 2-11 - Accountability Information Strategies Sub-System

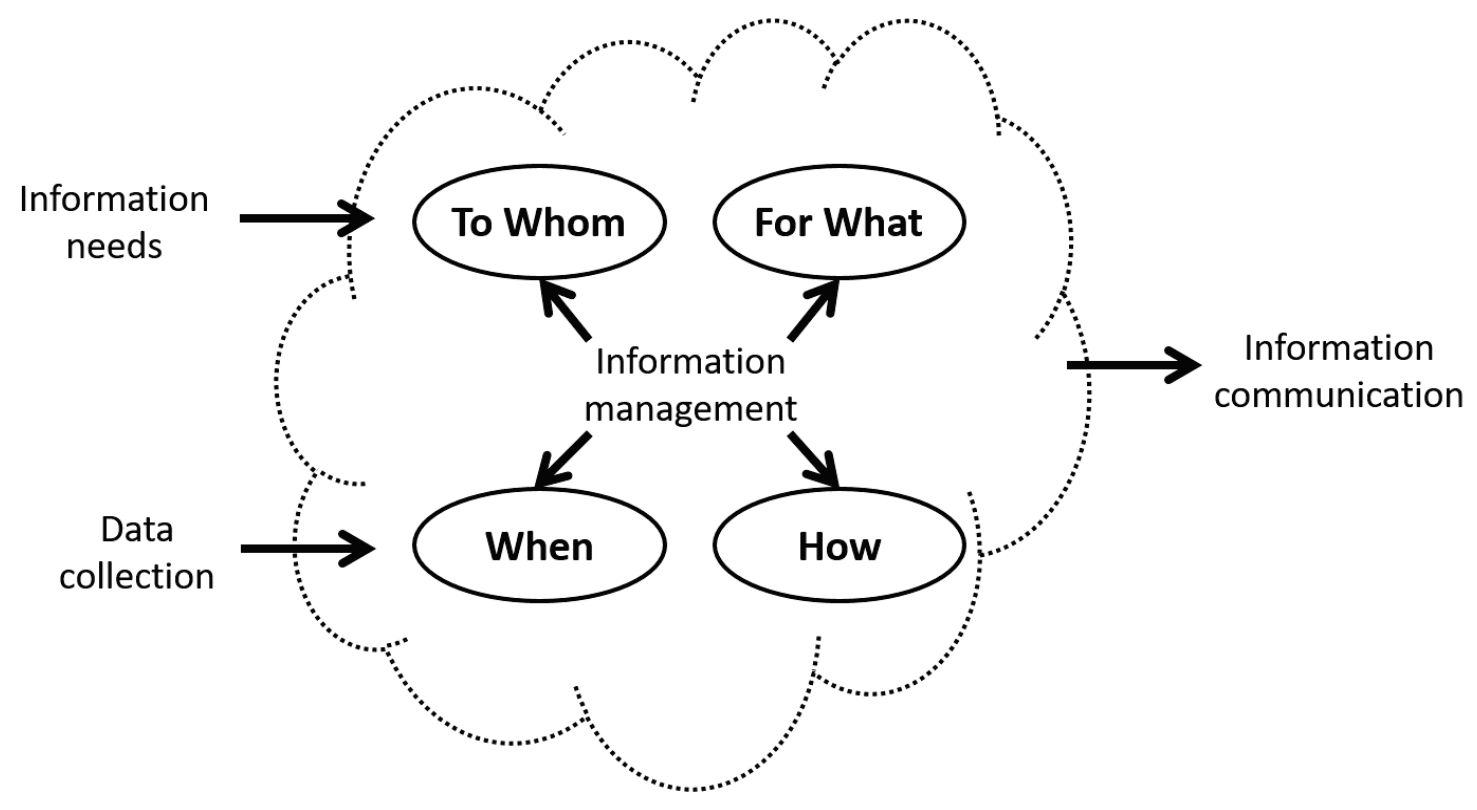




\section{CHAPTER 3: RESEARCH METHODOLOGY}

Research methodology is the series of research design choices used to conduct particular research and address a research problem. A research design is a plan used to gather and interpret data so as to answer the proposed research questions (Robson, 2002; Singleton \& Straits, 2010; Yin, 2009). In other words, the research design is the blueprint needed to conduct a particular study.

This chapter contains eight sections, which include type of research, epistemology, research approach, research strategy, data collection methods, selection of organisations and participants, data analysis, and ethical considerations.

\subsection{Type of Research}

The type of research establishes the general purpose of the study. There are generally three types of scientific research purposes, which range from exploratory, descriptive and explanatory studies (Robson, 2002; Yin, 2009). While each type of research serves a different purpose and can only be used in certain contexts, the types are not mutually exclusive, but reinforcing and may overlap. That said, because constructs on the topic of nonprofit accountability are not sufficiently developed to propose hypotheses to conduct an explanatory study and because the intention of this study is not simply to describe accountability phenomena, an exploratory study was determined to be the most appropriate type for answering the proposed research questions. An exploratory study is 
useful in identifying a problem or clarifying the nature of a problem (Armstrong, Adam, Denize, \& Kotler, 2015; Given, 2008; Robson, 2002). This type of study focuses on the discovery of key issues and variables and aims to understand more about an observed, yet unclear phenomenon.

Research types can also be viewed from the logic of induction and deduction. Under the principle of induction, theories are derived from the facts observed, while under the principle of deduction, theories are used to make predictions and offer explanations of observed phenomena (Chalmers, 1999). Each view reflects a different way of shifting from data to concepts or from concepts to data (Yin, 2011). While a conceptual framework helped guide the research developed here, explanations for the phenomenon studied were inductively derived from the data collected. This approach aligns with exploratory studies which tend to be inductive in logic (Robson, 2002).

\subsection{Epistemology}

It could be argued that a proper understanding of research methodologies necessarily requires an understanding of underlying paradigms. Only once the underlying paradigm is chosen (or assumed), can research design choices be made to answer the research questions.

Each paradigm has implications for social analysis and carries with it various assumptions (Burrell \& Morgan, 1979). As such, there is not necessarily a shared reality 
among all researchers and different paradigms can lead to different realities (Morgan, 1980; Poupart, 1997). It was therefore important to specify or frame the paradigmatic undertones of the research conducted here in order to set the boundaries of this study's reach.

While the paradigms are presented as rather dichotomic, caution should be made that these are 'extreme' mutually exclusive views. Burrell and Morgan (1979) specifically caution that conducting actual research is not all absolute. Actual research is accomplished on a continuum and has shades of different paradigms (Morgan \& Smircich, 1980). The following descriptions are but a simplification and are by no means definitive. In fact, it can be argued that all knowledge is social and historic, and none of it is either purely subjective nor purely objective (Laflamme, 2007).

For the purposes of this study, a subjectivist view was adopted because it aligns most closely with the research objective of gaining a better understanding of the nonprofit accountability system from the point of view of organisational leaders. Under a subjectivist approach, the ontological perspective assumes relativism, wherein reality is socially constructed (Guba \& Lincoln, 1994). The epistemology associated with subjectivism is constructivism. Constructivism assumes that social science cannot create true objective knowledge; instead, knowledge is created through social interactions (Burrell \& Morgan, 1979), acknowledging that "the reality conveyed, however carefully researched, is only one of a possible number of interpretations" (Ahrens \& Dent, 1998, p.10). Constructivist research is also based on the premise that the study is a collaboration 
between the researcher and the subject and in which reality is a joint and innate endeavor (Poupart, 1997).

Epistemologically, a constructivist view was adopted for this research and assumptions can be drawn to the study of organisations. Under a subjective paradigm, behavioural variability is accepted which in itself is not irrational and the objective of organisational study is to understand from the perspective of the individual, as it is their reality that is the one that matters. This made the collection of interview data dynamic, as participant answers varied based on their own lived experiences.

\subsection{Research Approach}

Research approaches can be broadly categorised as either quantitative, qualitative or mixed (Robson, 2002). An appropriate research approach depends on the state of previous research and generally drives the type of decisions made about the other research design choices (Edmondson \& McManus, 2007). For this study, a qualitative research approach was adopted because the subject area is emergent, there are not established constructs to test by way of hypotheses, and because the phenomenon under study is complex and embedded within its organisational context. Also, a mixed methodology design is not appropriate to answer the research question and given that a pragmatic paradigm is not assumed (Tashakkori \& Teddlie, 1998). Therefore, a qualitative research approach is best able to answer the proposed research questions. Qualitative research often follows an inductive logic; building theory based on the data 
collected (Bansal \& Corley, 2012; Eisenhardt \& Graebner, 2007) and is most appropriate for exploratory studies (Robson, 2002).

Qualitative research relies on words and descriptions to convey theory and answer research questions (Bansal \& Corley, 2012). It offers the ability to develop complex insights of relationships and processes that cannot be achieved through quantitative analysis (Eisenhardt \& Graebner, 2007). It produces ‘rich’ data (Bryman, 1984); by obtaining participants' viewpoint from within an organization. The rich descriptions of qualitative research cannot be summarized into tables or algorithms, but provide highly descriptive narratives to describe the findings of the study (Bansal \& Corley, 2012).

Ultimately, what is important in the process of determining a research approach is methodological fit. Methodological fit refers to the congruence between the philosophical paradigm, the research questions and a research design, wherein all elements of the research process are interconnected and interrelated (Creswell, 2013; Edmondson \& McManus, 2007). By adopting an inductive exploratory study using a constructivist paradigm and a qualitative research approach, methodological fit was established.

One of the advantages of qualitative research is its ability to give context to a theory. In this study, a qualitative research approach enabled the researcher to develop insights, explore ideas and gain a better understanding of the practices used to manage accountability. The intention was not to seek generalizability but to embrace the complexity of real organisational settings and explain the organisational phenomena 
under study. The data collected from the research put emphasis on descriptions of the stakeholder relationships, governance mechanisms and information strategies used to manage the accountability system. A qualitative research approach also provided the researcher with the opportunity to understand each organisation's unique situation.

\subsection{Research Strategy}

A research strategy is the process used to investigate the research topic and answer the research questions (Robson, 2002). The research strategy adopted for this study is a case study method, which "is an empirical study that investigates a contemporary phenomenon in depth and within its real-life context" (Yin , 2009, p.18). A case study is a bounded system (Creswell, 2013) that describes a single event or unit of analysis (Gephart, 2004). A collective case study research strategy was used (Creswell, 2013) wherein each organisation constituted a case study.

The case study method is particularly suited for the research conducted here because "the boundaries between phenomenon and context are not clearly defined", the phenomenon itself is not clearly or not sufficiently theorized, and it is complex (Yin, 2009, p.18). The case study method is also well suited as a research strategy to answer the proposed research questions because the study focuses on a 'how' question about a complex contemporary phenomenon within a real-life context and the investigator has little control over the phenomenon (Yin, 2009). 
The case study method uses rich, real world descriptions, and as a result usually involves some field-based data. It is conducted from within the organisation and in proximity to social actors. This method allows for detailed thick descriptions of contemporary events, rather than mere frequencies or incidences. It offers the ability to develop complex insights into relationships and processes that cannot be achieved through quantitative analysis (Eisenhardt \& Graebner, 2007) with the objective of building explanations that fit each individual case, even though the details within each case may vary (Yin, 2009).

The case study method is generally inductive in orientation (Eisenhardt \& Graebner, 2007), meaning that constructs often emerge from the analysis post hoc (Eisenhardt, 1989b) as the researcher immerses themselves in the data and attempts to extract theory from it (Langley, 1999).

The scope of data collection is vital to the execution of a satisfactory study (Yin, 2009). If too much data is collected, the researcher's and the participants' resources will be misused. If too little data is collected, it will prevent the researcher from properly analysing the material and drawing conclusions. Furthermore, unlike other data collection methods, there is no clear cut-off point to case study data. To manage the data collection process, data collection ceased when two things occurred: when triangulation occurred in that there was supporting evidence from two or more sources, and when evidence included attempts to explain any rival explanations (Yin, 2009). 
Triangulation is made possible by the use of multiple sources of evidence in order to obtain convergent lines of inquiry (Maxwell, 2013). The aim is to corroborate the same fact or phenomenon (Yin, 2009), thereby increasing the credibility of findings (Eisenhardt, 1989b; Singleton \& Straits, 2010) and reducing any inherent researcher bias (Bryman, 1984; Maxwell, 2013). The ability to obtain multiple sources of evidence is a major strength in case study research (Yin, 2009).

Attempts to explain rival explanations are made possible when the researcher searches for alternative interpretations and examines their plausibility (Maxwell, 2013; Miles, Huberman, \& Saldaña, 2014; Yin, 2009). While an exploratory study is not normally associated with attempts to explain rival explanations (Yin, 2009), potential explanations to the observed phenomena may appear and an explanation may be required. In this case, any rival explanations were addressed so as increase the credibility of findings (Maxwell, 2013; Miles et al., 2014; Yin, 2009). The process to address rival explanations was started during data collection. The aim was to address and rule out other possible justifications for the findings by demonstrating that the actual set of events within the case cannot be supported by the alternative interpretations (Yin, 2009). In doing so, the researcher collected sufficient data so as to investigate and test the credibility of rival explanations (Yin, 2009).

All research strategies present their own set of unique opportunities and challenges, and the case study method is no exception (Eisenhardt \& Graebner, 2007). 
There are two main limitations to this research strategy: limitations from the data sources and the transferability of the findings.

First, the case study data sources have some limitations. Interviews can be vulnerable to inaccuracies due to poor recall, reflexivity or inaccurate articulation on the part of the participant (Yin, 2009). Furthermore, access to some archival documents may be a challenge. To overcome the limitations from interview data, archival documents were obtained to corroborate the findings from the interviews. Interviews were also essential to corroborate the accuracy of documents obtained and to ensure some degree of completeness of information. As such, triangulation was achieved with the use of multiple data sources, which increased the credibility of the findings.

Second, the transferability of the study may be another limitation. One challenge to a case study method is the difficulty in transferring the findings to other contexts. This challenge was overcome by studying the same phenomena in multiple organisations. The use of multiple case studies tends to generate research that is more robust and transferable because it builds on relationships that come across in most, if not all, of the cases studied (Eisenhardt \& Graebner, 2007; Yin, 2009). By analysing multiple cases and recognizing patterns, this study constructed relationships both within the cases studied and across them (Eisenhardt \& Graebner, 2007). This allowed findings to be better grounded and more accurate because they were developed over multiple cases (Eisenhardt \& Graebner, 2007). 


\subsection{Data Collection Methods}

Data collection methods are the tools used to gather the necessary data to answer the research questions and are a central element of the research process (Robson, 2002). One advantage of the case study method is its ability to deal with a full range of data sources. A research project gains in quality when the researcher chooses data collection methods with incremental strengths and non-identical weaknesses (Singleton \& Straits, 2010). Therefore, this research project is based on interviews and archival documents.

\subsubsection{Interviews}

Interviews are one-on-one interactions in which researchers typically ask questions that participants answer (Gephart, 2004; Tashakkori \& Teddlie, 1998). Interviews offer the benefit of being targeted and focused directly on the topic at hand. Semi-structured interviews with open-ended questions were conducted with organisational leaders to gain insights into the organisations' accountability system. The interviews were semi-structured in that there were predetermined questions, but the order and amount of time spent on each question changed depending on how conversations developed and what seemed most appropriate, and also in that the wording of questions changed depending on the participant's level of understanding (Robson, 2002). The use of open-ended questions is desirable for understanding inductively how people think about different issues (Robson, 2002). Questions were used to gather information from participants about key facts relating to the accountability system. 
Interviews were approached from a position of learner and active listener. The participants were made to feel at ease so that they would speak freely. Participants were permitted to talk openly and at length, allowing them to move to ideas they felt were relevant. Prompting questions were used to refocus participants when the discussion veered off topic by repeating an important comment they previously made. Most interviews were terminated when it was determined that saturation had occurred (Ahrens \& Dent, 1998; Creswell, 2012; Glaser \& Strauss, 1967), that is, when participants provided no new information about the topic and the interviewer's understanding of the case circumstances was not further enlightened. Known as data saturation, it refers to the identification of recurring redundancy in the data: "decisions about when further data collection is unnecessary are commonly based on the researcher's sense of what they are hearing within interviews, and this decision can therefore be made prior to coding and category development" (Saunders et al., 2018, p.1899). A few interviews were terminated when the participant's imposed time limit was reached. The number of interviews and the number of organisations also achieved saturation, wherein it was determined by the researcher that additional interviews and adding additional case studies would not lead to any new emergent themes. A review of qualitative $\mathrm{PhD}$ studies found that the average number of interviews conducted as a method of data collection was 31 , presumably for saturation purposes (Mason, 2010).

In total, 37 interviews were conducted. The average interview lasted approximately 84 minutes, with the longest being 2 hours and 31 minutes and the shortest 
being 36 minutes. At the request of participants, two interviews at two different organisations were conducted in pairs. In total, there is 3,060 minutes (51 hours) of audio data, representing 944 pages of transcription. Interviews were conducted in 7 different cities within Ontario and approximately 3,400 kilometres were travelled by vehicle to reach participants. Interviews were collected between May 14, 2018 and February 8, 2019 , with the majority being conducted over the summer of 2018. 12 interviews were conducted before the June 7, 2018 provincial election and all were conducted before the new government announced plans on February 26, 2019 to make substantial changes to Ontario's health care system, including the integration of multiple health care agencies, most notably the LHINs, into a single health agency called Ontario Health (Office of the Minister of Health and Long-Term Care, 2019).

With the permission of participants, the interviews were audio-recorded with a digital voice-recorder to provide a more accurate rendition of the verbal exchange. Minimal notes were taken during the interviews so as not to disrupt the interview process. Audio data was transcribed to ensure accuracy and comprehension of the data. Transcription was outsourced to a recognised professional under supervision of the researcher with quality control throughout the process. Audio data and transcribed data were saved on a password protected computer. Both the computer and the voice-recorder were stored in the researcher's office. Participants were made aware of the use and protection of audio data in the consent form. 
As suggested by Hays (2004), a typical list of 15 to 20 questions focused on the issue should be generated. A total of 15 interview questions were derived from the conceptual framework and centred on the three core concepts of stakeholder relationships, governance mechanisms and information strategies. The interview guide is presented in Appendix B. An interview tool was also prepared and presented in Appendix C. The interview tool was used by the researcher to collect data more systematically and more efficiently, ensuring that nothing was overlooked and that the interview process did not lose focus.

\subsubsection{Archival Documents}

Documentary evidence constituted the other data collection source for this study. Archival documents are unobtrusive and non-reactive artefacts (Robson, 2002). Archival documents offer the benefit of being stable in that their content is not influenced by the researcher's enquiry, and therefore can help support or refute data collected through interviews (Robson, 2002). Archival evidence can be further divided into internal and external documents. Internal documents offer the advantage of providing more intimate and detailed information that may not be available through public records, while external documents offer the advantage of potentially being less biased as the source is a third party.

Documentary evidence was used before and after the interviews and focused on available documents that describe accountability management practices. First, 
preliminary archival documents from the organisation's website and other publicly available sources were obtained prior to the interviews in order to give context to the organisation's accountability system. Second, detailed internal documents were obtained in conjunction with or subsequent to the interviews in order to help corroborate the interview data. In total, approximately 2,600 pages of archival documents were obtained and reviewed, in addition to reviewing the organisations' websites and other online materials. These documents included accountability agreements (380 pages), financial statements (350 pages), strategic and business plans (350 pages), industry reports (300 pages), annual reports (290 pages), internal policies, procedures and memos (250 pages), MOHLT reports (240 pages), news articles (140 pages), Auditor General reports (100 pages), Quality Improvement Plans (100 pages), and other internal documents including performance reports (100 pages). Approximately $80 \%$ of the documents were accessible publicly, although not always on the organisation's website or in an easily accessible location, and $20 \%$ consists of strictly internal documents.

\subsection{Organisation and Participant Selection}

In this section, the selection of organisations and participants is described. The unit of analysis consists of organisations in the health care system and each unit of analysis was compared and contrasted for research purposes. As such, this study adopts a multiple-case design, wherein each organisational context serves as a single unit of analysis. 


\subsubsection{Selection of Organisations}

Organisations were selected by way of theoretical sampling (Eisenhardt, 1989b; Eisenhardt \& Graebner, 2007). In theoretical sampling, the objective is to choose specific organisations or phenomena that are of particular interest in developing theory, as such the samples are intentional and focused (Creswell, 2012; Eisenhardt, 1989b; Eisenhardt \& Graebner, 2007). With such a method, sample sizes are small, which allow the researcher to explore the multitude of real-life complexities. The number of samples were determined based on the need for theoretical saturation (Eisenhardt, 1989b; Glaser \& Strauss, 1967; Paillé \& Mucchielli, 2012).

The sampling strategy can be organised around six criteria, which include: relevance to the conceptual framework, potential to generate rich information, analytic generalizability, potential to generate believable explanations, feasibility and ethics (Curtis, Gesler, Smith, \& Washburn, 2000; Miles et al., 2014). The last criterion is of less importance to the selection of specific organisations, and as with any study with limited resources, compromises may be required between different criteria. In addition, the likely permanence of the organisation is added as a supplementary criterion.

Relevance of the conceptual framework refers to nonprofit organisations, which is the focus of this study. The potential to generate rich information refers to an organisation with diverging stakeholder interests. The presence of diverging stakeholder interests highlights the accountability challenges that need to be managed when dealing 
with multiple stakeholders with competing interests. The potential to generate rich information also requires an organisation to be large enough and have a sufficiently robust history to ensure that data is available to conduct the research.

Analytic generalizability refers to the possibility of transferring findings to theory, for which the theory can then be transferred to other contexts beyond the scope of the research conducted (Yin, 2009, 2011). The variability in types of organisations helped to achieve analytic generalizability. If variability is not achieved, it would be difficult to transfer the findings to other contexts beyond the scope of the research conducted. Therefore, site selection attempted to choose organisations with a high degree of variability in the type of organisation.

The potential to generate believable explanations refers to the ability to gain access to research sites. Permission from organisations to gain access to a sufficient number of participants and to relevant archival documents was important to the study's success. If sufficient data was not obtained, it would have been difficult to generate findings that are credible.

The feasibility of the research refers to the cost and timeliness in completing a research study. For this research, the possibility of completing case studies in geographical proximity to the researcher's residence, or at least within Ontario ensured that the research could be completed in a cost efficient and timely manner. 
Finally, permanence refers to organisations that are financially stable and their continued existence in the near future is not in doubt. The likely permanence of an organisation reduces the risk that an organisation closes during the research project. For this study, only registered or incorporated organisations were selected since they are more likely to have some degree of permanence (Hall et al., 2004). Table 3-1 summarizes the relevant sampling strategy criteria for this study. In summary, relevant organisations include registered or incorporated nonprofits with diverging stakeholder interests, within Ontario.

Table 3-1 - Sampling Strategy Criteria

\begin{tabular}{|l|l|l|}
\hline & Criteria & Description \\
\hline 1 & $\begin{array}{l}\text { Relevance to the conceptual } \\
\text { framework }\end{array}$ & Nonprofit organisations \\
\hline 2 & $\begin{array}{l}\text { Potential to generate rich } \\
\text { information }\end{array}$ & $\begin{array}{l}\text { Diverging stakeholder interests and } \\
\text { availability of data }\end{array}$ \\
\hline 3 & Analytical generalizability & $\begin{array}{l}\text { Variability in organisations (e.g. size, } \\
\text { sector, language, important events, } \\
\text { reputation) }\end{array}$ \\
\hline 4 & $\begin{array}{l}\text { Potential to generate believable } \\
\text { explanations }\end{array}$ & Access to research sites \\
\hline 5 & Feasibility & Within Ontario \\
\hline 6 & Permanence & Registered or incorporated nonprofits \\
\hline
\end{tabular}

To control for any variability that may exist between different sectors, site selection for this study was limited to the health care sector. Focusing the study on one sector increases comparability and increases the efficiency of the study. The health care sector offers several advantages for this study. While hospitals only represent $0.5 \%$ (less than $1 \%$ ) of all nonprofit organisations in Canada, they command $22 \%$ of all revenues, 
$24 \%$ of all paid staff (Hall et al., 2004). Of those revenues, the source of $82 \%$ of these revenues is the government (Hall et al., 2004).

The recruitment of organisations was done by asking colleagues for potential contacts and by doing a Google search. Recruitment was initiated by the researcher, who attempted to convince potential participants of the relevance of this study to their organisation on specific management and organisational issues (Ahrens \& Dent, 1998). Prior to contacting potential participants, the organisations' websites were reviewed to obtain contextual information about the organisations, such as size, longevity, structure, and financial stability.

Organisations were contacted via email individually, starting with those that seemed to best meet the selection criteria. Preliminary phone discussions were conducted to confirm interest on the part of the organisation and potential participants, and to confirm the suitability of the organisation as a research site. Suitability was established if organisations were willing to provide sufficient archival documents to enable the researcher to complete the case study. Once tentative organisations were sought and suitability had been shown, initial letters of request for organisational participation were sent to formalise the agreement. A copy of the letter of request is included in Appendix D.

To answer the research questions, it was important to choose organisations that had stakeholder relationships amongst themselves. To reach this objective, three types of 
organisations were chosen within the health care system. The organisations chosen include hospitals, Local Health Integration Networks (LHINs) and foundations. The reason for specifically choosing these three types of organisations, and why they complement each other, are detailed below.

As nonprofits, hospitals were chosen because they represent the largest proportion of spending in Ontario's health care system (Martin, 2017). Specifically, hospitals represent $34 \%$ of all public health care spending in Ontario (Canadian Institute for Health information, 2018). There are an estimated 492 hospitals in Ontario (Statistica, 2019). The next three highest public health care expenditures include publicly funded physicians at $23 \%$, other publicly funded institutions at $11 \%$ and publicly funded prescription drugs at $10 \%$ (Canadian Institute for Health information, 2018). The hospital sector is also where the vast majority of health care capital infrastructure is invested (Wilson, Mattison, \& Lavis, 2016a).

As registered charities, foundations were chosen because hospitals in Ontario typically have one or several affiliated foundations. To a significant extent, hospitals rely on their foundations to purchase, for the most part, capital infrastructure and medical equipment (Ontario Hospital Association, 2015).These foundations are responsible for generating donations, grants and fundraising revenues for the hospital.

LHINs were chosen because they are the primary funders of hospitals. LHINs also represent the largest proportion of government health care expenditures. Specifically, 
LHINs represent $51 \%$ of all spending by the Ministry of Health and Long-Term Care (MOHLTC) (Ministry of Health and Long-Term Care, 2017), and much of this funding is allocated to hospitals. Among the health service providers that LHINs fund are hospital, long-term care homes, community mental health and addiction agencies, community support service agencies, and community health centres. LHINs do not fund primary care, public health, laboratory services, OHIP, and ambulance services, to name a few (Office of the Auditor General of Ontario, 2015).

A LHIN is a nonprofit government agency that can be defined as "an organisational arrangement involving the creation of an intermediary administrative and governance structure to carry out functions or exercise authority previously assigned to either central or local structures" (Church \& Barker, 1998, p.468). It is an organisation that is intended to depoliticise health care that is "at once 'independent' yet part of the regulatory machinery of the state", (Davies, 2007, p.48). LHINs were founded by the Government of Ontario in 2007 (through the Local Health System Integration Act, 2006) with the mandate to plan, integrate and fund health services within a geographic region. 14 LHINs were created to facilitate greater regional integration in Ontario's health care system between organisations offering discrete units of care (Fierlbeck, 2011). The funding envelops that LHINs receive are determined by the Ministry of Health and LongTerm Care. LHINs then distribute over 99\% of these funds to health service providers located in their region. LHINs have little ability to collect and spend funds, and to make policy decisions. As such, fiscal responsibility and policy making authority remains with the provincial government, while some managerial responsibility has been decentralised 
within the 14 regional LHINs. The average LHIN covers a population of approximately $1,000,000$ people, receives an average of $\$ 1.9$ billion annually from the MOHLTC and is responsible for an average of 10 hospitals. Subsequent to data collection, the newly elected provincial government announced The People's Health Care Act, 2019 with plans to dissolve LHINs and other health care agencies in favour of a single provincial agency called Ontario Health (Government of Ontario, 2019b). In a recent cabinet shuffle, the provincial government also separated the Ministry of Health from the Ministry of LongTerm Care (Office of the Premier, 2019).

\subsubsection{Participating Organisations}

In total, 5 hospitals, 2 LHINs and 2 foundations constitute the participating organisations for this study. LHINs and foundations are fairly generic in their operational structures, but there is a wide variety in types of hospitals, and therefore it is important to review their classifications. Under the Public Hospitals Act, 1990, hospitals are classified under 6 types: general, convalescent, for chronic patients, psychiatric, for alcoholism and drug addiction, and regional rehabilitation. Hospitals are further grouped by their number of beds and based on a variety of other specialty care (including cancer care, treatment of disabled persons, transplantations, operation of specialty equipment, in vitro fertilization, biosynthetic human growth hormones, cystic fibrosis treatment, and thalassemia treatment) (Government of Ontario, 2001). A hospital can be classified under more than one group. 
The most relevant categories for this study include hospitals that are or are not regional, tertiary, teaching and large. A regional hospital is one that serves a larger catchment population than its immediate region by offering services and receiving referrals from nearby local or rural hospitals that cannot adequately meet the needs of patients. Hospitals may also be categorised by the level of acute care provided for different health conditions, which can be called secondary, tertiary, and quaternary care (Lavis \& Hammill, 2016a). The more advanced and specialised the care, the more it is considered tertiary and even quaternary care. This is in contrast to primary care, which is associated with family medicine, community health centres and long-term care. A teaching hospital is one that gives instruction to medical students. For the purposes of this study, a small hospital is one that has fewer than 200 beds (which differs from Ontario's small hospital classification for funding purposes which is based on the number of inpatient weighted cases). A weighted case is a measure of the intensity of resources used to provide acute care (Bluewater Health, 2015).

Table 3-2 provides an overview of the nine participating organisations, including statistics about their size, and other characteristics for hospitals. 
Table 3-2 - Overview of Participating Organisations

\begin{tabular}{|c|c|c|c|c|c|c|c|}
\hline \multirow{2}{*}{$\begin{array}{c}\text { Type of } \\
\text { organisation }\end{array}$} & \multirow[t]{2}{*}{ Entity } & \multirow{2}{*}{$\begin{array}{c}\text { Size } \\
\text { (\$ million) }\end{array}$} & \multicolumn{5}{|c|}{ Type of hospital } \\
\hline & & & Regional & Tertiary & Teaching & Small & $\begin{array}{l}\text { Northern } \\
\text { Ontario }\end{array}$ \\
\hline Hospital & H1 & $\$ 250$ & $\checkmark$ & $\checkmark$ & & & $\checkmark$ \\
\hline Hospital & $\mathrm{H} 2$ & $\$ 450$ & $\checkmark$ & $\checkmark$ & $\checkmark$ & & $\checkmark$ \\
\hline Hospital & $\mathrm{H} 3$ & $\$ 100$ & $\checkmark$ & & & $\checkmark$ & $\checkmark$ \\
\hline Hospital & $\mathrm{H} 4$ & $\$ 60$ & & & & $\checkmark$ & \\
\hline Hospital & H5 & $\$ 220$ & & $\checkmark$ & $\checkmark$ & & \\
\hline LHIN & L1 & $\begin{array}{l}\$ 5 / \\
\$ 1,500 *\end{array}$ & & & & & \\
\hline LHIN & L2 & $\begin{array}{l}\$ 4 / \\
\$ 1,000 *\end{array}$ & & & & & \\
\hline Foundation & F1 & $\$ 3$ & & & & & \\
\hline Foundation & F2 & $\$ 2$ & & & & & \\
\hline
\end{tabular}

* Operating budget / Funding received from the MOHLTC. Dollar figures have been rounded.

The summary demonstrates that the hospitals included in this study cover many groups as 3 are regional, 3 are tertiary, 2 are teaching, 2 are small, and 3 are located in northern Ontario.

H1 is a regional tertiary hospital located in Northern Ontario. The hospital has approximately 400 beds, 2,000 employees, 150 active physicians, serves a catchment population of over 100,000 and receives about 50,000 emergency department visits a year. Over the last 4 years, its annual revenues averaged just under $\$ 250$ million.

$\mathrm{H} 2$ is a regional teaching tertiary hospital located in Northern Ontario. The hospital has approximately 400 beds, 4,000 employees, 300 active physicians, serves a catchment population of over 200,000 and receives about 75,000 emergency department visits a year. Over the last 4 years, its annual revenues averaged just over $\$ 450$ million. 
H3 is a small regional hospital located in Northern Ontario. The hospital has approximately 150 beds, 850 employees, 100 active physicians, serves a catchment population of over 100,000 and receives about 40,000 emergency department visits a year. Over the last 4 years, its annual revenues averaged just under $\$ 100$ million.

H4 is a small hospital located in Southern Ontario. The hospital is located in a rural community. The hospital has approximately 100 beds, 630 employees, 100 active physicians, serves a catchment population of over 150,000 and receives about 45,000 emergency department visits a year. Over the last 4 years, its annual revenues averaged just under $\$ 60$ million.

H5 is a teaching tertiary hospital located in Southern Ontario. The hospital is located in a large urban area. The hospital has approximately 3000 beds, 1,800 employees, 300 active physicians, serves a catchment population of over 200,000 and receives about 55,000 emergency department visits a year. Over the last 4 years, its annual revenues averaged just under \$220 million.

L1 is a Local Health Integration Network that receives over $\$ 1.5$ billion annually from the Ministry of Health and Long-Term Care with an operating budget of approximately $\$ 5$ million. Of the funds distributed to health service providers, approximately $65 \%$ is allocated to hospitals, while the remaining funds are distributed to long-term care homes, community care access centres, community support services, 
assisted living services, community health centres, mental health services and addiction programs. L1 flows funds to almost 150 individual health service providers, including over 20 hospitals.

L2 is a Local Health Integration Network that receives just under $\$ 1$ billion annually from the Ministry of Health and Long-Term Care with an operating budget of approximately $\$ 4$ million. Of the funds distributed to health service providers, approximately $50 \%$ is allocated to hospitals, while the remaining funds are distributed to long-term care homes, community care access centres, community support services, assisted living services, community health centres, mental health services and addiction programs. L2 flows funds to almost 70 individual health service providers, including just under 10 hospitals.

F1 is a hospital foundation located in Northern Ontario. F1 has approximately $\$ 12$ million in accumulated net assets and manages 10 significant restricted funds and endowments. Over the last 4 years, the organisation generated approximately $\$ 3$ million in annual revenues, it disbursed an average of $\$ 2$ million per year to its hospital and incurred expenses over this same period of just under $\$ 800,000$ annually.

F2 is a hospital foundation located in Northern Ontario. F2 has approximately \$7 million in accumulated net assets and manages 4 significant restricted funds and endowments. Over the last 4 years, the organisation generated approximately $\$ 2$ million 
in annual revenues, it disbursed an average of $\$ 1.5$ million per year to its hospital and incurred expenses over this same period of just under $\$ 600,000$ annually.

Figure 3-1 describes the global relationships between participating organisations. One can see that there are sufficient organisations of all types.

Figure 3-1 - Relationship Between Participating Organisations

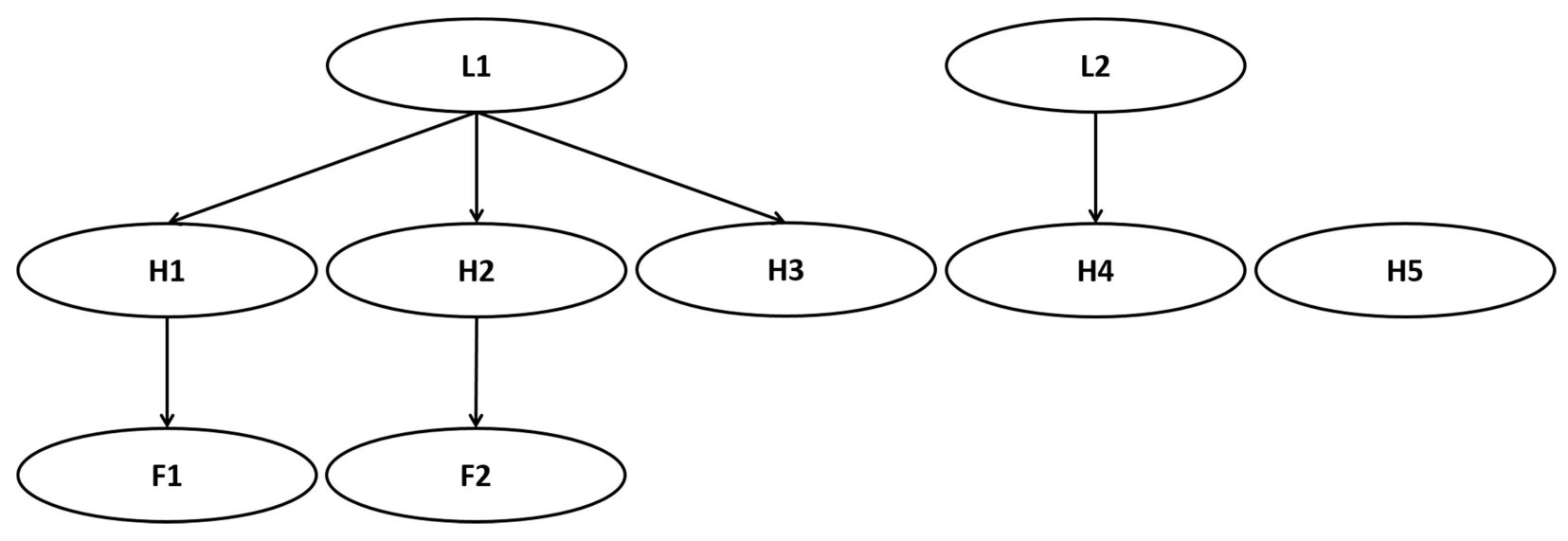

In total, 4 organisations declined to participate. Two foundations and a LHIN declined after receiving the letter of request. One hospital, after some delay in responding, asked to complete a Research Ethics Board (REB) application and a nondisclosure agreement. Both documents were submitted. After some time, the REB determined that the study did not require local ethics approval and that the project could be pursued. However, after more delay in responding, follow-up correspondence was sent to the hospital to obtain a status on approval. In the end, the organisation declined to participate after a period of 18 weeks from initial contact to rejection. A hospital foundation agreed to participate, but when the affiliated hospital declined, it was no 
longer practical to include the foundation. Contact was made with the foundation to thank them and inform them that their research site would be withdrawn for the time being. Two other hospitals did not decline but when 5 hospitals had been confirmed and interviews were conducted and the hospitals had not yet confirmed, an email was sent to thank them for considering the research request and inform them that access to sufficient research sites had been obtained.

\subsubsection{Selection of Participants}

Access to research participants is an important part of the data collection process. To obtain access, it was necessary to gain the trust of participants and demonstrate the value of their involvement in the research process. Once organisational access was obtained, preliminary face-to-face interviews were conducted with participants. One interview was conducted via Skype.

Interviews were conducted with board members, executives and managers engaged in the oversight and administrative responsibilities of the organisations because they are most likely to be involved with their organisation's accountability management practices. Participants were also used to gain access to archival documents for triangulation purposes, as well as other potential participants and organisations (i.e. snowballing). 
Between two and six participants per organisation were interviewed in order to increase the completeness and credibility of the data collected. Interviewing more than one individual per organisation was important to reduce the variability in the answers of any one participant by assessing that responses were not the opinions of only one individual ensuring, through triangulation, that the right unit of analysis was targeted (Yin, 2009).

Once tentative participants had been sought and suitability had been shown, initial letters of invitation were sent via email to formalise the agreement. A copy of the letter of invitation is included in Appendix E. Before conducting interviews, consent forms were provided and signed. A copy of the consent form is included in Appendix F.

\subsubsection{Participating Individuals}

A broad range of participants were selected and interviewed for this study. In total, 37 participants were interviewed from the nine different organisations. Table 3-3, panels A and B, provides a summary of the interview profiles of the participants. 
Table 3-3 - Interview Profiles

\begin{tabular}{|c|c|c|c|c|}
\hline \multicolumn{5}{|c|}{ Panel A (by participant title) } \\
\hline Participant title & Hospital & LHIN & Foundation & Total \\
\hline Board member & 7 & 1 & 2 & 10 \\
\hline $\mathrm{CEO}$ & 4 & 0 & 2 & 6 \\
\hline $\mathrm{CFO}$ or equivalent & 5 & 2 & 0 & 7 \\
\hline $\begin{array}{l}\text { Chief nursing officer (CNO) } \\
\text { or equivalent }\end{array}$ & 3 & 0 & 0 & 3 \\
\hline Chief of staff & 3 & 0 & 0 & 3 \\
\hline Manager or equivalent & 3 & 5 & 0 & 8 \\
\hline Total & 25 & 8 & 4 & 37 \\
\hline
\end{tabular}

Panel B (by participant profession)

\begin{tabular}{|l|l|l|l|l|}
\hline Participant profession & Hospital & LHIN & Foundation & Total \\
\hline Accountants & 9 & 4 & 1 & 14 \\
\hline $\begin{array}{l}\text { Administrators (other than } \\
\text { accountants) }\end{array}$ & 6 & 3 & 3 & 12 \\
\hline Nurses & 5 & 1 & 0 & 6 \\
\hline Doctors & 5 & 0 & 0 & 5 \\
\hline Total & 25 & 8 & 4 & 37 \\
\hline
\end{tabular}

Throughout the analysis in chapter 5, participants were coded in sequential order from the first to the last interview, such that I1 was the first interview conducted and I37 was the last.

\subsection{Data Analysis}

Data analysis is an important part of the research process, and every research project should have a well-developed set of procedures for analysing collected data. The goal of data analysis is to create concepts and relationships with the data collected (Maxwell, 2013). Known as sensemaking, the goal is to derive the meaning of a phenomenon from narrative information (Mukamurera, Lacourse, \& Couturier, 2006; Paillé \& Mucchielli, 2012; Weick, 1989). 
Ahead of entering the field for data collection, a range of theories were identified and a conceptual framework was developed to recognize and understand the data as it was collected. Iteratively, the theories that appeared most helpful were used to analyse data and construct significance (i.e. make sense of it) (Ahrens \& Chapman, 2006). As such, theoretical grounding was used to match empirical findings from the data to the underlying theories and help ensure that the findings were credible.

Interviews and archival documents for each organisation were integrated into a case study. Case study material was analysed by reading through the text, making margin notes and forming initial codes (Creswell, 2013). This research adopted the Straussian perspective and used thematic analysis ("analyse thématique") from grounded theory (Paillé \& Mucchielli, 2012) as the method for identifying the similarities and differences between the cases. Within thematic analysis, initial codes were identified and categorised into nodes. These nodes were regrouped, subdivided and ranked as the data was analysed and the researcher developed a deeper level of understanding of the data. Upon completing each specific case study, within-case analysis was conducted. In the withincase analysis, each case study formed a specific unit of analysis and an in-depth review of each individual case was conducted to understand each organisation's experiences in regards to accountability. In this step, the most significant observations in relation to the phenomenon under study were emphasized. Therefore, data collected was sorted and coded in accordance with what seems the most important (D'Amboise \& Audet, 2005). 
This step ensured a familiarity with the data collected and simplified the cross case analysis.

In the next step, a cross-case analysis was conducted to identify patterns of similarities and differences between each case (Eisenhardt, 1989b; Yin, 2009). Notably, the similarities and differences exposed how nonprofits manage their accountability systems. By comparing similarities and differences between cases, it was possible to develop a more profound understanding of the phenomenon in relation to the conceptual framework (D’Amboise \& Audet, 2005).

As qualitative data was gathered, it was coded and organised around the conceptual framework (Yin, 1981). Corresponding topics were formed and modified as the analysis progressed; ensuring that the number of topics was not too small to limit analysis and omit important nuances, nor too large so as to be unmanageable. Assessments were made as to whether the codes first used were still appropriate, whether they should be modified, or whether new codes had emerged; as such, previous data was re-analysed in light of the new codes. As data was gathered, it was continuously reviewed for accuracy and concordance with previous information and with the conceptual framework. Any discrepancies were questioned to identify the source of the discrepancy, whether it be from the data (i.e. the sources of the information contradicts), the interpretations of the researcher, or the applicability of the conceptual framework. Therefore, data analysis was iterative, meaning that the process was nonlinear (Bansal \& 
Corley, 2012; Eisenhardt, 1989b; Paillé \& Mucchielli, 2012). Table 3-4 lists the case study steps.

Table 3-4 - Case Study Steps

\begin{tabular}{|l|l|}
\hline Step no. & Step Description \\
\hline 1 & Scan publicly available archival documents about target organisations \\
\hline 2 & Approach target organisations and obtain approval for collaboration \\
\hline 3 & Perform detailed review of publicly available archival documents \\
\hline 4 & Approach participants and obtain approval for interviews \\
\hline 5 & Conduct interviews with participants \\
\hline 6 & Obtain and review non-publicly available archival documents \\
\hline 7 & Perform within-case analysis \\
\hline 8 & Perform cross-case analysis \\
\hline
\end{tabular}

Nvivo 12, a qualitative research software, was used to collect and analyse the case study data. It was used to facilitate sorting, coding and extraction of data collected. It also held the case study database to ensure the integrity of the data collection process and maintain the chain of evidence. In total, there were 1,670 individual codes within 78 nodes. A database is a crucial element for organising and documenting the data collected throughout the research project (Yin, 2009). It is a location to refer back to the initial data collected, making the data readily available, and in principle, it allows other investigators to review the evidence. The chain of evidence ensured that each link, from the initial research questions, to the underlying data, and to the final research paper, are all connected and support each other, wherein nothing is incompatible with the previous or subsequent link.

In summary, these steps have ensured the trustworthiness of the research in regards to four criteria: confirmability, credibility, transferability and dependability 
(Guba, 1981). Confirmability has been established by using multiple sources of evidence and establishing a chain of evidence. Credibility has been established by doing pattern matching and addressing rival explanations. Transferability has been established by using replication logic in multiple-case studies, and dependability has been established by using a case study protocol and developing a case study database.

In table 3-5, the synthesis of research design (from chapter 1, table 1-1) is integrated with the study's methodology. The synthesis explains how the different parts of the research design fit together into a coherent whole (Maxwell, 2013). 
Table 3-5 - Synthesis of Research Design with Methodology

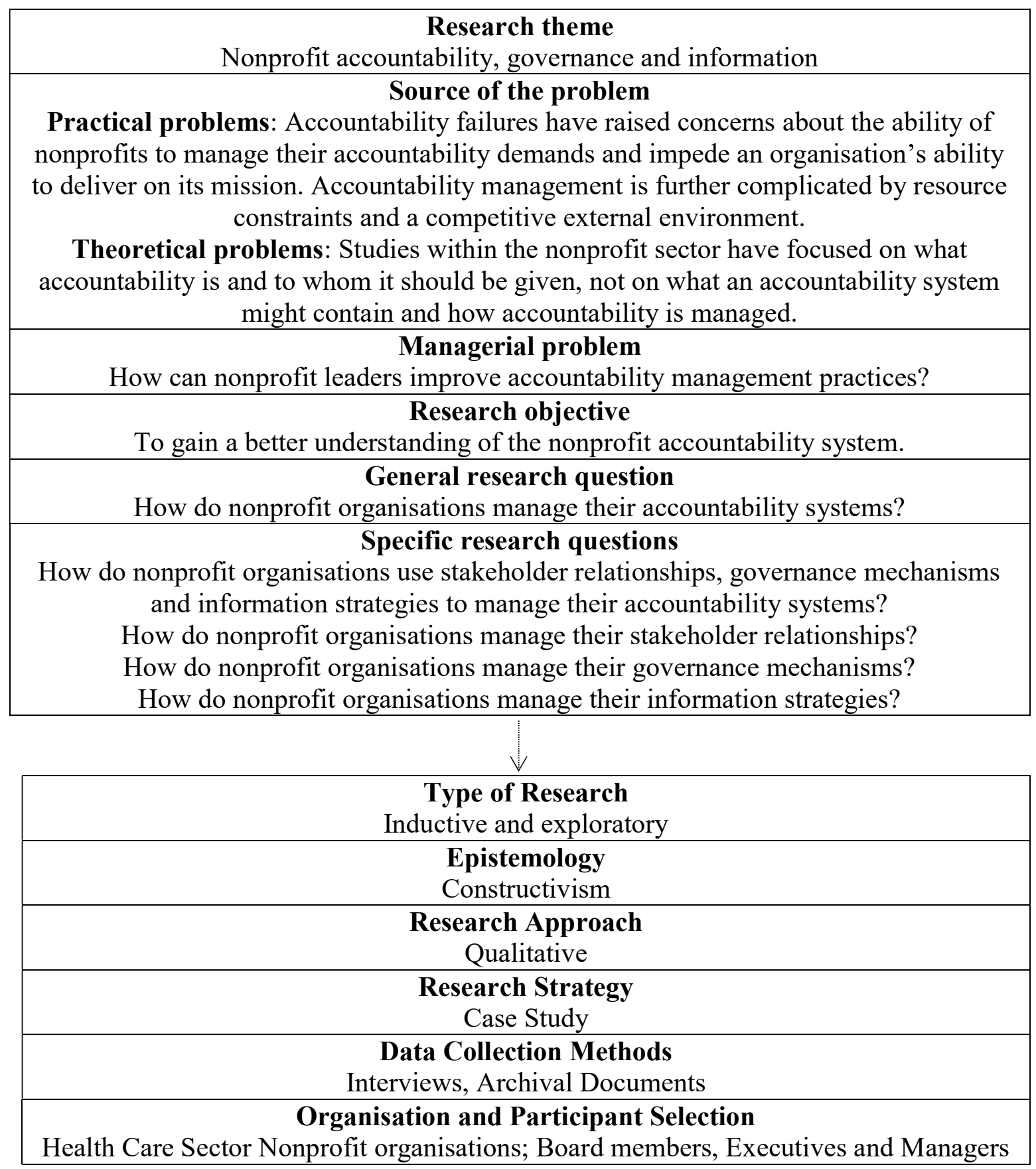




\subsection{Ethical Considerations}

An ethics clearance has been granted by Carleton University's Research Ethics Board (CUREB) and Laurentian University's Research Ethics Board (LUREB). While this $\mathrm{PhD}$ is being obtained at Carleton University's Sprott School of Business, research clearance has also been granted by Laurentian University since the researcher is a faculty member at this institution. Ethics applications were also submitted to the Research Ethics Boards of three hospitals, including to the hospital that declined to participate.

To comply with ethical standards, consent forms were provided to all participants prior to commencing interviews. This ensured that participants were informed of the nature of the study and their rights as participants. The researcher introduced the purpose of the study and followed the interview guide.

Participants were not considered vulnerable, no deception tactics were used, no conflicts of interests arose and participants were not exposed to any more risk than they would experience in their everyday lives.

In order to accommodate participants, interviews were conducted in person at the participant's place of work. Participants were able to withdraw from the study at any time during the interview and up until one week after the interview, as this is when data analysis began. No participants requested to withdraw from the study. 
To maintain anonymity, participants were assigned a code name and the interview transcripts were labelled with the code name. Transcripts were altered to remove all names and identifying information (e.g. place of work) so that responses may be nonattributable. Data collected from research sites was stored on a password protected computer, which was kept in the researcher's office. 


\section{CHAPTER 4: OVERVIEW OF ONTARIO'S HEALTH CARE SYSTEM}

Ontario’s health care system operates within a historical, legal, demographic, geographic, fiscal, and political context (Lavis \& Mattison, 2016). This chapter provides an overview of the foremost relevant contextual and operational environment within Ontario's health care system.

\subsection{Contextual Environment}

For the purposes of this study, there are four prominent groups of contextual factors that have an impact on Ontario's health care system. These factors include legal, organisational, demographic and geographic, and fiscal and political.

\subsubsection{Legal}

Health care in Canada is primarily the responsibility of provincial governments, albeit within certain broad federal laws. There are numerous laws and regulations that govern the operations of health care organisations. For instance, hospitals must conform to an estimated 117 laws and regulations at many levels of governance (Dubé, Brouard, \& Pilon, 2019). As such, Ontario's health care system can be characterised as highly regulated. 
There are four laws, and specific provisions within these laws, that are of significance to this research's contextual environment. The first important health care law is the British North America Act, 1867. Under this federal law, health care is the responsibility of provincial governments (British Parliament, 1867, para. 92). The second important law is the Canada Health Act, 1985. Under this federal law, the federal government is obliged to provide funds ("cash contributions") to the provinces in exchange for adhering to the rules set forth in the Act. Through this law, the federal government can use its funding to shape provincial health care. Notably, to receive federal funding, provincial health care systems must be publicly administered, comprehensive, universal, portable and accessible (Government of Canada, 1985, para. 7). Ontario's publicly funded health care system is administered through the Ontario Health Insurance Plan (OHIP).

The third important law is the Public Hospitals Act, 1990. Under this provincial law, hospitals, as a provider of last resort, cannot refuse any patient where refusal of admission would endanger life (Government of Ontario, 1990, para. 21). This rule is important because it removes some of a hospital's ability to control the supply of service and inevitably its ability to control some of its costs. Other health service providers, such as long-term care homes and community health centres, not subject to the Act, are able to waitlist people and better able control expenditures to align with revenues.

The fourth important law relates to health equity, which "is the absence of systematic, socially-produced (and therefore modifiable) and unfair differences in one or 
more aspects of health across populations or population groups; defined socially, economically, demographically, or geographically" (Tyler, Amare, Hyndman, \& Manson, 2014, p.8). Health Quality Ontario (HQO) describes health equity as allowing "people to reach their full health potential and receive high-quality care that is fair and appropriate to them and their needs, no matter where they live, what they have or who they are" (Health Quality Ontario, 2016, p.7). Health equity is less associated with a specific piece of legislation, but is nonetheless an important principle in understanding the regulatory context within Ontario's health care system. Health equity is found once in the Patients First Act, 2016, and states that health equity includes "equitable health outcomes, to reduce or eliminate health disparities and inequities [...]" (Government of Ontario, 2016, para. 4. (2)). The term is also mentioned once in the preamble to The People's Health Care Act, 2019 as a guiding principle (Government of Ontario, 2019b). Health equity provisions are often associated with the minority rights of First Nations and francophone communities.

Health equity can refer to equitable access or to equitable consumption (Fierlbeck, 2011). Equitable access means that those who need care can receive it, regardless of income. Equitable consumption means that those who use health care resources more, should pay more. Both forms of equity intervene in Ontario's health care system. Equity of access can be geographical (having health care services in close proximity to where one lives or having services at the same level of quality as in other parts of the province), demographical (having the same level of service regardless of income, class, age, race, sex, etc.), or cultural (being served in a way that is culturally appropriate or in one's 
language of choice). Applying health equity to a diverse and large population at a practical level is often problematic. But the regulation is nonetheless important in understanding how resources are allocated and how political decisions are influenced.

\subsubsection{Organisational}

Though health care in Canada is of provincial jurisdiction, the provincial government in Ontario does not directly deliver health care services. A mixture of public, for-profit and nonprofit organisations provide health care (Deber, 2002).

Although Ontario's health care system is publicly administered, it is quite decentralised (Devlin, 2019b; Fierlbeck, 2011; Martin, 2017) as many of the organisations that provide health care services within this system are nonprofit, as well as many for-profit organisations. In fact, there are over 1,800 health service provider organisations in Ontario (Office of the Minister of Health and Long-Term Care, 2019). The health care system in Ontario is also dependent on the private sector for publicly uninsured goods and services (Fierlbeck, 2011). Therefore, Ontario's health care system is largely provided privately by nonprofit or private sector organisations. The provincial government has also delegated some authority through the creation of various government agencies.

Health care organisations can be classified as funders, service providers, coordinators and philanthropic supporters. The public sector, through taxation, is the 
health care system's main funder, along with private insurers. Service providers include the following 10 types of organisations: public health units, community health centres, home and community care, hospitals, long-term care homes, other primary care organisations, pharmacies, medicine professional corporations, retirement homes and other health professional corporations. Coordinators are responsible for coordinating care across the health care system. Finally, philanthropic support is provided by hospital foundations and at the citizen level through donations (to foundations and other charities) and by volunteering. Citizens are also part of the health care system and include the population living within the geographic boundary of the health care system. Citizens may also include those living aboard but in need of health care services while visiting (which are paid for privately or through articulations with other jurisdictions). Engaged citizens include those that donate, volunteer or otherwise interact with the health care system as non-patients.

Figure 4-1 has combined these categories and breaks down health care organisations into three different levels of public, nonprofit and private, and a fourth level that captures citizens within the health care system. Figure 4-1 helps illustrate the complex web of stakeholder relationships that exist within Ontario's health care system. Identified in bold are the organisations under study in this research, with a focus on LHINs (Local Health Integration Networks), hospitals, and foundations. Figure 4-2 is also reproduced here from the Ontario Hospital Association's Guide to Good Governance report and provides an overview of pertinent stakeholders of the hospitals. 
Figure 4-1 - Overview of Organisations within Ontario's Health Care System

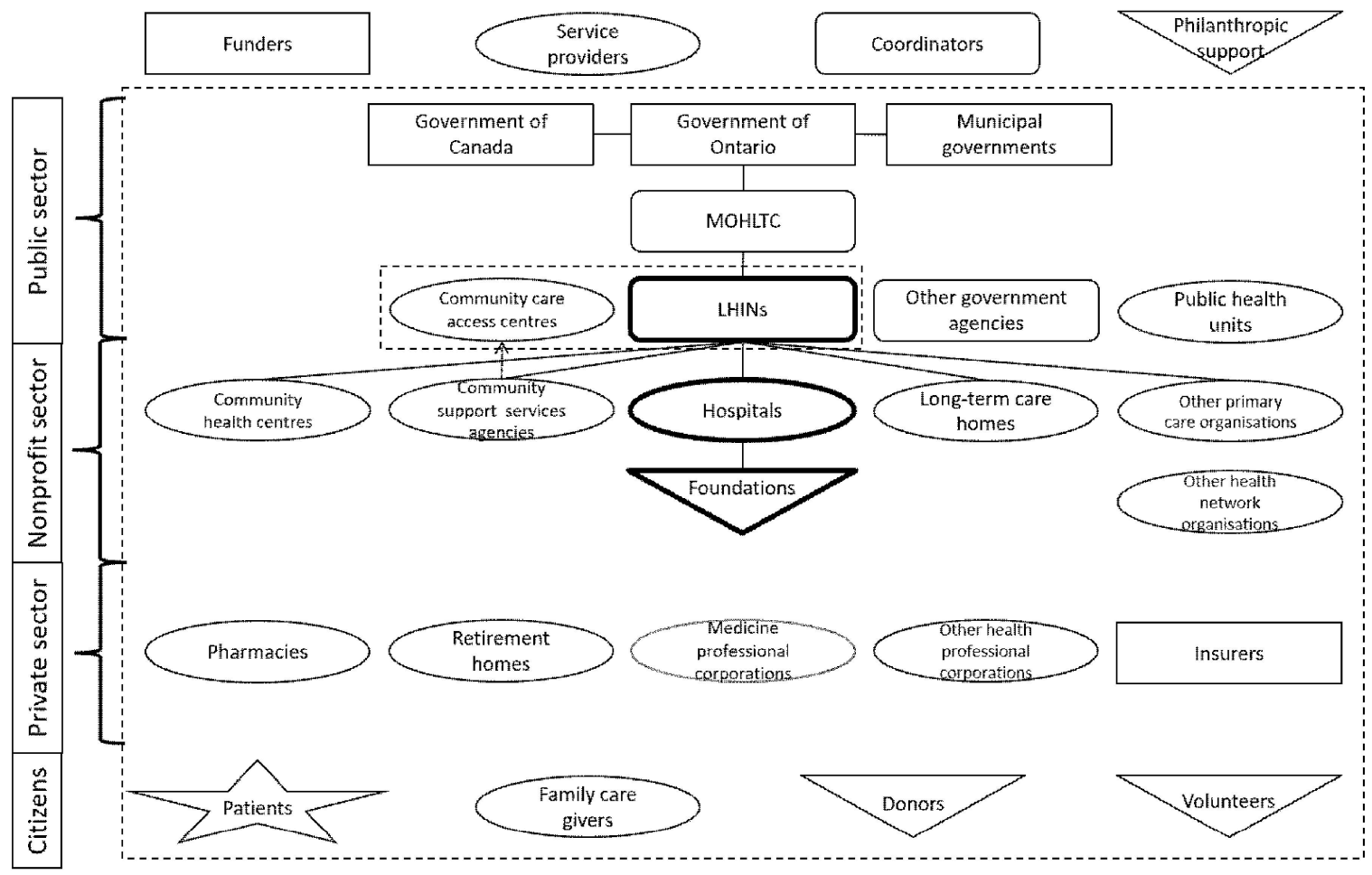

Figure 4-2 - Reproduction of Ontario Hospital Association's (2015) Stakeholders

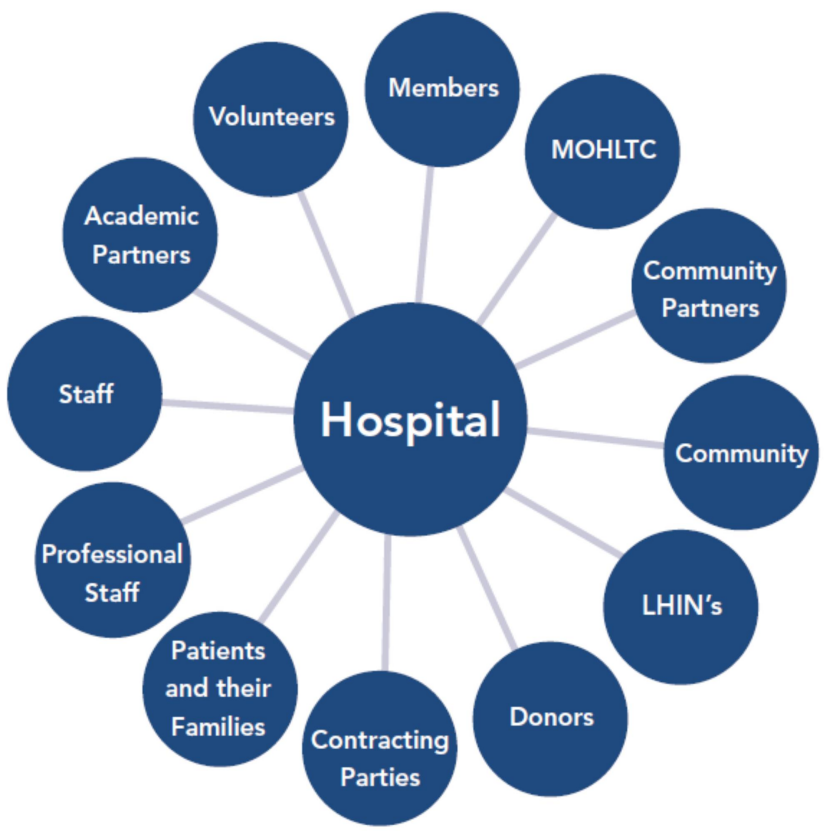

Source: Ontario Hospital Association (2015, p.7) 
Appendix G provides a non-exhaustive list of organisations within Ontario's health care system. Panel A lists provincial and federal government agencies, other primary care organisations, and other health network organisations directly identified in figure 4-1. Panel B lists some of the peripheral organisations that interact with the health care system regularly to advance the system's objectives. These organisations include regulatory colleges, trade unions, and interest groups and associations. Peripheral organisations may also include such institutions as police, schools and academia which are not listed in the appendix.

There is a large spectrum of care which requires the involvement of various organisations. As one can see, health care providers operate alongside a myriad of nonprofit, public, and private organisations with different resources and missions, offering services, ultimately, to a diverse, aging and demanding patient base. These organisations operate independently and have varying degrees of diverging interests which can complicate collaborative efforts. However, these organisations must nonetheless interact with each other to achieve their individual objectives, as well as system-wide objectives.

\subsubsection{Demographic and Geographic}

Currently $16.7 \%$ of Ontario's population is aged 65 and over. Over the next 25 years (by 2041) this age group is expected to increase by $48.5 \%$ to $24.8 \%$ of the 
population (Ministry of Finance, 2018). Ontario's population is therefore aging. As the population is living longer, the number of people living with chronic conditions or complex needs is increasing (Canadian Institute for Health information, 2011). Longer life expectancies also mean that the health care system deals with a lot of elderly patients (Lavis \& Mattison, 2016). This demographic shift in Ontario's population is putting capacity and cost pressures on the availability of health care resources and will continue to dominate health care management over the next two decades (Devlin, 2019b).

Geographically, Ontario can be divided into six regions: northwest, northeast, southwest, central, east and the Greater Toronto Area (GTA). 48.3\% of Ontario's population lives within the GTA, which constitutes $0.7 \%$ of Ontario's land mass, while only $4.6 \%$ lives within the two northern regions, which constitutes $88 \%$ of Ontario's land mass (Ministry of Finance, 2017). Therefore, Ontario has a very large land mass with an unevenly distributed population. This characteristic of Ontario's geography can complicate access to care in remote and rural parts of the province (Mattison \& Lavis, 2016).

Three of the hospitals included in this study are located in Northern Ontario. In Ontario's northern regions, there is an extremely low population density (1.4 people per square kilometre) and a higher rural ratio than the rest of the province (Health Quality Ontario, 2017). Therefore, the northern regions of Ontario are characterised by their large geography, low population density, higher rates of rural and remote communities. Citizens living in northern Ontario and other rural areas of the province can be 
characterised as having poorer health and worse access to care than those living in urban areas of southern Ontario (Office of the Auditor General of Ontario, 2015).

\subsubsection{Fiscal and Political}

Ontario's health care system is publicly funded. Currently, approximately $40 \%$ of government expenditures are attributable to health care (Government of Ontario, 2018), which represents approximately $70 \%$ of all health care related spending in the province (Canadian Institute for Health information, 2018). The other 30\% is privately funded through insurance premiums and out-of-pocket fees. The capacity pressures discussed in the previous section are what is driving the fiscal pressures. As the province continues to incur annual deficits, there are challenges in the ability of provincial government to increase funding rates to the health care sector (Lavis \& Mattison, 2016). This fiscal situation in Ontario is inevitably linked to politics.

To grapple with its growing budget deficit, the provincial government continues to introduce political reforms in health care to try and find efficiencies and establish appropriate levels of services (Wilson, Mattison, \& Lavis, 2016b). The provincial government introduced legislation under The People's Health Care Act, 2019 (Government of Ontario, 2019b) which will have significant implications on health care management in Ontario. This includes the amalgamation of LHINs and other government agencies into a single agency called Ontario Health (Office of the Minister of Health and Long-Term Care, 2019). In a June 20, 2019 announcement, the government also 
separated the Ministry of Health from the Ministry of Long-Term Care (Office of the Premier, 2019).

Political dynamics make it so that health care in Ontario is highly politicized (Fierlbeck, 2011). As a result of these dynamics, one can observe that there are fiscal constraints to both increasing revenues through higher taxation and reducing expenses through spending cuts. There are also electoral pressures to keep costs down at the macro level of governing a provincial budget, and yet to do the exact opposite of increasing spending at the electoral district level. Changes in government, as a result of elections, bring changes in policy direction such that government ideology affects which qualities of the health care system it will privilege (Fierlbeck, 2011). These qualities include cost containment, efficiency, equity, universality, comprehensiveness, and responsiveness (Fierlbeck, 2011). As such, "the health care system should not simply be seen as a large mechanism with various interlocking cogs and gears, but also as a battlefield of competing interests" (Fierlbeck, 2011, p.xi).

Political actors may use the opacity of information with the voting public to advance their agendas, which can contribute to inefficient health care investing if it can help win over an electorate (Martin, 2017). For example, governments may be inclined to keep medically unnecessary hospitals open when elections can be won or lost on the issue of hospital closures (Gratzer, 1999). As another example, LHINs require hospitals to balance their budgets. If a hospital is operating with a deficit, it is expected that the hospital will curb expenses and return to a balanced budget. However, political 
circumstances may arise where a LHIN, with the MOHLTC's blessing, will momentarily waive or disregard this requirement for political purposes. The MOHLTC may also disregard LHIN recommendations and make different decisions for political reasons. Election years can be particularly challenging for a government, and this can have an impact on the timing of funding and the efficiency of programs. This dynamic results in political uncertainty for health care organisations, which affects their ability to plan longterm.

Overall, the contextual environment within Ontario's health care system is marked by many legal constraints and can be characterised as highly regulated. Health care providers operate alongside a myriad of nonprofit, public, and private organisations with different resources and missions, offering services, ultimately, to a diverse, aging and demanding patient base. These organisations operate independently and have varying degrees of diverging interests which can complicate collaborative efforts. The health care system is facing major demographic challenges as Ontarians are living longer and are experiencing more chronic conditions and have more complex needs. Geographically, Ontario has a dispersed population over a large region. Ontarians living in rural and remote areas continue to have trouble accessing care which reduces the province's ability to achieve health equity. Health care organisations also face fiscal constraints and political uncertainty which affects their ability to plan long-term. As a result of these factors, the health care system in Ontario can be characterised as complex (Devlin, 2019b; Lavis \& Hammill, 2016b) and dynamic (Fierlbeck, 2011). 


\subsection{Operational Environment}

For this study, factors particularly relevant to the health care system's operational environment include the hospital funding model and organisational interdependency.

\subsubsection{Funding Model}

Since the focus of this study centres around hospitals, it is important to provide an overview of their funding model. The largest source of hospital revenue is from government funding. Between $85 \%$ to $100 \%$ of most hospitals' revenue flows from the MOHLTC through to LHINs or other government agencies (such as Cancer Care Ontario) (Ontario Hospital Association, 2015). Other sources of revenue, sometimes earned within the hospital's foundation, include revenue-generating activities (e.g. cafeteria, parking, rent, non-medical patient services such as private rooms and televisions), as well as grants, donations, and fundraising. Some of these 'extra' revenues, such as parking fees, face citizen backlash (Lavis \& Hammill, 2016a), others are set by the province or there are guidelines as to what they should be.

The provincial funding model for hospitals is called the Health System Funding Reform (HSFR). The HSFR uses a prescribed approach to funding which was designed to increase allocation equity and encourage hospital efficiency (Hay Group Limited, 2014). The HSFR has three components. First, hospitals receive a global funding amount to cover facility level operating costs and corporate services such as human resources, 
finances, decision support and information technology systems. The second component is the Health Based Allocation Model (HBAM). Under HBAM, health care dollars are provided for health services based on the number of patients served (i.e. service-volume) and the complexity of the care provided to those patients. The complexity of care is measured by what is known as a HBAM Inpatient Group (HIG) weight, which assigns a dollar weight to patients based on a number of factors including the intensity of care provided and the expected length of stay. The third component is Quality-Based Procedures (QBP). Under QBP, health care dollars are allocated to specific procedures based on a price times volume approach (Ministry of Health and Long-Term Care, 2018b).

As initially designed by the provincial government, hospital funding allocations between the three components were to represent up to $40 \%$ towards HBAM, up to $30 \%$ towards QBP, with the remaining 30\% towards global funding (Ministry of Health and Long-Term Care, 2018b). A funding reform began in 2012 and is being phase in over a number of years. However, modifications to its formula continue to occur in order to adjust for changes in government priorities, for unanticipated behaviour, and to promote or discourage specific activities. As such, the funding allocation break down of 40/30/30 is yet to occur.

Small hospitals (those with fewer than 4,000 inpatient weighted cases per year) are not included in the HSRF funding model and continue to be allocated funds on a global budget basis. Hospitals also regularly receive non recurring funding for specific 
initiatives such as construction projects, which varies from year to year and provider to provider.

To receive funding, hospitals in Ontario are required to negotiate a Hospital Service Accountability Agreement (HSAA) with their regional LHIN. The HSAA is a contract which stipulates the reporting and performance obligations of the hospital. HSAAs are generally signed by the hospitals' March 31 fiscal year end, while provincial funding for the upcoming fiscal year is not usually confirmed until late spring (between May and June). Therefore, this situation creates uncertainty by which hospitals have agreed to be held accountable, for revenue dollars which are unconfirmed until a later date.

\subsubsection{Organisational Interdependency}

In other provinces, regional health authorities fund programs and services directly. However, LHINs in Ontario generally fund other independent (often nonprofit) organisations (Moat, Mattison, \& Lavis, 2016; Office of the Auditor General of Ontario, 2015). Some of these organisations are quite disconnected, such as primary care (offered by physicians in medical professional corporations) and acute care settings (offered by hospitals), which can be a source of patient dissatisfaction and system level inefficiencies and ineffectiveness (Martin, 2017). Physicians, both in primary care and specialty care, have a considerable degree of autonomy within the health care system, even though physicians, hospitals, and the remainder of employees within the hospital are all publicly 
paid (Fierlbeck, 2011; Martin, 2017). As for hospitals, board membership of these organisations is usually anchored within the communities (and is often high profile for larger organisations) (Moat et al., 2016). These volunteer boards have their own interests that may differ from those of LHINs and the MOHLTC.

Fragmentation of the health care system is therefore a concern (Lavis, 2016) as patients and families deal with a cumbersome system that is difficult to navigate (Devlin, 2019b; Donner, 2015). Health care management is complicated by the need to integrate services between organisations to increase patient satisfaction and reduce patient safety risks (McNeil, 2015). Hospitals (and other health service providers) also rely on a network of relationships to achieve their objectives. These interdependent relationships between the nonprofit, for-profit, government sectors become fundamental to their operations (Abzug, 1999). For instance, hospitals rely on partner agencies to meet one of their important objectives of ensuring efficient patient flow from acute care to the next level of care, whether it be rehabilitative care, home care, palliative care, etc. As an example of this lack of integration, hospitals face a limited supply of long-term care homes and other settings to which they can discharge patients safely who no longer need acute care (Lavis \& Hammill, 2016a). When this or other discharge problems occur, these patients are commonly called 'alternative-level-of-care' (ALC) patients.

Patients designated as ALC have completed their acute phase of care, yet the hospital is unable to transfer them to the next level of care (Devlin, 2019b), either to a community bed (such as a long-term care home, a mental health and addictions centre, a 
hospice, etc.) or for home services (PSW support, retrofitting a home, etc.). ALC volumes are a measure of how many patients are in a hospital that should not be there. ALC is an inefficient use of hospital resources and is an indication of a system-wide integration problem (Office of the Auditor General of Ontario, 2015). ALC rates are a function of whether or not the health care system is working properly and is integrated; they are not associated with one single organisation. As a provider of last resort, hospitals are at the mercy of their partner agencies to take in these patients, and a high degree of fragmentation exasperates the problem. Based on the HSFR funding model, a hospital needs its high volume high-value beds rotating people through for its operations to be financially efficient. If ALC patients are occupying those beds, it negatively effects the hospital's ability to generate revenue.

Therefore, there is a pressing need to integrate health care services along the continuum of care (Fierlbeck, 2011) in order to increase patient satisfaction, reduce safety concerns and increase efficiencies. Greater integration of services is demanded by citizens (and by extension, governments), which require the elimination of silos that exist between organisations (either by coordinating their services, or through outright amalgamation) (Office of the Auditor General of Ontario, 2015). Policymakers, organisations and citizens are taking steps (and have been for many years) to reduce fragmentation and increase integration. For instance, the provincial government recently introduced the concept of Ontario Health Teams which are designed to coordinate care services among organisations to offer integrated services along the continuum of care to a defined geographic population (Ministry of Health and Long-Term Care, 2019). Ontario 
Health Teams may include primary care, acute care, long-term care, home care, community care, and mental health and addictions facilities. This approach stops short of requiring organisations to formally amalgamate.

The challenge with such an approach is the need to continue to maintain clear lines of accountability (in an environment where there is a high degree of 'life and death' stakes involved in much of the decision making process). This integration blurs the lines of organisational boundaries and the related delineated patterns of accountability (Bakvis \& Juillet, 2004). The more integration that is achieved between organisations, the less it is possible to hold specific organisations accountable for their performance. As Fierlbeck (2011, p.319) wrote: "we demand clearer accountability, but we want the system to become more integrated. We want system-wide efficiencies, but we will not let efficiencies be made where they threaten our own particular interests. We expect choice and quality, but resent the cost. It's a confusing dialectic. What health care is, and what we want it to be, is mediated by politics". Therefore, one has to ask: how do health care organisations manage their accountability systems in such an environment? The following chapter investigates exactly this. 


\section{CHAPTER 5: ANALYSIS AND DISCUSSION}

Chapter 5 contains four sections to analyse and discuss the findings of this study. The chapter covers the identification of salient stakeholders, stakeholder relationships, governance mechanisms, and information strategies.

\subsection{Identification of Salient Stakeholders}

Freeman (1994, p.46) defines a stakeholder as "any group or individual who can affect or is affected by the achievement of the organization's objectives". However, this foundational definition of a stakeholder is too broad, and open to criticism (Sternberg, 1997). A typology is needed to focus on those stakeholders that are most salient for the purposes of the research developed here, thereby excluding latent or secondary stakeholders. There exist numerous stakeholder classifications in the literature to achieve this objective (e.g. Mainardes, Alves, \& Raposo, 2012; Miles, 2017), but Mitchell, Agle, \& Wood's (1997) typology appears to be the most useful and parsimonious in operationalising health care stakeholder salience by narrowing stakeholders to specified characteristics.

Per Mitchell et al. (1997), a party to a relationship can be characterised as a stakeholder if it has some degree of power, legitimacy and urgency. Mitchell et al. (1997) describe these three attributes as the stakeholder's power to influence the organisation, the stakeholder's legitimacy in its relationship to the organisation, and the urgency of the 
stakeholder's claims for immediate attention from the organisation. Those stakeholders that possess at least two of the three attributes are considered salient, while other stakeholders possessing only one attribute are considered latent, and non-stakeholders are those that possess none of the attributes (Mitchell et al., 1997). The following sections analyse the salient stakeholders of hospitals, LHINs (Local Health Integration Networks) and foundations.

It should be highlighted that this conceptualisation is socially constructed, and others could classify these and other stakeholders differently as having more or less of the three attributes. Stakeholder attributes therefore exist on a continuum, and are also dynamic and shift from situation to situation and through time (Mitchell et al., 1997). Stakeholders may also build coalitions to advance each party's aligning interests (Mitchell et al., 1997). However, for the analysis put forward, it is argued that the stakeholders discussed below have some degree of salience to the organisations under study. The salience of stakeholders was also supported through a review of archival documents.

\subsubsection{Hospital Stakeholders}

In the hospital context, participants identified salient stakeholders as patients, the LHIN, physicians and the hospital's foundation. 
First, patients were identified as salient stakeholders of the hospital. Patients both legitimise the activities of the hospital and, when in need of care, require urgent attention of the hospital's resources. To simplify, the term patient will be used, but it includes the families of patients in this stakeholder group. It should be noted that patients were not directly interviewed because the focus of analysis was on the organisations and because access to patients brings ethical challenges with limited benefits for this specific research study. In addition, the core function of a hospital is to attend to patient needs and patient accountability demands were indirectly gathered through the review of archival documents and through the interviews with board members, who are intended to represent the constituency including the patient voice, and with executives.

Second, LHINs were identified salient stakeholders of hospitals because LHINs are responsible for providing financial resources to hospitals, and thus they have power over hospitals and confer hospitals their legitimacy to operate. At times, LHINs may also require urgent attention from hospitals, when, for instance, the MOHLTC makes policy changes that require hospitals to change their processes, make funding applications, or provide data for policy purposes. A hospital board member described the LHIN's salience: "All the time, the LHIN is really important. The LHIN I think is like the oxygen. So they can cut us off and make things really difficult so that we have to struggle or they can make it easy for us." (I24-Hospital board member). The parameters of this relationship are set forth in the Hospital Service Accountability Agreement (HSAA), agreed upon between the hospital and its LHIN. 
Third, physicians were identified as salient stakeholders because they have control over many of the hospital's resources. Physicians, as independent contractors, are not employees of the hospital; they are granted privileges to work at the hospital and retain responsibility for many facets of patient care and discharge. As such, physicians have some power over the hospital. Physicians also enjoy a high degree of legitimacy from patients and the public at large: "They call a lot of shots in terms of patient care [...]. So your doctors are a critical stakeholder in this whole thing." (I10- Hospital board member).

Fourth, foundations were identified as salient stakeholders because of their ability to help fund capital purchases and the legitimacy they are conferred from their donor base.

Using Mitchell et al.'s (1997) stakeholder typology, figure 5-1 conceptualises the qualitative classes of hospital stakeholders. 


\section{Figure 5-1 - Qualitative Classes of Hospital Stakeholders}

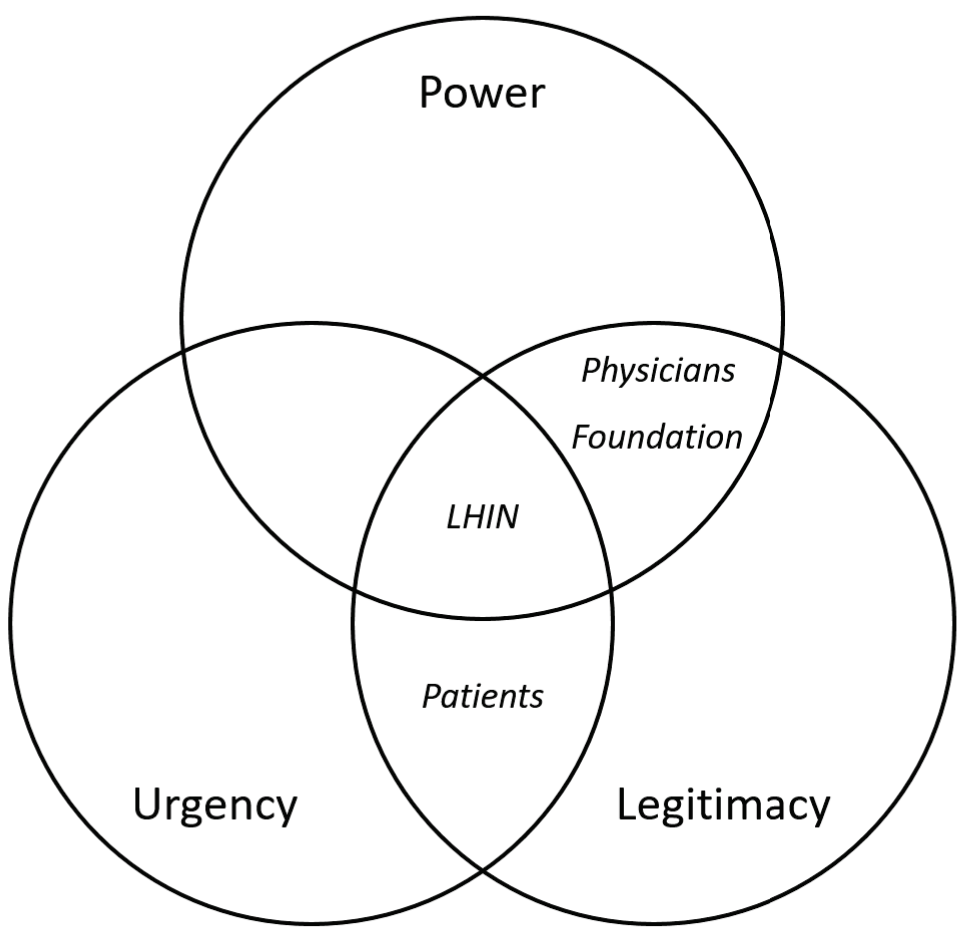

\subsubsection{LHIN Stakeholders}

Salient stakeholders of LHINs include the Ministry of Health and Long-Term Care (MOHLTC), hospitals (and other health services providers), and the communities within a LHIN's geographic region.

The MOHLTC has all the characteristics of a salient stakeholder, as it provides LHINs with their legitimacy, is the LHINs' sole funder, and often has urgent requests. LHINs and the MOHLTC enter into a formal accountability relationship through an 
MLAA (Ministry-LHIN Accountability Agreement): "Everything we do is at the will of the government. We do it because this is a program that the government decided they wanted to have for the residents." (I18-LHIN Director).

Hospitals, along with other health service providers, funded by LHINs are also salient stakeholders with some degree of negotiation power and confers LHINs with some degree of legitimacy.

The communities within LHINs' geographic reach are salient stakeholders because they provide LHINs with legitimacy and often have urgent requests. While communities are not direct recipients of LHINs' funding, the decisions made by LHINs as to where, when and how they fund health care have a direct impact on communities, residents within those communities and patients and families that ultimately interact with the health care system in a region.

Using Mitchell et al.'s (1997) stakeholder typology, figure 5-2 conceptualises the qualitative classes of LHIN stakeholders. 


\section{Figure 5-2 - Qualitative Classes of LHIN Stakeholders}

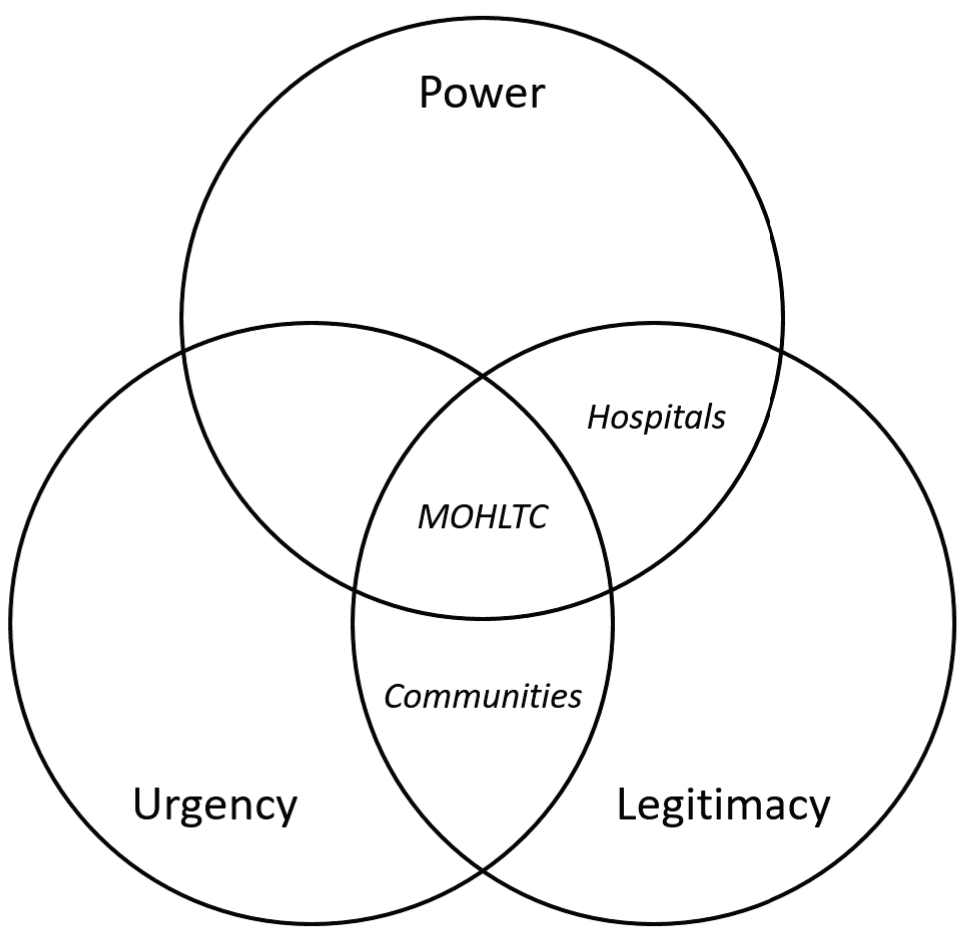

\subsubsection{Foundation Stakeholders}

In the foundation context, salient stakeholders were identified as donors (both past and prospective), whom provide the resources necessary to achieve a foundation's mission, legitimise a foundation's activities and are occasionally urgent in their requests. The hospital is also a salient stakeholder because the foundation distributes resources to the hospital and the hospital also sets capital purchase priorities for the foundation, and as such legitimises foundation activities. 
Using Mitchell et al.'s (1997) stakeholder typology, figure 5-3 conceptualises the qualitative classes of foundation stakeholders.

Figure 5-3 - Qualitative Classes of Foundation Stakeholders

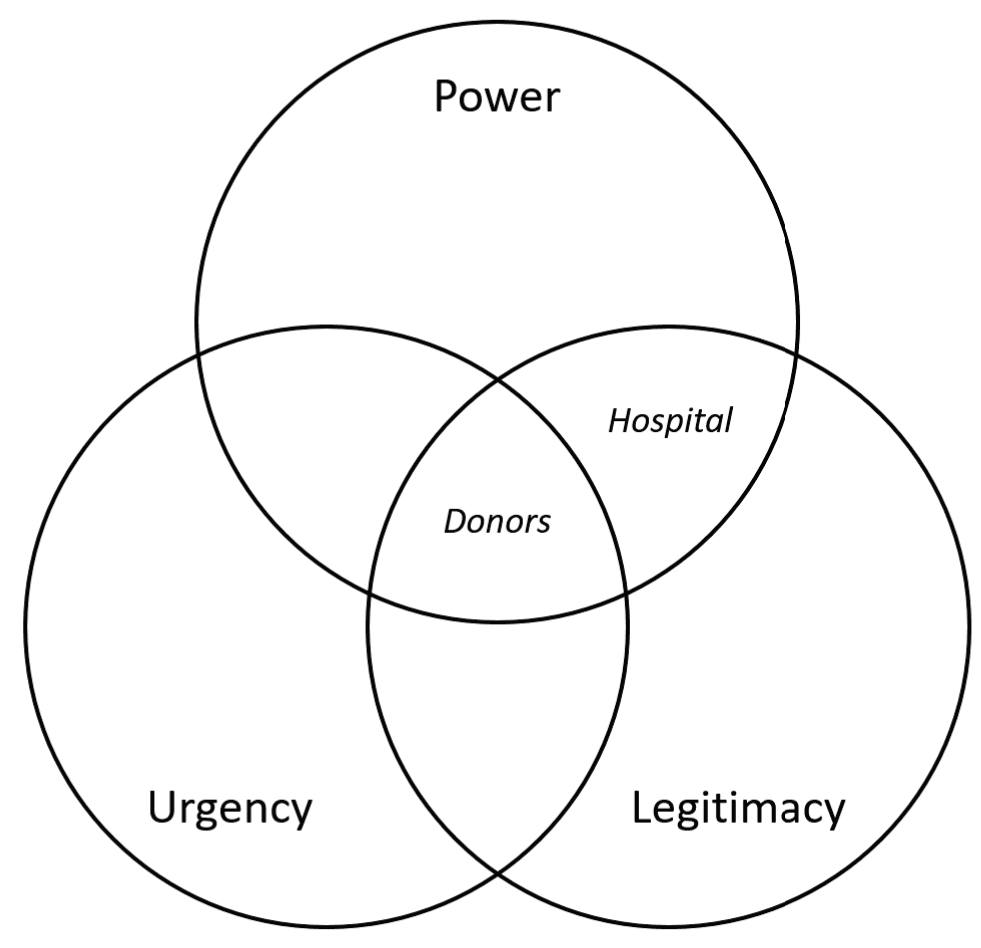

In summary, starting with hospitals as the central focus of this study, salient stakeholders identified during data collection include LHINs, patients, physicians, foundations, the MOHLTC, communities, and donors. 


\subsection{Stakeholder Relationships}

The concept of managing and negotiating competing stakeholder demands, called the 'subject' of accountability (Goodin, 2003), is well documented in the literature. Managing accountability is about negotiation with and among stakeholders (Anheier, Hass, \& Beller, 2013). Recent examples of studies include Andrews (2014), Abouassi and Trent (2016), Gore, McDermott, Checkland, Allen, and Moran (2018), Schwabenland and Hirst (2018). It is important for nonprofit organisations to understand and manage their stakeholder relationships as a way to achieve their organisational objectives (Shaw, Zink, \& Lynch, 2014).

This section reviews different facets of hospitals', LHINs', and foundations' stakeholder relationships, including accountability demands, nature of relationships, negotiation tactics, and accountability challenges. Accountability challenges are events or circumstances that make it harder for a party to advance its objectives in either being accountable, or holding another party to account. It should be noted that accountability demands on the organisations under study are wide ranging. However, not all accountability demands are addressed here, as to keep the discussion focused on the more predominant demands that emerged from the data collection. Also, to simplify, the term accountability will be used, acknowledging that organisations face many accountabilities. 


\subsubsection{Hospital-Patients Relationship}

The first stakeholder relationship is between the hospital and their patients. Unsurprisingly, participants described that patients' predominant accountability demand is for the hospital to provide them with the health care services they require. Specifically, patients expect to receive quality and timely care that is available as close to home as possible. For a sub-group of patients needing care services beyond the acute hospital phase, such as those patients designated as ALC, they especially want their health care services coordinated with community resources in order to ease the transition from the hospital to the next place of care, and to avoid returning to the hospital. This accountability demand is supported by government documentation on its website, stating: "Providers will work together to take the guesswork out of transitions, where we know patients often feel lost and unsupported" (Government of Ontario, 2019a).

In the continuous dialogue that occurs between parties, accountability negotiation between the hospital and patients is limited. One participant described the relationship as "a very authoritarian situation. You come in, you present yourself. The hospital decides whether they're going to serve you or not" (I4-Hospital board member). Another participant noted "It's not a negotiation process. We do ask for their perspective, but the responsibility is ours" (I13-Hospital CFO). For safety and security reasons, there are standards of practice a hospital must follow. Any negotiation with patients generally occurs with regards to the length of stay. While it is not unheard of for a hospital care team to ask a patient to stay longer to ensure the patient is clinically strong enough to 
leave the hospital, most of the length of stay negotiation occurs to try to get patients out of the hospital when their acute phase of care is complete. Patients will occasionally put up obstacles to their discharge for numerous reasons, including when they feel that their recovery is not sufficient for discharge. As one participant explained "Because people think health care is free. And the hospital should be here to be their safety net. 'I'm not ready to go home. I'm not going home. I don't think it's reasonable for you to ask me to pay for home care or have my family come in and be inconvenienced'. etc." (I14Hospital CNO). In describing this situation, another participant explained efforts made by the hospital to reassure patients and find solutions, because any extended length of stay adds costs to the hospital and increases ALC rates: "If there's a barrier that's put up, then there's a negotiation [...]. You wouldn't even imagine the barriers that might exist.” (I6Hospital Director).

The nature of the relationship with patients, as well as the greater community is supportive, as they both have a mutual interest in maintaining services within the community. However, the relationship can be challenged if patients, and by extension the community, feel they are being treated inequitably, by losing a service or not receiving a service at the same level of care as elsewhere. Therefore, service level expectation gaps exist between what a hospital offers and what some patients expect. As one participant commented: "We can't be all things to all people" (I29-Hospital board member). These expectation gaps create frustrations from both parties and hospitals must therefore try to manage expectations. Expectation management can be further challenged by revenues fluctuations as a result of one-time funding. One participant explained the challenge of 
managing community expectations: “That's what's even worse [a deficit] for [community members] is they don't know that fluctuations occur. The government gives you bail outs from year to year but doesn't change your next year.” (I31-Hospital CEO).

While attempting to reconcile this collision between needs and abilities, or expectations and resources, hospitals struggles with the diverging demands of patients in regard to the level of service hospitals should provide. One participant explained: "If we're here to treat people or to help them get better, does that mean that they have to be $100 \%$ before they leave, or at what level do you say 'okay, you don't need to be here anymore'. And that's not what I'm going to call a thin black line, that can be a pretty wide gray line". (I4-Hospital board member). The same participant gave another illustrative scenario: "We don't provide any active cardiac care; we ship them out as soon as we can. That seems to be acceptable. But in some levels, why do people have to go to Ottawa or Toronto [...]? I don’t know. How are we accountable for that?’. Managing service level expectations against resources is a delicate balancing act that is ongoing and highly dependent on the contextual environment surrounding hospitals. The capacity of partner organisations, disease outbreaks, elections, and changing government priorities can all affect the level of service a hospital can provide.

\subsubsection{Hospital-LHIN Relationship}

The predominant accountability demands of LHINs require hospitals to provide a certain scope of service delivery and be fiscally responsible by working within the 
funding provided. In return, LHINs are asked to provide funding to meet the service needs required of hospitals. LHINs are also asked to provide guidance and system-wide strategic direction to help improve hospital processes. Process improvements are geared towards increasing overall efficiencies and effectiveness in order to improve system performance. One participant gave the following example: "We have a provincial digital blueprint telling us which direction we want to go. We don't want to have hospitals going out and buying systems that are in a different direction.” (I25-LHIN CFO). To achieve this objective of strategic direction, it is essential that LHINs facilitate interorganisational interactions between health care providers in order to support the transformations required to improve system performance. As one participant described it: "They're looking to the LHIN to provide that role, whether it's to facilitate the discussion, to bring the partners around the table, to lead the planning, or to drive the implementation" (I32LHIN CFO).

LHINs, as a funder, 'hold the purse', yet negotiations around competing accountability demands still occur between parties. Specifically, negotiation between hospitals and LHINs centre around attempting to balance the financial constraints of hospitals while maintaining equity in service levels. As such, concessions are regularly made to privilege one accountability demand over another. In reference to the level of service provided, a participant explained: "If you're developing the HSAA, there's usually some conversations and negotiation around why you think that the target should change. [...] They always make you look at provincial targets or performance, and then negotiate what you think you can do as an organisation." (I30-Hospital CNO). 
For resource allocation and funding, negotiations between hospitals and LHINs occur around clinical programs that are not funded or under funded. Generally, when a hospital is in a deficit position, difficult decisions must be made to cut programs or obtain increases in funding. When budget constraints are required, hospitals may inform LHINs of their intentions to cut an underfunded program in order to meet the hospital's accountability demand of operating within a balanced budget. LHINs then decide to either provide additional funding to support programs or allow programs to be terminated. Through this negotiation process, hospitals may avoid or transfer blame to LHINs if the media is informed of the suppression of programs. LHINs understand this risk, and so funding decisions are carefully made in consideration of political risks. One participant described such a scenario: “[...] So that's a prime example where, as a hospital, you have to be able to set up pilots but say, 'okay, the pilot has worked or not worked'. And then you shut it down [if there's no more money coming in] and move on. [...] At the end of the day though, there was some money given towards it [the program] eventually." (I10-Hospital board member).

Hospitals negotiate with LHINs by providing supporting data to attempt to demonstrate that hospitals are efficient in providing services and that any funding shortfalls are due to an inequity in revenue sharing. A participant reflected on their organisation's effort in this regard: "I think we do a good job of providing them with enough information to show that we've done all that we can” (I22-Hospital CFO). Another participant provided a detailed explanation of their negotiation tactic: "With the 
LHIN, we do so from a point of providing evidence. So when we go to the LHIN now we make sure we're prepared with statistics, with evidence, with comparative benchmarks. So we're preparing an argument not just going to them with a request, we're now backing it up with arguments about why it's important to us, why equity is not being achieved, and $[\ldots]$ we want to provide them with enough evidence for them to be able to make sound decisions." (I24-Hospital board member).

Hospitals also attempt to negotiate by building coalitions with other institutions with similar interests, thereby increasing the legitimacy of a claim: "With the Ontario Hospital Association, we're working with the rest of Ontario's mid-sized community hospitals. [...] Instead of each of us sort of screaming and wailing that we don't have enough money, [we need to] have a unified voice to Queen's Park to say that this is not [one hospital or another hospital's] problem. This is a problem common to all of the midsize community hospitals, and you got to listen to us because we can't continue to deliver these services without adequate funding." (I29-Hospital board member). When determining what services to cut and what services to keep, hospitals and LHINs try to identify core services and meet the equity demands of communities. In this regard, LHINs and hospitals priorities align. One participant gave the following example: "So the decision was made by the committee to cut [a program] because it's not an acute service. $[\ldots]$. So we agreed that this is something that can go, rather that than, say, pediatric mental health or obstetrics.” (I24-Hospital board member). 
One of the ways hospitals are managing accountability demands of LHINs and patients is by moving non-acute health care services that are costing money out of hospitals and into communities to private providers or through public-private partnerships. A participant gave the following example: "We decided that we would farm [a program] out to the private sector and turn it into a money making venture rather a cost. Because we still hold the license to be able to bill OHIP, so a private vendor is interested in partnering with us because that's the only way that they can bill revenue to OHIP.” (I22-Hospital CFO). While these arrangements transfer costs to patients, it helps hospital finances (a LHIN accountability demand) while maintaining services within the community (a patient accountability demand), thereby aligning the priorities of the LHIN, hospital and community.

Most participants felt the nature of the relationship between hospitals and LHINs was positive. One participant described it as: "Warm and mutual trust. They really do try to work together to find a solution". (I11-Hospital Director). Another said: "I find that they really do a good job of balancing their directives" (I22-Hospital CFO). And another: "I don't fault the LHIN in any way. I've got most respect for them." (I23-Hospital CNO). Although, some participants did find the expectations of LHINs to be contradictory, in that LHINs want hospitals to take on more programs, but at the same time are required to balance their budgets. One participant explained this contradiction: "They encourage you to do things, and then they don't back you [financially]. And then they come after you and say, 'but you're not balancing your budget'." (I10-Hospital board member). 
This contradiction created feelings of frustration, which were mitigated by an understanding from most participants that LHINs were doing their best under difficult circumstances of managing the portion of health care delegated to them and managing their own conflicting accountability demands from the MOHLTC. As such, participants were generally sympathetic to LHINs' intermediary role: "I think we have to remember as well is that the LHIN isn't the ultimate decision maker, that they're marching orders from the government. So if the government says, 'You get your hospitals to do this,' then that's what they've got to get us to do." (I22-Hospital CFO). Conversely, LHIN participants were also sympathetic to the hospitals" precarious situation: "Hospitals have very, very tough mandates. [...] They're kind of where the pavement meets the road. And it's got to be very difficult for them sometimes to take a look at the LHIN and say, 'Well, gosh, get out of my way so I can get my job done,' [...] Sometimes they must just find it extremely frustrating, because at the end of the day they know that it's the Ministry that's going to make the decision anyway." (I26-LHIN board member).

Overall, the nature of the relationship with LHINs can be described as professional. One participant concluded that the accountability relationship with LHINs was: "Like a marriage, right? Sometimes, the conversation's not what you would want them to be, but we're stuck together." (I14-Hospital CNO).

In order to advance each party's objectives, LHINs and hospitals occasionally collaborate on projects to fix system wide problems and share best practices. These collaborations help build trust and strengthen relationships between parties. However, 
while both parties try to work collaboratively, there is still uncertainty about which party is responsible for certain objectives, which is a cause of frustration for both parties. One participant communicated this frustration: "But this thing about them telling us to fix the ALC when they're causing it, that's annoying" (I3-Hospital CEO). Specifically, the uncertainty about where responsibilities lie seems to be at the heart of the type of relationship which at times can be adversarial, rather than collaborative. When the relationship is adversarial, blame or responsibility is thrust on the other party. One participant provided the following example: "When we started our health restructuring plan, it was under a very, what I would call, combative atmosphere. It was, 'okay, YOU guys are this much in the hole, how are YOU guys going to fix this?' (I4-Hospital board member). Another participant commented: "I think in the past, the hospital was too combative. The LHIN said 'no'. We got into a big argument." (I5-Hospital board member). The interdependent nature of health care in Ontario makes it difficult to establish clear lines of responsibility, and as a result makes it harder to hold others to account and be accountable.

Occasionally, hospitals try to shift responsibility to others or blame other health service providers for poor performance. A participant explained this challenge: “Sometimes they don't take responsibility, sometimes they're [hospitals] blaming LHIN or they're blaming other community partners, so part of our job I think is just making the system talk to each other and work" (I17-LHIN Director). LHINs must try to hold hospitals accountable for the performance they can control. However, some facets of health care are system challenges, which hospitals cannot control. LHINs are left to 
decipher if hospitals are shirking responsibility or if performance results are outside the hospitals' scope of responsibility. This blurriness also hinders the development of strong accountability relationships because the inability to establish clear lines of responsibility breeds distrust or suspicions of not doing enough to tackle a problem.

Even with extensive formal agreements, there were still unclear lines of responsibility between hospitals and LHINs as there seems to be confusion about the LHINs' responsibilities and its roles. Some participants felt that LHINs have an advocacy role, and were critical of the LHINs' perceived or real efforts in this regard. To this point, one participant concluded that: "I really think our LHIN is not effective" (I12-Hospital Director). Other participants felt LHINs also had an advocacy role, but were less critical: “They tell us that they advocate. They haven't had a great deal of success. But that I don't know that anybody has had success in their advocacy." (I13-Hospital CFO). Another participant said: "I have to say that they are very good at advocating on our behalf" (I22-Hospital CFO). One participant viewed LHINs as having a much narrower role as a government intermediary: "Are they simply people that assess performance and assign accountability contracts so the money can flow and listen to government in terms of 'do what we tell you'? I would have to say it's that, that they really are just mechanisms for government to flow money." (I14-Hospital CNO). When asked if LHINs played strategic roles, another participant plainly stated "no" (I9-Hospital CEO). There is therefore a need for clear direction and lines of responsibility, which is an ongoing challenge due to the complexity and interdependent nature of health care in Ontario. 
This blurriness of responsibility is associated with the interdependencies required to meet organisational objectives. In the health care system, there is urgency in partner organisations working together by coordinating resources and processes. Stakeholders have an interest in collaborating because each party's individual performance is dependent on the cooperation of other parties and the coordination of resources and processes. This interdependency with LHINs and partner agencies is what makes health care accountability challenging: "If I have a metric that says, "the hospital is not going to be judged as performing well if you have over X ALC patients.' Well, that's great, but my ability to achieve that number is highly dependent. In fact, it's almost completely dependent, by definition, on the system functioning around me." (I14-Hospital CNO).

Another relationship challenge involves the encroachment of politics.

Occasionally, hospitals use indirect channels of communication to pressure LHINs:

"They can time it with elections. They can do it with politicians. They can do it with the community, get the community and the media involved." (I17-LHIN Director). Another explained: "If they feel a LHIN isn't moving quick enough on their request, they'll move it to the political side. They'll copy their request to their MPP, they'll send it off directly to the minister. So what they're trying to get is political pressure on the LHIN. [...] If they're [MPPs] not in the governing party, then they're looking for information that they can hold against the LHIN." (I18-LHIN Director). These actions may undermine trust in the accountability relationship. 


\subsubsection{Hospital-Physicians Relationship}

The predominant accountability demand of physicians working at hospitals is for hospitals to respect their time and make available to them the necessary resources to provide health care services and earn their income. Physicians, who bill OHIP directly, are generally paid on a fee-for-service model, and are not remunerated for meeting times and other administrative work.

Negotiation between hospitals and their physicians centre around resource allocations and the cost/benefit of providing services. These negotiations can be difficult because of a lack of control mechanisms since the use of hospital resources is at the discretion of physicians and there exist diverging priorities between parties. As one participant explained: "If you want physicians to change [...] you have to partner with them and hope they'll come along if they see the advantages in following" (I31-Hospital CEO). In many cases spending considerations by physicians are voluntary, except that the HSFR funding formula uses a prescribed approach to health care delivery as a means to control some spending. While there are minimal financial incentives for physicians to control spending, most physicians are conscientious of hospitals' resource constraints and the need to use resources efficiently: "It's a learning curve because it always used to be that you moved heaven and earth to do what was best for your patient, and now we're recognizing that there's limited resources and before you spend a million bucks on somebody, maybe the patient population would be better served by that money being distributed more equitably. [...] We know that the system' running out of money. And if 
we can do the same for less, then that saves everybody. And if I use up all the money, I'm not going to have a job next year." (I21-Hospital Chief of Staff).

There are also challenges relating to incentives for physicians to use resources efficiently and flow patients quickly through hospitals. For instance, the structure of some physician fees increase when patients are seen in the evening or on weekends, reducing incentives for physicians to see patients during daytime hours. This behaviour can reduce the efficiency of patient flow.

The negotiations that generally occur with physicians are done in an attempt to align the priorities of both parties by changing hospital and physician practice. For instance, one attempt was made to improve the clinical documentation of physicians, which is the basis by which hospitals are partially funded through the Health Based Allocation Model (HBAM). Over time, clinical documentation can become incomplete and it can have negative revenue implications for hospitals: "Nobody wants to end up having a less and less thorough chart but, $[\ldots]$ others start to condense. [It's] an important part of patient care $[\ldots]$ because that is the record that goes to the next physician and back to the family doctor so incomplete charts is a bad thing. [...] We had gotten to the stage where the documentation was so bad that a lot of the things that happen to patients wasn't making onto the chart. [We decided that] we're going to document better in order to improve the financial status of the hospital because [it was in] trouble." (I8-Hospital Chief of Staff). 
In this case, a negotiation occurred to align the two parties' priorities. To get physicians to improve their clinical documentation, the hospital was able to align both parties' priorities of ensuring adequate hospital resources for the physicians to earn their income and maximizing the hospital's revenues. To address this issue, the parties took a collaborative approach: "We wanted to change the physician practice. [...] My message to them was, 'we have to do good clinical documentation or else we'll lose money, and then we won't be able to hire nurses to support the care." (I3-Hospital CEO). In return for better clinical documentation, physicians were able to maintain or increase the availability of resources, and reduce some of the more administrative and burdensome aspects of clinical documentation which were time consuming (a physician accountability demand): "In order for us to preserve the integrity of our programs [...], we've got to get the money that the hospital truly is owed and is losing. So, that made people [physicians] accountable to the change that needed to happen." (I8-Hospital Chief of Staff).

In terms of the nature of the relationship between hospitals and physicians, it can be difficult to engage or dialogue with physicians to build stronger relationships and get their buy-in due to their limited availability as independent contractors: "They're a difficult group to engage because they're all in different schedules. And they're not paid for their time to engage. We don't pay them for meeting time unless they're department chief and then they have a stipend for that role. So it's difficult to say, 'Come spend the day visioning with us for free. You don't get paid for any work you're going to do'." (I31-Hospital CEO). The relationship with the physicians can be strained from a lack of resources, but there is understanding that the hospital's resources are often times limited: 
"I don't know if it's combative so much as we share the frustration. [...] I'm not sure it's warm and fuzzy, but I think there is mutual understanding of the roles people have. Do we like the fact that there's less money this year than last year? Hell no." (I21-Hospital Chief of Staff).

\subsubsection{Hospital-Foundation Relationship}

The predominant accountability demand of foundations on their hospitals is to collaborate in achieving fundraising goals. This accountability demand is supported by Ontario Hospital Association's Guide to Good Governance when mentioning that hospitals must "provide appropriate support to the foundation in its fundraising efforts" (Ontario Hospital Association, 2015, p.14). In return, a hospital's main accountability demand on the foundation is to disperse funds in a timely manner to help fund capital purchases.

While both foundations and the hospitals try to maximise how much foundations can raise, negotiations revolve around the types of capital purchases foundations should fundraise for. Hospitals and foundations negotiate in terms of when funds are dispersed, which is based on what hospitals deem they need, and what foundations are willing to purchase. Hospitals tend to prioritise capital purchases that do not increase or ideally will decrease operating costs. While foundations try to acquire them, hospitals must occasionally settle for purchases that are marketable to their donor base. A hospital CFO explained their negotiation process with its foundation: "We know that the foundation 
can raise about a million dollars a year. So we'll give them a list of \$2 million worth of equipment that we need. [...] We always ask for more and then they take that and they

say, 'Well, we think we can raise money for this and money for that.' And they basically build their own fundraising list off our wish list. [Because, while] it's our priority, it also has to be something that they can go out and market to the community and have it be something that somebody's going to want to donate money towards." (I22-Hospital CFO).

The nature of the relationship between hospitals and foundations is generally collaborative as the majority of their goals are aligned. Overall, the relationship between the two parties can be described as professional.

\subsubsection{LHIN-MOHLTC Relationship}

The accountability demands of the MOHLTC on LHINs include identifying system problems and proposing solutions, acting as oversight bodies, and being a voice for their regions.

LHINs are asked to identify system needs and problems and propose local solutions, which take into account the demographic, geographic and other characteristics of the population in their region. In identifying needs and proposing solutions, LHINs must work within the confines of and follow MOHLTC directives. 
LHINs are asked to act as oversight bodies for health care in their regions by holding health service providers accountable, considering contextual differences such as demographic and geographic, by verifying value-for-money and the delivery of services in accordance with funding agreements.

LHINs are also asked to be a voice for their regions in identifying emerging local issues. This allows the MOHLTC to take local concerns from each region and do its health care planning at a wider provincial level. In addition, this gathering of emerging local issues allows the MOHLTC to mitigate any risk that might occur, whether it be financial, reputational, or political. One participant gave the following summary: "If we are going to be making a decision to accept service cuts, and we predict that it will have a community uproar. People going down and marching at Queen's Park, letters to MPPs or the Ministry. Those things. We will notify the Ministry to give them the heads up. [...] Making the Ministry aware so that they're not caught off guard or blindsided by a busload of angry citizens from [a town] driving down and demanding to meet with the Health Minister.” (I25-LHIN CFO). Another participant described the LHIN's role simply as providing: "translations for the Ministry to help them understand what's really happening at the local issue" (I27-LHIN Director).

Negotiation with the MOHLTC is generally in pursuit of more funding to fill a gap in service needs. Data is used to convey need and support recommendations made by LHINs to the MOHLTC. Dialogue with the MOHLTC is in support of the region or in seeking clarity from the MOHLTC to ensure that LHINs are aware of MOHLTC 
priorities: "Certainly, when a hospital hasn't been able to meet their budget, you go [to the Ministry] and you present a case, and you advocate, and you act as a good intermediary" (I26-LHIN board member).

Participants described the nature of the relationship with the MOHLTC as professional and generally positive. As a crown agency, a LHIN's board of directors is composed of members that are appointed by an Order-in-Council from the Government of Ontario (Government of Ontario, 2016, para. 6. (1)). The actions and decisions of LHINs are therefore not intended to be combative or adversarial with the MOHLTC. This could be due to a self-serving bias in participants' description of their relationship with the MOHLTC.

Expectations of the MOHLTC were deemed clear overall, but there was confusion in instances of political overlay. One participant clarified his confusion: "I would say that $95 \%$ of the time their [demands are] quite very clear. We get a funding letter, [...] it's quite clear. Where it gets confusing is where there's political overlay. For example, [before the writ period] we have been given a memo that says a freeze on hiring, a freeze on discretionary spending. [...] The other example of political overlay or interference would be we had a hospital with a hospital improvement plan a couple years ago. So they submitted to the LHIN there's high risk because the communities, the municipalities, the districts are all getting involved. They're upset. So this happens often, too, is the mayors or the reeves or whoever they are of the areas, they go directly to the Minister of Health. They bypass the LHINs, and they go directly to the Ministry. They get an audience with 
them [...], and direction comes down as, 'LHINs don't do anything with the HIP [Hospital Improvement Plan]. It's with the Minister.' So, yeah. So that's where it starts to get confusing. So do we do our job as outlined in the SAA [service accountability agreement]? Does the Minister trump us? So that's where it starts to get a little confusing where there's that political overlay." (I25-LHIN CFO).

There was also some confusion about performance targets, and specifically when there was a perceived inability to achieve them and the lack of consequences: "So, we've always gone back to the Ministry, because they are setting targets. MRI's a perfect example. Let's say it's 28 days. The province is at 150 . No one in the province is going to achieve that, or 13 out of 14 LHINs won't achieve that. What is the consequence? And the answer that has been given in the past has been those are aspirational targets. So we set a goal, you're striving to achieve it, maybe because the agreements are over three years, you should strive to achieve it in three years. There is no consequence, financial penalty or otherwise, if you don't achieve it." (I25-LHIN CFO). Another participant explained: "So we have performance metrics to meet too. So we have an ALC rate that [the region] has to reach. And we never reach it. Or the timing for knee and hip replacements. It should be within a certain time period and we're never there. And we don't have a chance in getting there. Our MRIs are exactly the same. And as a board member, you say, 'Well, hold on a second. We can't be doing our job as board members. Or if this is an unrealistic goal, why are we setting it if we can't ever reach it? It just sets us up for failure" (I26-LHIN board member). To this point, the Auditor General also concluded in its audit of LHINs "that the Ministry has not clearly determined what would 
constitute a 'fully integrated health system,' or by when it is to be achieved, nor has it yet developed ways of measuring how effectively LHINs are performing specifically as planners, funders and integrators of health care" (Office of the Auditor General of Ontario, 2015, p.314-315) and that "the Ministry has not set any timelines for when all 14 LHINs are expected to meet the 11 provincial targets" (p.317). The Auditor General went on to conclude that "the Ministry takes little action to hold the LHINs accountable to make changes when low performance continues year after year." As such, it appears that the MOHLTC also struggles to hold LHINs accountable due to the complex nature of health care operations. The MOHLTC has trouble deciphering poor performing LHINs from contextual challenges.

Relationship challenges between LHINs and the MOHLTC originate from role ambiguity and legitimacy threats. First, participants did not agree on LHINs' advocacy role. This challenge is similar to the one faced in the Hospital-LHIN relationship. Some felt LHINs should compete for more funding for their regions, while others saw LHINs purely as a flow through of MOHLTC directives. This ambiguity affects the nature of the accountability relationship when roles are unclear. One participant said: "We're actually advocates. [...] We're advocating for the [region]." (I17-LHIN Director). Another participant had a nuanced view: "We don't advocate. [...] And it may be a play on semantics or wording but I would say our LHIN doesn't advocate for more funding etc. like a lobbyist role. We don't do that type of stuff. But we will present evidence-based or evidence-informed business cases. [...] So whether you call that advocacy or not, it's like a business case to the Ministry, outlining kind of the problem." (I25-LHIN CFO). A third 
participant was more clearcut in his assessment of the LHIN's role: "Because we've run into a situation a few years back and were quite explicitly told that our role is not health system advocates. So we're not advocating for individual residents, individual providers. The LHIN is a health system manager." (I18-LHIN Director). Based on the analysis, it is argued that clarifications of LHINs' role in a variety of situations could help improve stakeholder relationships between parties.

In addition, when the MOHLTC bypasses the LHIN, it negatively affects the LHIN's legitimacy and its ability to be an effective oversight body. For instance, the MOHLTC has veto power to overrule LHIN recommendations. When the MOHLTC uses such power, it undermines a LHIN's legitimacy. A participant described such a situation: "Our board approved it [a hospital merger] and it went to the Ministry of Health and Long-Term Care. [...] The Ministry came back and said, 'No, let's go back and do some more stakeholder reviews.' So, ultimately, the Ministry is going to make that decision. [... I think often times hospitals, boards, and CEOs kind of look at LHINs as lame ducks.” (I26-LHIN board member).

Legitimacy is also challenged when the MOHLTC bypasses LHIN discretion to fund at a system level in accordance with the LHIN's funding process, and decides to provide direct funding to specific health service providers for specific initiatives. Some of these funds flow through LHINs, while others by-pass LHINs and flow directly from the MOHLTC to hospitals. LHINs are left to interpret the intent of some of the funding and oversee its spending. This makes it harder for LHINs perform their system-wide planning 
role and threatens their legitimacy: "It blurs things when the Ministry goes directly to the hospital, and that happens, too, so it's difficult for us to be in this role of system manager when we're not given that credibility" (I32-LHIN CFO).

\subsubsection{LHIN-Communities Relationship}

The accountability demands of the community on LHINs include ensuring equity in access and quality of care, and helping residents navigate the health care system. LHINs are asked to ensure equity in access and quality of care for residents within communities. Residents interacting with the health care system also require LHINs to help them understand the rules and navigate the health care system.

Negotiations with communities are minimal or non existent because LHINs acts as an intermediary; their funding levels are at the discretion of the MOHLTC and they do not provide direct services to patients, like health service providers. There is some discretion as to where within the geographic reach of LHINs funds are invested. In this regard, LHINs try to be impartial. Dialogue with communities is done to establish priorities: "It was only through that kind of dialogue [with a local library about the opioid crisis] that you understand what the problems are" (I26-LHIN board member). At a more personal level, LHINs also engage with patients and their families to listen to complaints and understand why the current system and its processes may not meet their needs. Doing so, may help improve system-level processes. 
The nature of the accountability relationships with communities, as well as patients within these communities, happens at the personal level: "In terms of direct accountability to the patients, I think that happens on an individual level with every interaction" (I19-LHIN Director).

When managing their accountability relationships, LHINs are faced with many challenges. Relationship challenges with communities include expectation management and prioritising. Due to resource constraints, LHINs must manage expectations in their communities. Participants noted the necessary compromises between achieving health equity objectives and the reality of maintaining standards of care: "What I felt coming into this organisation is a real tension between Patients First legislation and what we're able to deliver" (I19-LHIN Director). Another participant gave the following example: "Somebody in [a small town] who needs heart surgery might think that it'd be great if there was a heart surgeon in [that town], that they didn't have to travel to [a large city]. The challenge is, if you've got a heart surgeon doing one patient a year, they're not going to be that good. So it's that trade-off." (I18-LHIN Director). Consistent processes around funding allocations are used to manage expectations: "[If] we both agree that the rules are open and transparent, $[\ldots]$ there isn't a room for people getting upset" (I25-LHIN CFO). There are also challenges when the LHIN must make resource allocation decisions or prioritise health care initiatives that have ethical implications on different patient groups: "We have very scarce and limited resources. So we're having to say, 'Okay, do we want to fund with our \$2 million this prenatal genetic counseling/genetic screening, additional cancer patients so patients who are quite ill with cancer, versus a 20 -year-old who needs 
the hip replacement and will never walk until they get one, versus an 80 -year-old with cataracts, so we're really getting into ethical decision-making with scarce resources. So they're very difficult. How do you put a cancer patient above a pregnant mother against someone who won't be able to see in a couple of years? So those are tough decisions to be made." (I25-LHIN CFO).

In managing the accountability demands of different stakeholders, LHINs are caught in the middle between their upward stakeholder, the MOHLTC, and their downward stakeholders, the health service providers and communities. Dialogue is important to help align priorities given the parameters imposed by each party. Achieving alignment between the MOHLTC, health service providers and communities can be difficult and challenge relationships.

\subsubsection{Foundation-Donors Relationship}

The accountability demand of donors is for foundations to comply with donation restrictions and wishes. Donors put trust in foundations to steward money for hospitals to make capital purchases that will benefit patients. If funds are restricted, this may be for the purchase of specific equipment or for specific causes and programs.

Since donations are, by definition, non reciprocal, negotiation with donors is somewhat limited to ensuring that the donation restrictions are within the mandate of foundations. When it comes to the needs of hospitals to fund capital asset purchases, and 
the desires of donors to fund specific programs, foundations are caught in the middle. When dealing with these demands that 'come from both sides', foundations act as liaisons between both stakeholder groups (a kind of principal-principal-agent association) and negotiate with both of them to find a program that is 1) needed by the hospital and 2) of interest to the donor. Once this has been established, foundations and hospitals also negotiate the amount and timing of purchases. A foundation CEO explained their process: "I'll have a donor come to me and say, 'I really want to support this program, do you have a project happening?' So I'll liaise back with the hospital and try to best match the desires of those donors to the needs of the hospital. So it doesn't always happen where the hospital's asking the community for significant dollars to do a project. Sometimes the community's asking to do a project for the hospital. So it can come from both directions." (I1-Foundation CEO). Another participant explained the negotiation process as a balancing act: "So it's a balancing act between what the donor wants and [what the hospital wants] because ultimately, they [the hospital] have the final say. I mean, I can raise money for this [equipment] but if they [the hospital] never agree to it, it's not coming. Now normally, when we have all the money for it, they tend to waiver a bit." (I16-Foundation CEO). Dialogue with stakeholders was important to help find alignment of priorities given the parameters imposed by each party. Achieving alignment between donors and hospitals can be difficult and challenge relationships: "I think sometimes it's been challenging. They [the hospital] may want us to provide support for something that we don't really think is something that should be supported at that particular time." (I15-Foundation board member). Conversely, having actual funds raised in the community puts bottom-up pressure on hospitals (and on the MOHLTC if the 
equipment is to be partially funded) to move a particular project forward and purchase equipment.

Recognising donors by thanking them through letters or donor recognition walls was seen as a way to nurture relationships: "I think they want us to be thankful $[\ldots]$ for their donation, so we have to thank them. Whether that's a letter or a phone call, we have to thank them." (I16-Foundation CEO). Therefore, the nature of relationships with donors occurs at a personal level which affects how information strategies are developed.

\subsubsection{Accountability Evaluations}

To better understand how the organisations managed stakeholder relationships, participants were asked how stakeholder relationships were evaluated. When asked how hospitals and LHINs evaluate their stakeholder relationships, participants were quick to respond that formal mechanisms were in place to enrich dialogue with patients through patient satisfaction surveys, patient and family advisory committees, patient experience surveys, and risk event feedback surveys. These dialogue mechanisms allowed organisations to identify challenges or barriers in managing stakeholder relationships: "We have certainly a patient engagement committee which reviews, kind of, opportunities for improvement. We have real-time patient satisfaction surveys, we have our patient quality initiatives, and those are reported to the board." (I23-Hospital CNO). Although one participant found the questions on patient surveys to be less than entirely useful: "It is more formal, but the problem I have with the surveys is they are, for lack of 
a better word, generic - the stupidest question I've seen on these things is, 'Would you recommend this hospital to your family and friends?' Who in their right mind would recommend a hospital? And this isn't downtown Toronto where you can look around and see three or four hospitals. You don't have that choice. So why would we even put that question on a patient satisfaction survey? It needs to be redefined." (I4-Hospital board member). The participant went on to note that the surveys are only as useful as the responses that are provided: "What do you infer from the lack of responses? No response means we're doing good? No. No response means 'can't be bothered to respond'." (I4Hospital board member). Hospital boards and committees also conduct regular selfevaluations following each meeting.

However, many hospital and LHIN participants were caught off guard by the question as it relates to non-patient stakeholders: "I'm stuck on that one. Evaluate the accountability. I don't know. It's either working or it isn't.” (I3-Hospital CEO). One participant described the process as informal: "I don't think there's a process in place. [...] We're very informal.” (I5-Hospital board member). While acknowledging the importance of managing accountability with stakeholders, participants conceded that no formal mechanism was in place to evaluate relationships, other than with patients and to some extent communities, and not on a regular basis: "Which is ironic because we talked about these accountability agreements between us and the LHIN and us and our community stakeholders if you will. But there's no mechanism for feedback to close that loop. [...] And from that perspective, yeah, that's an interesting thought. How do we do that as part of our broader accountability to the community?" (I4-Hospital board 
member). Another participant noted a lack of mechanisms to measure the relationship: “[...] you don't really have a substantive way to measure that." (I26-LHIN board member).

It appears that while participants noted the importance of managing accountability stakeholder relationships and that engagement can assist in relationship building, there remains a gap in how it is measured and subsequently managed which may be hindering the quality of relationships. The importance of stakeholder relationships is supported by the Ontario Hospital Association's Guide to Good Governance, which state "the hospital's reputation and standing in the eyes of its stakeholders can be enhanced through effective engagement. This, in turn, impacts a number of factors that each play a role in the quality of care, including staff retention and recruitment, staff morale, donor support, funder support and the public's confidence in the hospital's quality of care." (Ontario Hospital Association, 2015, p.9). Based on the analysis, it is argued that a more systematic approach to evaluating stakeholder relationships may help determine how relationships have evolved over time and assess when relationships are strained and in need of strengthening.

\subsubsection{Summary of Stakeholder Relationships}

In this summary, stakeholder relationships are analysed by reviewing the accountability demands, the nature of the relationships, and negotiation tactics. 
Dialogue was used to open up lines of communication. Dialogue with stakeholders is important to help align priorities given the parameters imposed by each party. Hospitals used dialogue to understand patient concerns at discharge and find solutions to their problems, thereby helping to reduce ALC rates and costs. LHINs, in collaboration with hospitals, used dialogue to see what the communities' priorities were in determining what services to keep and what services to cut. LHINs also used dialogue with the MOHLTC in the interest of the region to pursue more funding to fill a gap in service needs.

The stakeholder relationships described in this section only take into consideration the salient stakeholders identified by participants. The larger stakeholder typology is evidently broader and more complex. Of the stakeholders identified, relationships between government, nonprofits, private organisations, and citizens are not clearly delineated between upward and downward, but cycle through a loop. Citizens are both current, past or future patients of health care services in the province. Citizens are also donors who make contributions to hospital foundations and voters who elect members of Provincial Parliament (MPPs) to the Legislative Assembly of Ontario. The Government names Ministers to lead various portfolios of responsibility, including health care which falls under the responsibility of the MOHLTC. The MOHLTC also delegates some health care responsibilities to LHINs. LHINs then fund some health service providers (HSP), including hospitals, which are the organisations, along with physicians, that directly interact with patients. Figure 5-4 illustrates the broad stakeholder relationships web 
within Ontario's health care system. The figure limits stakeholders to those discussed in this chapter.

Figure 5-4 - The Stakeholder Relationships Web

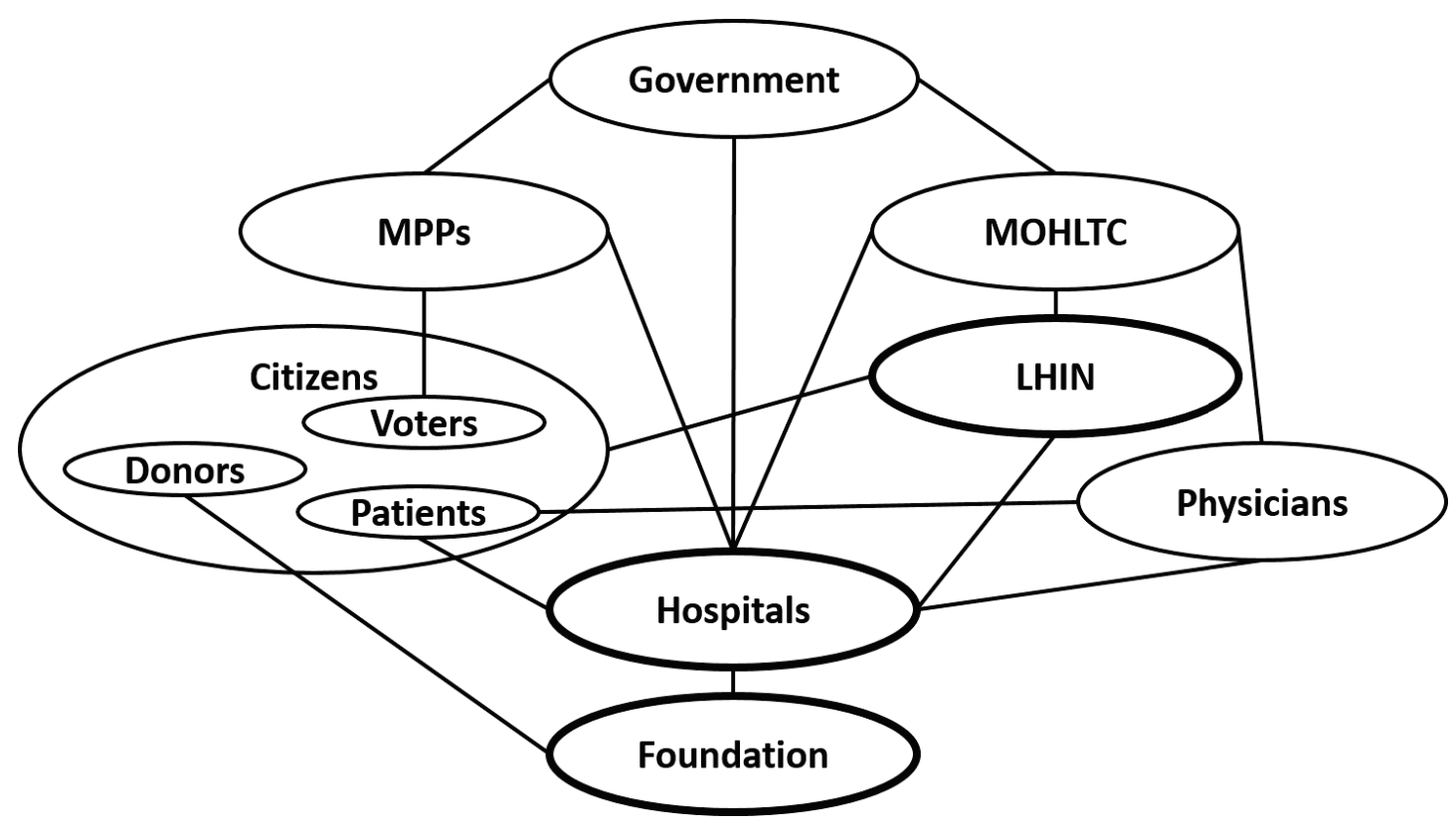

\subsubsection{Accountability Demands}

Hospitals have a large diversity of stakeholders, and incongruences between their demands are common (Eeckloo, Van Herck, Van Hulle, \& Vleugels, 2004). Some types of accountability may push away other types of accountability (Romzek \& Dubnick, 1987) and any perceived imbalance between organisational accountabilities can be detrimental to an organisation's success (Connolly \& Hyndman, 2013a). Table 5-1 demonstrates how different stakeholders are interested in different types of demands, and based on this, it is possible for hospitals to have multiple conflicting accountability demands among stakeholder groups. As such, trade-offs are continuously required. 
Hospitals are challenged by the need to manage the diverging accountability demands of different stakeholder groups. This finding is consistent with a health care related study in Brazil (Pascuci, Júnior, \& Crubellate, 2017). As one participant commented: “Competing priorities is a way of life" (I29-Hospital board member). For instance, patients' demand for quality care or physicians' demand for resources may be at the expense of a LHIN's demand for fiscal responsibility. A hospital participant explained the challenge of managing competing accountability demands: "How can we justify taking money that should go to patient care to pay down debt? And obviously, we used that money for patient care in the first place. That's why we got the accumulated debt. [...] So we've never really approached it from, 'okay, we need a plan to say, okay, in year what are we going to actually come out of this?'” (I4-Hospital board member).

These difficult decisions by those responsible for an organisation's governance go beyond calculations because not all accountability demands can be measured. This puts an ethical burden on organisations, and by no other option, to privilege one accountability demand over another at different points in time (Messner, 2009). An imperfect accountability is likely all that can be asked (Messner, 2009). This burden should not necessarily only be assumed by one organisation, but with and between the stakeholders themselves (Messner, 2009).

Table 5-1 summarises the organisations' accountability demands addressed in this chapter. 
Table 5-1 - Summary of Accountability Demands

\begin{tabular}{|l|l|l|}
\hline \multirow{2}{*}{ Accountability Demands } & Stakeholder Relationships \\
\cline { 2 - 3 } & Accountee & Accountor \\
\hline $\begin{array}{l}\text { Quality and timely care close to } \\
\text { home }\end{array}$ & Patient & Hospital \\
\hline $\begin{array}{l}\text { Coordinate care with community } \\
\text { resources }\end{array}$ & Patient & Hospital \\
\hline Scope of service & LHIN & Hospital \\
\hline Fiscal responsibility & LHIN & Hospital \\
\hline $\begin{array}{l}\text { Respect time and make necessary } \\
\text { resources available }\end{array}$ & Physicians & Hospital \\
\hline Collaborate to raise funds & Foundation & Hospital \\
\hline $\begin{array}{l}\text { Provide funding to meet service } \\
\text { needs }\end{array}$ & Hospital & LHIN \\
\hline $\begin{array}{l}\text { Provide guidance and system-wide } \\
\text { strategic direction }\end{array}$ & Hospital & LHIN \\
\hline $\begin{array}{l}\text { Identify system problems and } \\
\text { propose solutions }\end{array}$ & Ministry & LHIN \\
\hline Act as an oversight body & Ministry & LHIN \\
\hline Be a voice for the region & Ministry & LHIN \\
\hline $\begin{array}{l}\text { Ensure equity in access and quality } \\
\text { of care }\end{array}$ & Community & LHIN \\
\hline $\begin{array}{l}\text { Help citizens navigate the health } \\
\text { care system }\end{array}$ & Community & LHIN \\
\hline Flow funds in a timely manner & Hospital & Foundation \\
\hline Comply with donation restrictions & Donors & Foundation \\
\hline
\end{tabular}

An important objective of any health care system is to improve overall health outcomes of its population. Health outcomes relate to changes in health as a result of health care interventions or investments (Canadian Institute for Health information, 2019). A review of accountability demands shows that health outcomes are not directly tied to the performance of health service providers. As such, there does not appear to be any clear line of accountability for improving population health outcomes, a finding consistent with the reports from the Premier's Council on improving healthcare and ending hallway medicine (Devlin, 2019a, 2019b). Outcome performance appears to be less relevant and rarely measured in the health care system (Office of the Auditor General 
of Ontario, 2015). This is likely due to the inability to hold any one organisation responsible for the long term health outcomes of a population, since it inevitably implicates the integration of poverty, crime and other socio-economic factors. For instance, the LHIN-Hospital accountability relationship is generally based on output performance (Office of the Auditor General of Ontario, 2015), as the focus of the HSAA is based on output volumes (e.g. wait times, number of visits, number of surgeries). This focus on output performance over outcome performance may result in what is known as a performance paradox.

This performance paradox results from the introduction of performance measures that may result in lower performance over time "when organisations or individuals have learned which aspects of performance are measured (and which are not), they can use that information to manipulate their assessments" (Van Thiel \& Leeuw, 2002, p.271). The more organisations are scrutinized, the better they get in responding to the demands of their stakeholders, but not necessarily better at performing and achieving their organisational objectives (Van Thiel \& Leeuw, 2002). Performance indicators sometimes need to be replaced when underlying conditions and assumptions change. A challenge within the health care system is the difficulty in obtaining comparative information for benchmarking and longitudinal information to measure improvements. The longer performance measures are in place, the greater the risk of performance paradox. However, as performance measures are modified to reduce the risk of 'gaming', this reduces the availability of longitudinal information for comparisons over time. What has emerged in the health care system to compensate for the performance paradox is a large 
amount of performance indicators: “There's a significant amount of information and data collected in the hospital, and because we collect all this data, there's a desire to be able to use the data" (I7-Hospital CFO). However, even with all this data, it is unclear to what degree and in which area population health outcomes are improving. Government agencies, such as LHINs, Health Quality Ontario (HQO) and the Canadian Institute for Health Information (CIHI), have improved their collection and reporting of outcome measures, but these measures should be tied to health service provider accountability where possible.

\subsubsection{Nature of Relationships}

Relationships between hospitals, LHINs, the MOHLTC, physicians and foundations can all be characterised as professional as the lines of formal accountability are strong and negotiations between these parties are evidence-based. However, relationships that associated with patients, communities and donors can be characterised as personal, as the lines of accountability are much more informal and negotiations with these parties are much more emotionally-driven than evidence-based.

Overall, the nature of the relationships within the health care system can be described as positive, as many of the parties' goals were aligned. For instance, hospitals, patients, donors, communities, and even physicians have a mutual interest in maintaining hospital services. As such, the interests of various stakeholders can align. The nature of relationships between hospitals and foundations, as well as between LHINs and the 
MOHLTC was the most collaborative, as the majority of goals aligned. The relationship between hospitals and foundations was probably the simplest of those analysed, as the roles between parties were quite clear.

However, accountability relationships can be challenged when a party feels they are being treated inequitably. Expectation gaps between what the health care system offers and patient and community members expectations can create frustrations. Such was the case for patients and communities that felt they were losing a service or not receiving a service to the same level of care as elsewhere. Due to resource constraints, managing expectations is therefore an important aspect of stakeholder relationships. Health care organisations, such as LHINs and hospitals, must manage the expectations of their communities between achieving health equity objectives and the reality of maintaining standards of care through clear and ongoing communications in order to maintain positive relationships.

Relationships were also challenged when goals were not aligned. The nature of the relationship between hospitals and their physicians appeared to be the most adversarial, as both parties have some degree of power over the other and compete for the same resources. Both parties enjoy a high degree of community legitimacy and independence, neither being a downward stakeholder to the other. As such, physicians can be described as partner stakeholders because neither party is dominant and both parties mutually influence each other (Mainardes et al., 2012). 
The uncertainty about where responsibilities lie seems to be at the heart of relationships which at times could be adversarial, rather than collaborative. This challenge was particularly present within hospital-LHIN and LHIN-MOHLTC relationships. The inability to establish clear lines of responsibility makes it difficult to hold others to account and be accountable and also hinders the development of strong relationships because it breeds distrust. LHINs were left to decipher if hospitals were shirking responsibility or if performance results were outside a hospital's scope of responsibility. It is also unclear if LHINs have an advocacy role or not. There is therefore a need for clear direction and lines of responsibility, which is an ongoing challenge due to the complexity and interdependent nature of health care in Ontario. The quality of stakeholder relationships may be hindered by a lack of formal mechanisms to evaluate and subsequently manage non-patient relationships. A more systematic approach to evaluating stakeholder relationships may help determine how relationships have evolved over time and assess when relationships are strained and in need of strengthening.

One policy suggestion is that a LHIN's mandate should have been clarified so as to reduce ambiguity and frustration among health care administrators. Clarifications of a LHIN's role in a variety of situations could have helped improve stakeholder relationships. Clarifications would have also helped manage expectations. The disbanding of LHINs may have been partly due to their diminished legitimacy as a result of the MOHLTC undermining its authority. The new Ontario Health agency could provide an opportunity to introduce such measures to clarify the new agency's role. 
Moreover, as more coordination is demanded by patients, it will further blur the lines of responsibility between health service providers, making it harder for LHINs to achieve their oversight responsibilities.

\subsubsection{Negotiation Tactics}

Previous studies have shown that the risk of nonprofit financial dependency and loss of autonomy are high when funding sources are concentrated on the government (Salamon \& Toepler, 2015), which emphasise views of resource dependence theory. However, the findings from this research somewhat counter this finding because hospitals enjoy a high degree of legitimacy among their communities, which in turn can put pressure on governments at various times in favour of hospitals, such as during elections. As such, concerns about resource dependence were not found to be a significant factor in the hospital context, particularly that their survival was not generally a concern at the time of interviews. In addition, one way to minimise financial dependency risks is to diversify revenue sources. However, this is not possible to any real degree for hospitals. Due to these complex dynamics, LHIN negotiations with hospitals are less about command and control, and more about persuasion. As such, when hospitals are divested to nonprofits rather than government operated, it "requires complex negotiations with independent agencies over which government agencies have at best imperfect control" (Salamon \& Toepler, 2015, p.2167). The analysis in this chapter has demonstrated that stakeholders interact with and negotiate the specifics of their accountability demands in many ways. Negotiation tactics used by different parties to advance their objectives 
include equity as a guiding value, building coalitions, compromising, using intermediaries, collaborating, and political interventions.

Equity is a value that has underpinned much of the decision making surrounding accountability demands. Equity was part of a community's accountability on a LHIN to ensure fairness in access and quality of care for residents. When determining what services to cut, a LHIN and a hospital tried to identify core services and meet the equity demands of a community. Equity was also used by hospitals as an argument when applying for more funding or requesting a change to the funding formula. Hospitals negotiated with LHINs by providing supporting data to attempt to demonstrate that any funding shortfall was due to inequity in revenue sharing. Equity was also evoked by physicians in their need to help hospitals control spending and use resources efficiently. Equity is therefore a guiding accountability value used in the health care system as a negotiation tactic.

Relatedly, LHINs also used impartiality as a negotiation tactic. By applying a consistent funding formula to hospital revenue allocations, LHINs could avoid being accused of favoritism. LHINs also used a consistent process in how they distributed funds through their geographic regions to avoid blame by some communities if they felt they were being treated inequitably. As the literature suggests (Christensen, Laegreid, \& Rykkja, 2016), LHINs need to apply a consistent and impartial funding formula to be seen as legitimate and trustworthy. 
Regarding equity, it still appears to be a government priority from a recent publication stating that "the new system will be designed to ensure patients receive the best care - no matter when and where they need it" (Government of Ontario, 2019b). However, systematic inequity continues to exist in Ontario's rural, remote and northern regions, as well as francophone communities. The government may have to take a more direct leadership role if it is to achieve its health equity objectives.

Building coalitions among stakeholders was seen as a way to negotiate, particularly with upward stakeholders. When different stakeholders built coalitions together on congruent objectives, it changed power dynamics in the negotiation process. For instance, foundations and donors built coalitions to raise funds and put upward pressure on hospitals to purchase equipment that hospitals did not prioritise. Having actual funds raised in the community put bottom-up pressure on hospitals to move a particular project of interest in the community forward and purchase the equipment. Also, a hospital attempted to negotiate with their LHIN and the MOHLTC by building coalitions with other institutions with similar interests. Such was the case when mid-sized hospitals worked together along with the Ontario Hospital Association (OHA) to obtain more funding.

Compromise was used as a negotiation tactic when both parties reduced their demands in order to come to an agreement. Compromise was used as a negotiation tactic by hospitals during their negotiations with foundations. In one case, the hospital provided a capital purchase list well above what the foundation could acquire, and the foundation 
then chose items from that list. The hospital agreed to purchase these items, even though it may not have been purchases that were its top priority in order to settle for purchases that were marketable to the donor base. The hospital, LHIN and the community were also able to align their priorities and find a comprise by moving non-acute health care services from the hospital into the community to private providers or through public-private partnerships. This alignment was, however, at the cost to patients using these services.

A negotiation tactic that was particularly subtle was the use of intermediaries to advance stakeholder objectives. Communities used LHINs as intermediaries to negotiation with the MOHLTC to maintain or increase service levels in their regions. Foundations also acted as intermediaries between donors and hospitals. When dealing with the accountability demands from both sides, foundations acted as a liaison between both stakeholder groups to find a program that was needed by a hospital and of interest to donors.

Interestingly, the media plays an important intermediary role in the dialogue and negotiation process by applying indirect pressure. In the health care system, the media acts as a conduit for a community's interests. At times, the media can be an ally of hospitals, by which hospitals may avoid or transfer blame to LHINs for the suppression of a program. Hospitals may also at times use the media to try to put pressure on LHINs. As such, hospitals leverage their community legitimacy, using the media as a conduit when negotiating with LHINs. However, the media may not always report a story accurately due to the unavailability of key information, and so it can create confusion in 
the community and frustrations for hospital, LHIN and MOHLTC leadership. These parties may also suppress community participation mechanisms because of challenges in dealing with the media. This approach is not entirely without merit, as media stories can distort realities when the facts are not entirely known by the community, further exasperating relationships between health care organisations and the broader community. Nonetheless, the media is used as an important negotiation tactic by multiple parties at different times and to various ends.

Collaboration was used as a negotiation tactic when the strengths of several parties are combined to achieve results that were greater than what could have been achieved individually. For instance, collaboration was at the forefront of the relationship between hospitals and foundations in the latter's fundraising efforts. Hospitals and LHINs also regularly collaborated on projects to fix system wide problems and share best practices. Furthermore, a hospital and physicians were able to work collaboratively to address a clinical documentation problem. Common ground needed to be found for their collective objectives to be met. This was achieved when both parties were able to revisit the clinical documentation and work collaboratively on a solution to align their objectives. In return for better clinical documentation, the physicians were able to maintain or increase the availability of their resources and the hospital was able to increase its revenue. Collaboration also helps to build trust and strengthen relationships between parties. 
A negotiation tactic that was particularly heavy-handed was the use of political interventions. Political interventions were used by upward stakeholders to advance their agendas when other means of negotiation failed and created uncertainty for hospitals and LHINs. This was particularly the case in the LHIN-MOHLTC relationship in instances where the MOHLTC overruled the LHIN, threatening the latter's legitimacy. When the MOHLTC bypasses the LHIN, it negatively affects the LHIN's legitimacy and its ability to be an effective oversight body. As a policy recommendation, the MOHLTC should refrain from usurping or undermining the LHIN's role because such actions diminish the LHIN's legitimacy and the likelihood that health service providers will heed LHIN recommendations for change at the health service provider level. It also negatively affects the LHIN's ability to act as an oversight body for the health care system. The new Ontario Health agency could be an opportunity to introduce such measures to reduce the possibilities for political interventions by the MOHLTC. However, due to a concentration to a single agency, it could make it easier for government interference.

\subsection{Governance Mechanisms}

This section reviews the hospital, the LHIN and the foundation's governance system. First, the governance needs of the organisations are reviewed, followed by the governance mechanisms used to manage accountability practices. The section concludes with a summary tying the governance mechanisms used to accountability demands. 


\subsubsection{Governance Needs}

To manage the accountabilities of each organisation, two prominent governance needs were put forward by participants. These included decision support and alignment of performance indicators. Decision support was found to be important to participants because data was used as a way to support the decision-making and dialogue that occurred among different stakeholders. A hospital CFO described the need: "We wanted to know what was happening. [...] So there was a lot of emphasis put on making sure you capture the savings." (I7-Hospital CFO). If data is not obtained, it is difficult to understand the root cause of a problem: "Sometimes our problems are subjective, and we don't necessarily have the ability to identify the true data. It's people's opinions of when something isn't working because you can't get the data. So we think this is the problem, but it may not be the problem. If we were able to get everybody's data, it might be something different." (I31-Hospital CEO).

For instance, in managing the accountability demand of physicians, data was necessary to make informed decisions and take appropriate action: "A physician group $[\ldots]$ presented to the Board that the wait list in surgery were too high and the Board wasn't fulfilling its obligations in ensuring that we meet the needs [of patients] [...] [because] the budget had included some reductions in O.R. [operating room] blocks which they believed was wrong. So they had made this appeal to the Board. And so the Board said, 'We hear you, and we're going to look into this.' [...] 'If you're telling me your wait lists are higher in your office, $[\ldots]$ you need to contribute that data to the 
central database so that we can understand what the wait times are and then manage it. Gather that data.' [...] [The medical director] can't change that [the total number of O.R. blocks], but he can distribute them differently depending on demand. So they [the Board] fulfilled their obligation. They didn't jump to a conclusion and say, 'Yeah. This is wrong. Let's put 40 more blocks. We'll just run a deficit.' They said, 'Let's look at the wait times across all services and come up with a system'." (I13-Hospital CFO). In this case, the hospital decided not to agree to physician demands for more O.R. blocks, and chose to take action by allowing the medical director to reallocate O.R. blocks between surgical units. A participant summarised the need for data in the decision-making process: "A personal story's great. [But] if I don't see the data a personal story is nothing to me. The personal story is nice as an add-on, but I need hard evidence to persuade the Ministry." (I17-LHIN Director).

Another governance need was for health care organisations to create and align performance indicators with their strategic plans. Doing so, where possible, ensured that what was measured counted, and what was important got measured. Otherwise resources may be invested in areas that have less impact on an organisation's objectives: "They're asking us to measure that [the activities] and we've included it as part of our quality improvement plan and we're measuring that" (I19-LHIN Director). Over time, performance indicators may become obsolete and there becomes a need to realign performance indicators by creating new ones and removing others: "There was over 250 measures if you drilled down to the HSP level. But they don't cascade upwards and roll up into MLAA [Ministry-LHIN Accountability Agreement] and global. These are 
supposed to be global indicators in systemic performance. Why are we measuring these tiny little things? They didn't fit well. So in the past couple years they were to redo all those indicators to make sure there were clear linkages." (I20-LHIN Director). There is a challenge in identifying what is relevant, given the quantity of data collected and the difficulty in making clear connections between projects and priorities: “There's a significant amount of information and data collected in the hospital, and because we collect all this data, there's a desire to be able to use the data" (I4-Hospital board member). Another participant expressed a similar experience: "We struggle with that [making sense of data] all the time" (I11-Hospital Director).

The governance needs of decision support and alignment of performance indicators were often necessary for governance mechanisms to work effectively. Once governance mechanisms were in place, decisions were made and actions were taken. Such was the case when a hospital decided not to agree to physician demands for more operation room (O.R.) blocks, and chose to take action by allowing the medical director to reallocate O.R. blocks between surgical units.

\subsubsection{Governance Mechanisms}

Many governance mechanisms were used to manage accountability. The following analysis addresses prominent governance mechanisms discussed by participants, and are grouped into internal, external and collaborative governance mechanisms. 
Examples of internal governance mechanisms used in the health care system included case reviews, a management philosophy of 'tone at the top', tracking of adverse events, and risk analysis.

Case reviews allowed hospitals to identify outlier cases, investigate discrepancies in clinical documentation and determine if there were any errors or omissions. This allowed a hospital to increase its weighted cases, and subsequently its revenue for work performed or for patient complexity that did not make it to the patient's chart: "We can look and see what makes sense $[\ldots]$ and then we will pull them, look at charts, take it back to the doctors. Is this the correct coding for this? And then we also look at our data from CIHI [Canadian Institute for Health Information]. So we do that on a monthly and quarterly basis whenever it's ready, and now we can see if we have outliers. And so, with those ones we will be able to identify what case it is and we will go and do a case review." (I7-Hospital CFO).

Promoting a management philosophy of 'tone at the top' such as integrity and fiduciary duty helped hospitals control spending: "I made some changes to some policies and [people wanted] to have leniency to do A, and everyone else would follow B. But if people find out that you guys get A and everyone else has to get B. If you get to fly first class and everyone else flies economy, what's the tone at the top?" (I11-Hospital Director). Tracking of adverse events through quality committees was used to improve the quality of care: "We track medication errors because we want to learn from them, 
make sure that, if there is an error, or if there is an adverse event, that it's a learning experience. [...] There are various reports on adverse events [and] we have a quality committee [...] that looks at adverse events." (I30-Hospital CNO). Risk analysis was used by LHINs in their oversight functions: "The risk accountability framework we see almost at every board meeting. [...] There's various risks involved, i.e., falls or ALC being out of control; a hospital might be a risk if a hospital isn't going to meet its budget, etc. So those risks are monitored and we're able to see them." (I26-LHIN board member).

Examples of external governance mechanisms used in the health care system included benchmarking, disclosure requirements, performance reviews, audits, adoption of best practices, and government laws and regulations.

Benchmarking of performance indicators provided a way to promote competition in the industry and create expectations to perform within certain norms. Such a mechanism encourages organisations to demonstrate performance that is in line or better than the average in order to maintain an organisation's reputation (Enjolras, 2009). Hospitals and LHINs do not want to be seen as poorly performing, and face pressure from their peers to improve. A hospital CFO described the pressure: "The comparison to other hospitals motivates you too, because that's something we would share with the board and the board would say, 'Well why in the hell are we the 78th hospital in the province relative to time to see a doc in emerg'?” (I13-Hospital CFO). 
A LHIN used benchmarking to put pressure on its hospitals to improve their performance: "By putting the information in front of the group, they put the pressure on themselves, and that's the best way to do it. [...] Because sometimes, if they have any lack of respect for the LHIN, then they may respect their peers. So using the peers to put the pressure on them is actually a pretty effective strategy. [...] It's hard to give excuses when you have your peers saying, 'Look. We're doing it. This is what we do. Why can't you do that, too?'” (I17-LHIN Director).

Similarly, the MOHLTC used benchmarking to put pressure on its LHINs: "On a quarterly basis, the Ministry turns around, compiles all the information, and then sends us our performance. And they say, 'Okay, can you explain what's happening? [...] What's the LHIN doing to move performance towards provincial targets? [...] How does the LHIN plan to address these performance issues?'." (I20-LHIN Director).

Benchmarking was also used as an opportunity to learn from better performers: "I should call [another hospital and], see how they're operating. Is there an opportunity that I can learn from them that I can apply here.” (I11-Hospital Director). In the benchmarking process, both hospitals and LHINs were responsible for conducting variance analyses: "Every month I have to report to my VP if my revenues and my expenses are on track or not. If they're not on track what am I doing about it to make sure I'm going to be on budget next year? If there's no way in hell I'm going to be on budget then they need to know so they can try to find the money somewhere else." (I12-Hospital Director). A LHIN director similarly explained his responsibility in explaining variances 
through performance reports called stocktake reports which include results from approximately 30 indicators: "On a quarterly basis, the ministry turns around, compiles all the information, and then sends us our performance. And they say, 'Okay, can you explain what's happening? [...] They ask us these key questions. What is the LHIN doing to achieve or move performance towards provincial target?" (I20-LHIN Director).

Foundations also benchmarked themselves against other charities as a means to compare performance relative to their fundraising efforts: "I think one way of looking at the external is if your fundraising is declining or increasing. I think that tells you something." (I15-Foundation board member). Charity information returns, form T3010, were cited as an important benchmarking tool for the Board in its stewardship role, which provided board members: "the ability to be able to compare it to other foundations to make sure that nothing's out of whack, like spending too much money, for example, on administration versus back to the hospital for the main purpose" (I2-Foundation board member).

To encourage this peer pressure, hospitals have a disclosure requirement under the Excellent Care for All Act, 2010, to prepare a Quality Improvement Plan (QIP) which includes performance targets. Hospitals must make the document publicly available by posting QIPs on their websites and submitting them to Health Quality Ontario (HQO). HQO then compiles the results and prepares comparisons which are publicly reported. 
Audits, external third-party reviews and accreditation were also cited as important external governance mechanisms. For instance, an external review, known as a budget validation, conducted by an accounting firm helped to identify whether a hospital was overspending: "I think it was either Deloitte or KPMG that we had come in and to analyse where we were at. And it demonstrated that we were overspending severely." (I3Hospital CEO). A board chair at another organisation made a similar comment: "We had a third-party consultant come in four or five years ago now, I think, to do an operational review. And to their credit, they found a couple of ways that we could shave off a couple million dollars off of the budget." (I24-Hospital board member). Audits were also performed on LHINs, including by the Auditor General of Ontario who performed valuefor-money audits to review LHIN effectiveness. "We have so many eyes on us, if you will. We have all the mandatory requirements from the Ministry. We have the Auditor General of Ontario in auditing us several times. We have an internal HAS called the Health Audit System team auditing us. Obviously our external auditors at year end. We have accreditation standards we have to meet. So there's so many of these factors driving us to best practices." (I25-LHIN CFO).

Relatedly, all hospitals under study adopted Accreditation Canada standards and related disclosure requirements, which required periodic third-party reviews. Accreditation standards, as an external governance mechanism, 'force' the organisation to adopt internal governance mechanisms (Carman \& Fredericks, 2013). 
The adoption of best practices through templates and standardisation of clinical practices were used by hospitals. While some best practices are voluntarily adopted, many of the best practices in health care are externally imposed. LHINs required hospitals to implement LHIN, HQO and OHA (Ontario Hospital Association) best practices as a way to ensure procedural efficiency in the use of resources and consistency in the quality of care provided: "It's definitely the way the Health Quality Ontario is going is standardisation. [...] We really need standardisation across the system to say this is how we're doing it, and I think that will help alleviate a lot [of problems]. [...] With standardisation there has to be peer comparison. [For example, a] physician needs to get that feedback to say if it's c-sections, for instance, for obstetrician, your rate is $20 \%$ higher than the average obstetrician there's an issue. [...] Standardisation is the best way to go for health care because then you can identify the problems so much quicker" (I29Hospital board member). The adoption of best practices helped hospitals demonstrate operating efficiency and limited LHIN ability to blame under performance on hospitals. A hospital CEO gave the following example of a voluntary adoption: "[I said,] 'let's turn the page, whatever were doing it's not working, let's try something else' [...] [We will be] implementing the leading practices recommended by the LHIN. [And after 4 or 5 months,] then we plateau. [...] What else can we do? The conversation is shifting towards the home and community care [the partner agencies]." (I9-Hospital CEO).

Government laws and regulations were cited as an important governance mechanism to ensure hospitals provided quality care and foundations complied with donation restrictions. A foundation CEO explained the role of CRA regulations: "We're 
very careful about with CRA because of our charitable status. We are very careful about what we're receipting; the amounts we're receipting because we do a lot of special events so we have to be really careful what tax receipt we're giving out. [...] I think more than anything else that's our number one external governance is those rules and regulations." (I16-Foundation CEO). Also, while not discussed specifically by participants, it is clear that accountability agreements are an important external governance mechanism in managing accountability. For instance, the HSAA sets the scope of service required by the hospital, and the funding levels LHINs provide hospitals to meet service needs.

Beyond internal and external governance mechanisms, many participants emphasised the need for collaborative governance mechanisms. Unlike distinct internal or external governance mechanisms, collaborative governance mechanisms were found to straddle organisational boundaries and were an important part of the governance system given the interdependencies that exist in the health care system. Collaborative governance "has been used to describe the mechanisms by or through which two or more independent governing bodies can achieve a common goal”. (Ontario Hospital Association, 2015, p.15). Given these interdependencies, it is not surprising that participants emphasised collaborative governance mechanisms: "Part of that governance role that I think is to also listen to health service providers so that it's that engagement aspect of it [...]. So it's not just the LHIN telling providers what to do, we also expect to hear from providers." (I18LHIN Director). Examples of collaborative governance mechanisms and their purposes included cross-board representation to ensure strategies are clear and coordinated between organisations, working groups and steering committees to advance joint projects, 
web-based forums to share information, taskforces to monitor system-wide progress, care coordinators to ensure the efficient and effective flow of patients between discreet organisations, medical advisory committees (MAC) between hospitals and physicians, and patient and family advisory committees (PFAC).

A participant explained the need for cross-board representation to collaborate with the foundation to raise funds: "If I were to try to translate what's happening at the hospital at any given time to my board of trustees, I'm gonna lose some of that nuance that only the leadership of the hospital can provide" (I1-Foundation CEO). Another participant explained the need for working groups to help the hospital coordinate care with community resources: "So the ALC committee's a perfect example of relationship building with your external partners. You try to create common goals, common outcomes that you're trying to achieve, identifying issues you're going to work on together." (I14Hospital CNO). A LHIN participant explained the need for working groups to provide system-wide strategic direction: "Instead of having a 150 separate corporations making individual decisions in isolation for their organisation, we're wanting to bring them to a planning table [and] looking at areas of influence where we could plan together and then look at, what are we trying to achieve together, how do we utilise the resources we have, and then where do we need to make investments" (I32-LHIN CFO).

Care coordinators, or patient flow navigators, were used to help hospitals coordinate care with community resources, thereby helping citizens navigate the health care system. Care coordinators are employees of LHINs that conduct their work in 
communities and hospitals and are used to manage patient flow proactively by coordinating care among different health service providers.

Patient and family advisory committees (PFAC) were used by both hospitals and LHINs to improve their administrative and clinical processes. Patient and family advisory committees are involved in some policy and procedure development and were used to flag systemic problems and improve the patient experience: "They may actually uncover a trend where we find if we're discharging people too early after a procedure, maybe there's going to be an improvement in care, in the science of care. So it's really engaging patients to make it centred, but also engaging it for any improvements, what's working well, and what's not." (I23-Hospital CNO).

\subsubsection{Summary of Governance Mechanisms}

In summary, the analysis conducted above has shown that the health care system as a whole uses a combination of internal, external and collaborative governance mechanisms to manage its accountability. Examples of internal governance mechanisms included case reviews, 'tone at the top', tracking of adverse events, and risk analysis. Examples of external mechanisms included benchmarking, disclosure requirements, performance reviews, audits, external third-party reviews, accreditation, best practices and government laws and regulations. Examples of collaborative governance mechanisms included cross-board representation, working groups and steering committees, web-based forums, taskforces, care coordinators, MAC, and PFAC. 
Collaborative governance mechanisms were found to straddle organisational boundaries and were an important part of the governance system given the interdependencies that exist in the health care system. The governance needs of decision support and alignment of performance indicators were necessary for governance mechanisms to work effectively. Once governance mechanisms were in place, decisions were made and actions were taken. Such was the case when a hospital decided not to agree to physician demands for more O.R. blocks, and chose to take action by allowing the medical director to reallocate O.R. blocks between surgical units.

Interestingly, strategic plans were cited as an important governance mechanism. While this mechanism was not linked to any one accountability demand, strategic plans appear to tie the governance system together: "The strat plan, and the metrics the Board chooses are fundamental as part of an accountability system. To me, it's the most important tool we have." (I3-Hospital CEO). Another participant discussed their importance in determining how the organisation was managing its accountability: "We monitor our strategic plan performance and how far we're making progress on that. We look at quality indicators because that speaks directly to the level of service that we're able to provide, and we regularly look at financial indicators." (I24-Hospital board member).

While some governance mechanisms are specific to the health care system (like patient and family advisory committees and care coordinators), many of the mechanisms 
are universal (like benchmarking and audits). The diversity of governance mechanisms demonstrates that many mechanisms need to work together for the governance system to function properly. Like the mechanisms of a watch, no single component makes the system work, but rather, all pieces working together. Research that is conducted only on specific governance mechanisms, such as those that focus solely on characteristics of the Board of Directors, may be too narrow and miss important aspects of organisational governance practices. Also, while it may appear from this study that internal governance mechanisms were less utilised than external and collaborative governance mechanisms, this observation may simply be explained by the fact that internal governance mechanisms were less visible, both to participants during interviews and through the review of archival documents. Future research may benefit from a more holistic approach to governance research in the nonprofit sector.

Some of the more administrative governance mechanisms, such as 'tone at the top', risk analysis, audits, and external third-party reviews were used to manage hospitals' accountability demand for fiscal responsibility and the LHINs' accountability demand to act as an oversight body, and identify systemic problems and propose solutions. While the more clinical governance mechanisms, such as the tracking of adverse events were used to manage hospitals' accountability demand for quality and timely care. Some governance mechanisms accomplished both administrative and clinical objectives, such as benchmarking, accreditation and case reviews. 
In contrast to internal and external governance mechanisms, collaborative governance mechanisms between health care organisations were used to meet hospitals' accountability demand for coordinated care, to collaborate with its foundation and to manage the demands of physicians, and the LHINs' accountability demand to provide system-wide strategic direction and address system problems.

Table 5-2 summarises the organisations' accountability demands from table 5-1 and ties them to examples of governance mechanisms used to manage these demands. 
Table 5-2 - Summary of Accountability Demands with Governance Mechanisms

\begin{tabular}{|c|c|c|c|}
\hline \multirow{2}{*}{$\begin{array}{l}\text { Accountability } \\
\text { Demands }\end{array}$} & \multicolumn{2}{|c|}{ Stakeholder Relationships } & \multirow{2}{*}{$\begin{array}{l}\text { Examples of Governance } \\
\text { Mechanism }\end{array}$} \\
\hline & Accountee & Accountor & \\
\hline $\begin{array}{l}\text { Quality and timely care } \\
\text { close to home }\end{array}$ & Patient & Hospital & $\begin{array}{l}\text { Tracking adverse events, } \\
\text { PFAC, best practices, } \\
\text { benchmarking, disclosure } \\
\text { requirements }\end{array}$ \\
\hline $\begin{array}{l}\text { Coordinate care with } \\
\text { community resources }\end{array}$ & Patient & Hospital & $\begin{array}{l}\text { Working groups, care } \\
\text { coordinators }\end{array}$ \\
\hline Scope of service & LHIN & Hospital & HSAA \\
\hline Fiscal responsibility & LHIN & Hospital & $\begin{array}{l}\text { Case reviews, } \\
\text { benchmarking, disclosure } \\
\text { requirements, 'tone at the } \\
\text { top', audits, external third- } \\
\text { party reviews, accreditation, } \\
\text { best practices }\end{array}$ \\
\hline $\begin{array}{l}\text { Respect time and make } \\
\text { necessary resources } \\
\text { available }\end{array}$ & Physicians & Hospital & $\mathrm{MAC}$ \\
\hline $\begin{array}{l}\text { Collaborate to raise } \\
\text { funds }\end{array}$ & Foundation & Hospital & Cross-board representation \\
\hline $\begin{array}{l}\text { Provide funding to meet } \\
\text { service needs }\end{array}$ & Hospital & LHIN & HSAA \\
\hline $\begin{array}{l}\text { Provide guidance and } \\
\text { system-wide strategic } \\
\text { direction }\end{array}$ & Hospital & LHIN & Working groups \\
\hline $\begin{array}{l}\text { Identify system problems } \\
\text { and propose solutions }\end{array}$ & Ministry & LHIN & $\begin{array}{l}\text { PFAC, benchmarking, } \\
\text { audits, accreditation }\end{array}$ \\
\hline Act as an oversight body & Ministry & LHIN & Risk analysis, benchmarking \\
\hline Be a voice for the region & Ministry & LHIN & Steering committees \\
\hline $\begin{array}{l}\text { Ensure equity in access } \\
\text { and quality of care }\end{array}$ & Community & LHIN & Benchmarking \\
\hline $\begin{array}{l}\text { Help citizens navigate } \\
\text { the health care system }\end{array}$ & Community & LHIN & PFAC, care coordinators \\
\hline $\begin{array}{l}\text { Flow funds in a timely } \\
\text { manner }\end{array}$ & Hospital & Foundation & Cross-board representation \\
\hline $\begin{array}{l}\text { Comply with donation } \\
\text { restrictions }\end{array}$ & Donors & Foundation & CRA regulations \\
\hline
\end{tabular}

One way to explain the importance of collaborative governance mechanisms in the health care system is to look at the paradox of managing agency and stewardship 
approaches. Sundaramurthy \& Lewis (2003) explain the concepts of managing the paradox of agency and stewardship approaches to governance, and the tensions that exist between these two competing yet complementary perspectives. Agency theory would argue that control mechanisms such as monitoring and compliance are sufficient to satisfy the needs of principals. While stewardship theory would argue that organisations are motivated to improve each other's performance and mechanisms such as guidance and learning are sufficient to improve performance.

The tensions between agency and stewardship characterises the health care system because of the interdependencies that exist. This tension could be connected to the relations between narrow and broad forms of accountability described in chapter 2. Other accountability conceptions could be used as well. For instance, there was tension between LHIN controlling and partnering functions. Benchmarking was also used as a means to promote competition (agency), but also used as an opportunity to learn from better performers (stewardship), even though LHINs have all the attributes of powerful stakeholders because they control funding (Mitchel et al., 1997). What resonates throughout the case studies presented are the collaborative efforts found in stewardship theory.

While interdependency requires stakeholders to work together, with too much stewardship-based governance LHINs forgo their oversight responsibilities, which may result in increased opportunism from hospitals to shirk responsibility. However, too much agency-based governance breeds distrust, inhibits information flows and can lead to 
performance failures (Sundaramurthy \& Lewis, 2003), which may ultimately put health care system performance at risk. LHINs also need reliable and timely information from their health service providers to accomplish their objectives as health system coordinators and to demonstrate accountability to the MOHLTC. As such, stakeholder relationships between health care organisations can fluctuate between agency and stewardship approaches as situations merit. These governance approaches work together (Hyndman \& McDonnell, 2009) to achieve health care system objectives.

The agency-stewardship governance paradox could be viewed as having one foot on the gas, and one foot on the brake, but not necessarily at the same time. The vacillation that occurs between the positions of agency and stewardship inevitably suggests a temporal dimension. Future research is needed to investigate temporal boundaries surrounding this governance construct in order to clarify its applicability in accountability management. Demonstrating how agency and stewardship vacillate will increase our understanding of how governance mechanisms are used to manage accountability in the nonprofit sector.

\subsection{Information Strategies}

This section reviews the information strategies used by hospitals, LHINs and foundations to demonstrate accountability to their stakeholders. The analysis is divided between corporate-level information strategies that are intended for hospitals, physicians, LHINs and the MOHLTC and personal-level information strategies that are intended for 
patients, communities and donors. The split is supported by the argument that there are two characteristics of accountability communication: the rational level and the emotional level (Davison, 2007). The analysis here focuses on what the content of the information contains, how the information is shared (the methods or medium of communication), and to whom information is communicated. The strategies of when the information is communicated are less relevant to the analysis conducted here because the timing of communications is usually prescriptive. The section concludes with a summary of differences and examples of information strategies.

\subsubsection{Corporate-Level Information Strategies}

For hospitals, LHINs and foundations, there are information needs to accurately report financial and performance results to their corporate-level stakeholders. A hospital director explained the LHIN's information need: “In my mind, our priorities were financial statements. [...] We have to report back to somebody on every dollar." (I11Hospital Director). A hospital CNO explained the physicians' information need as it relates to their clinical practices: "Performance results and funding information, because the docs have to know the costs" (I14-Hospital CNO). A LHIN director also explained the MOHLTC's information need: "Measuring outcomes. And that's at the system level and also at the provider level. A lot of our focus is on measuring those outcomes and deciding if the outcomes are acceptable or not. And if they're not, then that informs the planning process." (I18-LHIN Director). 
For foundations, there is also an information demand to accurately report financial and performance results, but this is specific to cash flow projections given a foundation's accountability demand to flow funds in a timely manner. A foundation CEO explained the need: "I go and give updates on events, let them know how the mail appeal is doing, tell them about some big gifts that came in. [...] I actually report to them our progress on our goals and objectives at the board meetings. [...] The biggest thing that they just need to know is how much money we're gonna give them this year, next year, and the year after. So it's that financial forecast. That allows them to plan." (I1-Foundation CEO).

Corporate-level communications tend to be directed upwards from foundations to hospitals, from hospitals to LHINs and from LHINs to the Ministry. The documents to achieve this are prescriptive, formal and provided at regular intervals: "LHIN reports tend to be very specific and line-oriented" (I4-Hospital board member). A LHIN director explained his process: "On a quarterly basis that's us reporting to the LHIN on our MLAA indicators or performance results. We post the results on our website every quarter as part of our disclosure requirements. [...] Quarterly we update the website for our performance measures for the quarter." (I20-LHIN Director). Such formal documents include financial statements, funding reports, board and committee minutes, the Quality Improvement Plans (QIP), performance results, program outcomes, budgets, forecasts, operational plans and cash flow projections. The foundations also provided updates on fundraising activities and proposes new initiatives. 
Also, large donors of foundations require additional personalised information that is not necessarily publicly available (Connolly \& Hyndman, 2017). Such personalised communications include stewardship reports which are used as a way to connect input and output performance from restricted funds.

\subsubsection{Personal-Level Information Strategies}

Information needs at a personal-level are numerous and include providing patients with details of their care treatment and changes that may affect their experience, demonstrating transparency to community members and demonstrating impact to donors.

An important information need of patients (as well as from partner agencies) is to provide them with details of their care treatment and ongoing health care requirements in order to get healthier. A hospital CNO described the need: "They have informational demands that are pretty significant as we're moving patients from the hospital to the community. All transitions is just about information. Moving the person's not the hard part. Making sure that you're translating all of the care that happened back to the community, which is very different. [...] There's huge demands from people that say, 'well, what did you do? What medications are you on?'” (I14-Hospital CNO).

There are also related information needs to ensure that all parties are aware of the different avenues that exist once the acute phase of care is complete, for both patients and their primary care physician: "We would say, 'Yeah. You may end up in long-term care 
but you can wait for long-term care in your home. You don't have to wait here. We can give you community services.' So we've started that conversation much earlier now to say, 'Understand that we're going to have a discharge plan and you will be going home'." (I13-Hospital CFO). A hospital board member explained the information needs of physicians in this regard: "And the doctors are also resistant to sending mom home in some cases because they're not convinced that the services are there to take care of mom when mom goes home. So now you got to educate the docs, and the docs used the liability card. 'If something goes wrong and I discharged her, I'll be sued'. So they tend to be more cautious and reluctant to make these changes." (I10-Hospital board member).

There are information needs to proactively inform patients (and the community) of changes that may affect their patient experience and help them navigate the health care system: “They get very frustrated [when they are not informed of changes]. So I think that helped just by pushing the communication out so they would know what's happening. Because if you don't need the hospital's services, you're not researching what's going on with the hospital until you need it." (I31-Hospital CEO).

There are also information needs to demonstrate transparency to the community as a way to build trust and maintain hospital and LHIN legitimacy with the public. A LHIN CFO described their process: "I would say pretty much everything is shared. We are a very open and transparent organisation.[...] Everything is reported publicly and posted on the website. So that includes all of our financial results, audited financial statements, our annual report, the stocktake reports, as well as all of our health service 
provider performance reports. So we show on a quarterly basis who has met their targets, who hasn't met their targets, who's in deficit, and report all that on through our board reports. [...] We choose to be even in areas where we're not required to be so open and transparent, we try and provide all the information we can in an open manner." (I25LHIN CFO).

A hospital CNO also described her approach to build trust and maintain the organisation's legitimacy by proactively sharing information, which allowed the organisation to take control of the narrative: "The other thing we try to do, it's share more good news of the good things that are happening. So that reputational strengthening. From an accountability perspective to me that's important. Because people need to hear that you're doing a good job, that you're doing great things." (I30-Hospital CNO). A hospital board member explained the risk of not controlling the narrative: "We felt that if we don't say stuff like that [about the financial outlook, and the need for layoffs], the broader community will make inferences [...]. If the information isn't there, they will fill in with whatever they want to assume." (I4-Hospital board member). Another participant described a similar situation: "[Regarding a hospital decision to move a non-acute service outside the hospital to a community setting], we did not have a communications system in place to be able to control the narrative. And so it got out into the public, and the public just filled that vacuum with all kinds of dire consequences, and it got away from us. So this is where I think accountability to the general public cannot be executed as effectively as possible without having that sort of communication system to support it." (I24-Hospital board member). 
Donors, for their part, expect foundations to demonstrate how donations will impact on patient outcomes, as donors want to feel their donations are making a difference.

Personal-level communications of hospitals, LHINs and foundations were directed downward and varied in their content. Process and service changes that may affect the patient experience were communicated through brochures and educational material. Some were prepared by hospitals, while others were prepared by LHINs.

To demonstrate transparency, many reports were provided to the public. Some were corporate-level reports, such as board minutes, business plans, expense reports, performance results and audited financial statements. Other reports were humanised through nontextual information, such as images, pictures and graphs, and by telling patient stories and providing basic statistics such as the number of people helped, the number of babies born, or the number of volunteer hours. Other information included new collaborative programs, quality performance in terms of wait times, infection rates and awards won. Much of the communication occurred to recap the year that happened. Storytelling and especially success stories were particularly prevalent. Photographs and storytelling through beneficiary testimonies is seen as a particularly effective way of communicating outcome performance to the public (Yang \& Northcott, 2019). 
For instance, foundations and hospitals may struggle to establish a link between the purchase of a piece of equipment and the related outcome performance of patient health due to its indirect nature. To compensate, outcome performance may be communicated through storytelling because it resonates and gains the most traction with donors. Sharing stories helps organisations demonstrate the impact of past investments and the potential of future investments to purchase capital equipment and make a difference in the lives of the patients who will benefit from this equipment. The art of storytelling is therefore important: "We need a story. So if we can get a piece of equipment, and then we can do some research on it, find out who it will benefit. And then we'll go out and find somebody who can talk about how it would've benefited them or how it will benefit them. And then we weave that story together." (I16-Foundation CEO).

As the literature suggests, donors might have difficulty understanding quantitative measures, and so charities, such as foundations, rely on storytelling to convey performance (Connolly et al., 2018). Charities may also be reluctant to share quantitative results publicly, as it increases the risk of misinterpretation by the media (Connolly et al., 2018). The same can be said for hospitals and LHINs communicating with personal-level stakeholders. While stories humanise health care, they also provide organisations with a way to avoid having to quantify their performance with the general public. In presenting information this way the Auditor General of Ontario criticised LHINs for a "lack of quantifiable targets" (Office of the Auditor General of Ontario, 2015, p.337). 
Methods of communication with patients, community members and donors were accomplished through annual general meetings (AGM), annual reports, newsletters, newspapers, public presentations, blogs, social media and organisations' websites. Websites were the main medium of communication with these stakeholders and seem particularly useful because patients, community members and donors are dispersed and their information needs are wide ranging and sporadic occurring anytime during the year: "The website seems to be the preferred method of communication now as well as annual reports" (I4-Hospital board member). Hospitals may also communicate internally on the walls of the hospital, in waiting rooms, and through phone calls especially for patients seeking health care services.

Foundations also communicate by getting out into the community to meet with community members face-to-face and provide tangible and personalised experiences. Foundations also communicate with donors to promote themselves through campaign videos, commercials on local television and through social media: "We're very active on Facebook, but we also will boost it because it's 15 bucks. [...] We're having a better ROI with Facebook [...] and it's cheap." (I16-Foundation CEO). Foundations also have extensive mailing campaigns, segmented by type of previous donation or time of year. When making large disbursements to hospitals, public presentations are a forum of choice for both hospitals and foundations: "It [the presentation] was in the lobby of the [hospital] and it [the funding] was announced there. And [the donors] were invited, board members were invited, the general public was invited, all of it." (I15-Foundation board member). 
It is important to communicate with personal-level stakeholders in an appropriate format, which is less medically and financially technical. The information shared needs to be provided in an easy to read format: "[...] because for your average reader, the hospital [financial] statements are so complicated [and] I'm not sure that the average reader understands what an auditor's report means. [...] [We] made a decision to go with this [simplified financial summary] format because this is less confusing for people." (I31Hospital CEO). The challenge is in presenting information that is understandable (and relatable) and seen as transparent, but not overly detailed and complex: "It's translating it to something that is understandable for the average citizen to understand" (I27-LHIN Director). A hospital board member explained the challenge: "I think sometimes it [communications] still stays couched in medical or financial or hospital-speak language. And I think we could probably do a bit better in simplifying that, telling people what we're doing, and why we're doing it." (I29-Hospital board member). Simplifying information may increase user usefulness by making the information more understandable, but too much simplification may reduce information quality characteristics of faithful representation and comparability.

In addition to quality considerations, hospitals, LHINs and foundations are also challenged by the quantity of information that they should provide, and are unsure if they should be providing more or less information: "I think there's very little shared with the community really [...]. I think if you looked at our website, that would be what's shared with the community [...]. [But to give the community more information] I think it would 
be waste of time 'cause I really don't think they want to hear. They just want it to work. They don't need information. They don't want it." (I5-Hospital board member). The same participant argued as well that if there was an information need from the community it would be conveyed through the media. This shows that the media serves an important function of representing the community: "Your newspaper, or your radios, they would be at the meetings, the way they would attend 15 or 20 years ago. So, I just think it's always the status quo with the community until we have an announcement that we have to lay off 50 people, then it becomes a community matter." (I5-Hospital board member). The media was also used as a channel to communicate information: "Media for sure simply because you have to, that's one way to manage expectations is through the media. Or if you want to be accountable to the broader public, it's one of the few opportunities you have is to communicate your message through the media. Again, if you don't communicate with them, they are free to infer what they want." (I4-Hospital board member).

\subsubsection{Summary of Information Strategies}

As addressed in this section, the content of information communicated (what is communicated) and the method of delivery (how information is communicated) varies greatly by stakeholder groups. Table 5-3 summarises the information strategies of hospitals, LHINs and foundations. 
Table 5-3 - Summary of Information Strategies

\begin{tabular}{|c|c|c|c|}
\hline $\begin{array}{l}\text { To whom } \\
\text { (Stakeholders) }\end{array}$ & $\begin{array}{l}\text { Information } \\
\text { Needs }\end{array}$ & $\begin{array}{l}\text { What information is shared } \\
\text { (content) }\end{array}$ & $\begin{array}{l}\text { How information is } \\
\text { shared (methods of } \\
\text { communication) }\end{array}$ \\
\hline $\begin{array}{l}\text { Corporate-level: } \\
\text { Hospital } \\
\text { LHIN } \\
\text { MOHLTC } \\
\text { Physicians }\end{array}$ & $\begin{array}{l}\text { Accurately } \\
\text { report } \\
\text { financial and } \\
\text { performance } \\
\text { results }\end{array}$ & $\begin{array}{l}\text { Financial statements, variance } \\
\text { analysis, funding reports, } \\
\text { board and committee } \\
\text { minutes, QIP, performance } \\
\text { results (stocktake reports, } \\
\text { HSP performance reports), } \\
\text { program outcomes, budgets, } \\
\text { forecasts, operational plans, } \\
\text { cash flow projections, } \\
\text { stewardship reports }\end{array}$ & $\begin{array}{l}\text { Emails, web portal, } \\
\text { board committee } \\
\text { meetings }\end{array}$ \\
\hline \multirow{4}{*}{$\begin{array}{l}\text { Personal-level: } \\
\text { Patients } \\
\text { Communities } \\
\text { Donors }\end{array}$} & $\begin{array}{l}\text { Details of } \\
\text { care } \\
\text { treatment }\end{array}$ & $\begin{array}{l}\text { Ongoing health care } \\
\text { requirements }\end{array}$ & $\begin{array}{l}\text { Verbal, face-to-face, } \\
\text { through family } \\
\text { physician }\end{array}$ \\
\hline & $\begin{array}{l}\text { Changes that } \\
\text { effect } \\
\text { patient } \\
\text { experience } \\
\text { and navigate } \\
\text { health care } \\
\text { system }\end{array}$ & $\begin{array}{l}\text { Brochures, educational } \\
\text { material }\end{array}$ & $\begin{array}{l}\text { Website, } \\
\text { newspapers, walls of } \\
\text { hospital, waiting } \\
\text { rooms, phone calls }\end{array}$ \\
\hline & $\begin{array}{l}\text { Demonstrate } \\
\text { transparency }\end{array}$ & $\begin{array}{l}\text { Photographs, storytelling, } \\
\text { positive basic statistics, board } \\
\text { minutes, business plans, } \\
\text { expense reports, performance } \\
\text { results, audited financial } \\
\text { statements }\end{array}$ & $\begin{array}{l}\text { Website, AGM, } \\
\text { annual reports, } \\
\text { newsletters, } \\
\text { newspapers, public } \\
\text { presentations, blogs, } \\
\text { social media }\end{array}$ \\
\hline & $\begin{array}{l}\text { Demonstrate } \\
\text { how } \\
\text { donations } \\
\text { have impact }\end{array}$ & Storytelling, 'thank yous' & $\begin{array}{l}\text { Public presentations, } \\
\text { campaign videos, } \\
\text { commercials and } \\
\text { social media, mailing } \\
\text { campaigns, thank } \\
\text { you letters, donor } \\
\text { recognition walls }\end{array}$ \\
\hline
\end{tabular}

Information needs can differ between stakeholders, and communications were adapted to these realities. Hospitals, LHINs and foundations had to manage two different 
narratives; one directed towards corporate-level stakeholders, the other directed towards personal-level stakeholders. Information strategies towards corporate-level stakeholders are more prescriptive, structured and characterised by formal and regular reporting. In contrast, information strategies towards personal-level stakeholders are less prescriptive, less structured and more informal than with corporate-level stakeholders, because the former's information needs can change, and organisations had to adapt.

The challenge is in effectively managing these two different information strategies. While formal reporting requirements at the corporate-level are very complex, information must be simplified when communicating at a personal-level in order to increase understandability (and relatability). This was accomplished by making the information communicated less medically and financially technical and through the art of storytelling.

While many corporate-level documents were made public in the interest of transparency, documents that were simplified such as the annual reports, did not speak to outcome performance in any way that allowed for comparisons over time or against a standard. Consistent with the literature, organisations focused on 'individual outcome' (Hyndman \& McConville, 2018a) rather than societal outcomes as a means of demonstrating outcome performance. This was achieved through storytelling, which can be seen as filling a communication void because it speaks to outcome performance, but without holding organisations accountable to specific performance metrics. 
In addition to storytelling, annual reports of hospitals, LHINs and foundations had a lot of nontextual information, such as images, pictures, and graphs which is less evidence-based and 'professional', and more emotional-driven.

Overall, performance metrics were found to be more important to corporate-level relationships, while stories were found to be more important to personal-level relationships. From the corporate perspective, stories are dismissed as being isolated and anecdotal. From the personal perspective, metrics are hard to understand and difficult to transmit and convey meaning persuasively. Storytelling 'pulls at the heart strings' of readers to encourage an emotional reaction and a connection to the organisation (Hyndman \& McConville, 2018b). Therefore, for hospitals, LHINs and foundations, consistency and comparability of quantitative information communication with personallevel stakeholders were not deemed as important as was telling a compelling story.

To achieve the objective of demonstrating accountability, accountability information must be captured from many reports, as each only provides a partial element of each organisation's reality (Connolly \& Hyndman, 2013a). Consistent with Yang and Northcott (2019), information was communicated via numerous reports, including annual reports, organisations' websites and informal discussions at public events. In the health care system, annual reports were used to communicate to personal-level stakeholders and not to their funders, demonstrating that annual reports are an important medium of communication towards personal-level stakeholders (Hyndman, 1990). These annual 
reports were sometimes combined between hospitals and their foundations, blurring the lines of organisational boundaries in order to show a common front.

These communications appear to be driven to build legitimacy and trust, and to some extent, demonstrate performance. In relation to accountability purposes, both demonstrating performance and building trust were found to be important to information strategies at the corporate and personal levels. However, through the information strategies presented, the accountability purpose of legitimacy only appeared to be important at the personal-level. Corporate-level legitimacy was not necessarily an important objective in the information strategies observed, until such time as an organisation's legitimacy is in peril, which was not the case for the organisations under study.

Overall, organisations need to act legitimately, be perceived externally as legitimate and demonstrate legitimacy (Ossewaarde et al., 2008). Consistent with Connolly and Hyndman (2013b), information contained in the annual reports did not always meet the information needs of stakeholders, but as a formal document it likely played a legitimising role.

Consistent with findings of Hardy and Ballis (2013) who reported that account giving was refocused to develop commitment and loyalty around the organisation rather than to report organisational performance, highlighting "an account giving that is selective, partial and asymmetrical" (p.554). Such a strategy could be viewed as a form of 
impression management, such that the reporting of key facts was not undertaken in a systematic manner, but was instead timed to promote the organisations to their target audience in order to reduce any potential public criticism. This was apparent in annual reports. As such, account giving through information communication attempted to control the message (through sensegiving) at a personal-level. 


\section{CHAPTER 6: CONCLUSION}

Chapter 6 concludes the thesis with six sections. An overview of the thesis is presented, theoretical and practical contributions are put forward, the research's implications, limitations and avenues for future research are enumerated, and concluding remarks are given.

\subsection{Overview of Thesis}

This thesis sought to understand how nonprofit accountability is managed. From existing literature, an accountability system was proposed. To answer the research questions, a qualitative research strategy using case studies was conducted at nine organisations within Ontario's health care system, with a particular focus on nonprofit hospitals and two of the hospitals' salient stakeholders, Local Health Integration Networks (LHINs) and foundations.

This study was motivated by a need to better understand how organisations actually go about managing competing stakeholder demands (Messner, 2009) and for more qualitative research that engages with key stakeholders (Connolly \& Hyndman, 2004; Hyndman \& McConville, 2018a). By considering the voices of many of the hospitals' salient stakeholders, this study addresses a research gap that deemed stakeholder theory research to be "organisation-centric" (Miles, 2017). This study answers the calls from Bovens (2010) and Crofts and Bisman (2010, p.197) for more 
developments in accountability management frameworks. Specifically, "the design of $[\ldots]$ improved accountability frameworks would assist in promoting greater consistency in the usage of the 'accountability' concept in different contexts. [...] Such frameworks could then explicitly support empirical studies and more accurately highlight which conceptions and perspectives of accountability are investigated." This study also addresses an additional research gap by moving beyond the study of large for-profit businesses, and focusing on nonprofit accounting practices, and specifically accountability processes in managing competing stakeholder demands (Hall \& O’Dwyer, 2017). Part of this study also investigates the often overlooked facet of the intersection between government and nonprofit governance (Stone \& Ostrower, 2007).

While previous studies within the nonprofit sector have focused on what accountability is and to whom it should be given, less focus has been given to what an accountability system might contain and how accountability is managed. Through the concepts of stakeholder relationships, governance mechanisms and information strategies, an accountability system was proposed and served as the conceptual framework to understand how nonprofit accountability is managed. Systems theory was used as the framework for developing, operationalising and presenting what is known about nonprofit accountability. Also, this study contrasts with a majority of studies that have concentrated on specific aspects of accountability. This study distinguishes itself by looking at accountability as a holistic process and at a range of interconnected organisations, allowing for a system view of accountability in a specific sector of the nonprofit economy. 


\subsubsection{Stakeholder Relationships}

Based on the analysis, health care organisations are challenged by the conflicting accountability demands of stakeholder groups. Reconciling these conflicting accountability demands should not necessarily be assumed by one organisation, but with and between the stakeholders themselves.

A review of accountability demands shows that health outcomes are not directly tied to the performance of health service providers. As such, there does not appear to be any clear line of accountability for improving population health outcomes. This is likely due to the inability to hold any one organisation responsible for the long term health outcomes of a population, since it inevitably implicates the integration of poverty, crime and other socio-economic factors. As it stands, it is unclear to what degree population health outcomes are improving and in what areas. Government agencies, such as LHINs, HQO and CIHI, have improved their collection and reporting of outcome measures, but these measures should be tied to health service provider accountability where possible.

The nature of stakeholder relationships was generally positive across the organisations. Stakeholder relationships can be challenging when a party feels they are being treated inequitably. Due to resource constraints, managing expectations is therefore an important aspect of stakeholder relationships. Health care organisations, such as LHINs and hospitals, must manage the expectations of their communities between 
achieving health equity objectives and the reality of maintaining standards of care through clear and ongoing communications in order to maintain positive relationships.

Stakeholder relationships were also challenged by an uncertainty about where responsibilities lie, which seems to be at the heart of relationships which could be at times adversarial, rather than collaborative. The inability to establish clear lines of responsibility makes it difficult to hold others to account and be accountable and also hinders the development of strong relationships because it breeds distrust. There is therefore a need for clear direction and lines of responsibility, which is an ongoing challenge due to the complexity and interdependent nature of health care in Ontario. The LHIN's mandate could have been clarified so as to reduce ambiguity and frustration among health care administrators. Clarifications of the LHIN's role in a variety of situations could have helped improve stakeholder relationships and would have helped manage expectations. The disbanding of LHINs may have been partly due to their diminished legitimacy as a result of the MOHLTC undermining its authority. The new Ontario Health agency that will replace LHINs could provide an opportunity to introduce such measures to clarify the new agency's role and establish clear lines of responsibility.

Moreover, as more coordination is demanded by patients, it will further blur the lines of responsibility between health service providers, making it harder for LHINs to achieve their oversight responsibilities. While newly created Ontario Health Teams might help to coordinate care within the health care system, there does not appear to be any interest in the integration of services through formal amalgamations, which will continue 
to be a barrier to the government and patient objectives of obtaining efficient and seamless care. It is also not clear how such measures will clarify the lines of responsibility.

Overall, it appears that the quality of stakeholder relationships may be hindered by a lack of formal mechanisms to evaluate and subsequently manage non-patient relationships. A more systematic approach to evaluating stakeholder relationships may help determine how relationships have evolved over time and assess when relationships are strained and in need of strengthening.

The study has demonstrated that stakeholders interact with and negotiate the specifics of their accountability demands in many ways, including the use of equity as a guiding value, building coalitions, compromising, using the media, collaborating, and political interventions. Equity drove much of the decision-making at the hospital and LHIN levels. Building coalitions was seen as an effective way of exerting bottom-up pressure by changing power dynamics in the negotiation process. Compromise was used as a negotiation tactic when both parties reduced their demands in order to come to an agreement. Intermediaries were used as an indirect channel to advance stakeholder objectives. Collaboration was used when the strengths of several parties were combined to achieve results that were greater than what could have been achieved individually. Political interventions were used by upward stakeholders when other means of negotiation failed. 


\subsubsection{Governance Mechanisms}

The health care system as a whole uses a combination of internal, external and collaborative governance mechanisms to manage its accountability. While there are specific mechanisms to the health care system (like patient and family advisory committees and care coordinators), many of the governance mechanisms are universal (like benchmarking and audits). Collaborative governance mechanisms, such as crossboard representation, working groups and steering committees, were found to straddle organisational boundaries and are an important part of the governance system given the interdependencies that exist in the health care system. The diversity of governance mechanisms demonstrates that many mechanisms need to work together for the governance system to function properly. Like the mechanisms of a watch, no single component makes the system work, but rather, all pieces working together. While it may appear from this study that internal governance mechanisms were less utilised than external and collaborative governance mechanisms, this observation may simply be explained by the fact that internal governance mechanisms were less visible, both to participants during interviews and through the review of archival documents.

One way to explain the importance of collaborative governance mechanisms in the health care system is to look at the paradox of managing agency and stewardship approaches. The tensions between agency and stewardship approaches to governance is inherent to the health care system because of the interdependencies that exist between stakeholders. What resonates throughout the case studies presented are the collaborative 
efforts found in stewardship theory. As such, the stakeholder relationships between health care organisations can fluctuate between these two approaches as situations merit.

\subsubsection{Information Strategies}

The content of information communicated (what is communicated) and the method of delivery (how information is communicated) varies greatly by stakeholder groups and communications were adapted to these realities. The challenge is in effectively managing these two different information strategies. While formal reporting requirements at the corporate-level are very complex, information must be simplified when communicating at a personal-level in order to increase understandability (and relatability). This was accomplished by making the information communicated less medically and financially technical and through the art of storytelling. Overall, consistent and comparable quantitative information were found to be more important to corporatelevel relationships, while telling a compelling story was found to be more important to personal-level relationships.

\subsection{Contributions}

This thesis makes both theoretical and practical contributions by advancing our understanding of nonprofit accountability in a number of ways. This study provides rich insights into understanding the dynamics and intricacies of accountability management practices in the unique context of the health care system. At a time when nonprofits face 
calls for greater accountability, understanding how accountability is managed is of critical importance to researchers and practitioners alike. By approaching accountability as an interconnected system, it will help organisational leaders better manage their accountability management practices.

By integrating stakeholder relationships, governance mechanisms and information strategies into an accountability system, this study helps build on prior foundations and bring each of these research streams closer together, at least in regards to nonprofit accountability. By developing a framework to analyse accountability, it has helped to identify new developments and has moved accounting research towards more coherence (Hopwood, 1976). To advance cohesion in the field of nonprofit accountability research and beyond, the concept of study within the accountability system should be clearly distinguished, as each concept addresses different kinds of issues, and focuses on different parts of the accountability system.

The comparisons made in this research have helped to illuminate the relationships between stakeholders, and specifically the power dynamics and negotiation tactics that characterises these relationships, which has not been explored and analysed extensively in the literature. At the governance level, much of the research has focused on board characteristics or on the internal/external governance divide. This study has argued for a more holistic approach to governance research that looks beyond the board (Cornforth, 2012) and puts forward a third collaborative dimension to the internal/external governance divide. On the information side, health care organisations demonstrate 
accountability through two different strategies. While corporate-level communications are formal, complex and evidence-based, personal-level communications are simplified and emotionally-driven through the art of storytelling.

This study also contributes to the literature by clarifying terminology as the concept of accountability "resembles a dustbin filled with good intentions, loosely defined concepts and vague images of good governance" (Bovens, 2007, p.449). Words that evoke dimensions of accountability, such as transparency, responsiveness, responsibility, trust, answerability, effectiveness, equity, and good governance are sometimes used interchangeably as synonyms (Bovens, 2007, 2010; Mulgan, 2000; Raggo, 2014). In this research, accountability can be distinguished between its governance mechanisms, information strategies, values such as transparency, responsiveness and responsibility, and purposes such as trust, legitimacy and equity.

On the methodology side, the novelty of this study comes from a multi-faceted analysis that has analysed stakeholder demands from the perspective of both organisations and stakeholders. While most research on organisational accountability focuses on specific organisations and projects outward to its stakeholders, this research actively sought data from the stakeholders themselves, providing a somewhat three dimensional view of stakeholder relationships. While modest, this allowed the research to analyse not just the accountability management practices of a single or even several organisations, but the accountability management practices of a portion of the health care 
system, providing a deeper and more nuanced understanding of the negotiation tactics and accountability challenges between parties.

\subsection{Implications}

There are several theoretical, practical and policy implications which result from this study. Theoretically, accountability can be seen as incorporating many complex and interconnected concepts into a single system with related sub-systems. The conceptual framework developed will allow future researchers to test its validity and applicability to different contexts. The study also provides an opportunity to reconcile diverging research streams, specifically accountability, governance and reporting.

From a practical perspective, this study offers organisational leaders a more holistic approach to accountability management. Based on the interviews conducted, there is interest from organisations leaders for such a framework. A lack of a clear analytical framework (i.e. accountability system) has hindered practitioners' ability to respond effectively to stakeholder demands and manage their accountability (Kearns, 1994). This study has offered a visual schematic of the accountability system, which could be used as a governance tool for practitioners. The complexity in managing accountability is aided by the proposed accountability system which helps clarify how nonprofit organisations could better operationalise their accountability management practices through stakeholder relationships, governance mechanisms and information strategies. 
By deconstructing accountability into its concepts, it can help organisations identify which parts of the accountability system are well resourced, and which parts need to be addressed. This allows organisations to better manage their accountability systems, by being able to break them down into concepts, thereby allowing organisational leaders to isolate weaknesses and improve them. Based on the analysis, practitioners may not realise that managing stakeholder relationships is an important part of accountability management practices. In fact, the Ontario Hospital Association's (OHA) resource Guide to Good Governance dedicates an entire chapter to stakeholder relationships (Ontario Hospital Association, 2015). In managing stakeholder relationships, a more systematic approach to evaluating stakeholder relationships may help determine how relationships have evolved over time and assess when relationships are strained and in need of strengthening.

By gaining a better understanding of what is happening within the accountability system and providing nonprofit leaders with a framework from which to work, it may help nonprofit organisations and their leaders improve accountability management practices. As such, a better understanding of how nonprofits manage their accountability systems should help improve practices and allow nonprofits to be more resilient in difficult times, use available resources more efficiently and effectively, and compete more effectively for scarce resources. 
At the policy level, the analysis has revealed that the government may have to take a more direct leadership role if it is to achieve its health equity objectives. Also, while government agencies, such as LHINs, HQO and CIHI, have improved their collection and reporting of outcome measures, these measures should be tied to health service provider accountability where possible.

This study also provides a few cautions to the government's newly created agency, Ontario Health. The MOHLTC should refrain from usurping or undermining the new Ontario Health agency's role because such actions could diminish its legitimacy and the likelihood that health service providers will heed Ontario Health recommendations for change at the health service provider level. Reducing the possibilities for political interventions by the MOHLTC will reduce threats to the new agency's legitimacy. However, due to concentration to a single agency, it could make it easier for governments to interference. Also, clarifying the new Ontario Health agency's role in a variety of situations could also help to improve stakeholder relationships between the parties and could help with expectation management. Establishing clear lines of responsibility can reduce ambiguity and frustration among health care administrators.

Also, the LHINs were designed to gather local issues and find local solutions to problems. It remains to be seen if local issues will be sacrificed at the expense of a central agency, which may exacerbate existing inequities of rural and remote regions if their local concerns remain unaddressed. While achieving health equity in the province still appears to be a government priority from a recent publication stating that "the new 
system will be designed to ensure patients receive the best care - no matter when and where they need it." (Government of Ontario, 2019b). However, systematic inequity continues to exist in Ontario's rural, remote and northern regions, as well as francophone communities. The government may have to take a more direct leadership role if it is to achieve its health equity objectives.

\subsection{Limitations}

While this study contains many methodological strengths, it also contains certain inherent limitations, which must be taken into consideration when interpreting the results.

This study was conducted within the context of Ontario's health care system. The structures, processes, and dynamics may not apply to other jurisdictions, making the transferability of findings to other contexts unknown, although the study's design was not to generalise the findings to other contexts. However, many health care laws, most notably the Canada Health Act, 1985, are of federal jurisdiction. As such, there remain many similarities between the provinces.

The participation of organisational leaders constituted a crucial condition to the realisation of this project. Interviews were limited to individuals on the board of directors or working for hospitals, LHINs and foundations. While board members are community members and hospital Chiefs of Staff are physicians, interviews were not directly conducted with community members, physicians and MOHLTC leadership. As such, 
nuances in these stakeholder relationships might not have been taken into consideration in the analysis of this research. Relatedly, while the number of participating organisations is significant for a qualitative study, the participation of different or more organisations may have modified certain results.

Despite a balanced interview guide, most participants were more interested in discussing facets of the stakeholder relationships, such as their challenges, dialogue and negotiation tactics, and less interested in delving into the intricacies of their governance mechanisms and information strategies. The ability of semi-structured interviews to shift focus during participant interactions provided tremendous benefits to this research, which would not have been possible had questionnaires been used as a data collection method. It also appears that stakeholder relationships may be more important to organisational success than governance mechanisms and information strategies. Nonetheless, this focus by participants on stakeholder relationships limited the available time during interviews to address other aspects of the accountability system.

This study is also subject to limitations associated with qualitative research. The research conducted was heavily based on interview data, and as such, participants' recollections, biases and perceptions may affect the answers provided. Given the research design, this was expected. However, to minimise potential methodological risks, multiple individuals within the same organisation were interviewed, archival documents were consulted, and the data was analysed iteratively for inconsistencies. The anonymity of participants also helped to ensure some level of candour. 
Also, while the study was conducted with rigour, researcher biases are always a possibility which may affect the reproducibility of the findings. Researcher biases were reduced through triangulation by the use of multiple sources of evidence, the use of Nvivo 12, a qualitative data analysis software, to systematically collect and analyse the case study data, and the use of representative quotes throughout the analysis to provide the reader an opportunity to verify assertions made.

\subsection{Suggestions for Future Research}

While the contributions of this study to knowledge creation are substantive, there remain many promising avenues for future research. Since health care in Canada is of provincial jurisdiction, it would be worthwhile to investigate the accountability dynamics that exist in other provinces. From here, comparisons could be made with Ontario's health care system. Relatedly, it would also be valuable to conduct similar studies in different sectors of the nonprofit economy to compare the suitability of findings and link them to contingency factors particular to different contexts. The conceptual framework developed may also find usefulness in the corporate governance field in regards to corporate social responsibility (CSR) as stakeholder relationships, governance and reporting are all critical components of any adequate CSR strategy.

Ontario's health care system has recently undergone important changes such as the elimination of LHINs and the creation of a single government agency called Ontario 
Health, resulting in new and different dynamics to existing stakeholder relationships. While the decision to replace LHINs was made after data collection and will be phased in over a number of years, the coordinating and oversight work of LHINs will continue much like it did before. Nonetheless, it would be interesting to conduct follow-up interviews during these transition years, allowing for longitudinal comparisons.

Future research can look at other health care system stakeholders such as physicians, the MOHLTC, and other health service providers not covered in this study to see if findings are similar. Future research can also focus more on the governance mechanisms and information strategies of health care organisations through a more extensive use of archival documents. For instance, conflicts between stakeholders could originate from differences in their demands, among other things. Future research could investigate differences in performance types, such as input, process, output, and outcome performance, and tie them to accountability demands. Also, comparisons between sites were outside the scope of this study, however, a different methodological approach would make such comparisons possible.

It is argued in this study that many governance mechanisms need to work together for the governance system to function properly. Research that is conducted only on specific governance mechanisms, such as those that focus solely on characteristics of the Board of Directors, may be too narrow and miss important aspects of organisational governance practices. Future research may benefit from a more holistic approach to governance research in the nonprofit sector. 
At the governance level, the agency-stewardship governance paradox could be viewed as having one foot on the gas, and one foot on the brake, but not necessarily at the same time. The vacillation that occurs between the positions of agency and stewardship inevitably suggests a temporal dimension. Future research is needed to investigate temporal boundaries surrounding this construct in order to clarify its applicability in accountability management.

There has also been little research into cost and benefit analysis in decisionmaking for accountability purposes. Such issues are important considerations, especially for organisations with limited resources. Nonprofits therefore have 'reasonable' accountability limits. That is, they have resource constraints that limit their accountability capacities. However, many of the studies on nonprofit governance, including this one, do not address governance costs. Research could be conducted into the cost of designing, initiating and implementing the set of governance mechanisms used, or to be used, by nonprofits to manage their accountability.

\subsection{Concluding Remarks}

The question of how an accountability system is structured to meet the demands of stakeholders is paramount to nonprofit organisational effectiveness. Yet, few studies have investigated how accountability is managed holistically through the use of governance and information, and in a specific context. Through the conceptual 
framework proposed, this study sought to understand how nonprofit organisations manage their accountability system. A case study research design using interviews and archival documents was used to answer the research questions. This research has clarified our understanding of the relationship between stakeholder relationships, governance mechanisms and information strategies, and can help nonprofit leaders improve accountability management practices. 


\section{References}

Abouassi, K., \& Trent, D. L. (2016). NGO accountability from an NGO perspective: Perceptions, strategies, and practices. Public Administration and Development, 36(4), 283-296.

Abrahamson, E., \& Amir, E. (1996). The Information Content of the President's Letter to Shareholders. Journal of Business Finance \& Accounting, 23(8), 1157-1182.

Abzug, R. (1999). The Nonprofit Sector and the Informal Sector: A Theoretical Perspective. Voluntas, 10(2), 131-149.

Aggarwal, R. K., Evans, M. E., \& Nanda, D. (2012). Nonprofit boards: Size, performance and managerial incentives. Journal of Accounting and Economics, 53(1-2), 466487.

Ahrens, T., \& Chapman, C. S. (2006). Doing Qualitative Field Research in Management Accounting: Positioning Data to Contribute to Theory. Accounting, Organizations and Society, 31(8), 299-318.

Ahrens, T., \& Dent, J. F. (1998). Accounting and organizations: Realizing the richness of field research. Journal of Management Accounting Research, 10, 1-39.

Albrecht, K. (2000). Corporate Radar: Tracking the Forces that are Shaping Your Business. New York: AMACOM Books.

Alexander, J. A., \& Weiner, B. J. (1998). The Adoption of the Corporate Governance Model by Nonprofit Organizations. Nonprofit Management and Leadership, 8(3), 223-242.

Alter, K. (2007). Social Enterprise Typology. Virtue Ventures LLC.

Amans, P., Mazars-Chapelon, A., \& Villesèque-Dubus, F. (2015). Budgeting in institutional complexity: The case of performing arts organizations. Management Accounting Research, 27, 47-66.

Andrews, A. (2014). Downward Accountability in Unequal Alliances: Explaining NGO Responses to Zapatista Demands. World Development, 54, 99-113.

Anheier, H. K., Hass, R., \& Beller, A. (2013). Accountability and Transparency in the German Nonprofit Sector: A Paradox? International Review of Public Administration, 18(3), 69-84.

Armstrong, G., Adam, S., Denize, S., \& Kotler, P. (2015). Principles of Marketing (6th ed.). Melbourne: Pearson Australia.

Bacharach, S. B. (1989). Organizational Theories: Some Criteria for Evaluation. Academy of Management Review, 14(4), 496-515.

Baker, C. R. (2005). What is the meaning of "the public interest"?: Examining the ideology of the American public accounting profession. Accounting, Auditing \& Accountability Journal, 18(5), 690-703.

Bakvis, H., \& Juillet, L. (2004). The Horizontal Challenge: Line Departments, Central Agencies and Leadership. Ottawa: Canada School of Public Service.

Bansal, P., \& Corley, K. G. (2012). Publishing in AMJ-Part 7: What's Different About Qualitative Research? Academy of Management Journal, 55(3), 509-513.

Barney, J. B. (1990). The Debate Between Traditional Management Theory and Organizational Economics: Substantive Differences or Intergroup Conflict? Academy of Management Review, 15(3), 382-393. 
Barr, C. W., Brock, K., Brownlee, B., Frankel, S., Hall, M. H., Murray, V., ... Scott, K. (2006). Strengthening the Capacity of Nonprofit and Voluntary Organizations to Serve Canadians: Recommendations Based on the National Survey of Nonprofit and Voluntary Organizations. Toronto: Imagine Canada.

Bartimoro, M. (2006, June 12). The Ones Who Got Away. Bloomberg. Retrieved from http://www.bloomberg.com/news/articles/2006-06-11/the-ones-who-got-away

Bertalanffy, L. V. (1950). An Outline of General System Theory. The British Society for the Philosophy of Science, 1(2), 134-165.

Bertalanffy, L. V. (1972). The History and Status of General Systems Theory. Academy of Management Journal, 15(4), 407-426.

Blackwood, A. S., Roeger, K. L., \& Pettijohn, S. L. (2012). The Nonprofit Sector in Brief: Public Charities, Giving, and Volunteering. Urban Institute.

Bluewater Health. (2015). Cost per Weighted Case. Retrieved September 29, 2019, from https://www.bluewaterhealth.ca/sites/default/files/Bluewater_Health_Performance_ Costper_Weighted_Case.pdf

Blumberg, M. (2017, March 27). Blumberg's Snapshot of the Canadian Charity Sector 2015. Retrieved from

http://www.globalphilanthropy.ca/blog/blumbergs_canadian_charity_sector_snapsh ot_2015

Blumberg, M., \& Sawyer, M. (2018, October 6). Blumbergs' Snapshot of the Canadian Charity Sector 2016.

Bolton, P., \& Mehran, H. (2006). An introduction to the governance and taxation of notfor-profit organizations. Journal of Accounting and Economics, 41(3), 293-305.

Bovens, M. (2007). Analysing and assessing accountability: a conceptual framework. European Law Journal, 13(4), 447-468.

Bovens, M. (2010). Two Concepts of Accountability: Accountability as a Virtue and as a Mechanism. West European Politics, 33(5), 946-967.

Bradshaw, P. (2009). A Contingency Approach to Nonprofit Governance. Nonprofit Management and Leadership, 20(1), 61-82.

Brandsma, G. J., \& Schillemans, T. (2013). The Accountability Cube: Measuring Accountability. Journal of Public Administration Research and Theory, 23(4), 953975.

Brennan, N. M., Guillamon-Saorin, E., \& Pierce, A. (2009). Impression management: Developing and illustrating a scheme of analysis for narrative disclosures - a methodological note. Accounting, Auditing \& Accountability Journal, 22(5), 789832.

Brinkerhoff, D. W. (2004). Accountability and health systems: Toward conceptual clarity and policy relevance. Health Policy and Planning, 19(6), 371-379.

British Parliament. British North America Act, 1867 (1867). United Kingdom. Retrieved from https://www.justice.gc.ca/eng/rp-pr/csj-sjc/constitution/lawregloireg/p1t11.html

Broadbent, E., Brown, R., Godsoe, D., Kan, A. W. S., Kroeger, A., Vézina, M., ... Echenberg, H. (1999). Building on Strength: Improving Governance and Accountability in Canada's Voluntary Sector. Panel on Accountability and Governance in the Voluntary Sector.

Brouard, F. (2016). Note on Governance Mechanisms. Ottawa. 
Brouard, F., \& Di Vito, J. (2008). Identification des mécanismes de gouvernance applicables aux PME. In 9e Congrès International Francophone sur la PME (pp. 119). Louvain-la-Neuve, Belgium.

Brown, W. A. (2002). Inclusive Governance Practices in Nonprofit Organizations and Implications for Practice. Nonprofit Management and Leadership, 12(4), 369-385.

Bryman, A. (1984). The Debate about Quantitative and Qualitative Research: A Question of Method or Epistemology? The British Journal of Sociology, 35(1), 75-92.

Bujaki, M. L., \& Richardson, A. J. (1997). A Citation Trail Review of the Uses of Firm Size in Accounting Research. Journal of Accounting Literature, 16, 1-27.

Burrell, G., \& Morgan, G. (1979). Sociological Paradigms and Organisational Analysis: Elements of the Sociology of Corporate Life. Aldershot, England: Ashgate Publishing Company.

Canada Revenue Agency. (2013). How to draft purposes for charitable registration (reference number CG-019). Retrieved July 7, 2017, from http://www.craarc.gc.ca/chrts-gvng/chrts/plcy/cgd/drftprpss-eng.html

Canada Revenue Agency. (2015). Charities Program Update - 2015. Retrieved July 24, 2017, from https:/www.canada.ca/en/revenue-agency/services/charitiesgiving/charities/about-charities-directorate/charities-program-update-2015.html

Canada Revenue Agency. (2016). What is the difference between a registered charity and a non-profit organization? Retrieved May 27, 2016, from http://www.craarc.gc.ca/chrts-gvng/dnrs/rgltn/dffrnc-rc-np-eng.html

Canadian Institute for Health information. (2011). Seniors and the Health Care System: What Is the Impact of Multiple Chronic Conditions? Ottawa. Retrieved from https://secure.cihi.ca/free_products/air-chronic_disease_aib_en.pdf

Canadian Institute for Health information. (2018). National Health Expenditure Trends, 1975 to 2018. Ottawa. Retrieved from https://www.cihi.ca/en/healthspending/2018/national-health-expenditure-trends

Canadian Institute for Health information. (2019). Outcomes. Retrieved June 17, 2019, from https://www.cihi.ca/en/outcomes

Capurro, R., \& Hjorland, B. (2003). The Concept of Information. Annual Review of Information Science and Technology, 37(1), 343-411.

Carman, J., \& Fredericks, K. (2013). Nonprofits and Accreditation: Exploring the Implications for Accountability. International Review of Public Administration, 183(3), 51-68.

Carmichael, H. (2014, December 4). "Trusted" employee admits she stole from Sudbury centre. The Sudbury Star. Retrieved from http://www.thesudburystar.com/2014/12/04/trusted-employee-admits-she-stolefrom-sudbury-centre

Cavalluzzo, K. S., \& Ittner, C. D. (2004). Implementing performance measurement innovations: Evidence from government. Accounting, Organizations and Society, 29(3-4), 243-267.

CBC News. (2015, March 16). Lucia Motowidlo heads to jail in Christ the King fraud case. $C B C$. Retrieved from http://www.cbc.ca/news/canada/sudbury/luciamotowidlo-heads-to-jail-in-christ-the-king-fraud-case-1.2997159

Chalmers, A. F. (1999). What is this thing called Science? (3rd ed.). Indianapolis: Hackett Publishing Company, Inc. 
Checkland, P. (1994). Systems Theory and Management Thinking. American Behavioral Scientist, 38(1), 75-91.

Chisolm, L. B. (1995). Accountability of Nonprofit Organizations and Those Who Control Them: The Legal Framework. Nonprofit Management and Leadership, 6(2), 141-156.

Cho, C. H., Guidry, R. P., Hageman, A. M., \& Patten, D. M. (2012). Do actions speak louder than words? An empirical investigation of corporate environmental reputation. Accounting, Organizations and Society, 37(1), 14-25.

Christensen, A. L., \& Mohr, R. M. (2003). Not-for-Profit Annual Reports: What do Museum Managers Communicate? Financial Accountability \& Management, 19(2), $139-158$.

Christensen, R. A., \& Ebrahim, A. (2006). How Does Accountability Affect Mission? Nonprofit Management and Leadership, 17(2), 195-209.

Christensen, T., Laegreid, P., \& Rykkja, L. H. (2016). Organizing for Crisis Management: Building Governance Capacity and Legitimacy. Public Administration Review, 76(6), 887-897.

Church, J., \& Barker, P. (1998). Regionalization of health services in Canada: a critical perspective. International Journal of Health Services, 28(3), 467-486.

Cobb, C. (2014a, October 11). Charity's finance chief robbed most needy of vital support, court told. Ottawa Citizen. Retrieved from http://ottawacitizen.com/news/local-news/charitys-finance-chief-robbed-mostneedy-of-vital-support-court-told

Cobb, C. (2014b, November 14). Yolande Knight sentenced to four years for theft from Ottawa charity where she worked. Ottawa Citizen. Retrieved from http://ottawacitizen.com/news/local-news/yolande-knight-sentenced-to-four-yearsfor-theft-from-ottawa-charity-where-she-worked

Connolly, C., \& Hyndman, N. (2004). Performance reporting: a comparative study of British and Irish charities. The British Accounting Review, 36(2), 127-154.

Connolly, C., \& Hyndman, N. (2013a). Charity accountability in the UK: through the eyes of the donor. Qualitative Research in Accounting \& Management, 10(3/4), 259-278.

Connolly, C., \& Hyndman, N. (2013b). Towards Charity Accountability: Narrowing the gap between provision and needs? Public Management Review, 15(7), 945-968.

Connolly, C., \& Hyndman, N. (2017). The donor-beneficiary charity accountability paradox: a tale of two stakeholders. Public Money \& Management, 37(3), 157-164.

Connolly, C., Hyndman, N., \& Liguori, M. (2018). Performance accountability: a study of the UK and Irish charity practices at a time of change. Accounting, Finance and Governance Review, 24(1/2), 45-70.

Cordery, C. J. (2013). Regulating Small and Medium Charities: Does It Improve Transparency and Accountability? Voluntas, 24(3), 831-851.

Cordery, C. J., \& Baskerville, R. F. (2011). Charity Transgressions, Trust and Accountability. Voluntas, 22(2), 197-213.

Cordery, C. J., \& Sim, D. (2018). Dominant stakeholders, activity and accountability discharge in the CSO sector. Financial Accountability \& Management, 34(1), 7796.

Cornforth, C. (2004). The Governance of Cooperatives and Mutual Associations: A 
Paradox Perspective. Annals of Public and Cooperative Economics, 75(1), 11-32.

Cornforth, C. (2012). Nonprofit Governance Research: Limitations of the Focus on Boards and Suggestions for New Directions. Nonprofit and Voluntary Sector Quarterly, 41(6), 1116-1135.

Cornforth, C., \& Edwards, C. (1999). Board Roles in the Strategic Management of Nonprofit Organisations : theory and practice. Corporate Governance, 7(4), 346-362.

Cornforth, C., \& Simpson, C. (2002). Change and Continuity in the Governance of Nonprofit Organizations in the United Kingdom: The Impact of Organizational Size. Nonprofit Management and Leadership, 12(4), 451-470.

Cornwall, A., Lucas, H., \& Pasteur, K. (2000). Introduction: Accountability through Participation: Developing Workable Partnership Models in the Health Sector. IDS Bulletin, 31(1), 1-13.

Costa, E., Ramus, T., \& Andreaus, M. (2011). Accountability as a Managerial Tool in Non-Profit Organizations: Evidence from Italian CSVs. Voluntas, 22(3), 470-493.

Coule, T. M. (2015). Nonprofit Governance and Accountability: Broadening the Theoretical Perspective. Nonprofit and Voluntary Sector Quarterly, 44(1), 75-97.

Courtis, J. K. (1998). Annual report readability variability: tests of the obfuscation hypothesis. Accounting, Auditing \& Accountability Journal, 11(4), 459-472.

CPA Canada. (2019). CPA Canada Handbook. Toronto: Knotia Canada.

Crawford, L., Morgan, G. G., \& Cordery, C. J. (2018). Accountability and not-for-profit organisations: Implications for developing international financial reporting standards. Financial Accountability \& Management, 34(2), 181-205.

Creswell, J. W. (2012). Educational research: planning, conducting, and evaluating quantitative and qualitative research (4th ed.). Boston: Pearson Education, Inc.

Creswell, J. W. (2013). Qualitative Inquiry and Research Design: Choosing Among Five Approaches (3rd ed.). Los Angeles: Sage Publications.

Crofts, K., \& Bisman, J. (2010). Interrogating accountability: An illustration of the use of Leximancer software for qualitative data analysis. Qualitative Research in Accounting \& Management, 7(2), 180-207.

Cumberland, D. M., Kerrick, S. A., D’Mello, J., \& Petrosko, J. M. (2015). Nonprofit Board Balance and Perceived Performance. Nonprofit Management and Leadership, 25(4), 449-462.

Curtis, S., Gesler, W., Smith, G., \& Washburn, S. (2000). Approaches to sampling and case selection in qualitative research: examples in the geography of health. Social Science and Medicine, 50(7), 1001-1014.

D’Amboise, G., \& Audet, J. (2005). La comparaison intersites : une voie pour la recherche en gestion. Saint-Nicolas, Québec: Les presses de 1'Université Laval.

Daft, R. L., \& Lengel, R. H. (1986). Organizational Information Requirements, Media Richness and Structural Design. Management Science, 32(5), 554-571.

Daily, C. M., Dalton, D. R., \& Cannella, A. A. (2003). Corporate Governance: Decades of Dialogue and Data. Academy of Management Review, 28(3), 371-382.

Dainelli, F., Manetti, G., \& Sibilio, B. (2013). Web-Based Accountability Practices in Non-profit Organizations: The Case of National Museums. Voluntas, 24(3), 649665.

Dart, R. (2004). The Legitimacy of Social Enterprise. Nonprofit Management and Leadership, 14(4), 411-424. 
Davenport, T. H., \& Prusak, L. (1998). Working Knowledge: How Organizations Manage What They Know. Boston: Harvard Business School Press.

Davies, C. (2007). Grounding governance in dialogue? Discourse, practice and the potential for a new public sector organizational form in Britain. Public Administration, 85(1), 47-66.

Davis, J. H., Schoorman, F. D., \& Donaldson, L. (1997). Toward a Stewardship Theory of Management. Academy of Management Review, 22(1), 20-47.

Davison, J. (2004). Sacred vestiges in financial reporting: Mythical readings guided by Mircea Eliade. Accounting, Auditing \& Accountability Journal, 17(3), 476-497.

Davison, J. (2007). Photographs and accountability: cracking the codes of an NGO. Accounting, Auditing \& Accountability Journal, 20(1), 133-158.

Davison, J., \& Warren, S. (2009). Imag[in]ing accounting and accountability. Accounting, Auditing \& Accountability Journal, 22(6), 845-857.

Deber, R. B. (2002). Delivering Health Care Services: Public, Not-For-Profit, or Private? (Discussion paper no. 17). Ottawa: Commission on the Future of Health Care in Canada.

Deloffre, M. Z. (2016). Global accountability communities: NGO self-regulation in the humanitarian sector. Review of International Studies, 42(4), 724-747.

Descartes, R. (1996). Discours de la méthode : Pour bien conduire sa raison et chercher la vérité dans les sciences. Anjou, Québec: Les Éditions CEC inc.

Descartes, R. (2007). Discourse on Method. Newburyport, MA: Focus Publishing.

Devlin, R. (2019a). A Healthy Ontario: Building a Sustainable Health Care System.

Devlin, R. (2019b). Hallway Health Care: A System Under Strain.

Dhanani, A., \& Connolly, C. (2012). Discharging Not-for-profit Accountability: UK charities and Public Discourse. Accounting, Auditing \& Accountability Journal, 25(7), 1140-1169.

Donaldson, T., \& Preston, L. E. (1995). The Stakeholder Theory of the Corporation: Concepts, Evidence, and Implications. Academy of Management Review, 20(1), 6591.

Donner, G. (2015). Bringing Care Home. Toronto.

Downes, M., \& Russ, G. S. (2005). Antecedents and consequences of failed governance: the Enron example. Corporate Governance: The International Journal of Business in Society, 5(5), 84-98.

Drucker, P. F. (1988a). Management and the World's Work. Harvard Business Review, $66(5), 65-76$.

Drucker, P. F. (1988b). The Coming of the New Organization. Harvard Business Review, $66(1), 45-53$.

Dubé, M., Brouard, F., \& Pilon, M. (2019). Gouvernance dans le secteur de la santé hôpital: 2) Perspective du chef de la direction financière. In 87 e Congrès de l'ACFAS 2019, Association francophone pour le savoir (ACFAS), Colloque \#460 La gouvernance et l'innovation. Gatineau.

Dumay, J., \& Roslender, R. (2013). Utilising narrative to improve the relevance of intellectual capital. Journal of Accounting \& Organizational Change, 9(3), 248-279.

Duncan, C. M., \& Schoor, M. A. (2015). Talking Across Boundaries: A Case Study of Distributed Governance. Voluntas, 26(3), 731-755.

Duncan, R. B. (1972). Characteristics of Organizational Environments and Perceived 
Environmental Uncertainty. Administrative Science Quarterly, 17(3), 313-327.

Ebrahim, A. (2003a). Accountability in practice: Mechanisms for NGOs. World Development, 31(5), 813-829.

Ebrahim, A. (2003b). Making sense of accountability: Conceptual perspectives for northern and southern nonprofits. Nonprofit Management and Leadership, 14(2), 191-212.

Edmondson, A. C., \& McManus, S. E. (2007). Methodological Fit in Management Field Research. Academy of Management Review, 32(4), 1155-1179.

Edwards, M., \& Hulme, D. (1995). Beyond the Magic Bullet? Lessons and Conclusions. In M. Edwards \& D. Hulme (Eds.), Non-Governmental Organisations Performance and Accountability Beyond the Magic Bullet (pp. 219-228). London: Earthscan Publications Limited.

Edwards, M., \& Hulme, D. (1996). Too close for comfort? The impact of official aid on nongovernmental organizations. World Development, 24(6), 961-973.

Eeckloo, K., Van Herck, G., Van Hulle, C., \& Vleugels, A. (2004). From Corporate Governance To Hospital Governance: Authority, transparency and accountability of Belgian non-profit hospitals' board and management. Health Policy, 68(1), 1-15.

Eisenhardt, K. M. (1989a). Agency Theory: An Assessment and Review. Academy of Management Review, 14(1), 57-74.

Eisenhardt, K. M. (1989b). Building Theories from Case Study Research. Academy of Management Review, 14(4), 532-550.

Eisenhardt, K. M., \& Graebner, M. E. (2007). Theory Building From Cases: Opportunities and Challenges. Academy of Management Journal, 50(1), 25-32.

Elliott, R. K., \& Jacobson, P. D. (1994). Costs and Benefits of Business Information Disclosure. Accounting Horizons, 8(4), 80-96.

Emery, F. E., \& Trist, E. L. (1965). The Causal Texture of Organizational Environments. Human Relations, 18(1), 21-32.

Emmett, B., \& Emmett, G. (2015). Charities in Canada as an Economic Sector: Discussion Paper. Toronto: Imagine Canada.

Fama, E. F., \& Jensen, M. C. (1983). Separation of Ownership and Control. Journal of Law and Economics, 26(2), 301-325.

Federal Trade Commission. (2016). FTC, States Settle Claims Against Two Entities Claiming to Be Cancer Charities; Orders Require Entities to Be Dissolved and Ban Leader from Working for Non-Profits. Retrieved January 15, 2018, from https:/www.ftc.gov/news-events/press-releases/2016/03/ftc-states-settle-claimsagainst-two-entities-claiming-be-cancer

Feldman, M. S., \& March, J. G. (1981). Information in Organizations as Signal and Symbol. Administrative Science Quarterly, 26(2), 171-186.

Fierlbeck, K. (2011). Health care in Canada: a citizen's guide to policy and politics. Toronto: University of Toronto Press.

Finer, H. (1941). Administrative Responsibility in Democratic Government. Public Administration Review, 1(4), 335-350.

Fitzpatrick, D., \& Griffin, D. (2016, February 15). Cancer charity targeted by feds agrees to put itself out of business. CNN. Retrieved from

http://www.cnn.com/2016/02/15/us/cancer-fund-of-america-dissolution-agreement/

Flack, T., \& Ryan, C. (2005). Financial reporting by Australian nonprofit organisations: 
Dilemmas posed by government funders. Australian Journal of Public Administration, 64(3), 69-77.

Fowler, A. (1995). Assessing NGO Performance: Difficulties, Dilemmas, \& A Way Ahead. In M. Edwards \& D. Hulme (Eds.), Non-Governmental Organisations Performance and Accountability Beyond the Magic Bullet (pp. 143-156). London: Earthscan Publications Limited.

Fowler, C. J., \& Cordery, C. J. (2015). From community to public ownership: a tale of changing accountabilities. Accounting, Auditing \& Accountability Journal, 28(1), $128-153$.

Fox, J. A., \& Brown, L. D. (1998). Introduction. In J. A. Fox \& L. D. Brown (Eds.), The Struggle for Accountability: The World Bank, NGOs, and Grassroots Movements (pp. 1-48). Cambridge, MA: The MIT Press.

Freeman, R. E. (1994). Strategic Management: A Stakeholder Approach. Boston: Pitman. Friedrich, C. J. (1940). Public Policy and the Nature of Administrative Responsibility. In C. J. Friedrich \& E. S. Mason (Eds.), Public Policy (pp. 3-24). Cambridge, MA: Harvard University Press.

Froelich, K. A., Knoepfle, T. W., \& Pollak, T. H. (2000). Financial Measures in Nonprofit Organization Research: Comparing IRS 990 Return and Audited Financial Statement Data. Nonprofit and Voluntary Sector Quarterly, 29(2), 232254.

Fry, R. E. (1995). Accountability in Organizational Life: Problem or Opportunity for Nonprofits? Nonprofit Management and Leadership, 6(2), 181-195.

Geer, B. W., Maher, J. K., \& Cole, M. T. (2008). Managing Nonprofit Organizations: The Importance of Transformational Leadership and Commitment to Operating Standards for Nonprofit Accountability. Public Performance \& Management Review, 32(1), 51-75.

Gephart, R. P. (2004). Qualitative Research and the Academy of Management Journal. Academy of Management Journal, 47(4), 454-462.

Gibbins, M., Richardson, A. J., \& Waterhouse, J. (1990). The Management of Corporate Financial Disclosure: Opportunism, Ritualism, Policies, and Processes. Journal of Accounting Research, 28(1), 121-143.

Gibelman, M., \& Gelman, S. R. (2001). Very public scandals: Nongovernmental organizations in trouble. Voluntas, 12(1), 49-66.

Gibelman, M., \& Gelman, S. R. (2004). A loss of credibility: Patterns of wrongdoing among nongovernmental organizations. Voluntas, 15(4), 355-381.

Gioia, D. A., Corley, K. G., \& Hamilton, A. L. (2012). Seeking Qualitative Rigor in Inductive Research: Notes on the Gioia Methodology. Organizational Research Methods, 16(1), 15-31.

Giroux, G. (2008). What went wrong? Accounting fraud and lessons from the recent scandals. Social Research, 75(4), 1205-1238.

Given, L. M. (Ed.). (2008). The Sage Encyclopedia of Qualitative Research Methods. Thousand Oaks, California: Sage Publications, Inc.

Glaser, B. G., \& Strauss, A. L. (1967). The Discovery of Grounded Theory: Strategies of Qualitative Research. Piscataway, New Jersey: AldineTransaction.

Goodin, R. E. (2003). Democratic Accountability: the Distinctiveness of the Third Sector. European Journal of Sociology, 44(3), 359-396. 
Goodpaster, K. E. (1991). Business Ethics and Stakeholder Analysis. Business Ethics Quarterly, 1(1), 53.

Gore, O., McDermott, I., Checkland, K., Allen, P., \& Moran, V. (2018). Discretion drift in primary care commissioning in England: Towards a conceptualization of hybrid accountability obligations. Public Administration, online ver, 1-17.

Government of Canada. Canada Health Act, R.S.C., 1985, c. C-6 (1985). Canada. Retrieved from https://laws-lois.justice.gc.ca/eng/acts/c-6/page-1.html\#h-3

Government of Ontario. Public Hospitals Act, R.S.O. 1990, c. P.40 (1990). Ontario. Retrieved from https://www.ontario.ca/laws/statute/90p40

Government of Ontario. R.R.O. 1990, Reg. 964: Classification of Hospitals (2001). Ontario. Retrieved from https://www.ontario.ca/laws/regulation/900964

Government of Ontario. Patients First Act, 2016, S.O. 2016, c. 30 - Bill 41 (2016). Ontario. Retrieved from https://www.ontario.ca/laws/statute/S16030

Government of Ontario. (2018). The Estimates, 2018-19. Retrieved November 19, 2018 , from https://www.ontario.ca/page/summary-table-1-operating-2018-19

Government of Ontario. (2019a). Improving health care in Ontario. Retrieved June 10, 2019, from https://www.ontario.ca/page/improving-health-care-ontario

Government of Ontario. The People's Health Care Act, 2019, S.O. 2019, c. 5 - Bill 74 (2019). Ontario. Retrieved from https://www.ontario.ca/laws/statute/S19005

Gratzer, D. (1999). Code Blue: veviving Canada's health care system. Toronto: ECW Press.

Gray, R., Bebbington, J., \& Collison, D. (2006). NGOs, civil society and accountability: making the people accountable to capital. Accounting, Auditing \& Accountability Journal, 19(3), 319-348.

Gray, R., Dey, C., Owen, D., Evans, R., \& Zadek, S. (1997). Struggling with the praxis of social accounting: Stakeholders, accountability, audits and procedures. Accounting, Auditing \& Accountability Journal, 10(3), 325-364.

Greiling, D., \& Stötzer, S. (2015). Performance Accountability as a Driver for Changes in Nonprofit-Government Relationships: An Empirical Insight from Austria. Voluntas, 26(5), 1690-1717.

Guba, E. G. (1981). Criteria for Assessing the Trustworthiness of Naturalistic Inquiries. Educational Technology Research and Development, 29(2), 75-91.

Guba, E. G., \& Lincoln, Y. S. (1994). Competing Paradigms in Qualitative Research. In N. K. Denzin \& Y. S. Lincoln (Eds.), Handbook of Qualitative Research (pp. 105117). Thousand Oaks, California: Sage Publications, Inc.

Haggar-Guenette, C., Hamdad, M., Laronde-Jones, D., Pan, T., \& Yu, M. (2009). Satellite Account of Non-profit Institutions and Volunteering. Ottawa: Statistics Canada.

Hall, M. H., Andrukow, A., Barr, C. W., Brock, K. L., de Wit, M., Embuldeniya, D., ... Vaillancourt, Y. (2003). The Capacity to Serve: A Qualitative Study of the Challenges Facing Canada's Nonprofit and Voluntary Organizations. Toronto: Canadian Centre for Philanthropy.

Hall, M. H., Barr, C. W., Easwaramoorthy, M., Sokolowski, S. W., \& Salamon, L. M. (2005). The Canadian Nonprofit and Voluntary Sector in Comparative Perspective. Toronto: Imagine Canada.

Hall, M. H., de Wit, M. ., Lasby, D., McIver, D., Evers, T., Johnston, C., ... Murray, V. 
(2004). Cornerstones of Community: Highlights from the National Survey of Nonprofit and Voluntary Organizations. Ottawa: Statistics Canada.

Hall, M., \& O’Dwyer, B. (2017). Accounting, non-governmental organizations and civil society: The importance of nonprofit organizations to understanding accounting, organizations and society. Accounting, Organizations and Society, 63, 1-5.

Hardy, L., \& Ballis, H. (2013). Accountability and giving accounts: Informal reporting practices in a religious corporation. Accounting, Auditing \& Accountability Journal, 26(4), 539-566.

Harris, E. E. (2014). The Impact of Board Diversity and Expertise on Nonprofit Performance. Nonprofit Management and Leadership, 25(2), 113-130.

Harris, E. E., Petrovits, C. M., \& Yetman, M. H. (2015). The Effect of Nonprofit Governance on Donations: Evidence from the Revised Form 990. The Accounting Review, 90(2), 579-610.

Hay Group Limited. (2014). Northeastern Ontario Clinical Services Review: Executive Summary.

Hays, P. A. (2004). Case Study Research. In K. DeMarrais \& S. D. Lapan (Eds.), Foundations for Research: Methods of Inquiry in Education and the Social Sciences (pp. 217-234). Mahwah, New Jersey: Lawrence Erlbaum Associates.

Health Quality Ontario. (2016). Health Quality Ontario's Health Equity Plan. Toronto. Retrieved from http://www.hqontario.ca/Portals/0/documents/healthquality/Health_Equity_Plan_Report En.pdf

Health Quality Ontario. (2017). Health in the North: A report on geography and the health of people in Ontario's two northern regions. Toronto.

Hirsch, P., Michaels, S., \& Friedman, R. (1987). "Dirty hands" versus "clean models": Is sociology in danger of being seduced by economics? Theory and Society, 16(3), 317-336.

Hofer, C. W. (1975). Toward a Contingency Theory of Business Strategy. Academy of Management Journal, 18(4), 784-810.

Hopwood, A. G. (1976). The Path Ahead. Accounting, Organizations and Society, 1(1), $1-4$.

Hopwood, A. G. (1983). On trying to study accounting in the contexts in which it operates. Accounting, Organizations and Society, 8(2-3), 287-305.

Hug, N., \& Jäger, U. P. (2014). Resource-Based Accountability: A Case Study on Multiple Accountability Relations in an Economic Development Nonprofit. Voluntas, 25(3), 772-796.

Hyndman, N. (1990). Charity accounting - an empirical study of the information needs of contributors to UK fund raising charities. Financial Accountability \& Management, 6(4), 295-307.

Hyndman, N., \& McConville, D. (2018a). Making charity effectiveness transparent: Building a stakeholder-focussed framework of reporting. Financial Accountability \& Management, 34(2), 133-147.

Hyndman, N., \& McConville, D. (2018b). Trust and accountability in UK charities: Exploring the virtuous circle. The British Accounting Review, 50(2), 227-237.

Hyndman, N., \& McDonnell, P. (2009). Governance and charities: An exploration of key themes and the development of a research agenda. Financial Accountability \& Management, 25(1), 5-31. 
Imagine Canada. (2017). Sector Impact. Retrieved February 15, 2017, from http://sectorsource.ca/research-and-impact/sector-impact

Income Tax Act, R.S.C., 1985, c. 1 (5th Supp.). Canada.

International Co-operative Alliance. (2017). What is a co-operative? Retrieved October 21, 2017, from https://ica.coop/en/what-co-operative

Jensen, M. C., \& Meckling, W. H. (1976). Theory of the Firm : Managerial Behavior, Agency Costs and Ownership Structure. Journal of Financial Economics, 3(4), 305360.

Jepson, P. (2005). Governance and accountability of environmental NGOs. Environmental Science \& Policy, 8(5), 515-524.

Jones, T. M. (1995). Instrumental Stakeholder Theory: A Synthesis of Ethics and Economics. Academy of Management Review, 20(2), 404-437.

Josephson, M. (1988). Teaching Ethical Decision Making and Principled Reasoning. In Ethics: Easier Said Than Done (pp. 27-33). Los Angeles: The Josephson Institute.

Kahn, B. K., Strong, D. M., \& Wang, R. Y. (2002). Information Quality Benchmarks: Product and Service Performance. Communications of the ACM, 45(4), 184-192.

Kast, F. E., \& Rosenzweig, J. E. (1972). General Systems Theory: Applications for Organization and Management. Academy of Management Journal, 15(4), 447-465.

Katz, S. N. (1999). Where Did the Serious Study of Philanthropy Come From, Anyway? Nonprofit and Voluntary Sector Quarterly, 28(1), 74-82.

Kearns, K. P. (1994). The Strategic Management of Accountability in NonProfit Organizations: An Analytical Framework. Public Administration Review, 54(2), $185-192$.

Kearns, K. P. (1996). Managing for Accountability: Preserving the Public Trust in Public and Nonprofit Organizations. San Francisco: Jossey-Bass.

Keating, E. K., \& Frumkin, P. (2003). Reengineering Nonprofit Financial Accountability: Toward a More Reliable Foundation for Regulation. Public Administration Review, 63(1), 3-15.

Knutsen, W., \& Brower, R. S. (2010). Managing Expressive and Instrumental Accountabilities in Nonprofit and Voluntary Organizations: A Qualitative Investigation. Nonprofit and Voluntary Sector Quarterly, 39(4), 588-610.

Kochan, T. A., \& Rubinstein, S. A. (2000). Toward a Stakeholder Theory of the Firm: The Saturn Partnership. Organization Science, 11(4), 367-386.

Koppell, J. G. S. (2005). Pathologies of Accountability: ICANN and the Challenge of "Multiple Accountabilities Disorder." Public Administration Review, 65(1), 94-108.

Kostova, T. (1999). Transnational Transfer of Strategic Organizational Practices: A Contextual Perspective. Academy of Management Review, 24(2), 308-324.

Kreutzer, K. (2009). Nonprofit Governance During Organizational Transition in Voluntary Associations. Nonprofit Management and Leadership, 20(1), 117-133.

Kreutzer, K., \& Jacobs, C. (2011). Balancing Control and Coaching in CSO Governance. A Paradox Perspective on Board Behavior. Voluntas, 22(4), 613-638.

Kuhn, T. (1996). The Structure of Scientific Revolutions (3rd ed.). Chicago, USA: University of Chicago Press.

Laflamme, S. (2007). Analyses qualitatives et quantitatives : deux visions, une même science. Nouvelles Perspectives En Sciences Sociales: Revue Internationale de Systémique Complexe et d'études Relationnelles, 3(1), 141-149. 
Langley, A. (1999). Strategies for Theorizing from Process Data. Academy of Management Review, 24(4), 691-710.

Langley, A., Smallman, C., Tsoukas, H., \& Van de Ven, A. H. (2013). Process Studies of Change in Organization and Management: Unveiling Temporality, Activity, and Flow. Academy of Management Journal, 56(1), 1-13.

Lasby, D., \& Barr, C. W. (2014). Sector Monitor (Vol. 4). Toronto: Imagine Canada.

Lavis, J. N. (2016). Preface. In J. N. Lavis (Ed.), Ontario's health system: Key insights for engaged citizens, professionals and policymakers (pp. 9-13). Hamilton: McMaster Health Forum.

Lavis, J. N., \& Hammill, A. C. (2016a). Care by sector. In J. N. Lavis (Ed.), Ontario's health system: Key insights for engaged citizens, professionals and policymakers (pp. 209-269). Hamilton: McMaster Health Forum.

Lavis, J. N., \& Hammill, A. C. (2016b). Governance arrangements. In J. N. Lavis (Ed.), Ontario's health system: Key insights for engaged citizens, professionals and policymakers (pp. 45-71). Hamilton: McMaster Health Forum.

Lavis, J. N., \& Mattison, C. A. (2016). Introduction and overview. In J. N. Lavis (Ed.), Ontario's health system: Key insights for engaged citizens, professionals and policymakers (pp. 15-43). Hamilton: McMaster Health Forum.

Lawry, R. P. (1995). Accountability and nonprofit organizations: an ethical perspective. Nonprofit Management and Leadership, 6(2), 171-180.

Lee, M. (2004). Public Reporting: A Neglected Aspect of Nonprofit Accountability. Nonprofit Management and Leadership, 15(2), 169-185.

Lenczner, M., \& Phillips, S. (2012). From Stories to Evidence: How Mining Data Can Promote Innovation in the Nonprofit Sector. Technology Innovation Management Review, 2(7), 10-15.

Liu, S. (1998). Strategic scanning and interpretation revisiting: foundations for a software agent support system - Part 1: understanding the concept and context of strategic scanning. Industrial Management and Data Systems, 98(7), 295-312.

Madill, J., Brouard, F., \& Hebb, T. (2010). Canadian Social Enterprises: An Empirical Exploration of Social Transformation, Financial Self-Sufficiency, and Innovation. Journal of Nonprofit and Public Sector Marketing, 22(2), 135-151.

Maier, F., \& Meyer, M. (2011). Managerialism and Beyond: Discourses of Civil Society Organization and Their Governance Implications. Voluntas, 22(4), 731-756.

Mainardes, E. W., Alves, H., \& Raposo, M. (2012). A model for stakeholder classification and stakeholder relationships. Management Decision, 50(10), 18611879.

Martin, D. (2017). Better now: six big ideas to improve health care for all Canadians. Toronto: Penguin Canada.

Mason, D. E. (1992). Values for Ethical Choices: Rate Yourself. Nonprofit World, 10(3), $23-25$.

Mason, M. (2010). Sample Size and Saturation in PhD Studies Using Qualitative Interviews. Forum Qualitative Sozialforschung / Forum: Qualitative Social Research, 11(3), Art. 8.

Mattison, C. A., \& Lavis, J. N. (2016). Delivery arrangements 2: Workforce. In J. N. Lavis (Ed.), Ontario's health system: Key insights for engaged citizens, professionals and policymakers (pp. 175-207). Hamilton: McMaster Health Forum. 
Maxwell, J. A. (2013). Qualitative Research Design (3rd ed.). Thousand Oaks, California: Sage Publications, Inc.

Mayer, R. C., Davis, J. H., \& Schoorman, F. D. (1995). An Integratuve Model of Organizational Trust. Academy of Management Review, 20(3), 709-734.

McCambridge, R. (2004). Underestimating the Power of Nonprofit Governance. Nonprofit and Voluntary Sector Quarterly, 33(2), 346-354.

McKeever, B. S. (2015). The Nonprofit Sector in Brief: Public Charities, Giving and Volunteering. Washington, D.C.: Urban Institute.

McNeil, D. (2015). The Effectiveness of a Care Transitions and Rapid Response Nurse Intervention at Reducing Readmissions and Emergency Department Use for High Risk Patients: A Mixed Methods Study. (Doctoral Dissertation). Laurentian University.

Medawar, C. E. (1982). What is Accountability? In Kenneth Midgley (Ed.), Management Accountability and Corporate Governance (pp. 155-162). London: The Macmillan Press Ltd.

Melis, A. (2005). Corporate governance failures: To what extent is parmalat a particularly Italian case? Corporate Governance, 13(4), 478-488.

Ménard, L. (2014). Dictionnaire de la comptabilité et de la gestion financière (3e ed.). Toronto: CPA Canada. Retrieved from https://www.knotia.ca/Tools/Dictionnaire2014/desktop/index.aspx

Messner, M. (2009). The limits of accountability. Accounting, Organizations and Society, 34(8), 918-938.

Miles, M. B., Huberman, A. M., \& Saldaña, J. (2014). Qualitative Data Analysis: A Methods Sourcebook (3rd ed.). Thousand Oaks, California: Sage Publications, Inc.

Miles, S. (2017). Stakeholder Theory Classification: A Theoretical and Empirical Evaluation of Definitions. Journal of Business Ethics, 142(3), 437-459.

Miller-Millesen, J. L. (2003). Understanding the Behavior of Nonprofit Boards of Directors: A Theory-Based Approach. Nonprofit and Voluntary Sector Quarterly, 32(4), 521-547.

Ministry of Finance. (2017). Ontario Population Projections Update, 2017-2041, Table 5: Historical and projected share of Ontario population by census division, selected years - reference scenario. Retrieved November 19, 2018, from https://www.fin.gov.on.ca/en/economy/demographics/projections/table5.html

Ministry of Finance. (2018). Ontario Population Projections Update, 2017-2041, Regional components of population change. Retrieved January 21, 2019, from https://www.fin.gov.on.ca/en/economy/demographics/projections/\#s3cc

Ministry of Health and Long-Term Care. (2017). Expenditure Estimates for the Ministry of Health and Long Term Care. Retrieved November 27, 2017, from https://www.ontario.ca/page/expenditure-estimates-ministry-health-and-long-termcare-2017-18

Ministry of Health and Long-Term Care. (2018a). Community Health Centres. Retrieved November 19, 2018, from http:/www.health.gov.on.ca/en/common/system/services/chc/

Ministry of Health and Long-Term Care. (2018b). Health System Funding Reform (HSFR). Retrieved November 19, 2018, from http://www.health.gov.on.ca/en/pro/programs/ecfa/funding/hs_funding.aspx 
Ministry of Health and Long-Term Care. (2019). Ontario Health Teams: Guidance for Health Care Providers and Organizations.

Mitchell, R. K., Agle, B. R., \& Wood, D. J. (1997). Toward a theory of stakeholder identification and salience: Defining the principle of who and what really counts. Academy of Management Review, 22(4), 853-886.

Moat, K. A., Mattison, C. A., \& Lavis, J. N. (2016). Financial arrangements. In J. N. Lavis (Ed.), Ontario's health system: Key insights for engaged citizens, professionals and policymakers (pp. 73-122). Hamilton: McMaster Health Forum.

Morgan, G. (1980). Paradigms, Metaphors, and Puzzle Solving in Organization Theory. Administrative Science Quarterly, 25(4), 605-622.

Morgan, G., \& Smircich, L. (1980). The Case for Qualitative Research. Academy of Management Review, 5(4), 491-500.

Morrison, J. B., \& Salipante, P. (2007). Governance for Broadened Accountability: Blending Deliberate and Emergent Strategizing. Nonprofit and Voluntary Sector Quarterly, 36(2), 195-217.

Mukamurera, J., Lacourse, F., \& Couturier, Y. (2006). Des avancées en analyse qualitative : pour une transparence et une systématisation des pratiques. Recherches Qualitatives, 26(1), 110-138.

Mulgan, R. (2000). “Accountability”: An Ever-Expanding Concept? Public Administration, 78(3), 555-573.

Munro, R. J. B., \& Hatherly, D. J. (1993). Accountability and the New Commercial Agenda. Critical Perspectives on Accounting, 4(4), 369-395.

Murtaza, N. (2012). Putting the lasts first: The case for community-focused and peermanaged NGO accountability mechanisms. Voluntas, 23(1), 109-125.

Najam, A. (1996). NGO Accountability: A Conceptual Framework. Development Policy Review, 14(4), 339-353.

Nelson, R. R., Todd, P. A., \& Wixom, B. H. (2005). Antecedents of Information and System Quality: An Empirical Examination Within the Context of Data Warehousing. Journal of Management Information Systems, 21(4), 199-235.

Nonaka, I. (1994). A Dynamic Theory of Organizational Knowledge Creation. Organization Science, 5(1), 14-37.

O’Brien, J. A. (1999). Managing Information Systems: Managing Information Technology in the Internetworked Enterprise (4th ed.). New York: Irwin.

O’Brien, J. A. (2004). Managing Information Systems: Managing Information Technology in the Business Enterprise (6th ed.). Boston: McGraw-Hill.

O'Brien, T. (2010). Stuck in the Middle: Maintaining the Organizational Legitimacy of the Regional Environmental Center. Voluntas, 21(3), 339-357.

O’Dwyer, B., \& Boomsma, R. (2015). The co-construction of NGO accountability. Accounting, Auditing \& Accountability Journal, 28(1), 36-68.

O’Dwyer, B., \& Unerman, J. (2007). From functional to social accountability. Accounting, Auditing \& Accountability Journal, 20(3), 446-471.

O’Dwyer, B., \& Unerman, J. (2008). The paradox of greater NGO accountability: A case study of Amnesty Ireland. Accounting, Organizations and Society, 33(7-8), 801824.

O'Leary, S. (2017). Grassroots accountability promises in rights-based approaches to development: The role of transformative monitoring and evaluation in NGOs. 
Accounting, Organizations and Society, 63, 21-41.

O'Regan, K., \& Oster, S. M. (2005). Does the structure and composition of the board matter? The case of nonprofit organizations. The Journal of Law, Economics, and Organization, 21(1), 205-227.

Oakes, L. S., \& Young, J. J. (2008). Accountability re-examined: Evidence from Hull House. Accounting, Auditing \& Accountability Journal, 21(6), 765-790.

Office of the Auditor General of Ontario. (2015). 2015 Annual Report, Chapter 3, Section 3.08 LHINs - Local Health Integration Networks. Toronto: Queen's Printer for Ontario.

Office of the Minister of Health and Long-Term Care. (2019, February 26). Ontario's Government for the People to Break Down Barriers to Better Patient Care. Retrieved from https://news.ontario.ca/mohltc/en/2019/02/ontarios-government-for-thepeople-to-break-down-barriers-to-better-patient-care.html

Office of the Premier. (2019, June 20). Premier Ford Announces Changes to His Cabinet. Retrieved from https://news.ontario.ca/opo/en/2019/06/premier-ford-announceschanges-to-his-cabinet.html

Ontario Hospital Association. (2015). Guide to Good Governance (3rd ed.).

Ospina, S., Diaz, W., \& O'Sullivan, J. F. (2002). Negotiating Accountability: Managerial Lessons from Identity-Based Nonprofit Organizations. Nonprofit and Voluntary Sector Quarterly, 31(1), 5-31.

Ossewaarde, R., Nijhof, A., \& Heyse, L. (2008). Dynamics of NGO legitimacy: how organising betrays core missions of INGOs. Public Administration and Development, 28(1), 42-53.

Ostrower, F., \& Stone, M. M. (2010). Moving Governance Research Forward: A Contingency-Based Framework and Data Application. Nonprofit and Voluntary Sector Quarterly, 39(5), 901-924.

Paillé, P., \& Mucchielli, A. (2012). L'analyse qualitative en sciences humaines et sociales (3e ed.). Paris: Armand Colin.

Palmer, P. D. (2013). Exploring Attitudes to Financial Reporting in the Australian Notfor-profit Sector. Accounting \& Finance, 53(1), 217-241.

Pascuci, L. M., Júnior, V. M., \& Crubellate, J. M. (2017). Strategic Management in Hospitals: Tensions between the Managerial and Institutional Lens. Brazilian Administration Review, 14(2), 1-21.

Paul, S. (1991). Strengthening Public Service Accountability (No. 136). World Bank Discussion Papers. Washington, D.C.: The World Bank.

Paulus, O., \& Lejeune, C. (2013). What do board members in art organizations do? A grounded theory approach. Journal of Management and Governance, 17(4), 963988.

Pfeffer, J., \& Salancik, G. R. (1978). The External Control of Organizations: A Resource Dependence Perspective. New York: Harper and Row.

Picco, G. (2017). Cap in Hand: How Charities and Failing the People of Canada and the World. Toronto: Civil Sector Press.

Pilon, M., \& Brouard, F. (2016). Dimensions and Definitions of Nonprofit Accountability: A Comprehensive System. In 2016 ARNOVA Conference (pp. 151). Washington, D.C.

Poupart, J. (1997). L'entretien de type qualitatif : considérations épistémologiques, 
théoriques et méthodologiques. In J. Poupart, J.-P. Deslauriers, L.-H. Groulx, A. Laperrière, R. Mayer, \& A. P. Pires (Eds.), La recherche qualitative : Enjeux épistémologiques et méthodologiques (pp. 173-209). Montréal: Gaëtan Morin.

Premkumar, G., \& King, W. R. (1992). An Empirical Assessment of Information Systems Planning and The Role of Information Systems in Organization. Journal of Management Information Systems, 9(2), 99-125.

Puentes, R., Mozas, A., Bernal, E., \& Chaves, R. (2012). E-corporate social responsibility in small non-profit organisations : the case of Spanish "Non Government Organisations." The Service Industries Journal, 32(15), 2379-2398.

Raggo, P. (2014). Leaders' Accounts: A Study of Transnational NGOs Leadership Views on Accountability. (Doctoral Dissertation). Syracuse University.

Rehli, F., \& Jäger, U. P. (2011). The Governance of International Nongovernmental Organizations: How Funding and Volunteer Involvement Affect Board Nomination Modes and Stakeholder Representation in International Nongovernmental Organizations. Voluntas, 22(4), 587-612.

Roberts, J. (2009). No one is perfect: The limits of transparency and an ethic for “intelligent" accountability. Accounting, Organizations and Society, 34(8), 957-970.

Roberts, J., \& Scapens, R. W. (1985). Accounting systems and systems of accountability - understanding accounting practices in their organisational contexts. Accounting, Organizations and Society, 10(4), 443-456.

Robson, C. (2002). Real World Research (2nd ed.). Malden: Blackwell Publishing.

Romzek, B. S. (2000). Dynamics of public sector accountability in an era of reform. International Review of Administrative Sciences, 66(1), 21-44.

Romzek, B. S., \& Dubnick, M. J. (1987). Accountability in the Public Sector: Lessons from the Challenger Tragedy. Public Administration Review, 47(3), 227-238.

Ruiz, R. (2015, May 19). 4 Cancer Charities Are Accused of Fraud. The New York Times. Retrieved from http://www.nytimes.com/2015/05/20/business/4-cancer-charitiesaccused-in-ftc-fraud-case.html? $\mathrm{r}=0$

Salamon, L. M., \& Anheier, H. K. (1996). The International Classification of Nonprofit Organizations: ICNPO-Revision 1, 1996 (No. 19). Working Papers of the Johns Hopkins Comparative Nonprofit Sector Project. Baltimore: The Johns Hopkins University Institute for Policy Studies.

Salamon, L. M., \& Sokolowski, S. W. (2016). Beyond Nonprofits : Re-conceptualizing the Third Sector. Voluntas, 27(4), 1515-1545.

Salamon, L. M., Sokolowski, S. W., Haddock, M. A., \& Tice, H. S. (2013). The State of Global Civil Society and Volunteering: Latest findings from the implementation of the UN Nonprofit Handbook (No. 49). Working Papers of the Johns Hopkins Comparative Nonprofit Sector Project. Baltimore: Johns Hopkins Center for Civil Society Studies.

Salamon, L. M., \& Toepler, S. (2015). Government-Nonprofit Cooperation: Anomaly or Necessity? Voluntas, 26(6), 2155-2177.

Salm, J. (1999). Coping With Globalization: A Profile of the Northern NGO Sector. Nonprofit and Voluntary Sector Quarterly, 28(1_suppl), 87-103.

Salterio, S., \& Legresley, P. (2011). Developing a Culture of Reporting Transparency and Accountability: The Lessons Learned from the Voluntary Sector Reporting Awards for Excellence in Financial Reporting Transparency. The Philanthropist, 23(4), 555- 
573.

Sarstedt, M., \& Schloderer, M. P. (2010). Developing a measurement approach for reputation of non-profit organizations. International Journal of Nonprofit and Voluntary Sector Marketing, 15(3), 276-299.

Saunders, B., Sim, J., Kingstone, T., Baker, S., Waterfield, J., Bartlam, B., ... Jinks, C. (2018). Saturation in qualitative research: exploring its conceptualization and operationalization. Quality \& Quantity, 52(4), 1893-1907.

Saxton, G. D., \& Guo, C. (2011). Accountability online: Understanding the Web-based accountability practices of nonprofit organizations. Nonprofit and Voluntary Sector Quarterly, 40(2), 270-295.

Schmitz, H. P., Raggo, P., \& Bruno-van Vijfeijken, T. (2012). Accountability of Transnational NGOs: Aspirations vs. Practice. Nonprofit and Voluntary Sector Quarterly, 41(6), 1175-1194.

Schnurbein, G. V. (2009). Patterns of Governance Structures in Trade Associations and Unions. Nonprofit Management and Leadership, 20(1), 97-115.

Schoonhoven, C. B. (1981). Problems with Contingency Theory: Testing Assumptions Hidden within the Language of Contingency "Theory." Administrative Science Quarterly, 26(3), 349-377.

Schwabenland, C., \& Hirst, A. (2018). Hybrid accountabilities and managerial agency in the third sector. Public Administration, online ver, 1-41.

Shafritz, J. M. (1992). The HarperCollins dictionary of American government and politics. New York: HarperPerennial.

Shah, P., \& Shah, M. K. (1995). Participatory Methods for Increasing NGO Accountability: a Case Study from India. In M. Edwards \& D. Hulme (Eds.), NonGovernmental Organisations - Performance and Accountability Beyond the Magic Bullet (pp. 183-191). London: Earthscan Publications Limited.

Shaw, S., Zink, R., \& Lynch, P. (2014). Keeping People "In the Tent": Governance in the New Zealand Outdoor Activity Sector. Voluntas, 25(6), 1539-1558.

Shearer, T. (2002). Ethics and accountability: from the for-itself to the for-the-other. Accounting, Organizations and Society, 27(6), 541-573.

Shleifer, A., \& Vishny, R. W. (1997). A Survey of Corporate Governance. The Journal of Finance, 52(2), 737-783.

Sinclair, A. (1995). The Chameleon of Accountability: Forms and Discourses. Accounting, Organizations and Society, 20(2), 219-237.

Singleton, R. A. J., \& Straits, B. C. (2010). Approaches to Social Research (5th ed.). New York: Oxford University Press.

Skinner, D. J. (1994). Why Firms Voluntarily Disclose Bad News. Journal of Accounting Research, 32(1), 38-60.

Smith, S. R. (2008). The Challenge of Strengthening Nonprofits and Civil Society. Public Administration Review, 68(S1), S132-S145.

Speckbacher, G. (2008). Nonprofit Versus Corporate Governance: An Economic Approach. Nonprofit Management and Leadership, 18(3), 295-320.

Speklé, R. F., \& Verbeeten, F. H. M. (2014). The use of performance measurement systems in the public sector: Effects on performance. Management Accounting Research, 25(2), 131-146.

Spence, C. (2007). Social and environmental reporting and hegemonic discourse. 
Accounting, Auditing \& Accountability Journal, 20(6), 855-882.

Statistica. (2019). Number of hospital establishments in Canada as of 2016, by province. Retrieved September 29, 2019, from

https://www.statista.com/statistics/440923/total-number-of-hospital-establishmentsin-canada-by-province/

Statistics Canada. (2016). The International Classification of Non-profit Organizations.

Retrieved May 5, 2016, from http://www.statcan.gc.ca/pub/13-015-

$\mathrm{x} / 2009000 /$ sect13-eng.htm

Statistics Canada. (2019). Non-profit institutions and volunteering: Economic contribution, 2007 to 2017 . Retrieved June 10, 2019, from https://www150.statcan.gc.ca/n1/daily-quotidien/190305/dq190305a-eng.htm

Steen-Johnsen, K., Eynaud, P., \& Wijkström, F. (2011). On Civil Society Governance: An Emergent Research Field. Voluntas, 22(4), 555-565.

Sternberg, E. (1997). The Defects of Stakeholder Theory. Corporate Governance, 5(1), $3-10$.

Stone, M. M., \& Ostrower, F. (2007). Acting in the Public Interest? Another Look at Research on Nonprofit Governance. Nonprofit and Voluntary Sector Quarterly, 36(3), 416-438.

Suchman, M. C. (1995). Managing Legitimacy: Strategic and Institutional Approaches. Academy of Management Review, 20(3), 571-610.

Sugin, L. (2007). Resisting the Corporatization of Nonprofit Governance: Transforming Obedience Into Fidelity. Fordham Law Review, 76(2), 893-927.

Sundaramurthy, C., \& Lewis, M. (2003). Control and Collaboration: Paradoxes of Governance. Academy of Management Review, 28(3), 397-415.

Sundin, H., Granlund, M., \& Brown, D. A. (2010). Balancing Multiple Competing Objectives with a Balanced Scorecard. European Accounting Review, 19(2), 203246.

Tacon, R., Walters, G., \& Cornforth, C. (2017). Accountability in Nonprofit Governance: A Process-Based Study. Nonprofit and Voluntary Sector Quarterly, 46(4), 685-704.

Tandon, R. (1995). "Board games": Governance and Accountability in NGOs. In M. Edwards \& D. Hulme (Eds.), Non-Governmental Organisations - Performance and Accountability Beyond the Magic Bullet (pp. 41-49). London: Earthscan Publications Limited.

Tashakkori, A., \& Teddlie, C. (1998). Mixed Methodology: Combining Qualitative and Quantitative Approaches. Thousand Oaks, California: Sage Publications, Inc.

Taylor, D., Tharapos, M., \& Sidaway, S. (2014). Downward accountability for a natural disaster recovery effort: Evidence and issues from Australia's Black Saturday. Critical Perspectives on Accounting, 25(7), 633-651.

The Ontario Personal Support Workers Association. (2018). PSW Role \& Responsibilities. Retrieved November 19, 2018, from https://www.ontariopswassociation.com/scope-of-practice

Tihanyi, L., Graffin, S., \& George, G. (2014). Rethinking Governance in Management Research. Academy of Management Journal, 57(6), 1535-1543.

Townley, B., Cooper, D. J., \& Oakes, L. (2003). Performance Measures and the Rationalization of Organizations. Organization Studies, 24(7), 1045-1071.

Tremblay-Boire, J., \& Prakash, A. (2015). Accountability.org: Online Disclosures by 
U.S. Nonprofits. Voluntas, 26(2), 693-719.

Tyler, I., Amare, H., Hyndman, B., \& Manson, H. (2014). Health equity assessment: facilitators and barriers to application of health equity tools. Toronto: Ontario Agency for Health Protection and Promotion (Public Health Ontario).

U.S. Bureau of Economic Analysis. (2016). National Income and Product Accounts Table. Retrieved May 5, 2016, from http://www.bea.gov/iTable/iTable.cfm?ReqID=9\&step=1 reqid $=9 \&$ step $=3 \&$ isuri $=1 \& 903=24$ \#reqid $=9 \&$ step $=1 \&$ isuri $=1 \& 903=24$

Unerman, J., \& O'Dwyer, B. (2006a). On James Bond and the importance of NGO accountability. Accounting, Auditing \& Accountability Journal, 19(3), 305-318.

Unerman, J., \& O'Dwyer, B. (2006b). Theorising accountability for NGO advocacy. Accounting, Auditing \& Accountability Journal, 19(3), 349-376.

United Nations. (2003). Handbook on Non-Profit Institutions in the System of National Accounts. New York: United Nations Publication.

Van Thiel, S., \& Leeuw, F. L. (2002). The Performance Paradox in the Public Sector. Public Performance \& Management Review, 25(3), 267-281.

Walsh, J. P., \& Seward, J. K. (1990). On the Efficiency of Internal and External Corporate Control Mechanisms. The Academy of Management Review, 15(3), 421458.

Watts, R. L., \& Zimmerman, J. L. (1986). Positive Accounting Theory. Upper Saddle River: Prentice Hall.

Watts, R. L., \& Zimmerman, J. L. (1990). Positive Accounting Theory: A Ten Year Perspective. The Accounting Review, 65(1), 131-156.

Weerawardena, J., McDonald, R. E., \& Mort, G. S. (2010). Sustainability of nonprofit organizations: An empirical investigation. Journal of World Business, 45(4), 346356.

Weick, K. E. (1989). Theory Construction as Disciplined Imagination. Academy of Management Review, 14(4), 516-531.

Weir, C., Laing, D., \& McKnight, P. J. (2002). Internal and External Governance Mechanisms: Their Impact on the Performance of Large UK Public Companies. Journal of Business Finance \& Accounting Accounting, 29(5), 579-611.

Wellens, L., \& Jegers, M. (2011). Beneficiaries' participation in nonprofit organizations: a theory-based approach. Public Money \& Management, 31(3), 175-182.

Wellens, L., \& Jegers, M. (2014). Effective governance in nonprofit organizations: A literature based multiple stakeholder approach. European Management Journal, 32(2), 223-243.

Williams, A. P., \& Taylor, J. A. (2013). Resolving Accountability Ambiguity in Nonprofit Organizations. Voluntas, 24(3), 559-580.

Wilson, M. G., Mattison, C. A., \& Lavis, J. N. (2016a). Delivery arrangements 1: Infrastructure. In J. N. Lavis (Ed.), Ontario's health system: Key insights for engaged citizens, professionals and policymakers (pp. 123-174). Hamilton: McMaster Health Forum.

Wilson, M. G., Mattison, C. A., \& Lavis, J. N. (2016b). Reforms. In J. N. Lavis (Ed.), Ontario's health system: Key insights for engaged citizens, professionals and policymakers (pp. 375-400). Hamilton: McMaster Health Forum.

Wyatt, D. (2018). The Many Dimensions of Transparency: A Literature Review (No. 53). 
Legal Studies Research Paper Series. Helsinki: University of Helsinki.

Yang, C., \& Northcott, D. (2019). How can the public trust charities? The role of performance accountability reporting. Accounting \& Finance, online ver, 1-27.

Yetman, M. H., \& Yetman, R. J. (2012). The Effects of Governance on the Accuracy of Charitable Expenses Reported by Nonprofit Organizations. Contemporary Accounting Research, 29(3), 738-767.

Yin, R. K. (1981). The Case Study Crisis: Some Answers. Administrative Science Quarterly, 26(1), 58-65.

Yin, R. K. (2009). Case Study Research: Design and Methods (4th ed.). Thousand Oaks, California: Sage Publications, Inc.

Yin, R. K. (2011). Qualitative Research from Start to Finish. New York: The Guilford Press.

Young, D. R. (2002). The Influence of Business on Nonprofit Organizations and the Complexity of Nonprofit Accountability: Looking Inside as Well as Outside. The American Review of Public Administration, 32(1), 3-19.

Young, D. R., Bania, N., \& Bailey, D. (1996). Structure and Accountability. Nonprofit Management and Leadership, 6(4), 347-365.

Zekany, K. E., Braun, L. W., \& Warder, Z. T. (2004). Behind Closed Doors at WorldCom: 2001. Issues in Accounting Education, 19(1), 101-117.

Zimmermann, J. A. M., \& Stevens, B. W. (2008). Best Practices in Board Governance: Evidence from South Carolina. Nonprofit Management and Leadership, 19(2), 189202. 


\section{Appendix A - The International Classification of Non-Profit}

\section{Organizations}

The subgroups were obtained from Statistics Canada (Statistics Canada, 2016). The web page notes that the ICNPO is "the classification system recommended in the United Nations (UN) Handbook on Non-profit Institutions in the System of National Accounts. The ICNPO system groups organizations into 12 major activity groups". The 12 groups are summarized as followed:

Group 1: Culture and recreation Media and communications Visual arts, architecture, ceramic art

Performing arts

Historical, literary and humanistic societies Museums

Zoos and aquariums Sports Recreation and social clubs Service clubs

\section{Group 2: Education and research}

Elementary, primary and secondary education

Higher education Vocational/technical schools

Adult/continuing education Medical research Science and technology

Social sciences, policy studies

\section{Group 3: Health}

Hospitals

Rehabilitation

Nursing homes

Psychiatric hospitals
Mental health treatment

Crisis intervention

Public health and wellness

education

Health treatment, primarily

outpatient

Rehabilitative medical services

Emergency medical services

\section{Group 4: Social services}

Child welfare, child services and day care

Youth services and youth welfare

Family services

Services for the handicapped

Services for the elderly

Self-help and other personal

social services

Disaster/emergency prevention

and control

Temporary shelters

Refugee assistance

Income support and maintenance

Material assistance 


\section{Group 5: Environment}

Pollution abatement and control

Natural resources conservation

and protection

Environmental beautification and

open spaces

Animal protection and welfare

Wildlife preservation and

protection

Veterinary services

\section{Group 6: Development and housing}

Community and neighbourhood organizations

Economic development

Social development

Housing associations

Housing assistance

Job training programs

Vocational counselling and

guidance

Vocational rehabilitation and

sheltered workshops

\section{Group 7: Law, advocacy and politics}

Advocacy organizations

Civil rights associations

Ethnic associations

Civic associations

Legal services

Crime prevention and public

policy

Rehabilitation of offenders

Victim support

Consumer protection

associations

Political parties and

organizations
Group 8: Philanthropic

intermediaries and voluntarism

promotion

Grant-making foundations

Voluntarism promotion and

support

Fund-raising organizations

\section{Group 9: International}

Exchange/friendship/cultural

programs

Development assistance

associations

International disaster and relief

organizations

International human rights and

peace organizations

\section{Group 10: Religion}

Congregations

Associations of congregations

\section{Group 11: Business and professional} associations, unions

Business associations

Professional associations

Labour unions

\section{Group 12: Other}

Not elsewhere classified 


\section{Appendix B - Interview Guide}

\begin{tabular}{|c|c|c|}
\hline & $\begin{array}{l}\text { What do I } \\
\text { need to know? }\end{array}$ & Interview questions \\
\hline & $\begin{array}{l}\text { Accountability } \\
\text { Relationships } \\
(\text { Part A) }\end{array}$ & \\
\hline 1 & $\begin{array}{l}\text { Identify the } \\
\text { organisation's } \\
\text { stakeholders }\end{array}$ & $\begin{array}{l}\text { Who are the organisation's central, secondary and peripheral } \\
\text { stakeholders? } \\
\text { (e.g. funders, donors, regulators, recipients, beneficiaries, } \\
\text { board of directors, management, staff, clients, volunteers, } \\
\text { communities, public at large) }\end{array}$ \\
\hline 2 & $\begin{array}{l}\text { Understand the } \\
\text { accountability } \\
\text { demands of the } \\
\text { organisation's } \\
\text { stakeholders }\end{array}$ & $\begin{array}{l}\text { What are the accountability demands of the organisation's } \\
\text { stakeholders in 2-3 typical accountability relationships? }\end{array}$ \\
\hline & & In the context of each accountability relationship: \\
\hline 3 & $\begin{array}{l}\text { Understand the } \\
\text { nature of the } \\
\text { accountability } \\
\text { relationship }\end{array}$ & $\begin{array}{l}\text { How would you describe the accountability relationship in } \\
\text { regards to: } \\
\text { - the nature; } \\
\text { - the challenges; } \\
\text { - the expectations. }\end{array}$ \\
\hline
\end{tabular}

\begin{tabular}{|l|l|c|}
\hline $\begin{array}{l}\text { Governance } \\
\text { Mechanisms }\end{array}$ & $\begin{array}{l}\text { What are the governance demands? } \\
\text { governance } \\
\text { mechanisms } \\
\text { used to manage } \\
\text { accountability } \\
\text { demands }\end{array}$ & $\begin{array}{l}\text { What are the internal governance mechanisms used to } \\
\text { manage the accountability demands? } \\
\text { (e.g. beliefs and values, board of directors, audit } \\
\text { committee, other board committees, advisors board, } \\
\text { family groups and rules, remuneration plans, } \\
\text { management systems, ownership structure) }\end{array}$ \\
& $\begin{array}{l}\text { What are the external governance mechanisms used to } \\
\text { manage the accountability demands? } \\
\text { (e.g. market, member participation, employee } \\
\text { control, legal system, disclosure requirements, } \\
\text { audits, results and performance, media pressures, } \\
\text { societal ethics and morality) }\end{array}$ \\
\hline
\end{tabular}




\begin{tabular}{|l|l|c|}
\hline $\begin{array}{l}\text { What do I } \\
\text { need to know? } \\
\text { Information } \\
\text { Strategies }\end{array}$ & Interview questions \\
\hline 5 & $\begin{array}{l}\text { Understand the } \\
\text { information } \\
\text { strategies used } \\
\text { to manage } \\
\text { accountability } \\
\text { demands }\end{array}$ & $\begin{array}{c}\text { What are the information demands? } \\
\text { (e.g. financial situation, performance results, } \\
\text { program outcomes, funding reports, board and } \\
\text { committee minutes) }\end{array}$ \\
$\begin{array}{l}\text { How is this information communicated to the } \\
\text { stakeholders? } \\
\text { (e.g. web disclosures, annual reports, annual } \\
\text { reviews, AGM, other public oral presentations, } \\
\text { phone calls, informal gatherings) }\end{array}$ \\
$\begin{array}{c}\text { When is this information communicated to the } \\
\text { stakeholders? } \\
\text { (e.g. annually, when requested, when organisation } \\
\text { has time) }\end{array}$ \\
Who prepares this information?
\end{tabular}

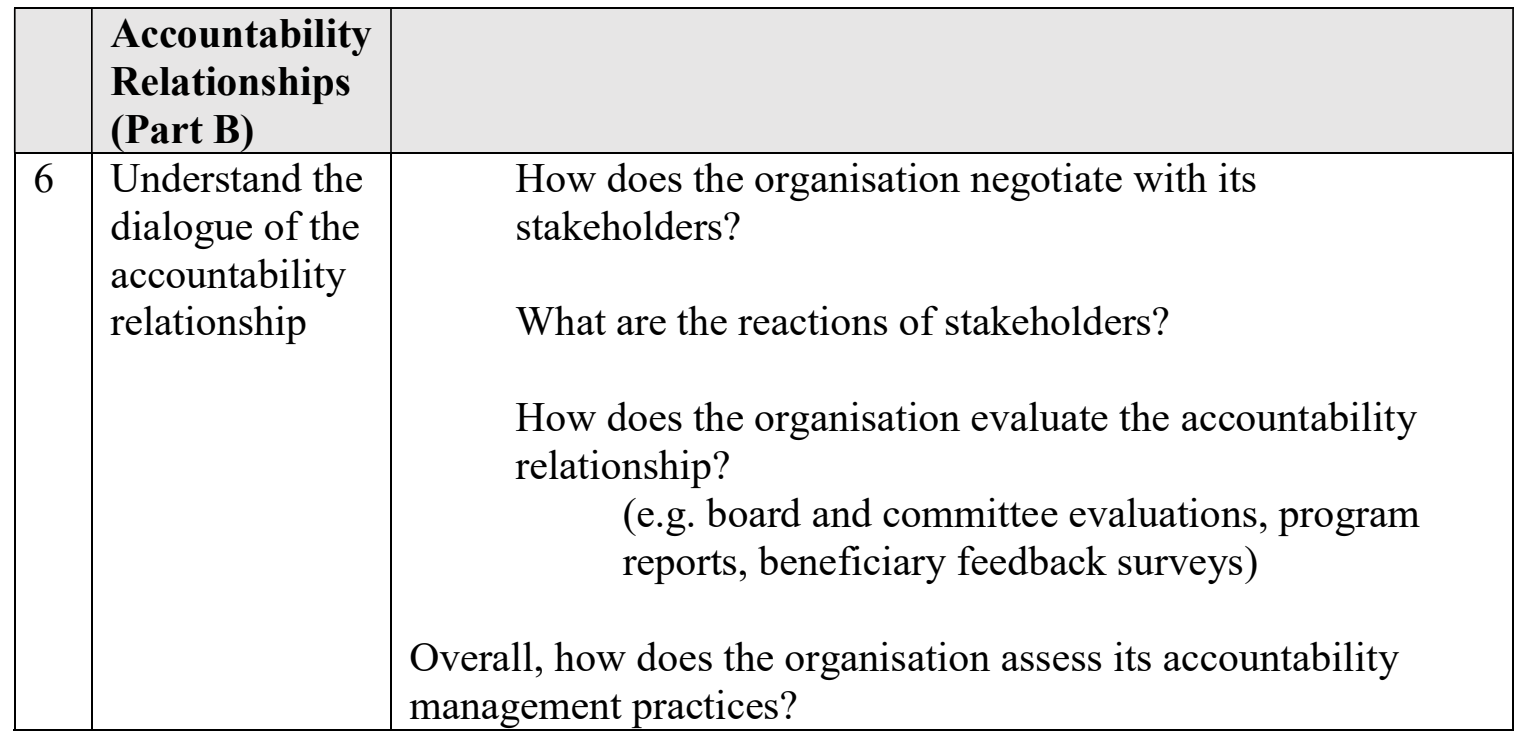




\section{Appendix C - Interview Tool}

Organisation:

Interviewee:

\begin{tabular}{|c|c|c|c|c|}
\hline $\begin{array}{l}\text { Interview } \\
\text { question }\end{array}$ & \multicolumn{4}{|l|}{ Guide } \\
\hline \multirow{14}{*}{$\begin{array}{l}\text { Who are the } \\
\text { organisation's } \\
\text { central, secondary } \\
\text { and peripheral } \\
\text { stakeholders? }\end{array}$} & & & & \\
\hline & Stakeholder & Central & Secondary & Peripheral \\
\hline & Funders & & & \\
\hline & Donors & & & \\
\hline & Regulators & & & \\
\hline & Recipients & & & \\
\hline & Beneficiaries & & & \\
\hline & Board of directors & & & \\
\hline & Management & & & \\
\hline & Staff & & & \\
\hline & Clients & & & \\
\hline & Volunteers & & & \\
\hline & Communities & & & \\
\hline & Public at large & & & \\
\hline $\begin{array}{l}\text { What are the } \\
\text { accountability } \\
\text { demands of the } \\
\text { organisation's } \\
\text { stakeholders in 2-3 } \\
\text { typical } \\
\text { accountability } \\
\text { relationships? }\end{array}$ & \multicolumn{4}{|c|}{$\begin{array}{l}\text { - } \text { Focus on a certain segment of the population } \\
\text { - Develop a specific project } \\
\text { - Achieve a certain benchmark } \\
\text { - } \quad \text { Provide training to employees/board members } \\
\text { - }\end{array}$} \\
\hline $\begin{array}{l}\text { How would you } \\
\text { describe the } \\
\text { accountability } \\
\text { relationship in } \\
\text { regards to: } \\
\text { - The nature; } \\
\text { - The challenges; } \\
\text { - The } \\
\text { expectations. }\end{array}$ & \multicolumn{4}{|c|}{$\begin{array}{l}\text { Nature: } \\
\quad \text { - } \text { Warm/mutual trust } \\
-\quad \text { Difficult/combative } \\
-\quad \text { None existent } \\
\text { Challenges: } \\
\quad \text { - Difficulty recruiting qualified staff } \\
\text { - } \quad \text { Limited financial resources }\end{array}$} \\
\hline
\end{tabular}




\begin{tabular}{|c|c|}
\hline $\begin{array}{l}\text { Interview } \\
\text { question }\end{array}$ & Guide \\
\hline \multicolumn{2}{|l|}{$\begin{array}{l}\text { What are the } \\
\text { governance } \\
\text { demands? }\end{array}$} \\
\hline $\begin{array}{l}\text { What are the } \\
\text { internal } \\
\text { governance } \\
\text { mechanisms used } \\
\text { to manage the } \\
\text { accountability } \\
\text { demands? }\end{array}$ & $\begin{array}{ll}\text { - } & \text { Beliefs and values } \\
\text { - } & \text { Board of directors } \\
\text { - } & \text { Audit committee } \\
\text { - } & \text { Other board committees } \\
\text { - } & \text { Advisors board } \\
\text { - } & \text { Family groups and rules } \\
\text { - } & \text { Remuneration plans } \\
- & \text { Management systems } \\
- & \text { Ownership structure } \\
\end{array}$ \\
\hline $\begin{array}{l}\text { What are the } \\
\text { external } \\
\text { governance } \\
\text { mechanisms used } \\
\text { to manage the } \\
\text { accountability } \\
\text { demands? }\end{array}$ & $\begin{array}{ll}\text { - } & \text { Market } \\
\text { - } & \text { Member participation } \\
\text { - } & \text { Employee control } \\
\text { - } & \text { Legal system } \\
\text { - } & \text { Disclosure requirements } \\
\text { - } & \text { Audits } \\
\text { - } & \text { Results and performance } \\
\text { - } & \text { Media pressures } \\
\text { - } & \text { Societal ethics and morality }\end{array}$ \\
\hline \multicolumn{2}{|l|}{$\begin{array}{l}\text { What are the } \\
\text { information } \\
\text { demands? }\end{array}$} \\
\hline $\begin{array}{l}\text { What information } \\
\text { is communicated } \\
\text { to the } \\
\text { stakeholders? }\end{array}$ & $\begin{array}{ll}\text { - } & \text { Financial situation } \\
\text { - } & \text { Performance results } \\
\text { - } & \text { Program outcomes } \\
\text { - } & \text { Funding reports } \\
\text { - } & \text { Board and committee minutes } \\
\text { - } & \text { Codes and policies } \\
\text { - } & \text { Processes taken for the choices made } \\
\text { - } & \text { How well the organisation achieved its mission }\end{array}$ \\
\hline $\begin{array}{l}\text { How is this } \\
\text { information } \\
\text { communicated to } \\
\text { the stakeholders? }\end{array}$ & $\begin{array}{ll}\text { - } & \text { Web disclosures } \\
\text { - } & \text { Annual reports } \\
\text { - } & \text { Annual reviews } \\
\text { - } & \text { AGM } \\
\text { - } & \text { Other public oral presentations } \\
\text { - } & \text { Phone calls } \\
\text { - } & \text { Informal gatherings }\end{array}$ \\
\hline $\begin{array}{l}\text { When is this } \\
\text { information } \\
\text { communicated to } \\
\text { the stakeholders? }\end{array}$ & $\begin{array}{ll}- & \text { Annually } \\
- & \text { When requested } \\
- & \text { When organisation has time }\end{array}$ \\
\hline
\end{tabular}




\begin{tabular}{|l|l|}
\hline $\begin{array}{l}\text { Interview } \\
\text { question }\end{array}$ & Guide \\
\hline $\begin{array}{l}\text { Who prepares this } \\
\text { information? }\end{array}$ & \\
\hline $\begin{array}{l}\text { How does the } \\
\text { organisation } \\
\text { negotiate with its } \\
\text { stakeholders? }\end{array}$ & \\
\hline $\begin{array}{l}\text { What are the } \\
\text { reactions of } \\
\text { stakeholders? }\end{array}$ & - Positive \\
\hline $\begin{array}{l}\text { How does the } \\
\text { organisation } \\
\text { evaluate the } \\
\text { accountability } \\
\text { relationship? }\end{array}$ & - Unsure \\
\hline $\begin{array}{l}\text { Overall, how does } \\
\text { the organisation } \\
\text { assess its } \\
\text { accountability } \\
\text { management } \\
\text { practices? }\end{array}$ & - - \\
\hline
\end{tabular}




\section{Appendix D - Letter of Request}

5

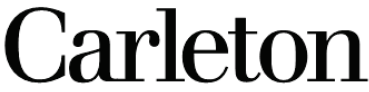

U N I V E R I T Y

Canada's Capital University

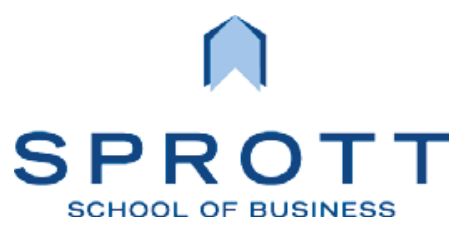

Letter of Request
LaurentianUniversity

UniversitéLaurentienne

Title: The Role of Governance and Information in Nonprofit Accountability Management

Date of ethics clearance: November 28, 2017

Ethics Clearance for the Collection of Data Expires: November 28, 2019

(Insert date)

Dear (Insert name and title),

My name is Marc Pilon and I am a PhD candidate in the Sprott School of Business at Carleton University. I am working under the supervision of Professor François Brouard.

I am writing to you today to invite your organization to participate in a study on nonprofit accountability.

This study aims to understand how nonprofit organizations manage their accountability systems. Managing accountability is a challenging feat for many organizations given the variety of stakeholder demands and the availability of resources. Given this difficult context, there is a need to better understand how organizations such as yours manage and demonstrate accountability.

We would appreciate hearing from you to learn more about your organization's accountability system. As such, this study does not aim to evaluate or critique your practices, but rather learn from your organization's accountability management practices.

The organization itself will benefit from participating in this study from the increased knowledge and awareness that participants will collect. Participants may gain expertise about accountability and how it relates to their role within the organization. Findings may also identify accountability weaknesses that the organization may choose to remediate. Ultimately, participating in this study may help you and your organization better understand and ultimately improve its accountability management practices. 
Specifically, this study is looking to conduct interviews with individuals within your organization. We are looking to interview between two and four individuals with oversight and administrative responsibilities, such as board members, directors, managers and executives. The research is also looking to review internal documents for the previous three to five years that describe the stakeholders' demands and the resulting ways in which the organization manages these demands. Such documentation may include program reviews, annual reviews, annual reports, funding agreements and reports, board and committee minutes, strategic plans, performance measurement metrics, budget and variance analysis and participatory mechanisms.

The ethics protocol for this project was reviewed and received ethics clearance by the Carleton University Research Ethics Board and the Laurentian University Research Ethics Board. Should you have questions or concerns related to your organization's involvement in this research, please contact: Dr. Andy Adler, Chair, Carleton University Research Ethics Board-A (by phone at 613-520-2600 ext. 2517 or via email at ethics@carle on.ca) or Dr. Susan Boyko, Vice Chair, Laurentian University Research Ethics Board (by phone at 705-615-1151 ext. 2436 or via email at ethics@laurentian.ca).

I hope that you will agree to participate in this study, as your contribution would be of great value to this research and very much appreciated. It is sure to be a rewarding experience for both myself and your organization.

If you would like your organization to participate in this research project, or if you have any questions, please contact me at 705-675-1151 (1-800-461-4030) ext. 230 or via email at marcpilon3@cmail.carleton.ca.

Thank you kindly for considering this research opportunity.

Sincerely,

(Insert signature)

Marc Pilon, CPA, CA, PhD Candidate

Sprott School of Business, Carleton University

Ethics clearance number 108114 (Carleton University) and 6012505 (Laurentian University) 


\section{Appendix E - Letter of Invitation}

F

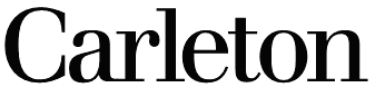

U N I V E R I T Y

Canada's Capital University

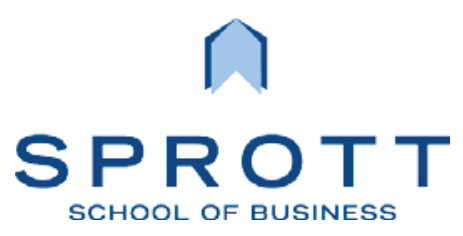

\section{Letter of Invitation}

LaurentianUniversity

UniversitéLaurentienne

Title: The Role of Governance and Information in Nonprofit Accountability Management

(Insert date)

Dear (Insert name and title),

My name is Marc Pilon and I am a PhD candidate in the Sprott School of Business at Carleton University. I am working under the supervision of Professor François Brouard.

I am writing to you today to invite you to participate in a study on nonprofit accountability. This study aims to understand how nonprofit organizations manage their accountability systems.

You have been identified as someone who has a great deal to share about your organization's accountability practices and we would appreciate hearing from you to learn more about your organization's accountability system. As such, this study does not aim to evaluate or critique your practices, but rather learn from your organization's accountability management practices. Participating in this study may also help you and your organization better understand and ultimately improve its accountability management practices.

While your participation is voluntary, your contribution would be of great value to this research and very much appreciated.

This study involves one approximately 1-2 hour interview that will take place in a mutually convenient location. With your consent, interviews will be audiorecorded. The recordings will be kept in a secure location, transcribed and anonymized to protect your identity. This will be done to reduce any potential professional risks.

You will have the right to end your participation in the study at any time, for any reason, up to one week after the interview takes place. If you choose to withdraw, all the information you have provided will be destroyed. 
The ethics protocol for this project was reviewed and received ethics clearance by the Carleton University Research Ethics Board and the Laurentian University Research Ethics Board. Should you have questions or concerns related to your involvement in this research, please contact: Dr. Andy Adler, Chair, Carleton University Research Ethics Board-A (by phone at 613-520-2600 ext. 2517 or via email at ethics@carleton.ca) or Dr. Susan Boyko, Vice Chair, Laurentian University Research Ethics Board (by phone at 705-675-1151 ext. 2436 or via email at ethics@laurentian.ca).

If you would like to participate in this research project, or if you have any questions, please contact me at 705-675-1151 (1-800-461-4030) ext. 2133 or via email at marcpilon3@cmail.carleton.ca.

Thank you for your support.

Sincerely,

(Insert signature)

Marc Pilon, CPA, CA, PhD Candidate

Sprott School of Business, Carleton University

Ethics clearance number 108114 (Carleton University) and 6012505 (Laurentian University) 
5

Canada's Capital University

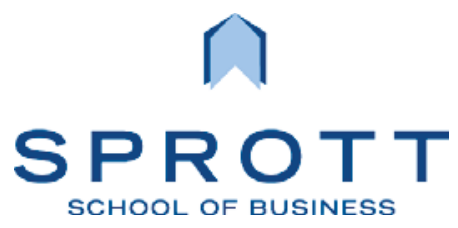

Consent Form
LaurentianUniversity

UniversitéLaurentienne

Title: The Role of Governance and Information in Nonprofit Accountability Management

I choose to participate in a study on nonprofit accountability. This study aims to understand how nonprofit organizations manage their accountability systems. The researcher for this study is Marc Pilon, PhD candidate in the Sprott School of Business at Carleton University. $\mathrm{He}$ is working under the supervision of Professor François Brouard.

This study involves one approximately 1-2 hour interview. With your consent, interviews will be audio-recorded.

As this project will ask you about your organization's accountability, there are some potential professional risks to you if your statements are critical of your fellow colleagues or the organization. While this risk is expected to be minimal, I will take precautions to protect your identity. This will be done by anonymizing your responses in any reports or publications. You may also request that certain responses not be included in the final project.

You have the right to end your participation in the study at any time, for any reason, up to one week after the interview takes place. You can withdraw by phoning or emailing the researcher or the research supervisor. If you withdraw from the study, all information you have provided will be destroyed.

All research data, including audio-recordings and any notes will be secured in the researcher's office. Data will be stored on a password protected computer. The computer will be kept in the researcher's office. Research data will only be accessible by the researcher and the research supervisor.

Once the project is completed, all research data will be kept for five years and potentially used for other research projects on this same topic. At the end of five years, all research data will be securely destroyed by erasing electronic data and shredding hard copies.

If you would like a copy of the finished research project, you are invited to contact the researcher to request an electronic copy which will be provided to you. 
The ethics protocol for this project was reviewed and received ethics clearance by the Carleton University Research Ethics Board and the Laurentian University Research Ethics Board. If you have any ethical concerns with the study, please contact Dr. Andy Adler, Chair, Carleton University Research Ethics Board-A (by phone at 613-520-2600 ext. 2517 or via email at ethics@carleton.ca) or Dr. Susan Boyko, Vice Chair, Laurentian University Research Ethics Board (by phone at 705675-1151 ext. 2436 or via email at ethics@laurentian.ca).

\section{Researcher contact information:}

Marc Pilon, PhD Candidate

Sprott School of Business

Carleton University

Tel: 705-675-1151 ext. 2133

(1-800-461-4030)

Email: marcpilon3@cmail.carleton.ca
Supervisor contact information:

Professor François Brouard

Sprott School of Business

Carleton University

Tel: 613-520-2600 ext. 2213

Email: francois.brouard@carleton.ca

Do you agree to be audio-recorded: Yes No

Signature of participant

Date

Signature of researcher

Date

Ethics clearance number 108114 (Carleton University) and 6012505 (Laurentian University) 


\section{Appendix G - List of Organisations within Ontario's Health Care}

\section{System}

\section{Panel A - Direct Organisations}

\begin{tabular}{|c|c|}
\hline Type of organisation & Name \\
\hline \multirow{11}{*}{$\begin{array}{l}\text { Other provincial } \\
\text { government agencies }\end{array}$} & Health Quality Ontario \\
\hline & Health Shared Services Ontario \\
\hline & Cancer Care Ontario \\
\hline & CorHealth Ontario \\
\hline & eHealth Ontario \\
\hline & HealthForceOntario Marketing and Recruitment Agency \\
\hline & $\begin{array}{l}\text { Ontario Agency for Health Protection and Promotion } \\
\text { (operating as Public Health Ontario) }\end{array}$ \\
\hline & Trillium Gift of Life Network \\
\hline & Workplace Safety and Insurance Board \\
\hline & Infrastructure Ontario \\
\hline & Ontario Mental Health Foundation \\
\hline \multirow{4}{*}{$\begin{array}{l}\text { Other federal } \\
\text { government agencies }\end{array}$} & Patented Medicines Prices Review Board \\
\hline & Canadian Institute for Health Research \\
\hline & \begin{tabular}{|l|} 
Canadian Institute for Health Information \\
\end{tabular} \\
\hline & Canada Revenue Agency \\
\hline \multirow{6}{*}{$\begin{array}{l}\text { Other primary care } \\
\text { organisations }\end{array}$} & Victorian Order of Nurses \\
\hline & CarePartners \\
\hline & ConnexOntario \\
\hline & Hospice care organisations \\
\hline & Mental health and addiction agencies \\
\hline & Aboriginal Health Access Centres \\
\hline \multirow{6}{*}{$\begin{array}{l}\text { Other health network } \\
\text { organisations }\end{array}$} & Canadian Blood Services \\
\hline & $\begin{array}{l}\text { St. John Council of Ontario (affiliation of St. John Ambulance } \\
\text { and St. John Priory of Canada) }\end{array}$ \\
\hline & Le Réseau du mieux-être francophone du Nord de l'Ontario \\
\hline & $\begin{array}{l}\text { Le Réseau des services de santé en français de l'Est de } \\
\text { l'Ontario }\end{array}$ \\
\hline & Le Réseau franco-santé du Sud de l'Ontario \\
\hline & Société Santé en français \\
\hline
\end{tabular}




\section{Panel B - Peripheral Organisations}

\begin{tabular}{|c|c|}
\hline Type of organisation & Name \\
\hline \multirow{29}{*}{$\begin{array}{l}\text { Regulatory colleges } \\
\text { (Governing bodies) }\end{array}$} & College of Physicians and Surgeons of Ontario \\
\hline & College of Nurses of Ontario \\
\hline & Royal College of Physicians and Surgeons of Canada \\
\hline & College of Family Physicians of Canada \\
\hline & College of Midwives of Ontario \\
\hline & $\begin{array}{l}\text { College of Audiologists and Speech-language Pathologists of } \\
\text { Ontario }\end{array}$ \\
\hline & College of Chiropractors Of Ontario \\
\hline & College of Chiropodists Of Ontario \\
\hline & Royal College of Dental Surgeons of Ontario \\
\hline & College of Dental Hygienists of Ontario \\
\hline & College of Dental Technologists of Ontario \\
\hline & College of Denturists of Ontario \\
\hline & College of Dietitians of Ontario \\
\hline & College of Homeopaths of Ontario \\
\hline & College of Kinesiologists of Ontario \\
\hline & College of Massage Therapists of Ontario \\
\hline & College of Medical Laboratory Technologists of Ontario \\
\hline & College of Medical Radiation Technologists of Ontario \\
\hline & College of Midwives of Ontario \\
\hline & College of Naturopaths of Ontario \\
\hline & College of Occupational Therapists of Ontario \\
\hline & College of Opticians of Ontario \\
\hline & College of Optometrists of Ontario \\
\hline & Ontario College of Pharmacists \\
\hline & College of Physiotherapists of Ontario \\
\hline & College of Psychologists of Ontario \\
\hline & College of Registered Psychotherapists of Ontario \\
\hline & College of Respiratory Therapists of Ontario \\
\hline & $\begin{array}{l}\text { College of Traditional Chinese Medicine Practitioners and } \\
\text { Acupuncturists of Ontario }\end{array}$ \\
\hline \multirow[t]{5}{*}{ Trade Unions } & Ontario Nurses' Association \\
\hline & Ontario Public Service Employees Union \\
\hline & Canadian Union of Public Employees \\
\hline & Service Employees International Union \\
\hline & Public Service Alliance of Canada \\
\hline \multirow{6}{*}{$\begin{array}{l}\text { Interest groups and } \\
\text { associations }\end{array}$} & Ontario Medical Association \\
\hline & Registered Nurses' Association of Ontario \\
\hline & Accreditation Canada \\
\hline & Health Standards Organisation \\
\hline & Canadian Institute for Health Information \\
\hline & Ontario Hospital Association \\
\hline
\end{tabular}




\begin{tabular}{|l|l|}
\hline Type of organisation & Name \\
\hline & Ontario Health Coalition \\
\hline & Home Care Ontario \\
\hline & Canadian Agency for Drugs and Technologies in Health \\
\hline Patients Canada \\
\hline & Addictions and Mental Health Ontario \\
\hline & Association of Ontario Health Centres \\
\hline Ontario Association of Community Care Access Centres \\
\hline Ontario Community Support Association \\
\hline & Ontario Long Term Care Association \\
\hline Ontario Public Health Association \\
\hline Alliance for Healthier Communities \\
\hline & Association of Family Health Teams of Ontario \\
\hline & Addictions and Mental Health Ontario \\
\hline & Ontario Association of Speech-language Pathologists and \\
Audiologists
\end{tabular}




\begin{tabular}{|l|l|}
\hline Type of organisation & Name \\
\hline & Heart and Stroke Foundation of Canada \\
\cline { 2 - 3 } & Canadian Cancer Society \\
\hline & Arthritis Society \\
\cline { 2 - 2 } & Ontario Lung Association \\
\cline { 2 - 3 } & Alzheimer Society of Ontario \\
\hline & Canadian Mental Health Association \\
\hline & Canadian Nurses Association \\
\hline & Canadian Medical Association \\
\hline & Canadian College of Health Leaders \\
\hline & Patients Canada \\
\hline & Canadian Patient Safety Institute \\
\hline & Canadio Personal Support Workers Association \\
\hline & Canadian Pharional Institute for the Blind \\
\hline & Canada Health Infoway Association \\
\hline & World Health Organisation (WHO) \\
\cline { 2 - 3 } & AdvantAge Ontario \\
\hline & Association of Local Public Health Agencies \\
\hline & Black Health Alliance \\
\cline { 2 - 3 } & Canadian Association of Physician Assistants \\
\hline & Canadian Geriatrics Society \\
\hline & Ontario Association of Cardiologists \\
\cline { 2 - 3 } & Ontario College of Family Physicians \\
\hline
\end{tabular}




\title{
Appendix $\mathbf{H}$ - List of Abbreviations
}

\author{
ALC: Alternate Level of Care \\ CEO: Chief Executive Officer \\ CFO: Chief Financial Officer \\ CNO: Chief Nursing Officer \\ CIHI: Canadian Institute for Health Information \\ HIP: Hospital Improvement Plan \\ MAC: Medical Advisory Committee \\ MOHLTC: Ministry of Health and Long-Term Care \\ HQO: Health Quality Ontario \\ HSAA: Hospital Service Accountability Agreement \\ LHIN: Local Health Integration Network \\ MLAA: Ministry-LHIN Accountability Agreement \\ MOHLTC: Ministry of Health and Long-Term Care \\ OHA: Ontario Hospital Association \\ OHIP: Ontario Health Insurance Plan \\ OR: Operating Room \\ PFAC: Patient and Family Advisory Committee \\ PSW: Personal Support Worker \\ QIP: Quality Improvement Plan
}




\section{Appendix I - Glossary}

Alternate Level of Care: Measure of how often a patient who could be treated elsewhere occupies a hospital bed (Office of the Auditor General of Ontario, 2015)

Community health centre: Community health centres are nonprofit organisations that provide primary health and health promotion services to individuals, families and communities (Ministry of Health and Long-Term Care, 2018a)

Continuum of care: A comprehensive range of services designed to meet all the health care needs of individuals (and especially those who are frail or chronically ill).

(Fierlbeck, 2011)

Health service provider: A health service provider could be a hospital, community support service agency, a mental health and addition agency, a community health centre, a community support services agency, or a long-term care home. (Office of the Auditor General of Ontario, 2015).

Long-term care: A wide spectrum of services provided over an indefinite period to individuals with chronic illnesses or permanent disabilities. These services are generally provided in an institutional setting. (Fierlbeck, 2011)

Personal support worker (PSW): PSW's provide care to any person in their home or long-term care who require personal assistance with activities of daily living, such as housekeeping, meal preparation, socialisation, and companionship (The Ontario Personal Support Workers Association, 2018)

Primary care: basic, preventative, and other non-specialty health services generally provided by family doctors or nurses. (Fierlbeck, 2011) 